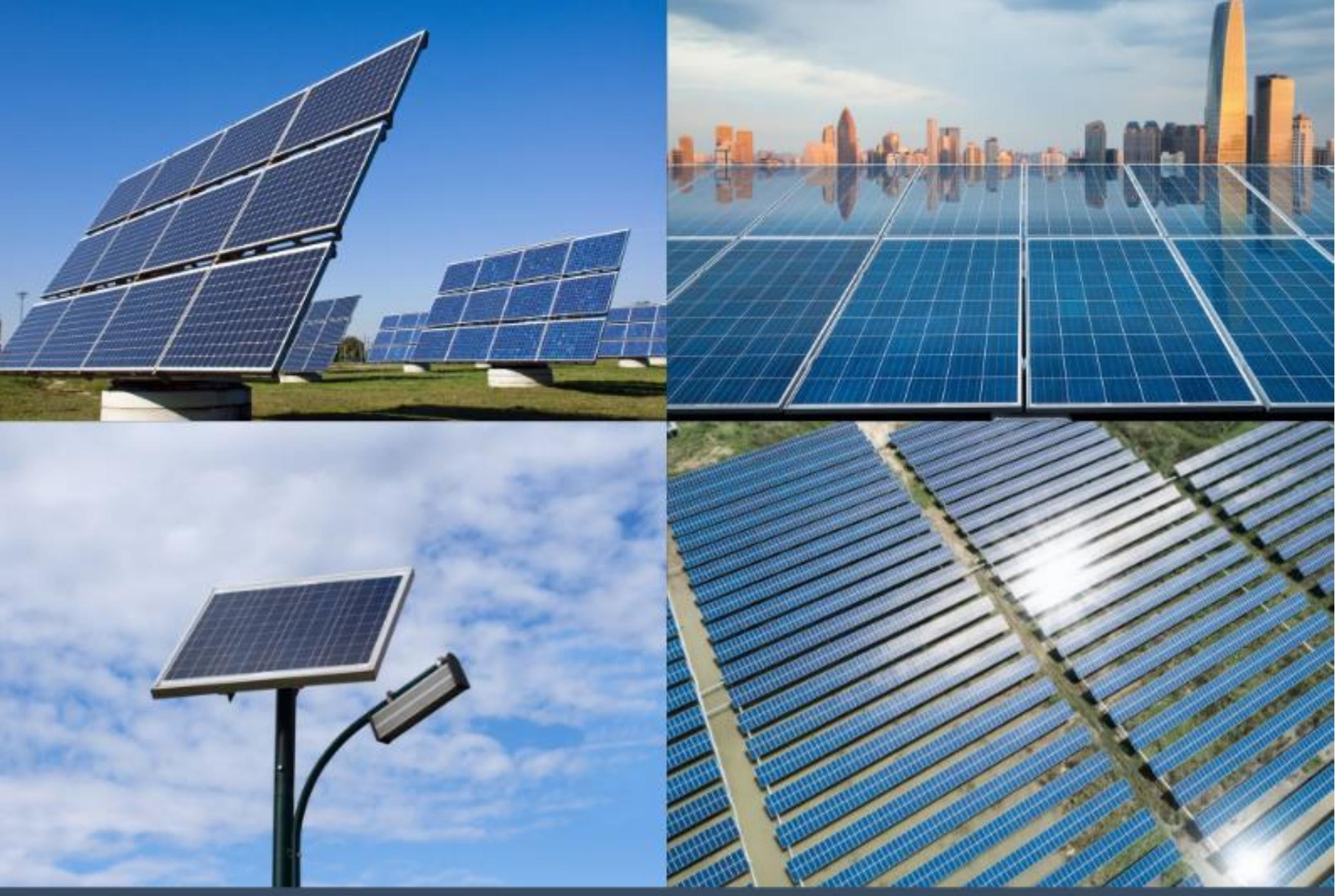

\title{
ANÁLISE DA VIABILIDADE ECONÔMICA DE INSTALAC̄̃EES DE PLACAS FOTOVOLTAICAS
}

\section{ANDRÉ GOMES BARROS}


André Gomes Barros

\title{
Análise da viabilidade econômica de instalações de placas fotovoltaicas
}

\author{
1a Edição
}

Belo Horizonte

Poisson

2019 
Editor Chefe: Dr. Darly Fernando Andrade

Conselho Editorial

Dr. Antônio Artur de Souza - Universidade Federal de Minas Gerais

Dr. José Eduardo Ferreira Lopes - Universidade Federal de Uberlândia

Dr. Otaviano Francisco Neves - Pontifícia Universidade Católica de Minas Gerais

Dr. Luiz Cláudio de Lima - Universidade FUMEC

Dr. Nelson Ferreira Filho - Faculdades Kennedy

Dados Internacionais de Catalogação na Publicação (CIP)

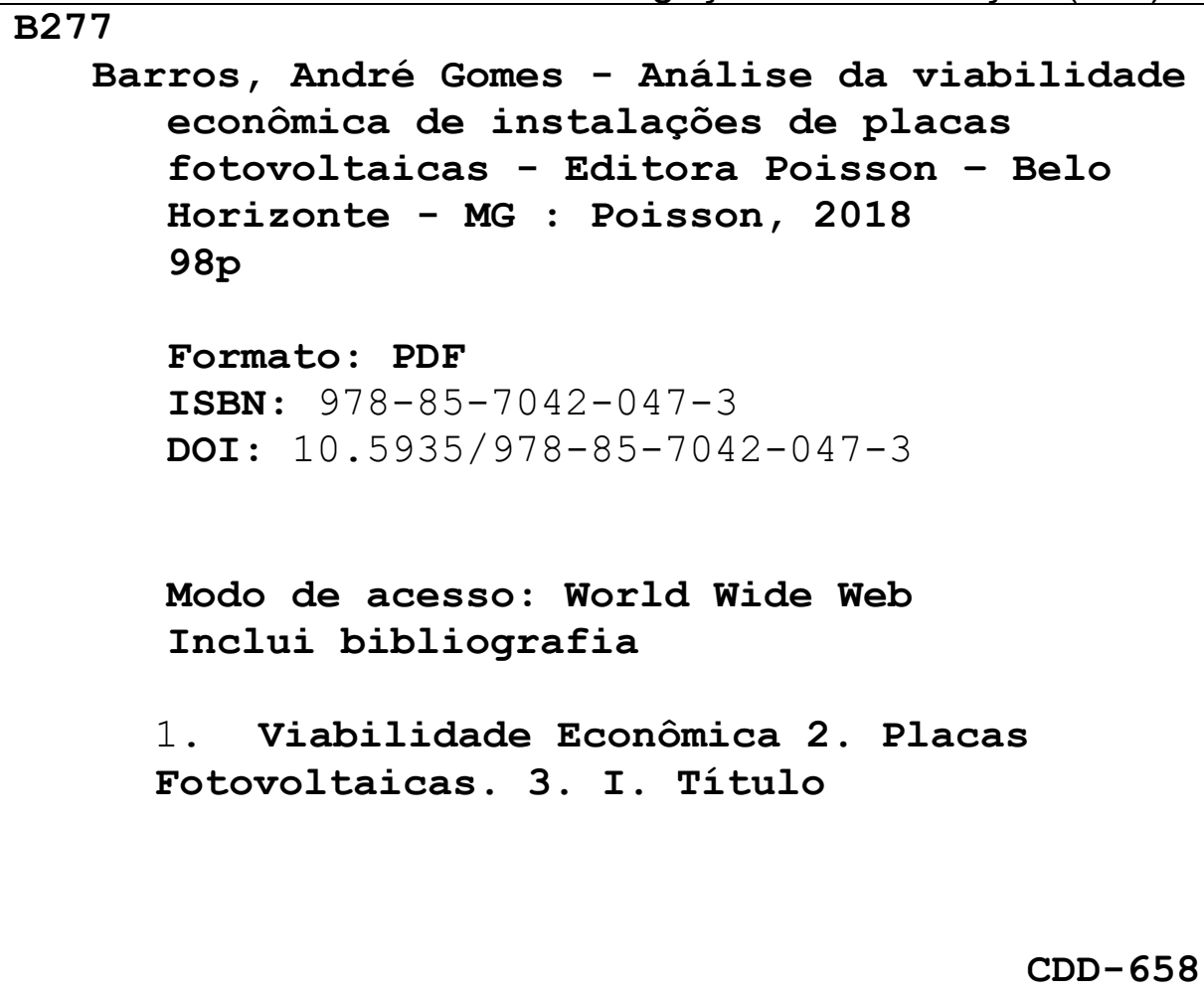

O conteúdo desse livro e seus dados em sua forma, correção e confiabilidade são de responsabilidade exclusiva do seu respectivo autor

$\underline{\text { www.poisson.com.br }}$

contato@poisson.com.br 
Gostaria de agradecer primeiramente a Deus, pela minha vida, por tudo. Depois agradeço ao mesmo, Senhor Jesus Cristo, verdadeiro Homem e verdadeiro Deus, por ter me concedido os pais maravilhosos e amorosos que servem como exemplo para mim e meus filhos. A todas as pessoas que me ajudaram, o meu muito obrigado e que Deus os abençoe. E a minha querida esposa e aos meus filhos, amo muito todos vocês. 


\section{Prefácio}

Estou colocando a disposição dos colegas professores e aos interessados em Viabilidade Econômica de Instalações de Placas Fotovoltaicas, este livro.

O conteúdo deste livro apresenta os conceitos bibliométricos com relação ao tema, e ao método utilizado, e um estudo de caso de uma empresa petrolífera com os resultados obtidos e suas respectivas análises, através de um simulador de placas fotovoltaicas, juntamente com um modelo apresentado pelo autor.

O tema possibilita aos estudantes de graduação e pós-graduação lato sensu e stricto sensu, adquirir os conhecimentos necessários para poder desenvolver e explorar de alguma forma esta fonte de energia renovável cada vez mais crescente em nosso país. A abordagem mais uma vez é essencialmente acadêmica, com a exemplificação através de um estudo de caso.

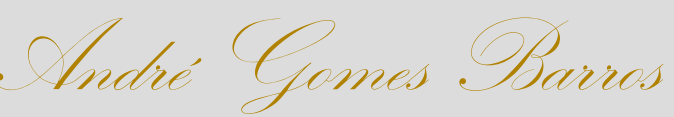




\section{Sumário}

Capítulo 1: Introdução

Capítulo 2: Viabilidade econômica em placas fotovoltaicas: uma revisão sistemática no portal de periódicos da capes e utilizando a base Scopus

Capítulo 3: Revisão sistematizada de literatura na base scopus: uma abordagem sobre "Viabilidade Econômica"

Capítulo 4: A viabilidade econômica de utilização de placas fotovoltaicas em uma empresa 71

Considerações Finais 88

Sobre o autor 97 


\section{Capítulo 1}

\section{INTRODUÇÃO}

É apresentada, nesta etapa do livro, a maneira como foi desenvolvida a pesquisa, baseando-se, sobretudo, nos materiais bibliográficos e quais as considerações que eles apresentam acerca do tema em análise. Sob essa perspectiva, os subitens abordam o contexto em que essa pesquisa se insere, os objetivos - geral e específicos - a fim de direcionar o estudo para uma linha em que sejam analisados os fatores previamente definidos. Além disso, há a justificativa, a qual deixa evidente o porquê de este trabalho ter sido desenvolvido, abrindo espaço para outro subtópico, a saber, a relevância do tema. Por fim, apresenta a síntese de cada etapa usada nesta pesquisa, algumas questões que foram analisadas no decorrer dela e a estrutura do trabalho. 


\subsection{CONTEXTUALIZAÇÃO}

A busca por novas matrizes de energia tem sido pautada, cada vez mais, na não degradação do meio ambiente. Nesse aspecto, algumas características são imprescindíveis no momento de aderir a uma nova fonte energética. Os fatores mais bem aceitáveis consideram, dentre outros benefícios, se ela é renovável, bem como se a matriz energética não polui tanto como as que dependem de combustíveis fósseis, o que evidencia a preocupação dos governos e das pessoas, de modo geral, com as questões sustentáveis.

Para Oliveira, Shayani e Silva (2018, p.3), "O Brasil está situado numa região com incidência mais vertical dos raios solares. Esta condição favorece elevados índices de irradiação em quase todo o território". Assim, - país oferece, naturalmente, condições favoráveis para a implementação da energia solar fotovoltaica, tendo em vista que dispõe dos principais fatores necessários para isso.

A considerar essa característica, a energia solar fotovoltaica é uma das fontes energéticas que tem se encaixado como promissora, sendo capaz de suprir uma grande necessidade por energia. Conforme Pereira e Oliveira (2011, p.61), um sistema fotovoltaico, para que gere energia, faz uso de um aglomerado de células fotovoltaicas, as quais capturam a irradiação solar, transformando-a em energia elétrica. A partir disso, o principal componente que esse sistema utiliza para a geração de energia elétrica são as placas fotovoltaicas.

Ademais, a energia solar apresenta muitas vantagens em relação a outras fontes. Uma das principais é o uso de painéis fotovoltaicos, que podem ser instalados em ambientes cujo acesso é difícil, na medida em que seu uso prescinde de investimentos custosos em linhas de transmissão. Dessa maneira, a inserção da energia solar é positiva se considerar os custos benefícios que envolvem a instalação e manutenção dessa matriz energética.

Em contrapartida, em relação às outras fontes, como a hidroelétrica, um dos fatores que é desvantajoso na energia solar é o sistema de armazenamento. Isso se deve ao fato de que as fontes que fazem uso de combustíveis fósseis conseguirem manter uma maior estabilidade quando os recursos estão disponíveis. Por outro lado, quando há uma instabilidade, a disposição de recursos torna-se mais agravante, uma vez que essas fontes não são renováveis, dependendo que os combustíveis fósseis sempre estejam disponíveis para que mantenham funcionando.

Outro aspecto que diferencia a energia solar, tornando-a mais vantajosa em comparação a estas supracitadas, diz respeito ao fato de ela não ser finita, isto é, não pode desaparecer em pouco tempo. Além disso, essa é uma fonte de energia abundante, sendo que o meio pelo qual ela é obtida não sofre interferência direta da atuação humana.

A respeito disso, Silva, Ferreira e Zukowski Junior (2017) consideram que uma das principais razões para o uso da energia solar fotovoltaica preside no fato de que ela é uma alternativa complementar à fonte hidrelétrica, reduzindo o risco de ausência de energia, especialmente se for considerado que os períodos de estiagem podem levar a isso.

Historicamente, o uso da energia solar foi necessário para as civilizações. Tal uso, decerto, era menos aperfeiçoado do que o que é possível encontrar na hodiernamente. Assim, de acordo com Carvalho e Calvete (2010), o sol e o calor eram usados diretamente para ajudar na manutenção dos afazeres domésticos.

Além disso, segundo Hémeru et al. (1993) apud Kemerich et al. (2016), desde a PréHistória a energia solar tem sido fonte de iluminação. Sendo assim, nota-se que, com o passar dos séculos, o uso desse sistema de energia foi se aperfeiçoando, sendo que, atualmente, ele pode ser convertido em energia elétrica e, dessa forma, contribuir para o desenvolvimento da sociedade de maneira sustentável em larga escala.

No que diz respeito à disponibilidade de adoção dessa matriz energética no Brasil, verifica-se que existe um grande potencial para a sua inclusão, uma vez que o país recebe fortes índices de irradiação solar. Todavia, de acordo com a Agência Nacional de Energia Elétrica (2017), o país atualmente conta com cerca de 12 mil instalações, o que o torna um baixo consumidor dessa fonte de energia, se comparado com países como Alemanha e Japão.

De acordo com Oliveira, Rodrigues e Shayani (2018, p.6) "um sistema fotovoltaico tende a produzir menos energia do que em lugares menos quente". Tal característica evidencia que a temperatura é requisito essencial para o 
sucesso da implantação do sistema fotovoltaico. Por essa razão, este estudo se baseou na simulação de uma região em que há altos índices de temperatura.

Essas características, somadas aos baixos índices de nebulosidade e a regular irradiação solar, fazem com que a Região atenda aos principais requisitos dos quais são precisos para a incrementação dessa fonte de energia, conforme a delimitação que esse sistema possui atualmente. Assim, é possível perceber que parte do país já tem disponibilidade de incrementar essa matriz energética.

No estado do Rio de Janeiro, também a favorável aceitação para a implementação da energia solar fotovoltaica, dado que o estado abrange muitos dos requisitos. O uso de materiais complementares a esse sistema, no país, ainda possui preço elevado, comparado a países como a Alemanha. Por essa razão, existe uma forte necessidade de que sejam incentivados pesquisas e desenvolvimentos de recursos de implementação.

\subsection{OBJETIVO GERAL}

Mensurar os custos da implantação de painéis fotovoltaicos que promovam a eficiência produtiva e econômica de uma determinada empresa do segmento offshore, que atua na bacia de Campos, no município de Macaé/RJ, e através dos resultados obtidos por simulação através de um software Pvsyst versão 6.73 e por indicadores econômicos, avaliar se o mesmo é viável.

\subsection{OBJETIVOS ESPECÍFICOS}

(A) Promover a sustentabilidade no negócio de uma determinada empresa; e

(B) Propor uma redução do consumo de energia elétrica através da energia solar fotovoltaica.

\subsection{JUSTIFICATIVA DO TEMA}

Tendo em vista que, cada vez mais, existe a necessidade de adoção de economia sustentável, a qual se pauta no desenvolvimento por meio de estratégias que não degradem o meio ambiente, esta pesquisa desenvolve um projeto que visa demonstrar a importância da adoção de energia solar e, a partir disso, comparar como ela é mais viável, tanto do ponto de vista econômico quanto do sustentável.

Para tanto, esta pesquisa usou como experimento a simulação de quanto uma determinada empresa gastaria para fazer uso da energia solar em detrimento da elétrica proveniente do sistema de hidrelétrica. Além disso, verificou-se os benefícios no que diz respeito aos aspectos econômico, social, acadêmico e ambiental.

Sob o ponto de vista econômico, este estudo justifica-se por buscar demonstrar como essa fonte de energia pode-se mostrar mais barato para a empresa, uma vez que ele será proveniente de uma fonte que é abundante e totalmente gratuita, sendo que os principais custos dão-se por conta da instalação e manutenção, mas que, ainda assim, é uma alternativa economicamente mais viável que a fonte de energia advinda da contida no fluxo de massas de água, isto é, a hidrelétrica.

Por outro lado, na perspectiva ambiental, esse estudo contribui com a demonstração de outra fonte alternativa de energia, sendo ainda menos degradante para a natureza do que a hidrelétrica. Nesse sentido, vale ressaltar que esta energia, em que pese ser renovável, traz impactos negativos para o meio ambiente, sobretudo por fazer com que seja necessário desviar o curso natural dos rios a fim de gerar massa que, por sua vez, é convertida em energia elétrica. A energia solar, por sua vez, além de também ser renovável, não causa impactos diretos à natureza, sendo assim, é mais viável que a energia hidrelétrica.

Ainda considerando o fator ambiental, é necessário destacar que é preciso a adoção de novas formas renováveis de energia, uma vez que a que é adotada atualmente sofre constantemente interferências por conta da baixa quantidade de água que possuem os reservatórios de água, ameaçando tanto o consumo quanto a produção de energia. Segundo dados da Agência Nacional de Energia Elétrica (2016), no ano de 2015 os reservatórios de água da Região Sudeste/Centro-Oeste contaram com apenas $19 \%$ da capacidade que têm, o que deixa notório a importância de reduzir a dependência da energia elétrica, sob pena de, no futuro, haver uma situação de calamidade devido à falta de capacidade de distribuição.

No que concerne aos fatores sociais, é possível destacar que a adoção da energia solar por parte das empresas e do poder 
público pode ocasionar uma consciência nos cidadãos de que é importante buscar formas estratégias alternativas naquilo que é possível, a fim de haver menos danos ao meio ambiente. Assim sendo, a adoção da energia solar permite que as pessoas reflitam que não só no espaço que envolve a energia é importante buscar formas menos invasivas, mas também na forma de consumo de produtos e afins.

Por seu modo, na perspectiva acadêmica, este estudo ajuda na divulgação desta forma de energia, permitindo que, a partir dele, sejam criadas novas pesquisas que aprimorem, cada vez mais, esta promissora fonte de energia, inclusive no que diz respeito à produção dos materiais, os quais, atualmente, apresentam-se como a maior barreira para a incrementação em larga escala dessa matriz.

Portanto, o estudo tem por base a análise de todos esses fatores, a fim de que se torne efetiva a adoção dessa fonte energética. A respeito disso, é importante destacar alguns dados acerca da perspectiva que se tem sobre o futuro da energia solar no Brasil. Assim, de acordo com a Bloomberg New Energy Finance (BNEF, 2016), daqui a 25 anos, o uso de energia eólica e solar deve ultrapassar o de energia hidrelétrica.

Dessa maneira, o país contaria com fontes variadas, dependendo substancialmente a dependência que há hoje pela predominante. No entanto, para que esses dados consigam realmente ser efetivar, é necessária uma consciência coletiva da importância dessas fontes. A energia solar, assim, depende que mais estudiosos aperfeiçoem a sua implantação a fim de que os custos desta se tornem mais atrativos.

\subsection{RELEVÂNCIA DO TEMA}

A energia solar fotovoltaica tem se mostrado em diversas pesquisas, e até na prática, como uma das mais promissoras dentre as que são renováveis. Por essa razão, é importante buscar entendê-la para que seu uso se torne cada vez mais constante, além de que sejam realizadas novas experiências a fim de ela se torne mais acessível para as organizações que buscam aderi-la.

Dentre os pontos que tornam esta fonte energética prominente, encontram-se os de que ela possui matéria prima interminável, o de que ela não emite poluição no momento de gerar eletricidade e, eles podem ser instalados em qualquer região que apresente contato com o sol. Assim, embora haja alguns pontos negativos, como o baixo fluxo de densidade energética que é essa fonte consegue captar, em comparação às alternativas fósseis, os benefícios ainda são maiores.

A questão do baixo fluxo capturado pode ser solucionada com a disposição uma grande área para fazer a captação. No que diz respeito aos investimentos iniciais para a implantação desse sistema, apesar de eles serem maiores do que os das fontes energéticas fósseis, seus benefícios a longo prazo são maiores, se for considerada a duração do projeto e os retornos que oferece.

Diante disso, o presente estudo aborda sete métodos financeiros para analisar a viabilidade econômica da aplicação de instalações do sistema de geração de energia através das placas fotovoltaicas ligadas a rede em uma empresa do município de Macaé/RJ. E assim:

(1) Desenvolver uma economia sustentável;

(2) Reduzir o custo com consumo de energia elétrica convencional;

(3) Gerar recursos sustentáveis; e

(4) Apresentar a viabilidade econômica da utilização de painéis fotovoltaicos.

\subsection{SÍNTESE DAS ETAPAS DE PESQUISA}

As Etapas para o desenvolvimento do presente estudo foram:

(I). Seleção dos artigos: Nessa etapa, foi realizada uma análise bibliométrica, utilizando as ferramentas de busca obtidas na base de dados Scopus Elsevier e no portal CAPES. Ao fazer essa pesquisa, foram consideradas as palavras-chaves e os resumos dos artigos selecionados que contribuíram para melhor contextualização com o tema específico da pesquisa. Com a seleção, podê-se delimitar o tema e definir o objeto de pesquisa, bem como quais referenciais teóricos seriam utilizados para a construção do texto.

(II). Levantamento bibliográfico dos principais métodos financeiros aplicáveis a viabilidade econômica da utilização de placas fotovoltaicas: Já nesse ponto, buscou-se analisar e, consequentemente, selecionar as principais ferramentas financeiras que retratam, do ponto de vista econômico, as 
reais possibilidades de investimento em placas fotovoltaicas nas empresas e quais serão os custos-benefícios adquiridos com a utilização da energia solar no dia a dia da empresa.

(III). Elaboração de uma viabilidade econômica sobre geração solar por meio de uma simulação de painéis fotovoltaicos (Pvsyst versão 6.73) feita pelo autor, em uma empresa do segmento de offshore do município de Macaé/RJ. Estudos dos principais critérios apontados nos referentes artigos para aprimoramento da pesquisa.

\subsection{QUESTÕES DE PESQUISA}

O presente estudo pretende responder a alguns tópicos que relata a respeito do real benefício da implantação da energia solar fotovoltaica, sendo assim, algumas questões que norteiam esta pesquisa são:

(I) Qual o custo-benefício na utilização de painéis fotovoltaicos para a promoção da utilização da energia solar na empresa?

(II) Quais os benefícios financeiros em médio e longo prazo que a utilização da energia solar irá promover?

(III) Qual é a viabilidade econômica da utilização de placas fotovoltaicas em companhias?

(IV) Quais são os métodos financeiros aplicáveis a viabilidade econômica para a utilização de placas fotovoltaicas em uma determinada empresa?

(V) Quais são os resultados obtidos na realização da pesquisa e sua conclusão?

\subsection{ESTRUTURAÇÃO DO TRABALHO}

Este estudo se divide em quatro capítulos, além da Introdução. Nesse sentido é importante destacar os aspectos abordados em cada uma dessas etapas, a fim de que haja uma descrição de quais critérios foram analisados em cada uma delas.

Na Introdução, é feita uma abordagem, de maneira geral, de como cada capítulo foi desenvolvido, apresentando-se o contexto e os objetivos da pesquisa. Além disso, é mostrada a justificativa e a relevância do tema, apontando como este estudo contribuirá para a aplicação prática. Ademais, é feita uma síntese a fim de evidenciar quais são os pontos que norteiam este estudo, bem como são expostas as questões que o direcionam.

No capítulo 2, é apresenta a Viabilidade Econômica em Placas Fotovoltaicas: Uma Revisão Sistemática na base de dados Scopus Elsevier por meio do Portal de Periódicos da Capes, trazendo assim uma revisão sistemática no Portal CAPES e na base de Dados Scopus seguido de metodologia, resultados e discussões. Além disso, são apresentados resultados de como a implementação desse sistema contribui para o desenvolvimento de uma empresa específica.

No capítulo 3, são apresentados os Métodos financeiros aplicáveis à viabilidade econômica. Nesse ponto, mostram-se os cálculos que devem ser considerados durante a implementação do sistema.

O capítulo 4 apresenta a energia solar sob o aspecto da Sustentabilidade do negócio e os resultados. Foi realizada uma simulação utilizando o software Pvsyst versão 6.73, a qual permitiu que fosse identificado como funciona a implementação, em termos de resultados estatísticos, da energia solar fotovoltaica.

E, por fim, o capítulo 5 apresenta as Considerações Finais da presente pesquisa, abordando a que resultados a pesquisa chegou, apresentando se foi ou não viável a implementação do sistema objeto de estudo desta pesquisa. 


\section{Papítulo 2}

\section{VIABILIDADE ECONÔMICA \\ FOTOVOLTAICAS: UMA REVISÃO \\ EM \\ PLACAS PORTAL DE PERIÓDICOS DA CAPES E UTILIZANDO A BASE SCOPUS}

Resumo: Para a concretização deste trabalho, faz-se necessária a realização de um levantamento de trabalhos que fizeram o estudo de viabilidade econômica do uso de placas fotovoltaicas. Realiza-se através de uma revisão de literatura, que é de fundamental importância para fornecer aporte teórico para estudos futuros. O objetivo deste estudo consiste em uma investigação sobre o tema em trabalhos que abordam a viabilidade econômica e a utilização de placas solares, a partir de um conjunto preliminar de referências bibliográficas, visando auxiliar o aporte teórico deste trabalho. O webibliomining foi o modelo adotado para realizar a mineração das fontes bibliográficas que compõem esta revisão sistematizada de literatura, fundamentado em ferramentas de busca e acesso a informações bibliográficas com base na internet. A base de dados escolhida foi a Scopus Elsevier, pois é a mais abrangente frente às demais opções. Os termos de busca utilizados foram ("solar photovoltaic system board" OR "pv" AND "economic viability") nos seguintes campos: título, resumo e palavras-chave. Este estudo também aponta a relevância da pesquisa para os empreendimentos que têm interesse em utilizar as placas fotovoltaicas. Os resultados encontrados apontam que os Estados Unidos são o país que mais publica sobre o tema, bem como a área que mais publica é a de Energia. Nota-se também que o Brasil está presente entre os países de maior interesse neste contexto. Dessa forma, conclui-se que a análise da amostra de artigos encontrados e analisados neste estudo mostra que a energia solar tem ganhado visibilidade e tem sido implantada em plantas domésticas, rurais, comerciais e industriais. Porém ainda faltam incentivos ou abono de impostos para que esta fonte de energia seja competitiva e viável.

Palavras-chave: Webibliomining. Viabilidade Econômica. Sistema Solar Fotovoltaico. 


\subsection{INTRODUÇÃO}

Preservação do meio ambiente, desenvolvimento sustentável, mudança da matriz energética, aumento da demanda de energia e desenvolvimento industrial são alguns fatores que fomentam a substituição dos combustíveis fósseis por fontes renováveis e limpas, como a fonte solar (NASCIMENTO, 2017)

A energia solar fotovoltaica é a energia obtida da incidência solar que chega à superfície da Terra em ondas eletromagnéticas (fótons), podendo ser de forma difusa ou direta convertidas em eletricidade (IMHOFF, 2007). $\mathrm{Na}$ Terra, a energia solar pode ser considerada como a origem do ciclo da água, do vento e da fotossíntese do reino vegetal e do reino animal, que também depende do reino vegetal por meio das cadeias alimentares.

Dessa forma, este artigo aborda o método webibliomining, proposto por Costa (2010), pois fornece uma seleção de trabalhos acadêmicos ao pesquisador recém-ingresso em uma área de conhecimento, e sua metodologia se baseia em seis etapas. Este método está sendo aplicado de forma que facilite o encontro de um referencial teórico sobre a temática viabilidade econômica e placas fotovoltaicas.

Jesus e Costa (2015) afirmam ainda que, geralmente, mecanismos diretos são utilizados na realização deste tipo de pesquisa. Assim, busca-se o texto por palavras-chave, autor ou título, não havendo filtragens adicionais dos registros encontrados.

No decorrer do trabalho, alguns questionamentos começaram a manifestar-se, como: este tema tem sido foco de estudo há muito tempo? Qual ano foi o de maior procura? Algum autor se destaca ou se destacou por ter maior número de documentos publicados sobre o tema? Qual a área que mais possui documentos relacionados? Qual o país que mais publica dentro da busca das palavras-chave em questão? O que se tem falado a respeito deste tema? Quais universidades têm desenvolvido projetos e estudos?

Nesse contexto, o objetivo deste artigo é o de oferecer aporte teórico de forma a embasar e a complementar estudos futuros, por meio da realização de uma revisão sistematizada de literatura, identificando os trabalhos que abordam a viabilidade econômica da utilização de placas fotovoltaicas, bem como de apresentar uma visão da produção científica, utilizando a base de dados Scopus Elsevier, pelo Portal de Periódicos da Capes.

Os resultados deste estudo foram apresentados em forma de tabelas, gráficos e quadros, contendo o número de publicação sobre o tema, os autores que mais relatam sobre o mesmo, além do quantitativo de trabalhos publicados por ano, por país e por área, de forma que possam auxiliar futuros trabalhos.

\subsection{REVISÃO DE LITERATURA}

\subsubsection{ENERGIA SOLAR NO MUNDO}

É de se notar que, desde os tempos antigos, já havia a necessidade de usar o sol para fins além do sentir seu calor e sua luz diretos (CARVALHO; CALVETE, 2010). Kemerich et al. (2016) relata que o "aproveitamento da energia solar para fins de iluminação deu-se no período Paleolítico". Ainda, Kemerich et al. (2016) abordam que, desde o início, já havia a preocupação em relação à "obtenção de uma forma de luz artificial", sendo que, no período de produção do fogo, mediante o uso de um graveto de vegetal grudento, o homem conseguiu dar seu primeiro passo em direção ao seu objetivo.

Segundo, Carvalho e Calvete (2010), nota-se que há um, hiato de tempo de dois milênios, que vai desde os tempos da arquitetura Greco-Romana até a produção em série de placas finas fotovoltaicas atuais.

Porém segundo, Carvalho e Calvete (2010), na antiguidade, romanos e gregos conseguiram eficientemente usar a arquitetura em um design solar passivo para usufruir da capacidade de aquecer e iluminar espaços arquitetônicos interiores, construindo a parte da casa mais importante voltada para o sul. Dir-se-á que a necessidade aguça o engenho humano, e, nesse âmbito, os romanos foram mais audazes ao cobrir partes abertas dos edifícios com mica ou vidro para reter o calor do sol invernal.

Também Carvalho e Calvete (2010) relatam que no século dezenove, Auguste Mouchot, o "inventor francês do primeiro motor solar ativo", responsável por transformar energia solar em energia de vapor, fez questionamentos quase proféticos sobre $\mathrm{o}$ 
modo de pensar que os combustíveis fósseis usados na data, especialmente o carvão.

Segundo Reis (2012), os sistemas mais promissores pela busca de fontes sustentáveis e renováveis de energia limpa são as células fotovoltaicas, pois possuem capacidade de conversão direta da luz solar em energia elétrica.

Além disso, o grande mercado do fotovoltaico teve um crescimento considerável, impulsionado pelas políticas iniciadas em países como o Japão e a Alemanha e que ocorreram neste século. Na década de 2000, o Japão instalou 25.000 painéis solares em habitações, por exemplo. Tal crescimento deu origem a uma diminuição dos custos de produção, criando assim economias de escala e impondo um crescimento do fotovoltaico em 30 por cento anuais em nível global, embora com um continuado apoio estatal em vários países (CARVALHO; CALVETE, 2010).

Por volta de 2050, segundo dados da Agência Internacional de Energia (IEA, 2017), a geração solar de energia elétrica corresponderá a cerca de $11 \%$ do total, algo em torno dos 5000 TWh. Para obter tal capacidade de geração, as instalações solares ocuparam, somadas, cerca de $8 \mathrm{mil}$ $\mathrm{Km} 2$

Há a possibilidade de que a geração de energia solar se transforme na maior fonte de renda do norte da África, que exportaria energia para a Europa, para a Rússia, para o Oriente Médio e para outras partes da Ásia (MME, 2015)

Dados de 2015, segundo a revista (Energia solar no Brasil e no Mundo, 2015) demonstram que a potência solar instalada até esse ano era de $234 \mathrm{GW}$, sendo $229 \mathrm{GW}$ de geração fotovoltaica (FV) e 5 GW de Concentrating Solar Power (CSP).

Com um fator de capacidade média da ordem de 13,9\%, a geração total foi de 253 TWh. Segundo dados do Núcleo de Estudos Estratégicos de Energia, do Ministério de Minas e Energia (MME, 2015), a Itália apresentou o maior percentual de geração de energia solar em relação à sua geração total, de 9,3\%, seguida da Grécia (7,8\%). A Espanha fica com o maior fator de capacidade, de 29,3\%, em razão da presença de mais de $40 \%$ de potência instalada de CSP, boa parte com estoque de calor entre 7 e 8 horas, para gerar nos períodos sem sol.
Os cinco primeiros países em potência instalada respondem por $68 \%$ do total mundial. Em 2015, China ficou em primeiro lugar e os Estados Unidos em segundo lugar, superaram a Alemanha na geração (MME, 2015).

Em 2018, o Brasil deverá estar entre os 20 países maiores geradores de energia solar, ao se considerar a operação da potência já contratada, de 2,6 GW. Em termos de área geográfica, os 234 GW de 2015 correspondem a $1.635 \mathrm{~km}^{2}$ de painéis solares, ou um quadrado de 40,4 km de lado, considerando $143 \mathrm{~W} / \mathrm{m}^{2}$ (eficiência de $15 \%$ de absorção solar) (ANEEL, 2018).

\subsubsection{A ENERGIA SOLAR E O BRASIL}

Para Nascimento (2017) apud MME (2017), o Brasil possuía $81 \mathrm{MWp}$ de energia solar fotovoltaica instalados ao final de 2016, o que tinha representatividade de $0,05 \%$ da total capacidade instalada no País. Ainda, "total de 81 MWp existentes em 2016, 24 MWp correspondiam à geração centralizada e 57 MWp à geração distribuída" (NASCIMENTO, 2017 apud MME, 2017).

De acordo com Nascimento (2017), o Brasil, por sua localização e extensão territorial, possui "grandes reservas de quartzo de qualidade, que podem gerar vantagem competitiva para produção de silício com alto grau de pureza, células e módulos solares, produtos esses de alto valor agregado".

A Agência Nacional de Energia Elétrica (ANEEL), em seu relatório sobre energia solar, afirma que suas maiores aplicações atuais são para o aquecimento de água e geração fotovoltaica de energia elétrica, sendo o segundo mais encontrado nas Regiões Norte e Nordeste, em comunidades que não têm acesso à rede de energia elétrica (ANEEL, 2018).

A utilização da fonte solar para gerar energia elétrica proporciona diversos benefícios, citados pela Associação Brasileira de Energia Solar Fotovoltaica (ABSOLAR), tanto do ponto de vista elétrico como do ambiental e do socioeconômico (ABSOLAR, 2017).

Há o amparo legal da resolução 482 da ANEEL, de 7 de abril de 2012, que permite o acesso da microgeração distribuída à rede elétrica nacional, garantindo, assim, um subsídio jurídico para a resposta às soluções socioeconômicas e ambientais da geração e 
da distribuição de energia elétrica (MME, 2015).

Sobre a questão ambiental, Imhoff (2007) reforça que a energia solar é uma das fontes primárias menos poluentes; é silenciosa, possui baixo nível de manutenção, é menos agressiva à fauna e à flora do que outras fontes e, como pode ser gerada na própria unidade consumidora, não necessita de linhas de transmissão, diminuindo, assim, grandemente, seu impacto ambiental.

Após a introdução do regulamento da medição líquida, em 2012, Holdermann et al. (2014) analisaram a viabilidade do desenvolvimento do sistema fotovoltaico em pequena escala e conectado à rede como alternativa para as questões ambientais e socioeconômicas. Rocha et al. (2017) complementando esses estudos, indicam que há uma forte pressão para mudança nos meios de produção de energia e que a leitura é um mecanismo importante na disseminação de sistemas fotovoltaicos de pequena escala.

Como uma grande solução para a questão socioeconômica da energia, Vale et al. (2017) conduziram estudos no Programa Minha Casa Minha Vida (MCMV) no intuito de se analisar a redução de custos e impactos econômicos da instalação de sistemas fotovoltaicos de pequena escala ligados à rede nas moradias desse Programa.

Para Mitscher et al. (2012), que realizaram um estudo da competitividade econômica da microgeração de energia elétrica conectada à rede, esse sistema já se mostra comercialmente competitivo desde que havendo isenções fiscais.

Tal estudo recebe apoio das bases lançadas por Byrne; Shin; Wallace. (1998), que conduziram experimento semelhante na Mongólia, provando sua viabilidade econômica. Observando-se algumas diferenças de ordem técnica, os quadros socioeconômicos são bastante semelhantes, o que tem valor para respaldar a pesquisa realizada por Mitscher et al. (2012).

O Brasil, pela sua localização e extensão territorial, possui a matriz energética mais renovável do mundo industrializado, com quase metade de sua produção proveniente de fontes como recursos hídricos, biomassa e etanol, além das energias eólica e solar. $\mathrm{Na}$ Figura 1, é possível observar a matriz energética do Brasil.

Figura 1: Abastecimento Total de Energia Primária do Brasil

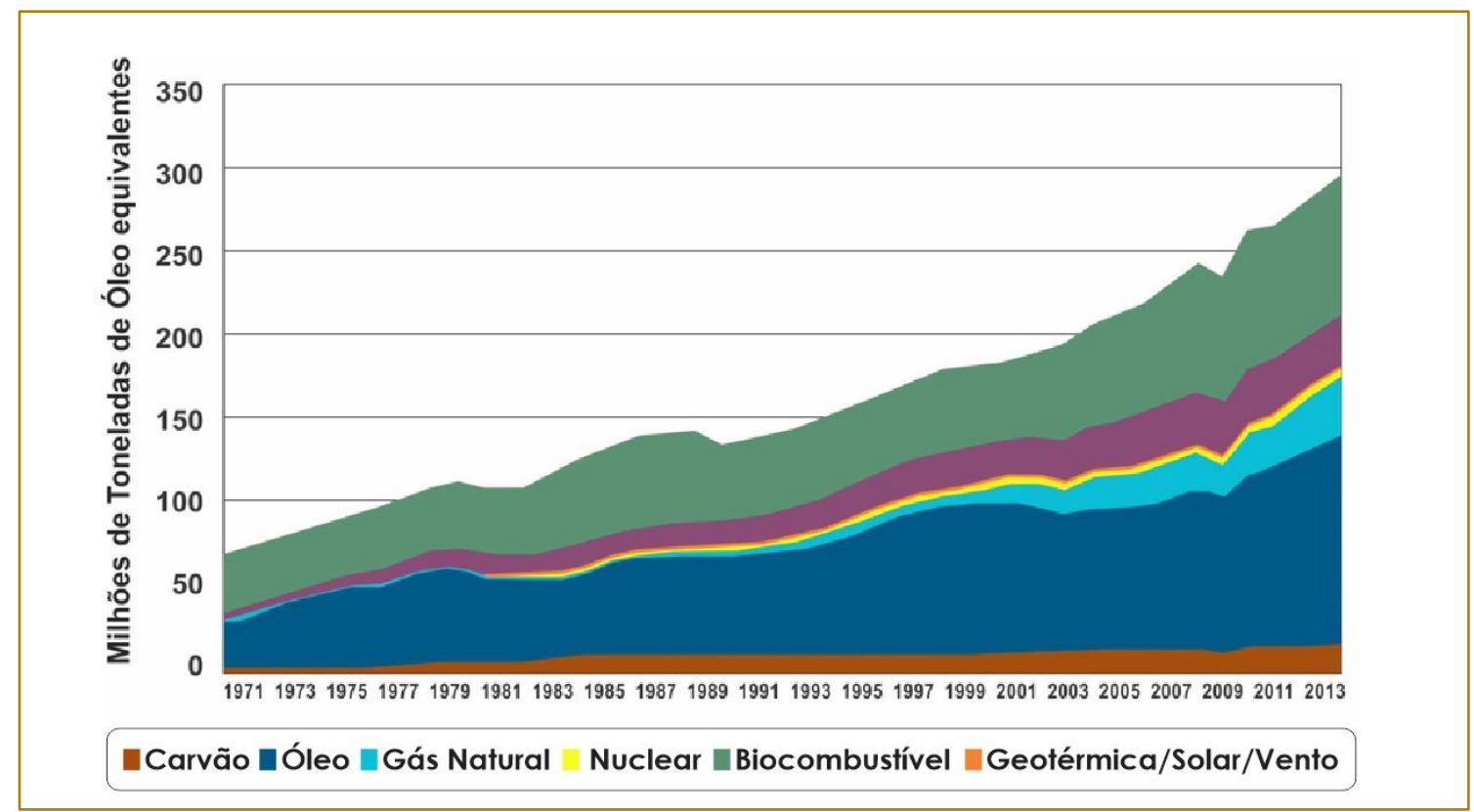

Fonte: International Energy Agency (IEA) Energy Statistics (2018).

Os dados contidos na Figura 1 trazem a relação entre milhões de toneladas de óleo equivalentes em um intervalo de tempo, no qual é possível observar a matriz energética do Brasil, em que se pode notar, em verde, que a produção de biocombustíveis está em ascensão no Brasil. Observa-se também que Hidro, Nuclear, Geotérmica, Gás Natural e 
Óleo tiveram um crescente no decorrer do período datado, e, por fim, o Carvão foi o que manteve maior linearidade se comparado aos outros.

Como a maior parte do território brasileiro encontra-se entre a linha do Equador e o Trópico de Capricórnio, não há variações consideráveis na duração solar do dia. Porém, com o intuito de maximizar o aproveitamento da radiação solar, faz-se necessário o ajuste da posição do coletor ou painel solar ou fotovoltaico com a latitude do local e o período do ano em que se requer mais energia (ANEEL, 2018).

Segundo Pereira e Oliveira (2011), os painéis fotovoltaicos são os componentes principais de um sistema fotovoltaico de geração de energia, os quais são formados por um aglomerado de células voltaicas, que podem estar associadas eletricamente em paralelo e/ou em série. Estas células têm o objetivo de captar a irradiação solar e transformá-la em energia elétrica.

\subsubsection{CUSTOS DA ENERGIA SOLAR NO BRASIL}

Segundo Nascimento (2017), o MME (2009) "ressalta dois mecanismos regulatórios básicos de incentivos: o sistema de preços e o sistema de quota".

O primeiro se define por um valor pago ao dono do gerador de energia solar fotovoltaica em um dado período igual ou superior a vinte anos. Já o segundo estabelece metas de potência e (ou) energia oriunda de fontes específicas para as concessionárias, distribuidoras, grandes consumidores e outros agentes do setor elétrico (NASCIMENTO, 2017).

Mais adiante, dados informados pela Enel $X$ (2018) descreve de forma literal a energia solar como gratuita, conforme abaixo:

Por exemplo, um sistema de energia solar fotovoltaico de $3.3 \mathrm{KWp}$ no valor de $\mathrm{R} \$ 25 \mathrm{mil}$, mais $\mathrm{R} \$ 6$ mil de manutenção no período de 25 anos, é igual a um investimento total de $\mathrm{R} \$ 31$ mil. Em 25 anos, a energia gerada será de aproximadamente 94 mil KWh. Se dividirmos o valor do investimento pela energia gerada chegaremos ao preço de $\mathrm{R} \$ 0,31 / \mathrm{kWh}$. Um valor $57,6 \%$ mais barato que a tarifa de energia elétrica atual no estado do Rio de Janeiro, que custa $R \$ 0,73$.
Não especificados aqui, os custos ambientais da geração solar de energia, em termos de impacto ambiental, são mínimos quando comparados aos de outras fontes. Diferentemente da geração hidrelétrica, por exemplo, na qual são necessários desvios nos rios e formação de grandes reservatórios, há um custo de enormes áreas, quer sejam de mata nativa, quer sejam de terras produtivas ou habitadas.

\subsubsection{TIPOS DE ENERGIA SOLAR NO BRASIL}

O tipo mais encontrado de conversão de energia solar em elétrica no Brasil é o uso do painel Fotovoltaico (FV).

Segundo Brasil (2015), na década de 1950, os "painéis solares convertiam apenas 4,5\% da energia solar em eletricidade", equivalendo a $13 \mathrm{Wp} / \mathrm{m} 2$ e custando US\$1.785/Wp. Ainda, relata que a eficiência mundial triplicou para $15 \% \quad(143 \mathrm{Wp} / \mathrm{m} 2)$, custando 1.370 vezes mais barato, de US\$1.30/Wp.

A grande maioria dos painéis Fotovoltaicos (FV) empregados hoje, com participação de 95\% do mercado, é confeccionada em silício cristalino puro (c - SI) e possuem rendimento energético entre 13\% e 17\% (MME, 2015).

Há também uma variante mais barata de FV, com menor eficiência energética, as chamadas células de película fina, compostas por finas camadas de materiais semicondutores fotovoltaicos (silício amorfo a-Si, telureto de cádmio - CdTe e disselenito de cobre-índio-gálio - CIGS) sobre uma base geralmente de vidro, aço inoxidável ou plástico.

No caso da conversão fotovoltaica em energia elétrica, seu uso atende a pequenos sistemas e microssistemas autônomos, em geral Geração Distribuída (GD) ou em grandes centrais, que utilizem energia solar de modo centralizado. Já o processo do CSP é indicado para grandes centrais.

Geração Distribuída (GD) é o tipo de geração que ocorre próximo ou na unidade consumidora.

A ANEEL aprovou, em 2012, Resoluções Normativas 482 e 517, que regulamentam a microgeração de energia elétrica, além de estabelecer o sistema de compensação de energia elétrica (net metering), sendo utilizado atualmente em muitos países (ANEEL, 2018). 
O processo envolve apenas a troca de kWh entre o consumidor - gerador e a distribuidora de energia.

Também se registra no Brasil o uso da energia solar por concentração, no processo conhecido como Concentrating Solar Power (CSP), para geração de energia elétrica ou aquecimento.

No processo CSP, a energia solar é concentrada em um receptor, que recebe e transfere a energia para um fluido de transferência de calor, que pode fornecer calor para aplicações finais, ou acionar motores térmicos ou turbinas convencionais a vapor, para a geração de energia elétrica (MME, 2015).

Nas grandes instalações CSP, há armazenadores de calor para permitir o fornecimento de calor e eletricidade à noite ou em condições de céu nublado.

Há quatro tipos de tecnologia CSP: Calha parabólica (CP), Refletor Fresnel (RF), Torre Solar (TS) e Disco Solar (DS) (MME, 2015).

Nas plantas CP e RF, a energia solar é concentrada em uma linha focal, atingindo temperaturas operacionais entre $300^{\circ} \mathrm{C}$ e $550^{\circ}$ C. Nas plantas TS e DS, a luz solar é concentrada em um único ponto, o que faz com que atinjam temperaturas operacionais mais altas do que nas plantas CP e RF. Os espelhos refletores podem ser fixos ou móveis, e em conjunto ou não com o plano focal (MME, 2015).

Constata-se através das pesquisas realizadas, que a tecnologia $\mathrm{CP}$ é a que está mais madura e é a mais empregada no mercado atualmente.

\subsubsection{LEGISLAÇÃO SOBRE ENERGIA SOLAR NO BRASIL}

Para a Portal Solar LTDA - ME (2018), a Resolução Normativa n. ${ }^{\circ}$ 482/2012 da ANEEL estabelece "as condições gerais para a conexão dos sistemas de energia solar fotovoltaica na rede de energia elétrica".
Outrossim, a Portal Solar LTDA - ME (2018) reforça que esta é "resolução que permite a você fazer esta "troca" de energia com a rede elétrica".

O Conselho Nacional da Política Fazendária Ministério da Fazenda (CONFAZ, 2015), por meio do Ajuste SINIEF 2, revogou o Convênio que "orientava a tributação da energia injetada na rede". A decisão quanto ao tributar ou não a energia solar que é injetada na rede da distribuidora passou a ser de cada estado.

Além do mais, alguns estados ainda não isentaram a energia solar de ICMS: Amazonas, Paraná e Santa Catarina.

Por fim, o Governo Federal, por meio da Lei n. ${ }^{\circ}$ 13.169, isentou o PIS e COFINS à energia solar injetada na rede (PORTAL SOLAR LTDA - ME, 2018).

\subsection{METODOLOGIA}

Nesta etapa, é explicado como a busca foi realizada no mês de janeiro de 2018 , de forma detalhada, na base de dados Scopus Elsevier, que foi escolhida por ser a mais abrangente frente às demais opções.

\subsubsection{QUANTO AOS FINS}

No que se refere aos procedimentos técnicos, este é um artigo teórico-conceitual, de natureza exploratória e abordagem da pesquisa qualitativa, inspirado no método webibliomining, sugerido por Costa (2010), para realizar a revisão sistematizada de literatura.

\subsubsection{QUANTO AOS MEIOS}

Motivado pelos modelos de Freitas e Costa (2017), Jesus e Costa (2015) e Neves et al. (2015, p.61), o trabalho seguirá seis etapas, sendo estas descritas no Quadro 1. 
Quadro 1: Modelo de desenvolvimento para a realização de uma bibliometria

\begin{tabular}{|c|r|}
\hline Etapa 1 & Etapas \\
\hline Etapa 2 & Pesquição da amostra da pesquisa; \\
\hline Etapa 3 & Identificação dos periódicos com maior número de artigos publicados sobre o tema; \\
\hline Etapa 4 & Identificação dos autores com maior número de publicações; \\
\hline Etapa 5 & Levantamento da cronologia da produção, identificando ciclos de maior produção; \\
\hline Etapa 6 & Seleção dos artigos para composição do "núcleo de partida" para a pesquisa \\
bibliográfica.
\end{tabular}

Fonte: Adaptado de Costa (2010).

Para a consumação da primeira etapa, foi realizada uma revisão de literatura na base de dados Scopus Elsevier, acessada em janeiro de 2018, por meio do Portal de Periódicos da Capes, uma vez que esta contém, não apenas artigos acadêmicos, mas outros tipos de publicações, como as de acesso livre, publicações comerciais, entre outros (ELSEVIER, 2018). Os filtros de exclusão não foram utilizados para que o intervalo de documentos da área encontrada fosse maior.

Apenas os campos: título, palavra-chave e resumo foram incluídos como campo de pesquisa. Este estudo abrangeu todas as áreas de conhecimento presentes no banco de dados. O operador "AND" garante que as publicações encontradas contenham todas as palavras pesquisadas, enquanto $\mathrm{o}$ uso do operador "OR" possibilita um ou outro termo.

Após a escolha da base de dados, foram estabelecidos os critérios de busca. Com a finalidade de realizar uma ampla cobertura das publicações sobre o tema de viabilidade econômica da utilização de placas fotovoltaicas, foi investigada a área como um todo, de forma a coletar todos os possíveis estudos desenvolvidos.

Para a segunda etapa foram definidas o conjunto de keywords ou termos-chave ("solar photovoltaic system board" OR "pv" AND "economic viability") no campo de busca correspondente a "título, palavras-chave, resumo", alcançando 187 resultados. Estes termos foram selecionados de modo que pudessem ser encontrados no título do artigo, no resumo, ou nas palavras-chave do mesmo.

Houve restrição de pesquisa quanto ao período de tempo, abrangendo apenas os anos que apresentavam pelo menos duas publicações, até janeiro de 2018, e quanto aos outros tópicos, foram abordados apenas os dez principais retornados pela base de dados. Foi utilizada esta metodologia para que os dados possam ser mais significativos e recentes.

A terceira e quarta etapas permitiram identificar os autores, periódicos, países, tipo e ano de publicação e áreas de conhecimento com maior número de publicações. Este estudo se baseou nos dez principais dados fornecidos pela base, ou seja, para cada categoria foram considerados os dez primeiros dados fornecidos pela mesma.

A quinta etapa permitiu a visualização das produções e autores com mais citações. Por fim, a sexta etapa da metodologia proposta por Costa (2010) trata de um estudo cronológico das produções acadêmicas realizado com o objetivo de apresentar a evolução científica sobre o tema. Essa pesquisa foi realizada de 01/01/2018 até 31/01/2018.

\subsection{RESULTADOS E DISCUSSÕES}

Nesta etapa, foram analisados os 187 artigos resultantes e, a partir dessa análise, foi composto um núcleo de dez artigos, que mais se aproximaram, de fato, com o tema deste estudo.

Dessa forma, utilizando esse núcleo, são apresentados aqui gráficos e tabelas, contendo essas publicações, que se relacionam com a quantidade de publicações por ano, com quais autores publicaram sobre o tema, com as origens dos artigos, bem como suas afiliações. Também são mostradas as quantidades de publicações por países e por área, apresentando aqueles que possuem destaque. 


\subsubsection{NÚMERO DE PUBLICAÇÕES POR ANO}

Os dados contidos na Figura 2 apresentam o número de publicações em um recorte temporal. Foram considerados apenas os anos que apresentaram, pelo menos, duas publicações sobre o tema.

Figura 2: Frequencia das publicações por ano no perído de 1985-2018

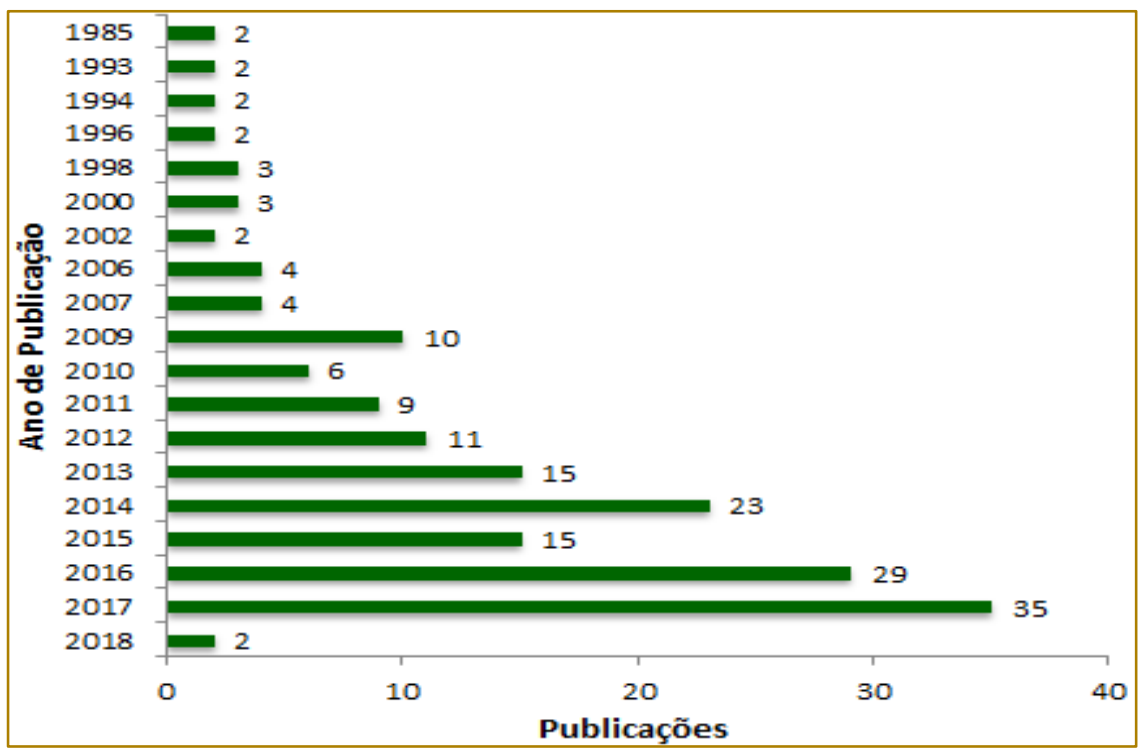

Fonte: Adaptado da Scopus (2018).

Pode-se observar que, a partir do ano de 2013, o volume de publicação aumenta. O ano de 2017 foi o que apresentou um número maior, com 35 publicações. O presente ano de 2018 já apresenta duas publicações.

\subsubsection{AUTORES QUE PUBLICARAM SOBRE O TEMA E NÚMERO DE CITAÇÕES}

Os dados contidos na Figura 3 demonstram os autores que mais publicaram sobre o tema e também o número de citações.

Figura 3: Autores com maior frequência de publicação

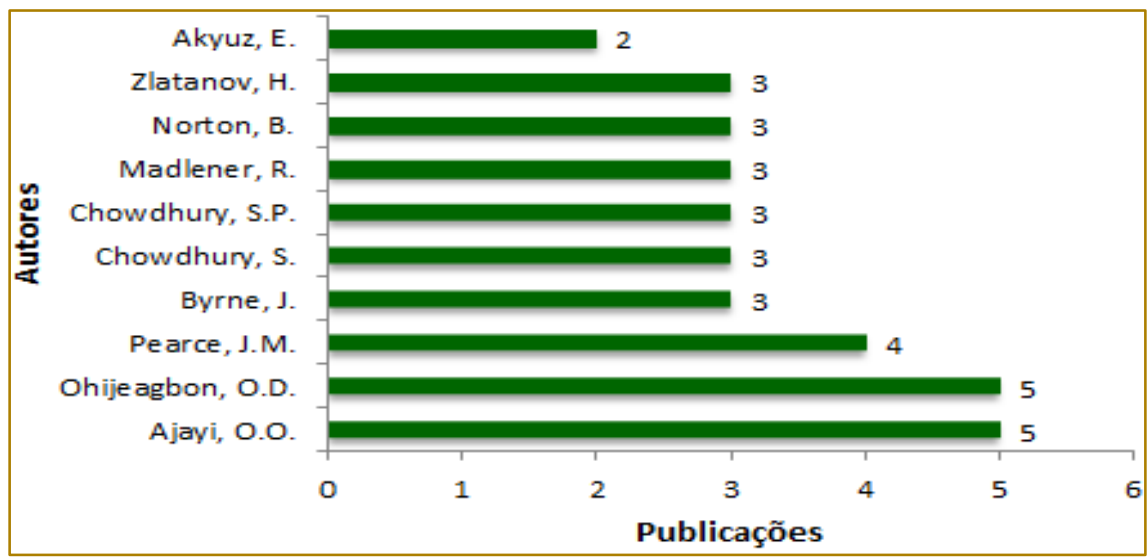

Fonte: Adaptado da Scopus (2018)

Pode-se observar que os autores Ohijeagbon, O.D. e Ajayi, O.O. foram os que tiveram maior número de publicações em relação à temática estudada nesta obra.

\subsubsection{ORIGEM DE PUBLICAÇÃO}

Na Tabela 1, são apresentados os dados das origens das publicações, bem como quantos 
documentos cada uma possui. Além disso, também são expostos os fatores de impacto pelo Scientific Jornal Rankings ou Ranking
Científico de Revistas (SJR) e o impacto de citações por documentos.

Tabela 1: Número de documentos publicados por origem de publicação

\begin{tabular}{|l|c|c|c|}
\multicolumn{1}{c}{ Origem de publicação } & \multicolumn{2}{c}{$\begin{array}{c}\text { Números de } \\
\text { documentos }\end{array}$} & \multicolumn{2}{c|}{$\begin{array}{c}\text { Sator de Impacto } \\
\text { Cites per doc. }\end{array}$} \\
\hline Renewable and Sustainable Energy Reviews & 14 & 3.05 & 8.78 \\
\hline Renewable Energy & 12 & 1.7 & 4.8 \\
\hline Energy Policy & 11 & 2.2 & 4.4 \\
\hline Applied Energy & 8 & 3.06 & 7.58 \\
\hline Energy Procedia & 6 & 0.47 & 1.02 \\
\hline Energy & 5 & 2 & 4.95 \\
\hline Journal of Renewable and Sustainable Energy & 5 & 0.42 & 1.17 \\
\hline International Journal of Hydrogen Energy & 4 & 1.14 & 3.71 \\
\hline Energy Conversion and Management & 3 & 2.29 & 6.06 \\
\hline Conference Record Of the IEE Photovoltaic & 1 & 0.23 & 0 \\
\hline
\end{tabular}

Fonte: Adaptado da Scopus (2018).

Os dados das dez principais origens das publicações são apresentados na Tabela 1, bem como quantos documentos cada uma possui. Destacam-se o Renewable and Sustainable Energy Review, com 14 publicações na área, seguido do Renewable Energy, com 12 e a Energy Policycom 11.

Já em relação ao SJR, a origem que se destaca é a Applied Energy, com 3.06, e Renewable And Sustainable Energy Reviews, com valor 3.05 .
Por outro lado, nas citações, percebe-se que, em primeiro lugar, se tem Renewable and Sustainable Energy Reviews, com valor 8.78 por citação, seguido da Applied Energy com 7.58 e da Energy Conversion and Management, com 6.06.

\subsubsection{AFILIAÇÃO}

Conforme exposto nos dados na Figura 4, são apresentadas as dez Universidades ou Organizações, também conhecidas como afiliações, mais relevantes, bem como quantos artigos cada uma delas abrange.

Figura 4: Afiliações com maior frequência de publicação

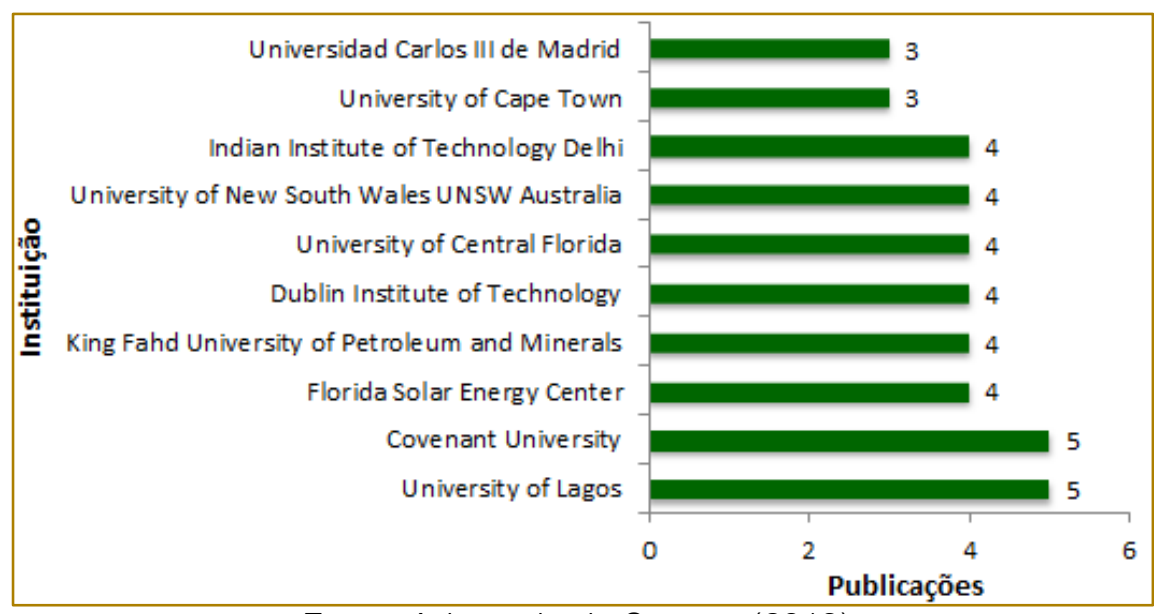

Fonte: Adaptado da Scopus (2018).

Pode-se destacar, nos dados da Figura 4, a Covenant University e a University of Lagos, com cinco publicações cada.

\subsubsection{NÚMERO DE PUBLICAÇÕES POR PAÍSES \\ Os dados contidos na Figura 5 ilustram a quantidade de publicações existente por país.}


Figura 5: Países com maior frequência de publicação

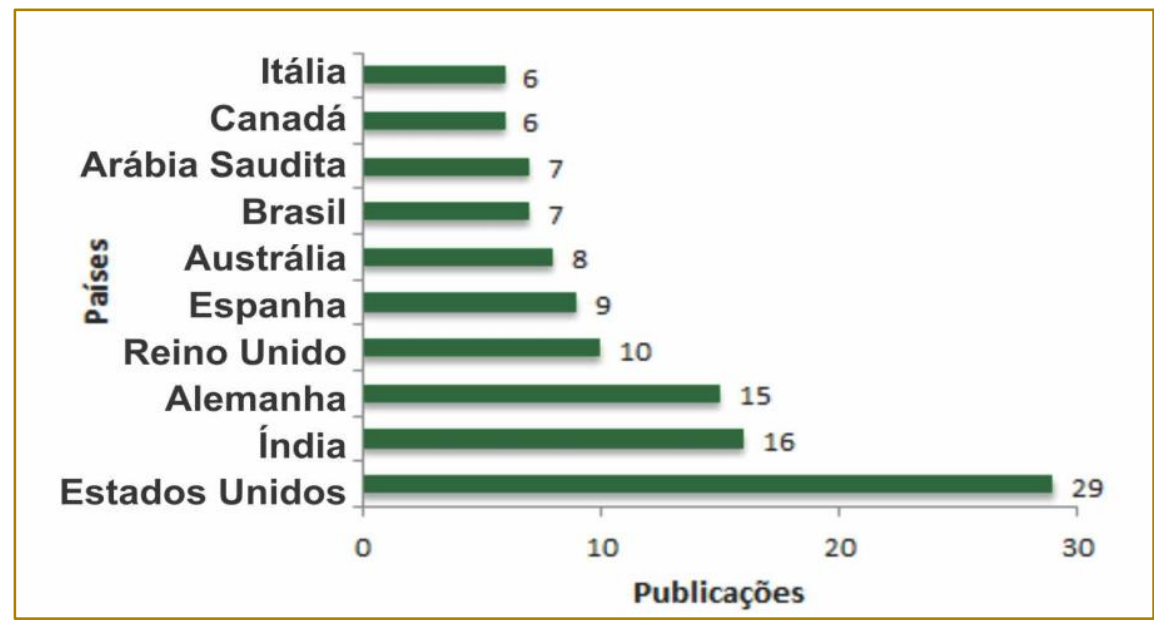

Fonte: Adaptado da Scopus (2018).

De acordo com os dados da Figura 5, observa-se que os Estados Unidos são o país que mais pesquisa sobre o tema, contando com 29 publicações, quase o dobro do país seguinte. Após este, destacam-se a Índia, com 16 publicações, e a Alemanha, com 15. O Brasil está presente entre os dez países mais relevantes, com sete publicações, superando a Itália e o Canadá.

\subsubsection{NÚMERO DE PUBLICAÇÕES POR ÁREA}

Os dados contidos na Figura 6 ilustram, em forma de gráfico, as áreas de conhecimento com maior frequência de publicação.

Figura 6: Áreas de conhecimento com maior frequência de publicação

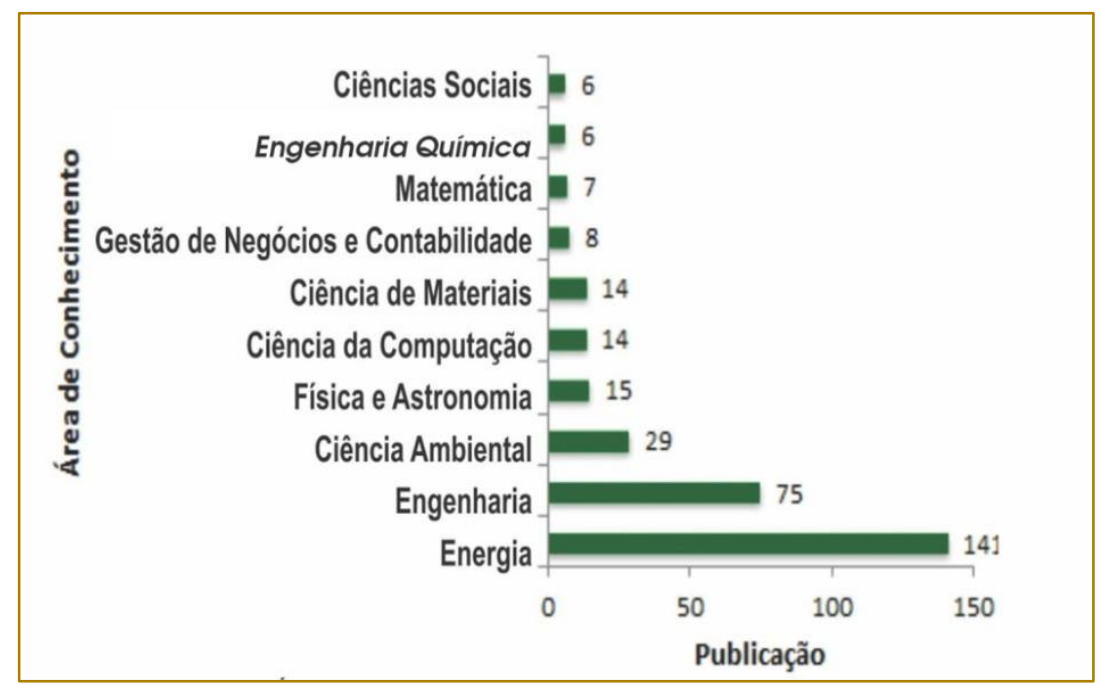

Fonte: Adaptado da Scopus (2018).

Dentre as diversas áreas de conhecimento existentes, as publicações foram classificadas em dez áreas: Energia; Engenharia; Ciência Ambiental; Física e Astronomia; Ciência da Computação; Ciência de Materiais; Negócios, Gestão e Contabilidade; Matemática; Engenharia Química; e Ciências Sociais, como pode ser visto na Figura 6. A área de Energia se destaca com 141 publicações, quase 0 dobro da segunda área de conhecimento, Engenharia, com 75 publicações. 


\subsubsection{ANÁLISE DA AMOSTRA DE ARTIGOS QUE FORMARAM O NÚCLEO ADERENTE AO TEMA}

Nesta etapa, os 187 documentos foram analisados e dez artigos foram selecionados entre os demais, com base na análise de seus resumos científicos. Estes, dispostos a seguir no Quadro 2, são aqueles considerados pelo autor como os de maior relevância para o tema proposto, por melhor correlacionarem a viabilidade econômica e as placas de sistema solar fotovoltaicas em nível mundial, além de focar na análise dos artigos elaborados no Brasil com o intuito de identificar os resultados encontrados em relação aos autores brasileiros.

\section{Quadro 2: Artigos selecionados}

\begin{tabular}{|c|c|c|c|}
\hline TÍTULO & AUTOR & ANO & CITAÇÕES \\
\hline $\begin{array}{l}\text { THE ECONOMICS OF SUSTAINABLE ENERGY FOR RURAL } \\
\text { DEVELOPMENT: A STUDY OF RENEWABLE ENERGY IN } \\
\text { RURAL CHINA }\end{array}$ & $\begin{array}{l}\text { Byrne, J., Shen, B., } \\
\quad \text { Wallace, W. }\end{array}$ & 1998 & 95 \\
\hline $\begin{array}{l}\text { THE POTENTIAL AND ECONOMIC VIABILITY OF SOLAR } \\
\text { PHOTOVOLTAIC POWER IN GHANA }\end{array}$ & $\begin{array}{l}\text { Asumadu-Sarkodie, } \\
\text { S., Owusu, P.A. }\end{array}$ & 2016 & 23 \\
\hline $\begin{array}{l}\text { ECONOMIC VIABILITY OF SOLAR HOME SYSTEMS: CASE } \\
\text { STUDY OF BANGLADESH }\end{array}$ & $\begin{array}{l}\text { Asumadu-Sarkodie, } \\
\text { S., Owusu, P.A. }\end{array}$ & 2010 & 43 \\
\hline $\begin{array}{l}\text { DOMESTIC APPLICATION OF SOLAR PV SYSTEMS IN } \\
\text { IRELAND: THE REALITY OF THEIR ECONOMIC VIABILITY }\end{array}$ & $\begin{array}{l}\text { Li, Z., Boyle, F., } \\
\text { Reynolds, A. }\end{array}$ & 2011 & 37 \\
\hline $\begin{array}{l}\text { STUDY OF ECONOMIC VIABILITY OF PHOTOVOLTAIC } \\
\text { ELECTRIC POWER FOR QUETTA - PAKISTAN }\end{array}$ & Khalid, A., Junaidi, H. & 2013 & 22 \\
\hline $\begin{array}{l}\text { DISTRIBUTED PHOTOVOLTAIC GENERATION IN BRAZIL: } \\
\text { AN ECONOMIC VIABILITY ANALYSIS OF SMALL-SCALE } \\
\text { PHOTOVOLTAIC SYSTEMS IN THE RESIDENTIAL AND } \\
\text { COMMERCIAL SECTORS }\end{array}$ & $\begin{array}{l}\text { Holdermann, C., } \\
\text { Kissel, J., Beigel, J. }\end{array}$ & 2014 & 15 \\
\hline $\begin{array}{l}\text { ECONOMIC PERFORMANCE AND POLICIES FOR GRID- } \\
\text { CONNECTED RESIDENTIAL SOLAR PHOTOVOLTAIC } \\
\text { SYSTEMS IN BRAZIL }\end{array}$ & $\begin{array}{l}\text { Mitscher, M., Rüther, } \\
\text { R. }\end{array}$ & 2012 & 33 \\
\hline $\begin{array}{l}\text { PHOTOVOLTAIC ELECTRICITY PRODUCTION IN BRAZIL: A } \\
\text { STOCHASTIC ECONOMIC VIABILITY ANALYSIS FOR } \\
\text { SMALL SYSTEMS IN THE FACE OF NET METERING AND } \\
\text { TAX INCENTIVES }\end{array}$ & $\begin{array}{l}\text { Rocha, L.C.S., Aquila, } \\
\text { G., Pamplona, E.D.O., } \\
\text { Chieregatti, B.G., } \\
\text { Lima, J.D.S.B. }\end{array}$ & 2017 & 0 \\
\hline $\begin{array}{l}\text { ANALYSIS OF THE ECONOMIC VIABILITY OF A } \\
\text { PHOTOVOLTAIC GENERATION PROJECT APPLIED TO THE } \\
\text { BRAZILIAN HOUSING PROGRAM "MINHA CASA MINHA } \\
\text { VIDA" }\end{array}$ & $\begin{array}{l}\text { Vale, A.M., Felix, } \\
\text { D.G., Fortes, } \\
\text { M.Z.Dias, B.H., } \\
\text { Santelli, B.S. }\end{array}$ & 2017 & 0 \\
\hline $\begin{array}{l}\text { IMPACT OF RURAL GRID-CONNECTED PHOTOVOLTAIC } \\
\text { GENERATION SYSTEMS ON POWER QUALITY }\end{array}$ & $\begin{array}{l}\text { Pinto, R., Mariano, S., } \\
\text { Calado, M.D.R., De } \\
\text { Souza, J.F. }\end{array}$ & 2016 & 7 \\
\hline
\end{tabular}

Fonte: Elaboração própria (2018).

Byrne et al. (1998) examinaram os estudos de caso e os esforços de modelagens mais recentes que avaliaram a viabilidade econômica das tecnologias das energias fotovoltaica e off-grid para aplicações rurais em países em desenvolvimento. Estes realizaram estudos de caso em 41 famílias da
Região Autônoma da Mongólia, situada no interior da China. Foi observado nas análises realizadas que os custos nivelados dos sistemas fotovoltaicos e off-grid à escala doméstica são competitivos, em termos de custos, com os conjuntos convencionais a diesel, e os sistemas híbridos solar-eólica 
aparentam ser um meio econômico de fornecer serviços elétricos durante todo o ano, além de atender às demandas de energia das famílias que estão mais remotas no interior da Mongólia.

Asumadu-Sarkodie et al. (2016) avaliaram a potencialidade e a viabilidade econômica da energia solar fotovoltaica em Gana, utilizando o software RETScreen. Um sistema de energia solar de 5 megawatts é conectado à rede usando um módulo solar SunPower SPR320E-WHT-D, o qual pode ser aproveitado para as seguintes localidades: Navrongo, Bawku, Wa, Tema, Bolgatanga, Axim, Salaga, Kintampo, Kete Krachi, Tamale, Hohoe, Koforidua, Ejura, Takoradi, Bole, Sunyani, Bibiani, Cape coast, Prestea e Akuse. Porém, faz-se necessário um investimento de 17.752.179 dólares e 25.313 metros quadrados de terreno para a instalação do sistema. Como o potencial de 5 megawatts é limitado para Accra, Kumasi, Wenchi e Tafo, existem potenciais de energia solar fotovoltaica para módulos fotovoltaicos de baixa capacidade, como é o caso dessas localidades. Para o desenvolvimento da tecnologia solar em um país em desenvolvimento, como Gana, faz-se necessário investimentos governamentais, como subsídios e criação de ambientes econômicos favoráveis para o investimento do setor privado, fato que impulsionará as possibilidades de investimento em energia renovável em Gana, além de reduzir as quedas de energia e vazamento de carga e aumentar a produtividade e a resiliência econômica.

Hossain Mondal (2010) disserta que a cidade Bangladesh é rica em incidência solar, assim, o sistema solar fotovoltaico aparenta ser um bom investimento em energia renovável. O uso mais atrativo para o sistema solar doméstico (SHS) em Bangladesh é a produção de luz. Na área rural, as lâmpadas mais utilizadas são à base de querosene. As baterias de celulares secas estão sendo utilizadas nos rádios e gradativamente as baterias de carro são utilizadas em televisões em localidades onde as instalações de carregamento de baterias estão disponíveis. O custo do querosene e do carregamento de baterias é elevado e o sistema solar pode competir com eles. Seis casos foram analisados com o intuito de descobrir a viabilidade e sustentabilidade econômica em sistemas solares implantados em aldeias selecionadas do distrito de Gazipur em
Bangladesh, no período de outubro de 2004 a dezembro de 2004, e o método de coleta de dados aplicado foi por meio de questionários. Como resultado, obteve-se que o sistema solar é financeiramente atraente para pequenos negócios rurais e para iluminação doméstica. Porém, somente para fins de iluminação doméstica, o sistema não é financeiramente e economicamente viável, sem considerar os benefícios sociais.

Li et al. (2011) acreditam que, no futuro, as fontes renováveis de energia vão desempenhar um papel importante na geração de eletricidade na Irlanda. A eletricidade é gerada majoritariamente por gás importado e carvão, já que a Irlanda apresenta falta de combustíveis fósseis. Como a energia solar é onipresente, livremente disponível e favorável para o meio ambiente, esta vem se tornando atraente para todo o mundo, porém não tem sido muito popular em grande escala e em escala doméstica na Irlanda. O maior obstáculo encontrado para a expansão desta tecnologia é a economia pouco clara. Assim, os autores buscaram apresentar uma metodologia para avaliar com precisão a viabilidade econômica de um sistema solar doméstico. Para isso, utilizaram os softwares HOMER e Microsoft Excel ano 2007 a fim de realizarem as análises energéticas e econômicas. Executaram a análise realista de oito exemplos de sistemas fotovoltaicos domésticos disponíveis na Irlanda e chegaram à conclusão que estes sistemas ainda não parecem promissores mesmo se for dado um melhor suporte financeiro.

Khalid et al. (2013) buscaram avaliar a viabilidade de uma usina de energia fotovoltaica. Para isso, analisaram qual seria o local mais adequado comparando os dados mensais médios de radiação solar de oito cidades paquistanesas, e a cidade escolhida para a planta de 10 megawatts foi Quetta. O software utilizado foi o RETScreen, que apresentou que a usina pode gerar 23.206 GWh de energia em um ano. Com um custo total de US\$ 50 milhões, taxa de dívida de $50 \%$, taxa de desconto de 9\%, a planta fotovoltaica proposta gera eletricidade a uma taxa de US\$ 0,1557/kWh. Porém, a eletricidade gerada é 30,8\% mais dispendiosa do que a eletricidade fornecida pela rede. A análise de emissões demonstrou que a planta de energia fotovoltaica proposta evitou a produção de dióxido de carbono em 17.938 toneladas / ano. Concluiu que atualmente a 
planta de energia fotovoltaica proposta não é viável se apenas fatores econômicos forem considerados. Se o custo total instalado da fábrica for de cerca de US\$35 milhões, o custo da energia da usina fotovoltaica será igual à energia elétrica fornecida pela rede sem qualquer subsídio.

Holdermann et al. (2014) examinaram a viabilidade econômica do sistema fotovoltaico em pequena escala e conectado à rede nos setores comercial e residencial brasileiro após a introdução do regulamento de medição líquida em abril de 2012. Utilizaram o método de fluxo de caixa descontado para calcular os custos de investimentos específicos necessários para que os sistemas fotovoltaicos sejam economicamente viáveis para cada uma das 63 redes de distribuição no Brasil. Em seu cálculo, incluiu taxas e impostos, obtidos por entrevistas telefônicas e informações publicamente disponíveis. Outro parâmetro adotado foi o da utilização do programa $\mathrm{PV}^{\star}$ Sol para realizar simulações de local da sede da empresa de distribuição. No cenário da situação atual, a energia fotovoltaica não é economicamente viável em nenhuma das redes de distribuição nos setores comercial ou residencial. Sendo assim, no ambiente para a energia fotovoltaica conectada à rede, os setores comercial ou residencial assumem os custos mais baixos do sistema fotovoltaico e uma menor taxa de desconto para determinar o efeito sobre a viabilidade fotovoltaica.

Mitscher et al. (2012) analisaram a competitividade econômica da geração solar fotovoltaica conectada à rede e distribuída por meio de instalações de telhado em pequena escala em cinco capitais do estado brasileiro. Os locais representam um conjunto abrangente dos dois parâmetros essenciais para a viabilidade econômica da irradiação solar fotovoltaica e as tarifas locais de eletricidade. Os autores apresentaram os custos de eletricidade nivelados para a geração fotovoltaica e os valores presentes líquidos para um sistema fotovoltaico específico. A análise compreende três diferentes cenários de taxa de juros, que refletem diferentes condições de aquisição de capital para financiar os geradores: Mercado subsidiado, Maduro e ajustado pelo risco específico do país. Na análise de valores presentes líquidos, o fluxo da receita é modelado pela venda de eletricidade fotovoltaica em tarifas residenciais atuais assumindo a medição líquida. Utilizando taxas de juros subsidiadas, a análise mostrou que a eletricidade solar fotovoltaica já é competitiva no Brasil, enquanto que na taxa ajustada ao risco específico do país, os custos de capital declinantes, mas ainda altos, de fotovoltaico tornam economicamente inviável. Na taxa de juros de mercado maduro, a competitividade da fotovoltaica depende em grande parte da tarifa residencial. A competitividade econômica neste cenário é dada para locais com altas tarifas residenciais. $O$ estudo demonstrou $\mathrm{o}$ alto potencial de geração distribuída com instalações fotovoltaicas no Brasil e mostrou que, sob certas condições, o sistema fotovoltaico conectado à rede pode ser economicamente competitivo em um país em desenvolvimento.

Rocha et al. (2017) ressaltam que há uma pressão crescente para uma mudança no consumo e na produção de padrões de energia no Brasil. Neste cenário, a medição de rede é um mecanismo importante que promove a disseminação de pequenos sistemas solares voltaicos. Como suporte complementar à medição líquida, atualmente, uma isenção de impostos está sendo oferecida em alguns estados brasileiros. O objetivo do trabalho foi analisar o impacto da isenção de impostos sobre a circulação de bens e serviços e retornos e riscos de um projeto de microgeração fotovoltaica em quatro cidades localizadas em diferentes regiões do Brasil: Belém, Petrolina, Uberaba e Uruguaiana. O método de simulação utilizado foi o Monte Carlo (MCS), o qual considera incertezas relacionadas às variáveis financeiras e ambientais. Os resultados da análise estocástica da viabilidade econômica permitiram concluir que a isenção do imposto sobre circulação de bens e serviços (ICMS) é fundamental para viabilizar a microgeração fotovoltaica no Brasil. Nas cidades analisadas, a microgeração fotovoltaica apresentou inviabilidade econômica para o investidor quando o ICMS é cobrado. Ao considerar a política de isenção de ICMS, as cidades de Petrolina e Belém obtiveram altas probabilidades de viabilidade. Em relação à análise de risco, a microgeração fotovoltaica obteve os melhores resultados em Petrolina, tanto em termos de condição de coleta quanto de isenção de ICMS. Existe um alto potencial de aproveitamento solar em todo o território brasileiro, porém, no atual estágio de evolução e devido à cadeia produtiva da indústria fotovoltaica brasileira, altos custos limitam a expansão desta tecnologia. O estudo colabora com os formuladores de 
políticas na avaliação de programas de incentivos, destacando que a isenção de impostos atende diretamente a um dos objetivos para os quais foi criado o ICMS, que é incentivar o desenvolvimento de setores produtivos, como a indústria fotovoltaica.

Vale et al. (2017) ressaltam que a energia solar fotovoltaica conectada à rede distribuída no Brasil desempenha cada vez mais um papel importante devido aos avanços na tecnologia fotovoltaica, combinada com a redução de custos de capital e subsídios. Assim, os autores objetivaram conduzir uma análise econômica de dois projetos no programa governamental "Minha Casa Minha Vida" (MCMV), um no estado de São Paulo e outro no estado do Piauí, utilizando a geração de energia fotovoltaica distribuída. O MCMV é - programa de habitação do governo brasileiro que dá acesso à propriedade de casa para os brasileiros de baixa renda em áreas urbanas e rurais. A análise se baseou na avaliação do valor do presente líquido e da taxa de retorno interna, considerando uma taxa de retorno mínima atraente e variando o crescimento anual das tarifas em energia em 25 anos de operação, o que representa o tempo de vida esperado dos painéis solares. Essas duas cidades foram escolhidas porque seus estados federais têm ações diferentes em relação a questões fiscais. Os resultados mostraram que, apesar de Piauí apresentar uma incidência solar média mais alta do que a de São Paulo, o impacto da isenção de imposto sobre circulação de bens e serviços garante uma vantagem de investir em São Paulo.

Pinto et al. (2016) ressaltam que os sistemas de geração fotovoltaica (PV) têm sido cada vez mais utilizados para gerar eletricidade a partir de fontes renováveis, atraindo um interesse crescente. As instalações de microgeração de PV conectadas em redes em casas individuais aumentaram devido a políticas governamentais, assim como a uma maior atenção dada pela indústria. Como os sistemas de distribuição de baixa tensão (LV) foram construídos para fazer o fluxo de energia em uma direção, o feed-in da geração de PV em redes de baixa tensão rural pode influenciar a qualidade de energia Photovoltaic Quality (PQ), assim como a operação e a confiabilidade das instalações. Os autores buscaram apresentar os resultados da análise de $P Q$ de uma instalação de geração de PV real conectada a uma rede de baixa tensão rural. Observaramse as flutuações de tensão e os conteúdos harmônicos de tensão. A análise estatística mostrou um impacto negativo sobre $\mathrm{O} P Q$ produzido por esta instalação fotovoltaica e também uma pequena fração da energia dia ensolarado é convertida, provocando perdas de receita e forçando o conversor a funcionar de um modo de operação indesejável. Os autores discutiram os distúrbios impostos à rede e seus resultados em termos de viabilidade técnica e econômica do sistema fotovoltaico, bem como possíveis soluções. Foi sugerido e implementado um fortalecimento de rede de baixa tensão. Após essa mudança, uma nova análise $P Q$ apresentou uma melhoria no impacto sob sobre $O P Q$, tornando esta facilidade economicamente viável.

\subsubsection{PALAVRAS EM DESTAQUE NOS ARTIGOS ANALISADOS}

Inspirado no modelo de Jesus e Costa (2015), foi utilizado o site Wordle para formar uma "nuvem de palavras", que também funciona como uma análise de consistência do texto, como é mostrado na Figura 7.

Figura 7: Nuvem de palavras do banco de dados

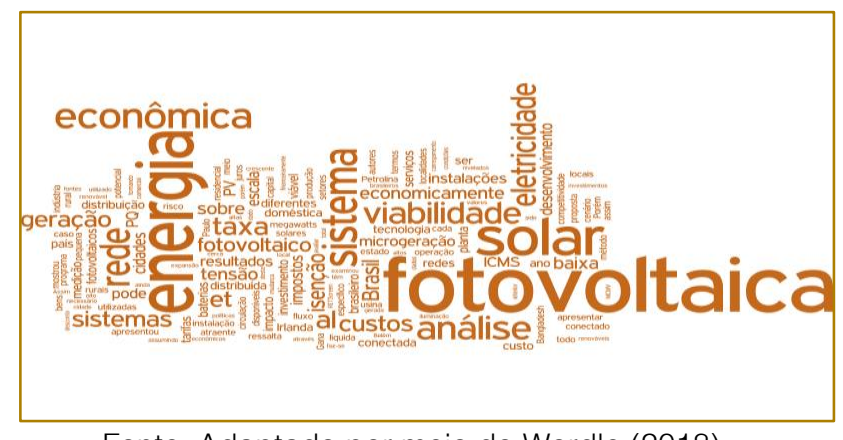

Fonte: Adaptado por meio do Wordle (2018). 
As palavras apresentadas na Figura 7 são as que mais se repetem no texto de análise dos dez artigos selecionados para compor este estudo. As palavras que estão em destaque se repetem mais do que as outras. Elas também abrangem as palavras-chave que foram utilizadas para realizar a busca dos artigos na Scopus.

\subsection{CONSIDERAÇÕES FINAIS}

O presente artigo objetivou apresentar um estudo entre a viabilidade econômica e a implantação de placas fotovoltaicas ao indicar uma coleção de artigos acadêmicos referentes à área de estudo.

O modelo de bibliometria utilizado é válido ao direcionar o pesquisador quanto aos estudos sobre uma determinada área, já que trabalhos acadêmicos baseados em um tema específico são reunidos de acordo com sua relevância e credibilidade, além de apresentarem os autores que mais publicam, periódicos mais interessados no tema, países que desenvolvem pesquisas a respeito, áreas de conhecimento relacionadas, tipos de publicação e instituições com maior número de publicação.

Foi observado que o tema é relevante e global, e ainda há muito a ser explorado, uma vez que o número de resultados retornados pela base é relativamente baixo. Mesmo o Brasil estando presente entre os países que se destacam no tema, não há trabalhos acadêmicos referentes a ele em português. $\mathrm{O}$ idioma mais utilizado para publicações de trabalhos acadêmicos atualmente é o inglês, uma vez que o país com maior número de publicações são os Estados Unidos .

A frequência de publicações por ano tem aumentado gradativamente, mostrando 0 aumento da conscientização e da

\section{REFERÊNCIAS}

[1], AGÊNCIA NACIONAL DE ENERGIA ELÉTRICA (ANEEL). Energia Solar. Disponível em: $<$ http://www2.aneel.gov.br/aplicacoes/atlas/pdf/03energia_solar(3).pdf>. Acesso em: 22 jan. 2018.

[2] ASSOCIAÇÃO BRASILEIRA DE ENERGIA SOLAR FOTOVOLTAICA (ABSOLAR). Geração Distribuída Solar Fotovoltaica. In: ENCONTRO NACIONAL DOS AGENTES DO SETOR ELÉTRICO, 2017. Anais... Rio de Janeiro: ENASE, 2017. preocupação com as condições ambientais, revelando 0 interesse na utilização das energias renováveis.

O ano de 2017 foi o que apresentou o maior número de publicações, reafirmando que o tema proposto pelo trabalho é atual.

É possível perceber, na análise dos resultados, que este assunto ainda pode ser muito explorado, visto que o número de publicações encontradas com as palavraschave utilizadas foi de 187 artigos, um número relativamente baixo. Os anos que se destacaram na pesquisa por possuírem três artigos publicados, indexados na base Scopus, foram 1998, 2012, 2013 e 2016.

Há um baixo número de publicação entre os autores. Os dois mais relevantes possuem cinco trabalhos acadêmicos cada. Quanto à origem de publicação, o Renewable and Sustainable Energy Review se destaca por conter 14 documentos indexados, seguido do Renewable Energy, com 12 documentos.

Em relação às afiliações, a Covenant University e a University of Lagos destacamse com cinco documentos indexados na base. Os Estados Unidos saem na frente com 29 artigos publicados. E, por fim, a área que mais se destaca por conter o maior número de documentos publicados é a Energia, com 141 documentos indexados.

Com base nos resultados e na discussão, nota-se que a energia solar é uma energia renovável que, com o passar dos anos, chama cada vez mais a atenção e tem sido implantada em plantas domésticas, rurais, comerciais e industriais. Porém, ainda são necessários incentivos ou abono do imposto para que esta fonte de energia seja competitiva e viável.

[3] ASSOCIAÇÃO BRASILEIRA DE ENERGIA SOLAR FOTOVOLTAICA (ABSOLAR). Geração Distribuída Solar Fotovoltaica. In: Encontro Nacional dos Agentes do Setor Elétrico, 14., 2016, 17 e 18 de maio de 2017. Anais... Rio de Janeiro: ENASE, 2017.

[4] ASUMADU-SARKODIE, S. et al. The potential and economic viability of solar photovoltaic power in Ghana. Energy Sources, v. 38, n. 5, p. 709-716, 2016. Disponível em: 
[5] <https://www.tandfonline.com/doi/abs/10.1 080/15567036.2015.1122682?journalCode=ueso20 >. Acesso em: 20 jan. 2018.

[6] BRASIL. Conselho Nacional de Política Fazendária - Confaz. Ministério de Minas e Energia. Ajuste SINIEF 2, de 22 de abril de 2015. 2015. Disponível em: $<$ https://www.confaz.fazenda.gov.br/legislacao/ajus tes/2015/AJ_002_15>. Acesso em: 10 jan. 2018.

[7] BRASIL. Conselho Nacional de Política Fazendária - Confaz. Ministério de Minas e Energia. Energia Solar no Brasil e Mundo: 2015. Disponível em:

<http://www.mme.gov.br/documents/10584/358049 8/17+-+Energia+Solar+-+Brasil+e+Mundo++ano+ref.+2015+\%28PDF\%29/4b03ff2d-14524476-907d-d9301226d26c? version=1.3>. Acesso em: 10 jan. 2018

[8] BYRNE, J.; SHEN, B.; WALLACE, W. The economics of sustainable energy for rural development: a study of renewable energy in rural China. Energy Policy, v. 26, n. 1, p. 45-54, 1998. Disponível em: <https://doi.org/10.1016/S03014215(97)00099-2>. Acesso em: 20 jan. 2018.

[9] CARVALHO, E. F. A.; CALVETE, M. J. F. Energia Solar: Um passado, um presente... um futuro auspicioso. Revista Virtual de Química, v. 2, n. 3, p. 192-203, 2010.

[10] COSTA, H. Modelo para webibliomining: proposta e caso de aplicação. Revista. FAE, Curitiba, v. 13, n. 1, p. 115-126, jan./jun. 2010. Disponível em: <https://revistafae.fae.edu/revistafae/article/view/22 6>. Acesso em: 20 jan. 2018.

[11] CUNHA KEMERICH, P. D. et al. Paradigmas da energia solar no Brasil e no mundo. Electronic Journal of Management, Education and Environmental Technology (REGET), v. 20, n. 1, p. 241-247, 2016.

[12] ELSEVIER, B. V. Pesquisadores e Profissionais de P\&D: O maior acervo de soluções eletrônicas para pesquisadores da comunidade científica. Rio de Janeiro, 2016. Disponível em: <https://www.Elsevier.com.br/solucoes-digitais/>. Acesso em: 20 jan. 2018.

[13] ENEL $X$. Disponível em: $<$ https://www.enelx.com.br/blog/2017/01/custo-deenergia-solar-despenca-nos-ultimos-40-anos/>. Acesso em: 04 set. 2018.

[14] ENERGIA SOLAR 3. Disponível em: <http://www2.aneel.gov.br/aplicacoes/atlas/pdf/03energia_solar(3).pdf>. Acesso em: 10 jan. 2018.

[15] HOLDERMANN, C. et al. Distributed photovoltaic generation in Brazil: An economic viability analysis of small-scale photovoltaic systems in the residential and commercial sectors. Energy Policy, v. 67, p. 612-617, 2014. Disponível em:

<https://energypedia.info/images/temp/2/27/20140
508121514! phpS4CvG4.pdf>. Acesso em: 20 jan. 2018.

[16] IMHOFF, J. Desenvolvimento de Conversores Estáticos para Sistemas Fotovoltaicos Autônomos. 2007. 146 f. Dissertação (Mestrado em Engenharia Elétrica) - Engenharia Elétrica Universidade Federal de Santa Maria, Santa Maria. 2007. Disponível em:

[17] <http://repositorio.ufsm.br/bitstream/handl e/1/8608/JOHNINSONIMHOFF.pdf>. Acesso em: 23 fev. 2018.

[18] INTERNATIONAL ENERGY AGENCY (IEA). Energy statistics: matriz energética do Brasil. Disponível em: <https://www.iea.org/stats/WebGraphs/BRAZIL5.pd f>. Acesso em: 23 jan. 2018.

[19] KHALID, A.; JUNAIDI, H. Study of economic viability of photovoltaic electric power for Quetta - Pakistan. Renewable Energy, v. 50, p. 253-258, 2013. Disponível em: $<$ https://www.infona.pl/resource/bwmeta1.element. elsevier-c1a8057e-b848-3448-9f9a-

6e957f26220d>. Acesso em: 23 jan 2018.

[20] JESUS, I. R. D. de; COSTA, H. G. Interfaces between production engineering and the public affairs: evidences from bibliometric analysis. Scientometrics, [s.I.], v. 105, n. 2, p.1183-1193, 30 ago. 2015. Springer Nature.

[21] LI, Z.; BOYLE, F.; REYNOLDS, A. Domestic application of solar PV systems in Ireland: The reality of their economic viability. Energy, v. 36, n. 10, p. 5865-5876, 2011. Disponível em: <https://doi.org/10.1016/j.energy.2011.08.036> Acesso em: 23 jan. 2018.

[22] MINISTÉRIO DAS MINAS E ENERGIA MME. Energia Solar no Brasil e no Mundo - Ano de referência 2015. Disponível em: <http://www.mme.gov.br/documents/10584/358049 8/17+-+Energia+Solar+-+Brasil+e+Mundo++ano+ref.+2015+\%28PDF\%29/4b03ff2d-14524476-907d-d9301226d26c? version=1.3>. Acesso em: 22 jan. 2018.

[23] MITSCHER, M.; RÜTHER, R. Economic performance and policies for grid-connected residential solar photovoltaic systems in Brazil. Energy Policy, v. 49, p. 688-694, 2012. Disponível em:

$<$ https://ideas.repec.org/a/eee/enepol/v49y2012icp 688-694.html>. Acesso em: 23 jan. 2018.

[24] MONDAL, A. H. Economic viability of solar home systems: Case study of Bangladesh. Renewable Energy, v. 35, n. 6, p. 1125-1129, 2010. Disponível <https://doi.org/10.1016/j.renene.2009.10.038> Acesso em: 20 jan. 2018.

[25] NASCIMENTO, R. L. Energia solar no Brasil: situação e perspectivas. Câmera dos Deputados, 2017. 
[26] NeVES, R. B.; PEREIRA, V.; COSTA, H. G. Auxílio multicritério à decisão aplicado ao planejamento e gestão na indústria de petróleo e gás. Production, [s.I.], v. 25, n. 1, p.43-53, mar. 2015 . FapUNIFESP

(SciELO). <http://dx.doi.org/10.1590/s0103 65132013005000060>.

[27] PEREIRA, F. A. de S.; OLIVEIRA, M. A. S. Curso técnico instalador de energia solar fotovoltaica. 2 ed. Porto: Publindústria, 2015.

[28] PINTO, R. et al. Impact of rural gridconnected photovoltaic generation systems on power quality. Energies, v. 9, n. 9, p. 739, 2016. Disponível em:

[29] <https://pdfs.semanticscholar.org/299a/5a 21a7b4495f04f99e3d36d58fc693568d2b.pdf>. Acesso em: 20 jan. 2018.

[30] PORTAL SOLAR LTDA. A regulamentação dos créditos de energia solar. São Paulo. Disponível em: <https://www.portalsolar.com.br/aregulamentacao-dos-creditos-de-energia.html> Acesso em: 10 jan. 2018.

[31] REIS, Lineu Belico dos. Energia, recursos naturais e a prática de desenvolvimento sustentável. 2.ed. Barueri, SP: Manole, 2012.
[32] ROCHA, L. C. S. et al. Photovoltaic electricity production in Brazil: A stochastic economic viability analysis for small systems in the face of net metering and tax incentives. Journal of Cleaner Production, v. 168, p. 1448-1462, 2017. Disponível em: <DOI: 10.1016/j.rser.2018.03.078>. Acesso em: 20 jan. 2018.

[33] SYLVA, Cylon Gonçalves da. De sol a sol: energia do século XXI. São Paulo: Oficina de Textos, 2010

[34] VALE, A. et al. Analysis of the economic viability of a photovoltaic generation project applied to the Brazilian housing program "Minha Casa Minha Vida". Energy Policy, v. 108, p. 292-298, $2017 . \quad$ Disponível em: <DOI: 10.1016/j.enpol.2017.06.001>. Acesso em: 20 jan. 2018.

[35] WORDLE. Nuvem de palavras. Disponível em:

<http://www.wordle.net/show/wrdl/7813322/nuvem_ de_palavras/>. Acesso em: 02 jan. 2018.

[36] ZILLES, R. et al. Sistemas fotovoltaicos conectados à rede elétrica. São Paulo: Oficina de Textos, 2012. 208 p. 


\section{Gapítulo 3}

\section{REVISÃO SISTEMATIZADA DE LITERATURA NA BASE SCOPUS: UMA ABORDAGEM SOBRE "VIABILIDADE ECONOMICA"}

Resumo: O presente trabalho teve como objetivo realizar uma busca detalhada sobre os métodos aplicáveis ao cálculo da viabilidade econômica. A base de dados utilizada para desenvolver essa revisão sistematizada de literatura foi a Scopus Elsevier, acessada através do Portal de Periódicos da Capes. O estudo permitiu obter um aporte teórico para a realização do objetivo geral desta dissertação. Para cada método, os artigos resultantes foram analisados e três foram selecionados para apresentação de um breve resumo, a fim de exemplificar o teor conteúdo disponibilizado. Foi possível observar o estado da arte do tema, uma vez que a metodologia permitiu identificar os anos com maior frequência de publicação, periódicos e autores que mais publicaram sobre o tema, os países com maior engajamento neste contexto, os tipos de publicação mais utilizados e as áreas de conhecimento com maior volume de artigos publicados. Em conjunto, é possível constatar que o método tende a ser cada vez mais aplicado, principalmente dentro da área de Engenharia, que foi a área que se destacou nesse estudo, por sua flexibilidade de aplicá-lo em diferentes cenários. Constatou-se também que a China é o país que mais possui documentos indexados nessa base, de acordo com o assunto em questão

Palavras-chave: Métodos Financeiros. Viabilidade Econômica. Estudo Bibliométrico. 


\subsection{INTRODUÇÃO}

Conforme Capaz e Nogueira (2016), embora os projetos elaborados com base na eficiência energética tragam grandes benefícios no sentido de reduzir as perdas energéticas e contribuir para com o meio ambiente, estes fatores, por si só, não são suficientes para atrair os investidores. Os projetos de eficiência energética precisam também ser economicamente viáveis, para que assim um investimento externo possa ser melhor justificado por parte daqueles que pretendem executá-lo. Deste modo, antes de optar pela captação de investimento para um determinado projeto, é necessário calcular a sua viabilidade econômica.

De acordo com Neumann (2017) a viabilidade econômica de um projeto é calculada através de métodos que têm como objetivo a análise de dados em comparação à meta que se tem para este projeto em particular. Ou seja, diferentes empresas têm metas diferentes e, portanto, podem fazer uso de diferentes métodos. O que todas as empresas têm em comum, independentemente do método utilizado, é a necessidade de análise da eficiência econômica de determinado projeto, ou seja, ao agrupar todos os custos de elaboração e execução do projeto, o valor obtido precisa ser menor do que o valor estimado que ele poderá gerar como receitas ou benefícios.

Com base neste cenário, este estudo pretende abordar oito métodos financeiros que são considerados mais compatíveis e recomendados para a análise da viabilidade econômica para projetos como o que sera aplicação das placas fotovoltaicas em uma empresa do município de Macaé/RJ. Para este fim, serão pontuados conceitos e um estudo bibliométrico relativos aos métodos selecionados, com o objetivo analisar e identificar os autores, periódicos, países, tipo de publicação e áreas de conhecimento com maiores publicações a respeito de oito métodos financeiros. Buscou-se apresentar três trabalhos de aplicação prática do tema estudado para cada método selecionado.

\subsection{REVISÃO DE LITERATURA}

De acordo com Jaffe et al. (2015, p. 443) "ao avaliar um projeto, começamos determinando a taxa de desconto correta e utilizamos os fluxos de caixa descontados para determinar o VPL (Valor Presente Líquido)". Os autores ainda ressaltam, que a primeira medida a ser tomada quando da determinação do fluxo de caixa de uma empresa, é analisar as atividades ligadas à sua operação, ou seja, toda a movimentação que compõe suas transações envolvendo produtos ou serviços, de acordo com a finalidade do empreendimento.

Para Marques (2007, p. 7) "a verdadeira força da empresa, o que realmente importa para os acionistas, baseia-se no fluxo de caixa". O autor baseia sua afirmação na justificativa de que o fluxo de caixa apresenta uma grande variedade de informação a ser analisada como, por exemplo, prazos de recebimento comparados aos prazos de pagamento, redução no volume de receitas, extrapolação de custos frente ao planejado, entre outros. Segundo o Sebrae (2018), o fluxo de caixa é um "instrumento de gestão financeira que projeta para períodos futuros todas as entradas e as saídas de recursos financeiros da empresa, indicando como será o saldo de caixa para o período projetado".

Desta forma, o fluxo de caixa se torna uma ferramenta que possibilita tomadas de decisão mais conscientes e que afetam o resultado geral da empresa diretamente. $\mathrm{Da}$ mesma forma, o fluxo de caixa pode ser segmentado de acordo com as informações que se deseja analisar, tornando os resultados mais precisos. Por exemplo, os retornos sobre investimento e os custos de obtenção de recursos são os juros pagos, os juros dividendos e os juros recebidos sobre o capital próprio. Estes são classificados como: fluxos de caixa de investimento e fluxos de caixa de financiamento (CRCRJ, 2018).

Marques (2007, p. 82) afirma que "VPL é a diferença entre os fluxos de entrada e saída de dinheiro de um investimento trazido a preços de uma mesma data pelo custo de oportunidade". Na prática, é preciso que seja definida uma base para comparação, para que se possa realizar uma análise mais aprofundada e baseada em outras opções de investimento disponíveis. Para realização do cálculo, deve-se atentar para o uso de uma Taxa Mínima de Atratividade - TMA ou Custo de Capital de forma adequada (USIRONO, 2015).

A Taxa Mínima de Atratividade - TMA, de acordo com Camargo (2007, p. 25) "corresponde à taxa de desvalorização imposta a qualquer ganho futuro pelo fato de não estar disponível no momento. Sua escolha 
exige muito cuidado, pois a análise de um mesmo investimento pode mostrar diferentes resultados". Esta afirmação reforça a importância de utilizar um conjunto de indicadores para realizar a análise de viabilidade financeira de qualquer projeto, a fim de mitigar os riscos de uma análise parcial e pouco fundamentada.

Chenço (2009) destaca que no caso do fluxo de caixa descontado, é preciso estar atento para fatores externos e que podem interferir diretamente em seus resultados futuros, como a situação econômica do país ou até mesmo a nível mundial. Isso significa que nem sempre um projeto que apresente VPL - Valor Presente Líquido ou TIR - Taxa Interna de Retorno favoráveis, serão, de fato, bons investimentos. Para que o investidor possa se proteger dos riscos que ocasionam tomadas de decisão incorretas, o autor dá dicas como, por exemplo, se questionar sobre os motivos que levam o projeto a apresentar VPL positivo; se é possível produzir e distribuir o produto ou serviço de maneira eficiente, e se será possível comercializar o produto ou serviço com preço atrativo ao consumidor final.

Já a respeito da taxa de desconto, Jaffe et al. (2015, p. 139) afirmam que "conceitualmente, a taxa de desconto de um projeto arriscado é o retorno que se pode esperar auferir em um ativo financeiro de risco comparável". Ou seja, taxa de desconto é a taxa utilizada para que as parcelas seguintes do fluxo de caixa sejam deduzidas. Estes três instrumentos estão relacionados entre si, assim como afirma Chenço (2009, p. 113), ao ressaltar que "valor presente, taxa de desconto e equivalência de fluxos de caixa são conceitos absolutamente interligados".

A Taxa Interna de Retorno - TIR, também tem importância central no processo de tomada de decisão. Jaffe et al. (2015, p. 143) afirmam que "como regra geral, a TIR é a taxa que faz com que o VPL do projeto seja zero". Este método tem como principal objetivo reunir o máximo de informações para facilitar a análise do investidor, levando em conta aspectos internos do projeto em questão e focando sua análise na questão que tem maior impacto na visão geral de viabilidade econômica: o fluxo de caixa esperado. Segundo Gitman (2010) a Taxa Interna de Retorno é composta pela taxa de desconto na qual o VPL - Valor Presente Líquido seja igual a zero, haja vista que este alcança o mesmo valor do investimento inicial na oportunidade de investimento em questão. $\mathrm{Na}$ prática, conhecer a TIR do projeto tem como finalidade comparar este percentual com as taxas de juros oferecidas pelo mercado, chegando a conclusão de que é ou não um investimento rentável (CHENÇO, 2009).

Jaffe et al. (2015) afirmam que o Payback é uma forma de concentrar a atenção apenas aos projetos que interessam à empresa, de acordo com o seu prazo estipulado de retorno. Ou seja, se a empresa espera trabalhar com um retorno máximo de três anos poderá descartar os projetos que tem retorno em prazo maior e analisar com maior detalhamento apenas os que atendem ao requisito estabelecido. Chenço (2009) faz uma comparação entre o uso do Payback e do VPL para análise de investimentos, afirmando que o primeiro é mais indicado para projetos com maior risco envolvido, haja vista que o segundo não leva em consideração o aspecto de tempo do investimento.

Quando se fala em Payback, sua análise ainda pode ser segmentada de acordo com o tipo de análise que se deseja fazer, que no caso deste método pode ser classificado como Payback Simples e Payback Descontado. Segundo a Fapan (2018), o Payback Simples é o atingimento do ponto no qual o valor arrecadado a fins de lucro líquido é igual ao valor total do investimento previamente realizado. Já no Payback Descontado os valores recebidos à título de lucro líquido são ainda descontados para que possam ser comparados com o volume de investimento inicial, de acordo com o método de análise utilizada.

"Outro método utilizado para avaliar projetos é o chamado Índice de Lucratividade - IL. Ele é o quociente do valor presente dos fluxos de caixa futuros esperados após o investimento inicial dividido pela quantia do investimento inicial" (JAFFE et al., 2015, p. 154) O índice de lucratividade é utilizado para avaliar projetos de orçamento de capital. Este considera o considera o valor do dinheiro no tempo, podendo assim ser utilizada como o início para a seleção de projetos sob condições de racionamento de capital (GITMAN, 2010).

A análise do resultado obtido na operação realizada para descobrir do IL de determinado projeto é bem simples, conforme afirma Bourdeux-Rego et al. (2013), bastando verificar se o resultado é menor, maior ou igual a 1. Se for menor que 1 , significa que 0 investidor conseguirá ao menos recuperar seu 
investimento, e terá um retorno proporcional à quanto maior do que 1 for o resultado. Se o IL for igual a 1, o investidor deve saber que irá ter seu investimento recuperado, porém, à mesma taxa que foi exigida inicialmente. Porém, se o IL for menor do que 1, significa que não haverá o retorno dos valores investidos, significando perdas ao investidor.

De acordo com Romeiro Filho (2011) o Retorno sobre o Investimento - ROI "mede o retorno de determinado investimento realizado e contabilizado em meses nos quais ele será amortizado para então começar a gerar lucros". O autor ainda reforça que o cálculo do ROI pode ser realizado de diversas formas, de acordo com a necessidade de análise. Por exemplo, dividindo o lucro líquido pelo total de ativos, o investidor saberá o percentual de retorno oferecido pela empresa. Já dividindo o lucro líquido pelo montante investido, será possível conhecer o valor percentual dos investimentos. Fazendo esta última operação da forma inversa, o investidor descobrirá o tempo necessário para que possa reaver o capital investido.

\subsection{METODOLOGIA}

A metodologia selecionada para a elaboração deste trabalho foi o estudo bibliométrico, uma vez que este tem o intuito de apresentar as contribuições científicas sobre determinado tema ou fenômeno (JUNG, 2004). Realiza o estado da arte através da investigação ou rastreio da produção científica (OKUBO, 1970). Desta forma, será realizada uma pesquisa utilizando palavras chave relacionadas a oito diferentes métodos financeiros de análise econômica, tendo como fonte a Base Scopus, sendo acessada através da Plataforma CAPES.

Os métodos financeiros são utilizados para auxiliar no controle e obtenção de lucros de uma empresa. Este estudo pretende abordar oito métodos financeiros que são mais comumente utilizados para analisar a viabilidade econômica nas empresas, e deste modo, analisa-los do ponto de vista da aplicação das placas fotovoltaicas em uma empresa do município de Macaé/RJ. Para este fim, serão pontuados conceitos e um estudo bibliométrico relativos aos métodos selecionados.

O modelo utilizado é o proposto por Costa (2010), o qual é dividido em seis passos. A definição da amostra da pesquisa, a pesquisa na amostra, identificação dos periódicos e dos autores com maior número de publicações sobre o tema, levantamento da cronologia da produção, identificando ciclos de maior produção e a seleção dos artigos para composição do "núcleo de partida" para a pesquisa bibliográfica.

Apresentado este panorama, traça-se como objetivo analisar e identificar os autores, periódicos, países, tipo de publicação e áreas de conhecimento com maiores publicações a respeito de oito métodos financeiros. Buscouse apresentar três trabalhos de aplicação prática do tema estudado para cada método selecionado.

\subsubsection{QUANTO AOS FINS}

No que se refere aos procedimentos técnicos, este é um artigo teórico-conceitual, de natureza exploratória e abordagem da pesquisa qualitativa, inspirado no método, sugerido por Costa (2010), para realizar a revisão sistematizada de literatura.

\subsubsection{QUANTO AOS MEIOS}

O trabalho seguiu seis etapas propostas: definição da amostra da pesquisa, utilização das palavras-chaves na pesquisa das amostras, identificação dos periódicos com maior número de artigos publicados sobre o tema, realizar a identificação dos autores com maior número de publicações, a cronologia da produção é levantada, para que os ciclos de maior produção sejam identificados. Por fim, os artigos são selecionados para a composição do "núcleo de partida" para que a pesquisa bibliográfica seja realizada.

A base de dados utilizada foi a Scopus Elsevier, acessada em janeiro de 2018, através do Portal de Periódicos da Capes. Os filtros de exclusão não foram utilizados para que o número de documentos econtrados fosse maior. Os critérios de busca foram estabelecidos com a finalidade de realizar uma ampla cobertura das publicações sobre os oito métodos financeiros escolhidos. Essa pesquisa foi realizada de 01/01/2018 até 31/01/2018. 


\subsection{RESULTADOS E DISCUSSÃO}

Dessa forma, utilizando esse núcleo, são apresentados aqui gráficos contendo essas publicações, no que se relaciona com a quantidade de publicações por ano, quais autores publicaram sobre o tema, de onde são as origens dos artigos, bem como suas afiliações. Também são mostradas as quantidades de publicações por países e por área, apresentando aqueles que possuem destaque.

Tabela 2: Pesquisa de Termos Chave

\begin{tabular}{|c|c|c|}
\hline Método & Keywords ou termos chave & Resultados \\
\hline Valor Presente Líquido - VPL & "Net" AND "Present" AND "Value" & 17.187 \\
\hline Taxa Interna de Retorno - TIR & "Internal" AND "Rate" AND "of" AND "Return" & 4.610 \\
\hline Índice de Lucratividade - IL & "Profitability" AND "Index" & 2.797 \\
\hline Payback Simples & "Simple" AND "Payback" & 769 \\
\hline Payback descontado & "Discounted" AND "Payback" & 304 \\
\hline Taxa Mínima de Atratividade - TMA & "minimum" AND "attractiveness" AND "rate" & 55 \\
\hline Fluxo de Caixa & "Cash" AND "Flow" & 14.521 \\
\hline Retorno sobre Investimento_ ROI & "Return" AND "on" AND "Investment" & 35.152 \\
\hline
\end{tabular}

Fonte: Elaborado pelo Autor (2018)

\subsubsection{VALOR PRESENTE LÍQUIDO - VPL}

Para este método, foram utilizadas como termos para pesquisa as palavras "Net" AND "Present" AND "Value", retornando um total de 17.187 resultados.

\subsubsection{ANO DAS PUBLICAÇÕES}

Os dados contidos na Figura 8, ilustrada abaixo, demonstram através do gráfico a frequência das publicações por ano no período de 2000-2018.

Figura 8: Frequência das publicações por ano no período de 2000-2018

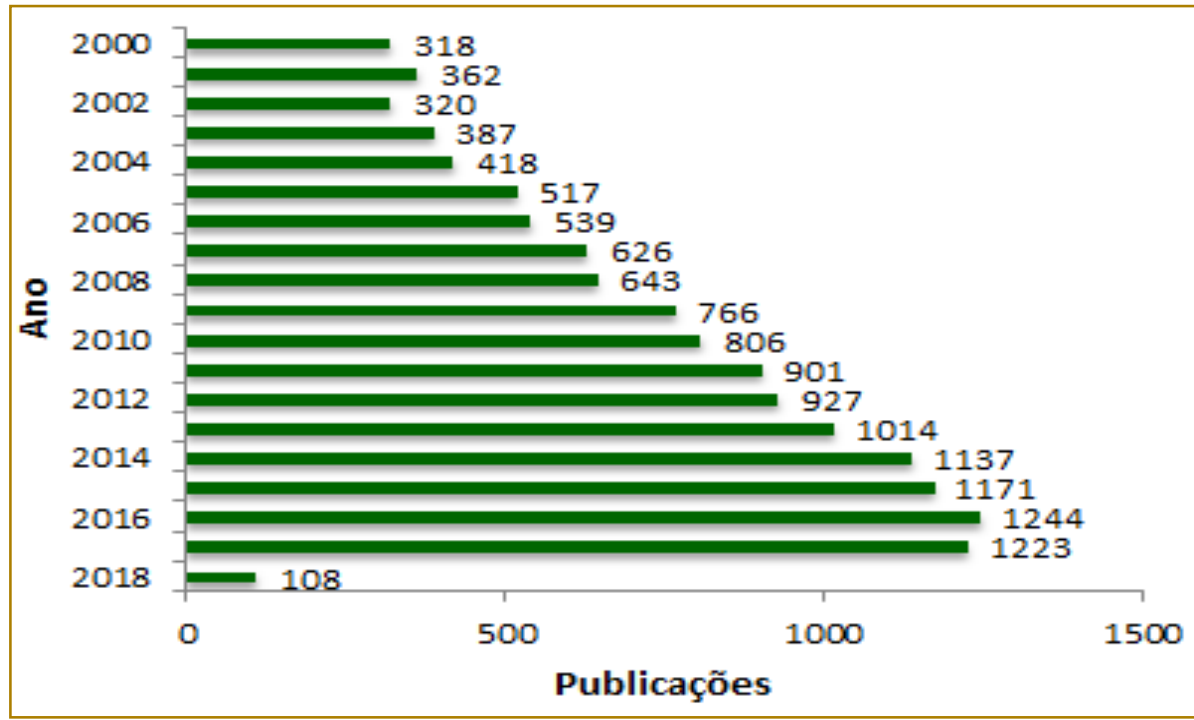

Fonte: Adaptado da Scopus (2018)

É possível observar que, a partir de 2003, houve uma progressão nos valores de publicação. O ano de 2017 é aquele que possui maior número de publicação, enquanto o ano de 2018 apresenta 108 artigos publicados .

\subsubsection{AUTORES QUE PUBLICARAM SOBRE O TEMA}

Os dados contidos na Figura 9 demonstram através do gráfico os autores com maior frequência de publicação. 
Figura 9: Autores com maior frequência de publicação

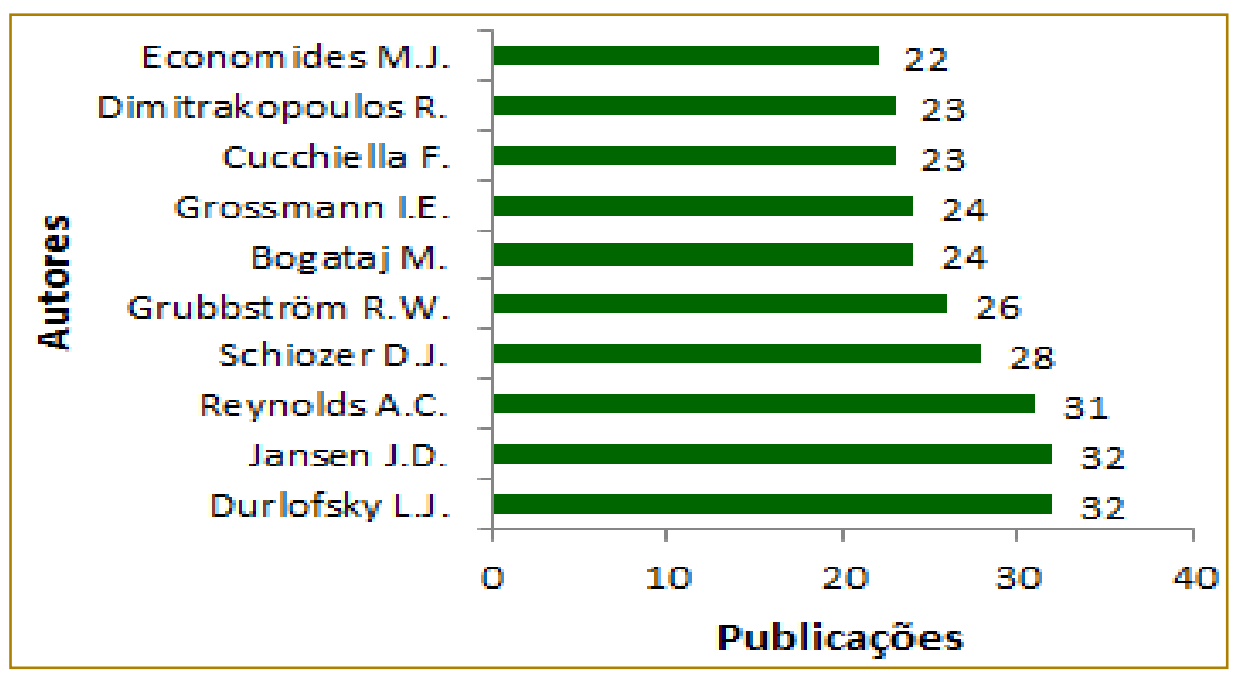

Fonte: Adaptado da Scopus (2018).

Pode-se verificar com a imagem que entre os autores que mais publicam sobre o tema, destacam-se o Durlofsky L.J. e Jansen J.D., com 32 publicações.

\subsubsection{ORIGEM DE PUBLICAÇÃO}

Os dados contidos na Figura 10 demonstram através do gráfico os periódicos com maior frequência de publicação.

Figura 10: Periódicos com maior frequência de publicação

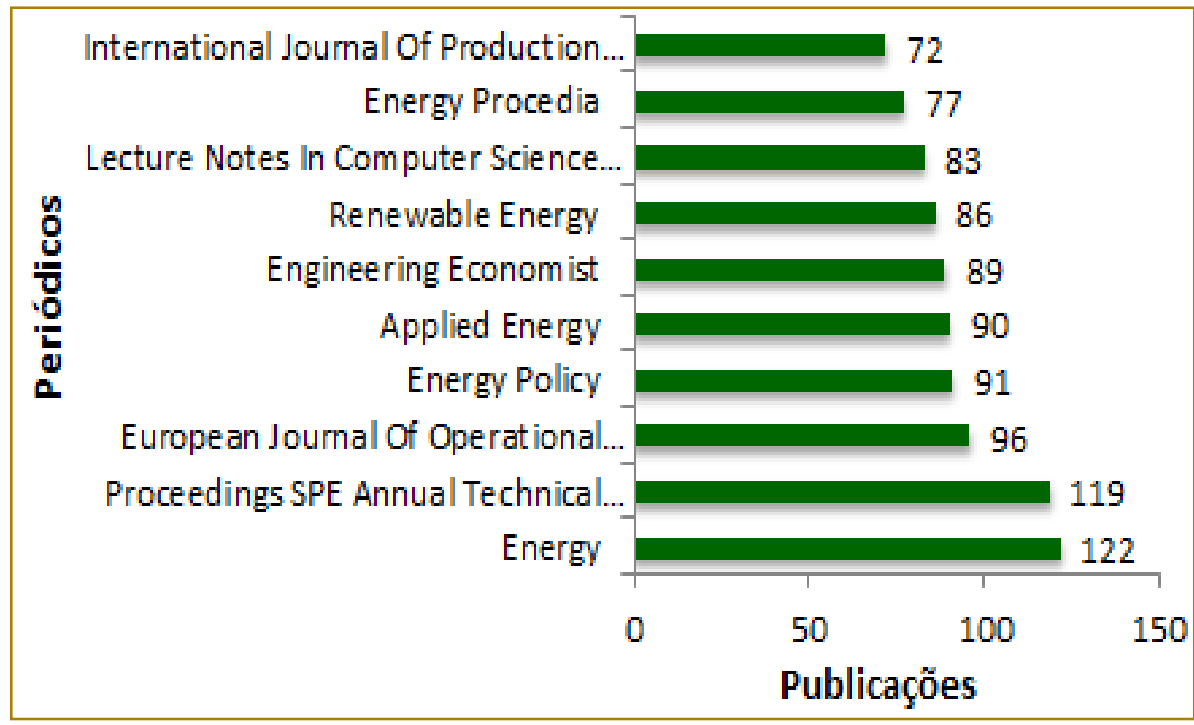

Fonte: Adaptado da Scopus (2018).

O principal é o Energy Policy, seguido do European Journal of Operational Research e o Proceedings SPE Annual Technical Conference and Exhibition.

\subsubsection{AFILIAÇÃO}

Os dados contidos na Figura 11 demonstram através do gráfico as afiliações com maior frequência de publicação. 
Figura 11: Afiliações com maior frequência de publicação

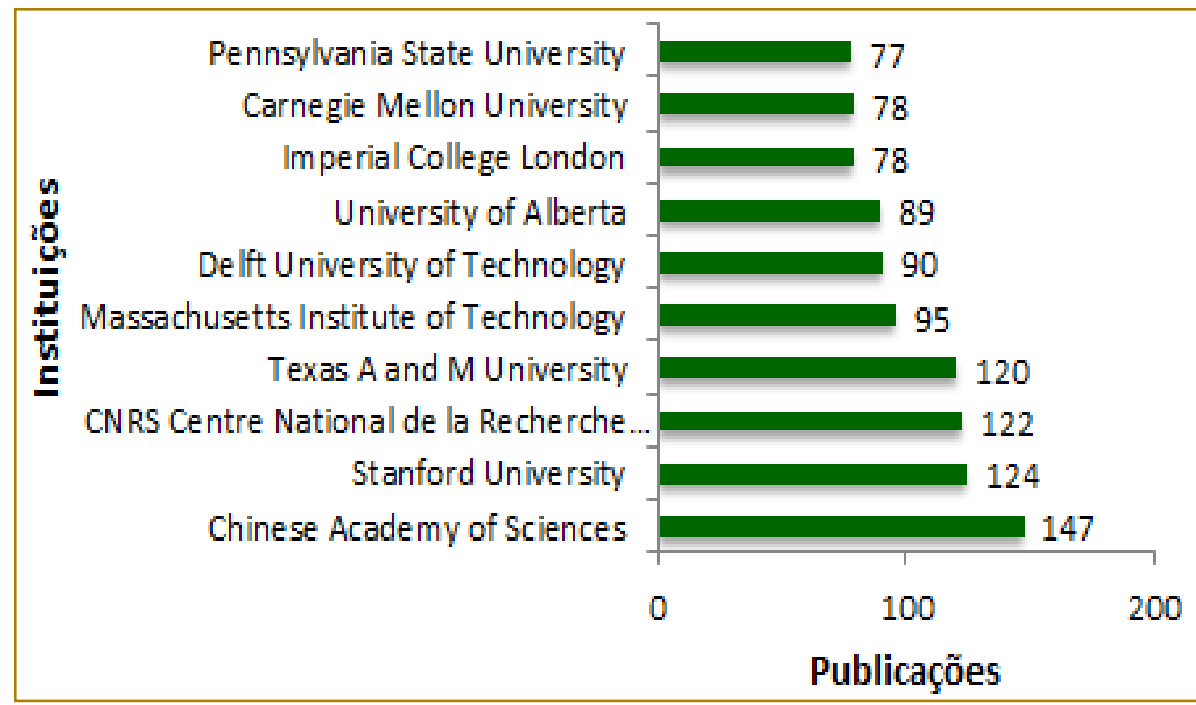

Fonte: Adaptado da Scopus (2018).

Pode-se verificar que a Chinese Academy of Sciences é a instituição com mais publicações, com 147, seguida pela Stanford University (124), CNRS (122) e Texas A and M University (120).

\subsubsection{NÚMERO DE PUBLICAÇÃO POR PAÍSES}

Os dados contidos na Figura 12 demonstram através do gráfico os países com maior frequência de publicação.

Figura 12: Países com maior frequência de publicação

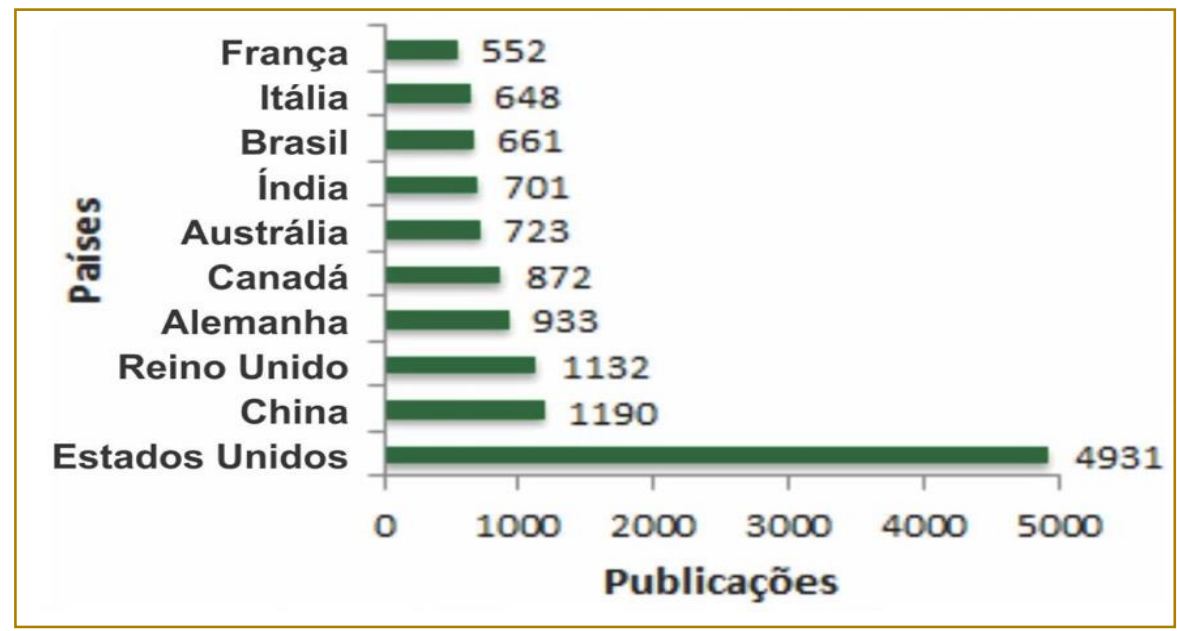

Fonte: Adaptado da Scopus (2018).

Conforme apresentado na imagem, os Estados Unidos seguem liderando entre os países que publicam sobre o método financeiro em questão, com 4.931 publicações, muito acima dos demais, como a China (1.190), Reino Unido (1.132) e a Alemanha (933).

\subsubsection{NÚMERO DE PUBLICAÇÃO POR ÁREAS}

Os dados contidos na Figura 13 demonstram através do gráfico as áreas de conhecimento com maior frequência de publicação. 
Figura 13: Áreas de conhecimento com maior frequência de publicação

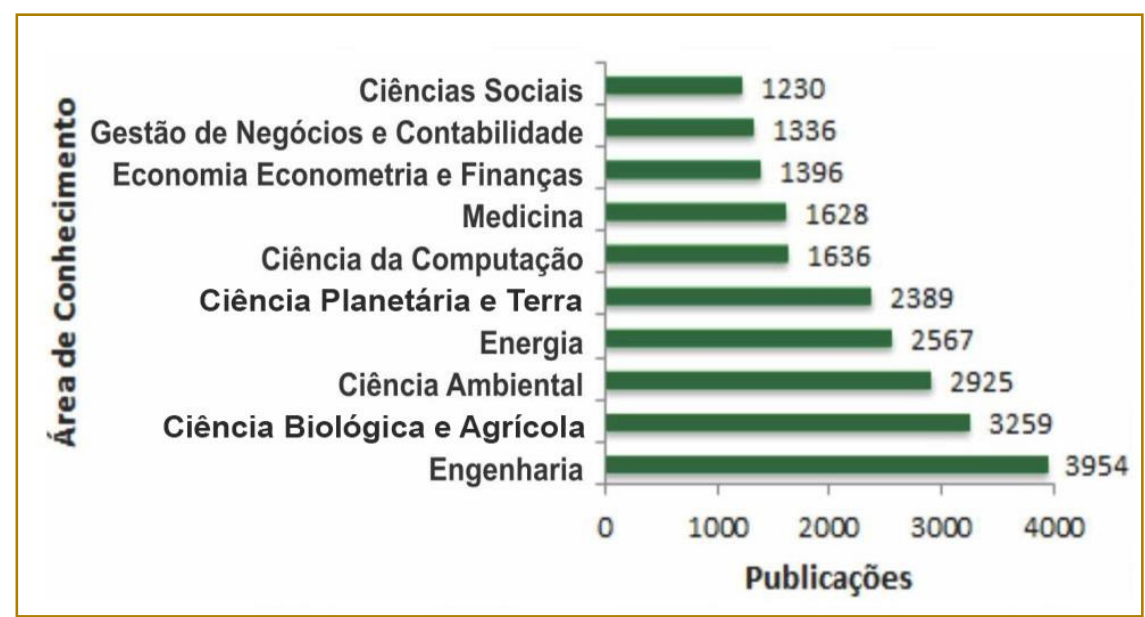

Fonte: Adaptado da Scopus (2018).

Entre as áreas que podem ser visualizadas, destacam-se a Engenharia, Agricultura e Ciências Biológica e Ciência Ambiental.

\subsubsection{ANÁLISE DOS ARTIGOS}

$\mathrm{Na}$ Tabela 3 são apresentados os artigos selecionados como mais relevantes pelo autor, e que foram fornecidos pela base.

Tabela 3: Artigos selecionados para o Método Valor Presente Líquido - VPL

\begin{tabular}{|c|c|c|c|}
\hline Título & Autor & Ano & Citação \\
\hline Managerial discretion and optimal financing policies & STULZ, R. & 1990 & 1105 \\
\hline $\begin{array}{l}\text { Valuation and clean surplus accounting for operating and financial } \\
\text { activities }\end{array}$ & $\begin{array}{l}\text { FELTHAM G. A. } \\
\text { et al. }\end{array}$ & 1995 & 732 \\
\hline $\begin{array}{l}\text { The effects of management buyouts on operating performance and } \\
\text { value }\end{array}$ & KAPLAN, S. & 1989 & 456 \\
\hline $\begin{array}{l}\text { On the welfare significance of national product in a dynamic } \\
\text { economy }\end{array}$ & $\begin{array}{l}\text { WEITZMAN, M. } \\
\text { L. }\end{array}$ & 1976 & 365 \\
\hline $\begin{array}{l}\text { A real option approach to renewable electricity generation in the } \\
\text { Philippines }\end{array}$ & $\begin{array}{l}\text { AGATON, C. B. } \\
\text { et al. }\end{array}$ & 2018 & 0 \\
\hline
\end{tabular}

Fonte: Adptado da Scopus (2018).

Stulz (1990) analisou as políticas de financiamento em uma empresa de propriedade de acionistas atomísticas que não observam fluxos de caixa nem decisões de investimento da administração. Foi observado, que a administração obtém benefícios de investimento e investe o máximo possível. Uma vez que o fluxo de caixa for muito baixo, o autor orienta o financiamento de todos os projetos de valor presente líquido positivo, assim, sua reivindicação não será credível quando o fluxo de caixa for realmente baixo. Consequentemente, o gerenciamento será forçado a investir muito pouco quando o fluxo de caixa for baixo e deve optar por investir mais quando este for alto. As políticas de financiamento, ao influenciar os recursos sob o controle da administração, podem reduzir os custos de sobre e subinvestimento.
Kaplan (1989) apresentou evidências sobre as mudanças nos resultados operacionais para uma amostra de 76 grandes compras gerenciais de empresas públicas, que foram concluídas entre 1980 e 1986. Notou-se que, nos três anos após a compra, essas empresas experimentaram aumentos no lucro operacional (antes da depreciação) e diminuição nos gastos de capital e aumentos no fluxo de caixa líquido. Assim, de acordo com as mudanças operacionais, os aumentos médios e médios no valor de mercado (ajustados para os retornos do mercado) são $96 \%$ e $77 \%$ dos dois meses antes do anúncio de compra para a venda pós-compra. Foi observado que a evidência sugere que as mudanças operacionais são devidas a incentivos melhorados, em vez de demissões 
ou exploração gerencial de acionistas através de informações privilegiadas.

A atratividade de investir em fontes de energia renováveis ao continuar usando petróleo para geração de eletricidade. O método utilizado foi a abordagem de opções reais para analisar como o tempo de investimento em energia renovável depende da volatilidade do preço do diesel, do preço da eletricidade e da externalidade para o uso do petróleo. Em seus resultados, apresentaram um Valor Presente Líquido - VPL positivo para investimento em energia renovável. Sob a incerteza nos preços do petróleo, a otimização dinâmica descreve como espera ou atrasa o investimento em energias renováveis em perdas.

Reduzir o preço local da eletricidade e incorporar externalidades negativas favorece o investimento em energia renovável sobre a continuação do uso de petróleo para geração de eletricidade. Concluíram que a abordagem de opções reais destaca a flexibilidade no momento da tomada de decisões de investimento. No atual regime de energia nas Filipinas, a substituição de energia renovável é uma opção melhor do que continuar importando petróleo para geração de eletricidade. As políticas devem ter como objetivo apoiar o investimento em fontes de energia mais sustentáveis, impondo externalidades para o uso do petróleo ou diminuindo o preço da eletricidade (AGATON et al., 2018).

\subsubsection{TAXA INTERNA DE RETORNO - TIR}

Utilizando as palavras chave "Internal" AND "Rate" AND "of" AND "Return", a pesquisa realizada em busca de publicações sobre o método Taxa Interna de Retorno - TIR retornou 4.610 resultados, que foram incorporados à base de dados da pesquisa para a elaboração das análises.

\subsubsection{ANO DAS PUBLICAÇÕES}

Os dados contidos na Figura 14 demonstram através do gráfico a frequência das publicações por ano no período de 2000 até 31 de janeiro 2018.

Figura 14: Frequência das publicações por ano no período de 2000-2018

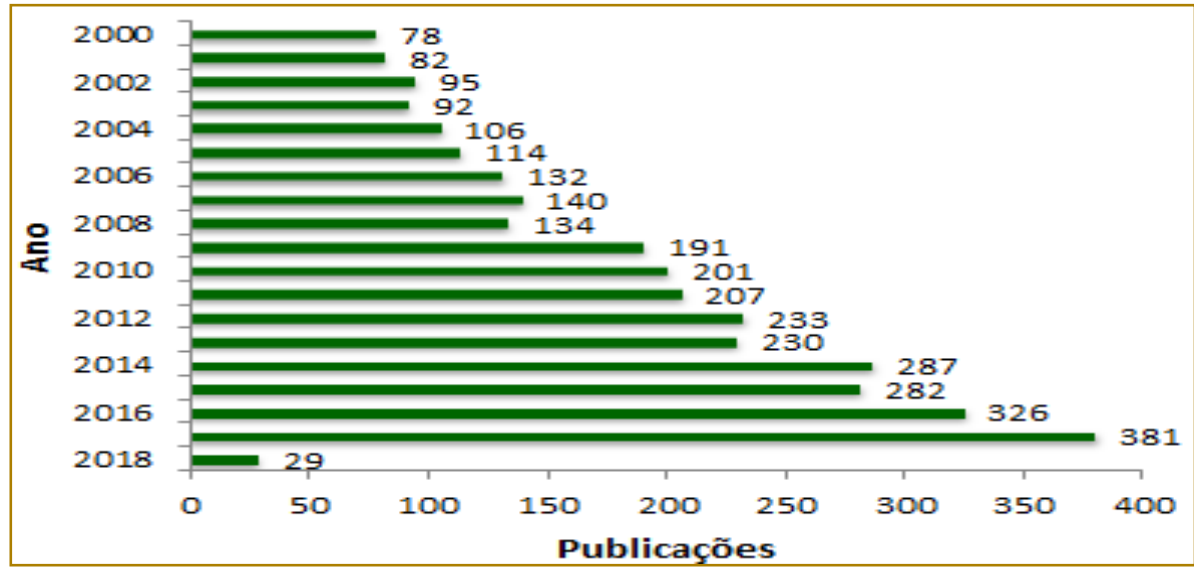

Fonte: Adaptado da Scopus (2018).

Observa-se o mesmo comportamento encontrado anteriormente, ou seja, o ano de maior publicação foi 2017 e o ano de 2018 já apresenta 29 publicações . 


\subsubsection{AUTORES QUE PUBLICARAM SOBRE O TEMA}

Os dados contidos na Figura 15 demonstram através do gráfico os autores com maior frequência de publicação.

Figura 15: Autores com maior frequência de publicação

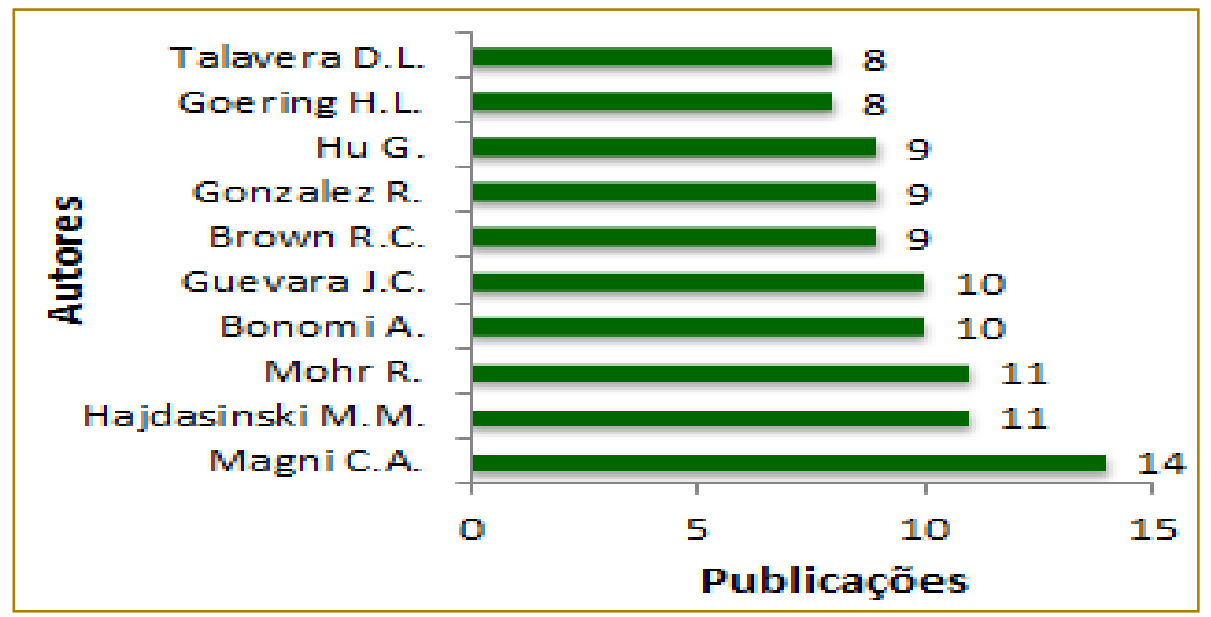

Fonte: Adaptado da Scopus (2018).

Os dados coletados permitem verificar que, entre os autores, destacam-se Magni, C. A. com 14 artigos publicados, e Hajdasinski, M. M. e o Mohr, R. com 11 publicações cada um.

\subsubsection{ORIGEM DE PUBLICAÇÃO}

Os dados contidos na Figura 16 demonstram através do gráfico os periódicos com maior frequência de publicação.

Figura 16: Periódicos com maior frequência de publicação

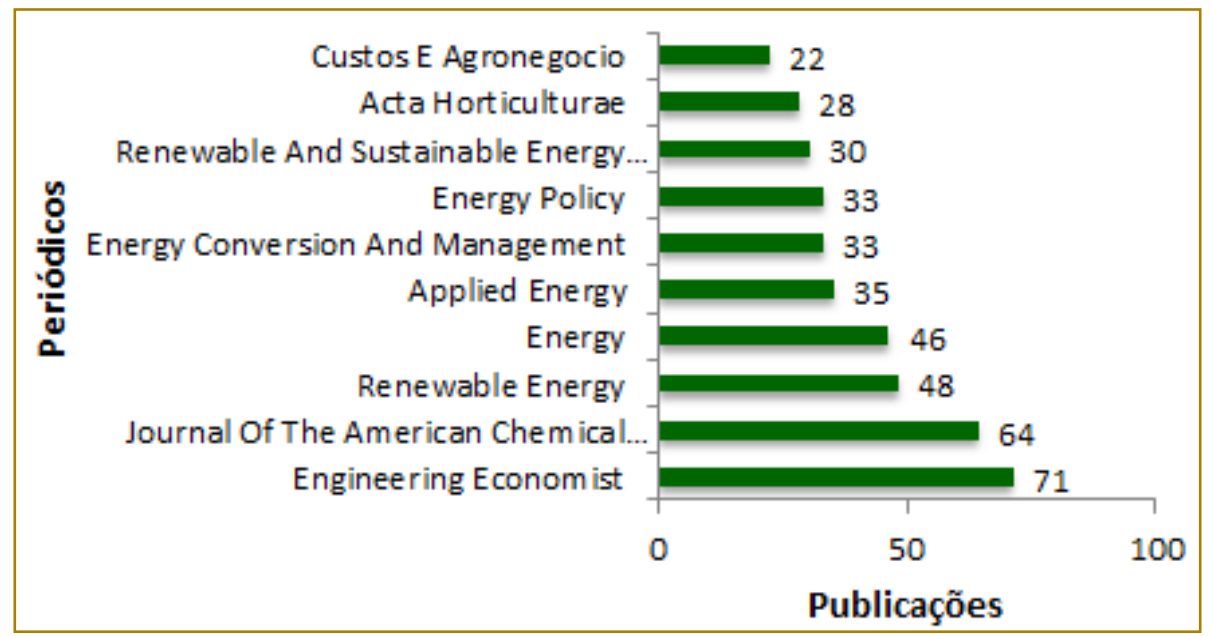

Fonte: Adaptado da Scopus (2018).

Na Figura 16 nota-se que um periódico brasileiro chamado Custos e Agronegócio está presente na lista, porém, este ocupa a última posição entre os mais publicados. O destaque fica para Engineering Economist, com 71 publicações. 


\subsubsection{AFILIAÇÃO}

Os dados contidos na Figura 17 demonstram através do gráfico as afiliações com maior frequência de publicação.

Figura 17: Afiliações com maior frequência de publicação

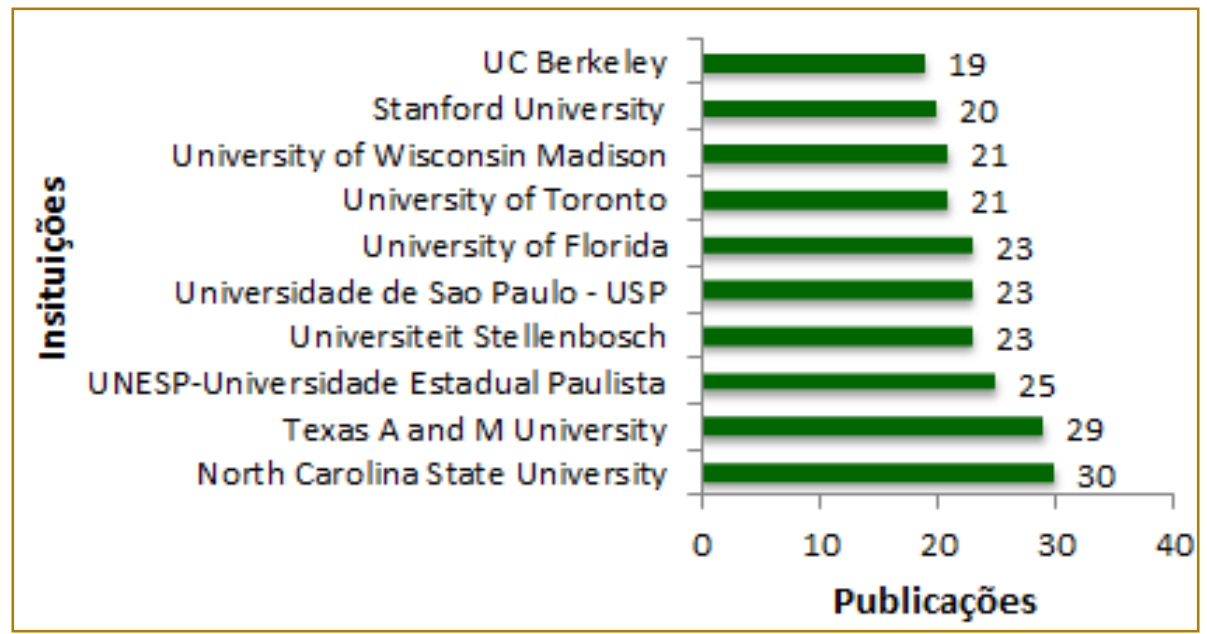

Fonte: Adaptado da Scopus (2018).

É possível observar que há duas universidades brasileiras na lista, sendo Universidade de São Paulo (USP) com 23 publicações e a Universidade Estadual Paulista (UNESP), com 25. Porém, as principais são North Carolina State University com 30 publicações e a Texas $A$ and $M$ University com 29 artigos publicados.

\subsubsection{NÚMERO DE PUBLICAÇÃO POR PAIISES}

Os dados contidos na Figura 18 demonstram através do gráfico os países com maior frequência de publicação.

Figura 18: Países com maior frequência de publicação

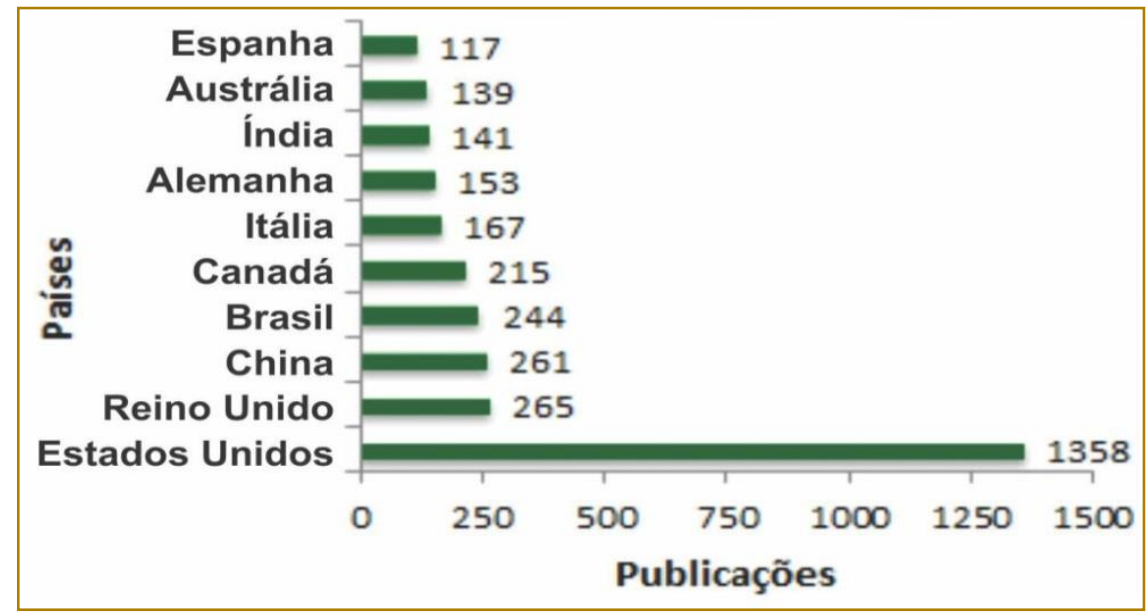

Fonte: Adaptado da Scopus (2018).

Os Estados Unidos continuam sendo o principal entre os outros países, com um número de publicação bem acima de todos os outros, com 1.358 publicações, enquanto o segundo colocado (Reino Unido) tem apenas 265 publicações. É interessante observar também na Figura 18 que o Brasil está presente na lista, com 244 artigos publicados, o que o coloca em quarto lugar na lista entre os 10 países selecionados como base para a pesquisa. 


\subsubsection{NÚMERO DE PUBLICAÇÃO POR} ÁREAS

Os dados contidos na Figura 19 demonstram através do gráfico as áreas de conhecimento com maior frequência de publicação.
As publicações foram agrupadas em 10 áreas de conhecimento, conforme mostradas na Figura 19. A Engenharia se destaca com 1.038 artigos publicados, seguido de Medicina, com 832 publicações e Energia com 815.

Figura 19: Áreas de conhecimento com maior frequência de publicação

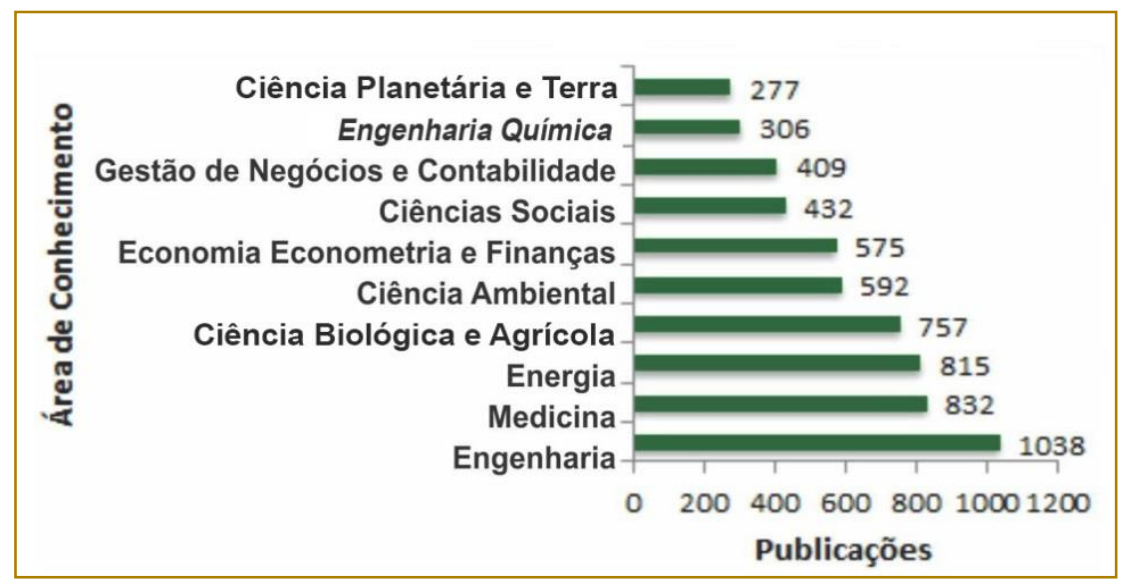

Fonte: Adaptado da Scopus (2018).

\subsubsection{ANÁLISE DOS ARTIGOS}

$\mathrm{Na}$ Tabela 4 são apresentados os artigos selecionados como mais relevantes pelo autor fornecidos pela base.

Tabela 4: Artigos selecionados para o Método Taxa Interna de Retorno - TIR

\begin{tabular}{|l|c|c|c|}
\hline \multicolumn{1}{c|}{ Título } & Autor & Ano & Citação \\
\hline Combustion in swirling flows: A review & SYRED, N. et al. & 1974 & 350 \\
\hline $\begin{array}{l}\text { School subsidies for the poor: Evaluating the Mexican } \\
\text { Progresa poverty program }\end{array}$ & SCHULTZ, T. P. & 2004 & 316 \\
\hline Economic considerations and class size & KRUEGER, A. B. & 2003 & 247 \\
\hline $\begin{array}{l}\text { Migration incentives, migration types: the role of relative } \\
\text { deprivation }\end{array}$ & STARK, O. et al. & 1991 & 246 \\
\hline $\begin{array}{l}\text { Some formal connections between economic values and } \\
\text { yields and accounting numbers }\end{array}$ & PEASNELL, K. V. & 1982 & 203 \\
\hline
\end{tabular}

Fonte: Adaptado da Scopus (2018)

Schultz (2004) buscou avaliar como o programa Progresa, que oferece as mães de baixa renda bolsas de educação nas áreas rurais do México, afetou a quantidade de matrículas efetuadas. As crianças pobres que residem em comunidades selecionadas aleatoriamente para participar da fase inicial do Progresa são comparadas às que residem em outras comunidades (de controle). As comparações pré-programa verificam o design e os estimadores de diferença dupla do efeito do programa no tratamento são calculadas por grau e sexo. Os modelos
Probit também são estimados quanto à probabilidade de inscrição de uma criança, controlando as características adicionais da criança, seus pais, escolas locais e comunidade, e para o atrito da amostra, para avaliar a sensibilidade das estimativas do programa.

Essas estimativas dos efeitos de curto prazo do programa na matrícula são extrapoladas para a escolaridade vitalícia e os ganhos dos adultos para se aproximarem da taxa interna de retorno sobre os subsídios escolares 
públicos, pois aumentam os salários privados esperados. Um estudo recente encontrou evidências empíricas de que a privação relativa inicial das famílias em seu grupo de referência da aldeia desempenha um papel significativo na migração do México para os EUA. Controlando a renda absoluta inicial e os ganhos de renda esperados da migração, a propensão das famílias para participar da migração internacional estava diretamente relacionada à privação relativa inicial das famílias.

O raciocínio para a análise é triplo. Primeiro, há razões para esperar que o papel da privação relativa seja diferente entre migração internacional e migração dentro de um país, como explicamos abaixo. Em segundo lugar, as descontinuidades acentuadas nos retornos do capital humano entre os mercados de trabalho do país de origem e do país de acolhimento podem afetar a capacidade das famílias que diferem em suas dotações de capital humano para alcançar ganhos de posição de renda através da migração internacional. Em terceiro lugar, uma abordagem de privação relativa da migração tem implicações importantes para a política de desenvolvimento.

Na seção I do artigo, descreveram o modelo de privação relativa de migração e apresentaram uma ilustração das implicações políticas divergentes de um modelo de privação relativa versus um modelo de renda absoluta. Na seção II, um modelo de decisão de migração é estimado e é usado para explorar motivos de renda absolutos e relativos para a migração interna e internacional em uma amostra de famílias mexicanas rurais, bem como para testar até que ponto a descontinuidade no mercado de trabalho molda a escolha do migrante destino. $\mathrm{Na}$ seção III apresentou as conclusões (STARK et al., 1991).

Peasnell (1982) apresentou uma série de resultados relativos à relação entre números contábeis e valores econômicos e rendimentos. Alguns dos resultados apareceram anteriormente na literatura e alguns são novos. Estes foram reunidos em um quadro analítico comum para demonstrar seu caráter formal e matemático. É mostrado que o valor presente pode ser obtido por descontar quase todos os números de lucro; que as taxas contabilísticas de retorno definem uma função de desconto diretamente análoga à estrutura do termo e à taxa interna de retorno; e que a taxa interna de retorno pode ser expressa como uma soma linear ponderada das taxas contábeis de retorno.

\section{5 ÍNDICE DE LUCRATIVIDADE - IL}

Com as palavras chave "Profitability" AND "Index", a pesquisa retornou 2.797 periódicos. Dados estes que foram utilizados para as análises evidenciadas a seguir.

\subsubsection{ANO DAS PUBLICAÇÕES}

Os dados contidos na Figura 20 demonstram através do gráfico a frequência das publicações no período de 2000-2018.

Figura 20: Frequência das publicações por ano no período de 2000-2018

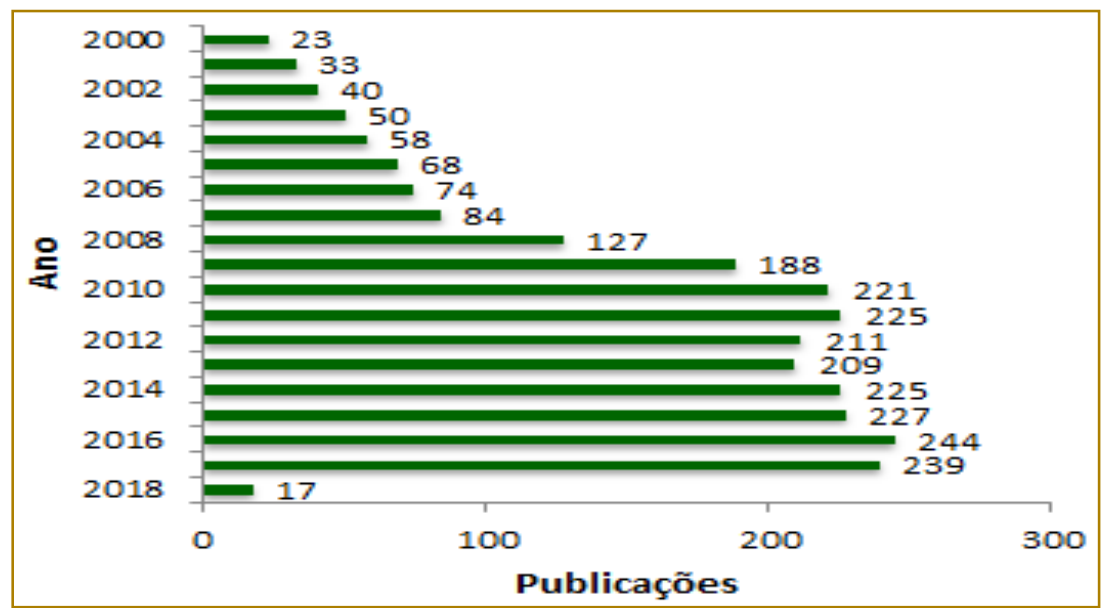

Fonte: Adaptado da Scopus (2018). 
Pode-se verificar que a partir no ano 2000 houve um aumento gradativo no número de publicações. Porém, o ano de 2016 apresentou uma quantidade de artigos publicados maior que o ano de 2017, 244 e 239, respectivamente.

\subsubsection{AUTORES QUE PUBLICARAM SOBRE O TEMA}

Os dados contidos na Figura 21 demonstram através do gráfico os autores com maior frequência de publicação.

Figura 21: Autores com maior frequência de publicação

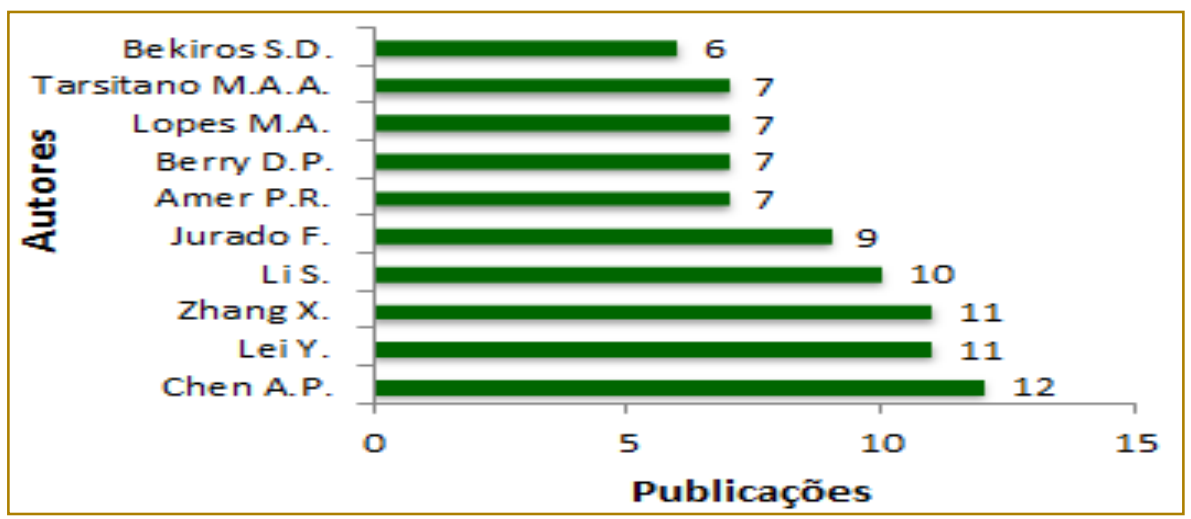

Fonte: Adaptado da Scopus (2018)

É possível observar na Figura que o autor Chen, A. P. é o que mais tem artigos publicados (12), seguido por Lei, Y. e Zhang, X., com 11 publicações cada um. Os autores apresentados na Figura 21 foram os 10 mais relevantes fornecidos pela base de dados.

\subsubsection{ORIGEM DE PUBLICAÇÃO}

Os dados contidos na Figura 22 demonstram através do gráfico os periódicos com maior frequência de publicação.
Conforme os dados apresentados na Figura 22 verifica-se que o periódico mais influente nesse tema é o Indian Journal of Agronomy com 31 publicações, seguido do Expert Systems with Aplication, com 27, e Journal of Dairy Science, com 24.

Figura 22: Periódicos com maior frequência de publicação

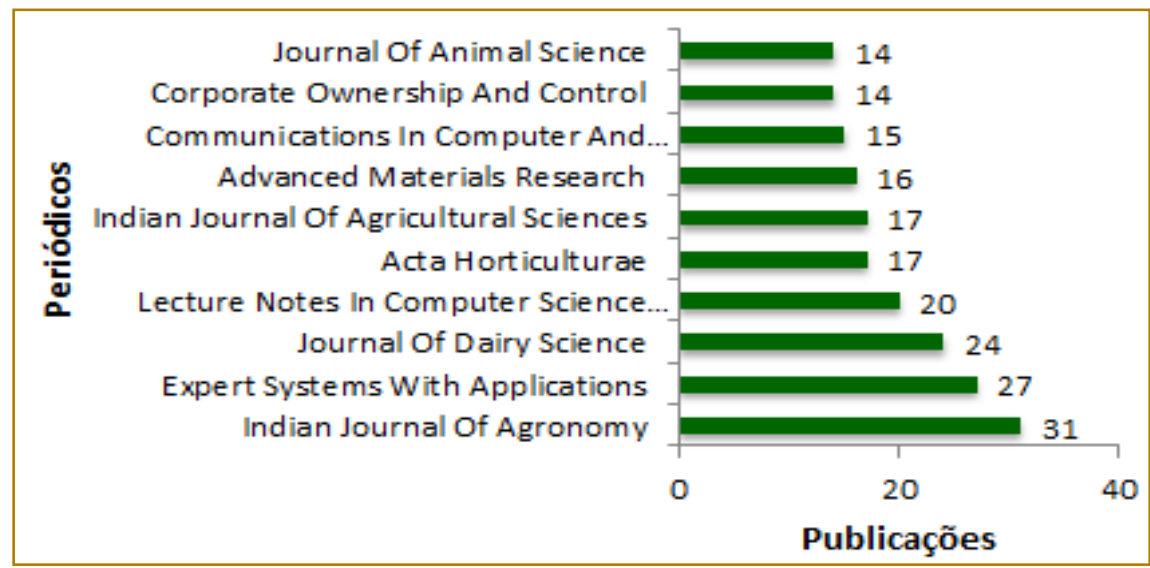

Fonte: Adaptado da Scopus (2018). 


\subsubsection{AFILIAÇÃO}

Os dados contidos na Figura 23 demonstram através do gráfico as afiliações com maior frequência de publicação.

Figura 23: Afiliações com maior frequência de publicação

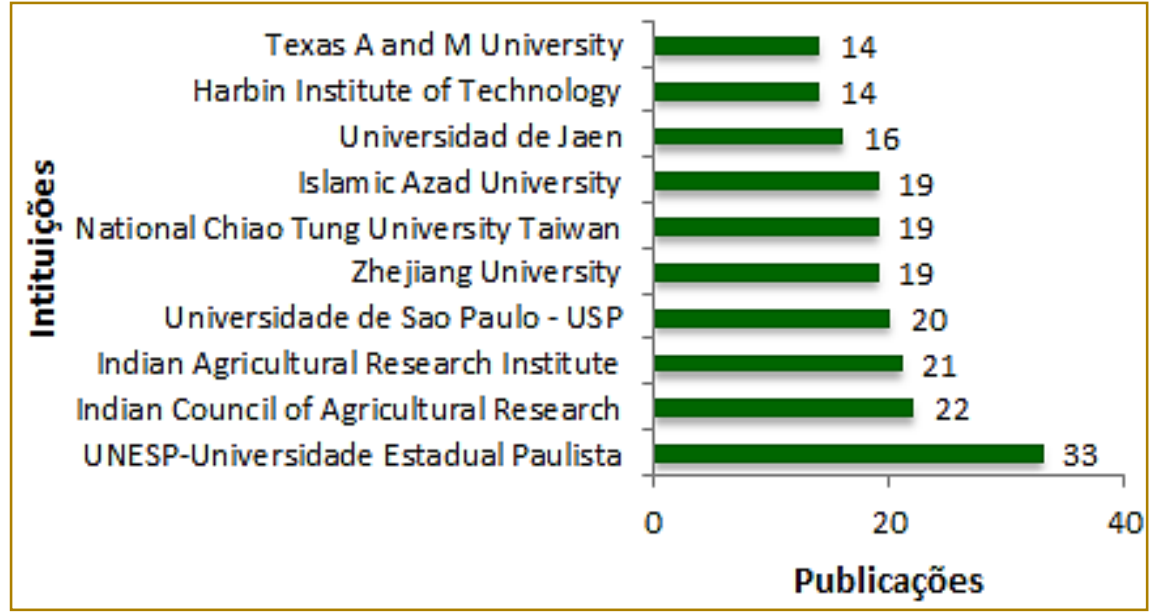

Fonte: Adaptado da Scopus (2018).

Um ponto significativo dos dados apresentados na Figura 23 é que a Universidade Estadual Paulista (UNESP) é o destaque entre as instituições que estudam e publicam sobre o método Índice de Lucratividade - IL, depois desta destacam-se duas instituições indianas, a Indian Council of Agricultural Research e a Indian Agricultural Research Institute.

\subsubsection{NÚMERO DE PUBLICAÇÃO POR PAÍSES}

Os dados contidos na Figura 24 demonstram através do gráfico os países com maior frequência de publicação.

Figura 24: Paises com maior frequência de publicação

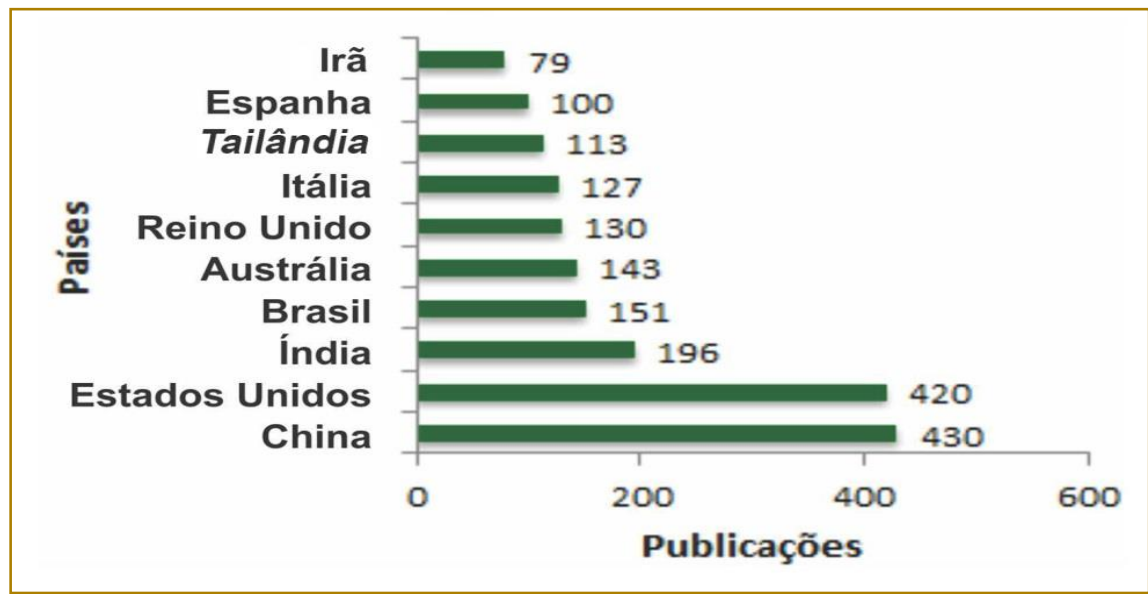

Fonte: Adaptado da Scopus (2018)

Os dados mostram que o Brasil figura novamente entre os principais países fornecidos pela base de dados, quarto lugar após a China (430), Estados Unidos (420) e Índia (196). 


\subsubsection{NÚMERO DE PUBLICAÇÃO POR} ÁREAS

Os dados contidos na Figura 25 demonstram através do gráfico as áreas de conhecimento com maior frequência de publicação.

Figura 25: Áreas de conhecimento com maior frequência de publicação

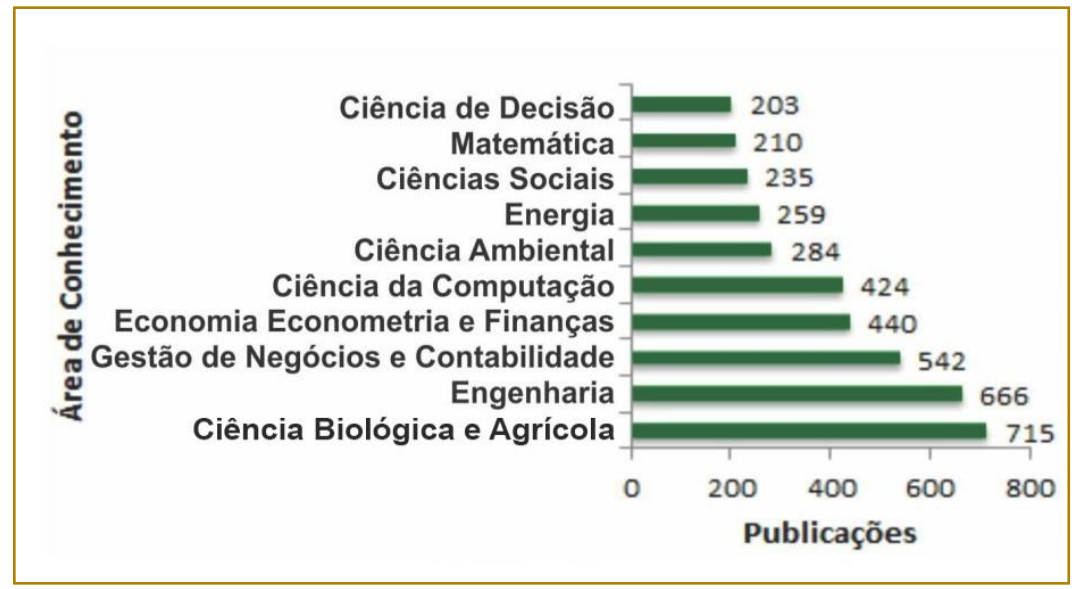

Fonte: Adaptado da Scopus (2018)

Como se pode analisar, as áreas de conhecimento que mais publicaram foram: Agricultura e Ciência Biológica com 715 publicações, Engenharia com 666 e Gestão e Contabilidade com 542.

\subsubsection{ANÁLISE DOS ARTIGOS}

$\mathrm{Na}$ Tabela 5 são apresentados os artigos selecionados como mais relevantes pelo autor fornecidos pela base no método Lucratividade $-\mathrm{IL}$.

Tabela 5: Artigos selecionados para o Método Lucratividade - IL

\begin{tabular}{|c|c|c|c|}
\hline Título & Autor & Ano & Citação \\
\hline $\begin{array}{l}\text { Customer satisfaction, productivity, and profitability: } \\
\text { Differences between goods and services }\end{array}$ & $\begin{array}{l}\text { ANDERSON, E. W. et } \\
\text { al. }\end{array}$ & 1997 & 558 \\
\hline $\begin{array}{l}\text { The impact of culture and governance on corporate social } \\
\text { reporting }\end{array}$ & HANIFFA, R. M. et al. & 2005 & 348 \\
\hline $\begin{array}{l}\text { Annual report readability, current earnings, and earnings } \\
\text { persistence }\end{array}$ & LI, F. & 2008 & 294 \\
\hline $\begin{array}{l}\text { Associations between corporate characteristics and } \\
\text { disclosure levels in annual reports: A meta-analysis }\end{array}$ & AHMED, K. et al. & 1999 & 264 \\
\hline $\begin{array}{l}\text { The determinants of voluntary financial disclosure by swiss } \\
\text { listed companies }\end{array}$ & RAFFOURNIER, B. & 1995 & 237 \\
\hline
\end{tabular}

Fonte: Adapatado da Scopus (2018).

Com o objetivo de investigar se existem condições de troca entre a satisfação do cliente e a produtividade, analisa-se uma escola de pensamento que argumenta que a satisfação e a produtividade do cliente são compatíveis, uma vez que as melhorias na satisfação do cliente podem diminuir o tempo e esforço dedicados ao manuseio de retornos, retrabalhos, garantias e gerenciamento de queixas, ao mesmo tempo em que reduz o custo de fazer transações futuras. Importante ressaltar que o aumento da satisfação do cliente pode aumentar os custos, pois, muitas vezes, exige esforços para melhorar os atributos do produto ou o design geral do produto. É desenvolvida uma estrutura conceitual útil para resolver esses pontos de vista contraditórios (ANDERSON et al., 1997). 
O modelo prevê que a satisfação e a produtividade do cliente são menos propensas a serem compatíveis quando: 1) a satisfação do cliente é relativamente mais dependente da personalização, o grau para o qual a oferta da empresa é confiável, padronizada e livre de deficiências; e 2) quando é caro fornecer altos níveis de personalização e padronização simultaneamente. A característica central deste banco de dados é o conjunto de índices de satisfação do cliente fornecidos pelo Barômetro de Satisfação do Cliente Sueco (SCSB). O SCSB fornece um conjunto uniforme de medidas comparáveis de desempenho de empresas baseadas no cliente e oferece uma oportunidade única para testar as hipóteses do estudo.

Os achados indicam que a associação entre mudanças na satisfação do cliente e mudanças na produtividade é positiva para os bens, mas negativa para os serviços. Além disso, enquanto a satisfação $e$ a produtividade do cliente estão positivamente associadas ao ROI para bens e serviços, a interação entre os dois é positiva para os bens, mas significativamente menos para os serviços. Em conjunto, os resultados sugerem suporte para a afirmação de que as compensações são mais prováveis para os serviços. Assim, as tentativas simultâneas de aumentar a satisfação e a produtividade do cliente provavelmente serão mais desafiadoras nessas indústrias. As descobertas devem fornecer motivação para pesquisas futuras sobre a natureza da satisfação e produtividade do cliente, bem como estratégias e táticas apropriadas para cada uma (HANIFFA et al., 2005).

Vale ressaltar que este é um problema que não é apenas importante hoje, mas certamente se tornará ainda mais importante no futuro. À medida que o crescimento dos serviços continua e os mercados mundiais se tornam cada vez mais competitivos, a importância da satisfação do cliente também aumentará. Para competir em tal mundo, as empresas devem encontrar o equilíbrio certo entre seus esforços para competir de forma eficiente e seus esforços para competir efetivamente (ANDERSON et al., 1997).

Desde 1961, os pesquisadores de contabilidade investigaram associações entre características corporativas e divulgações em relatórios anuais corporativos. E foi observado que os resultados apresentaram consistentemente que o tamanho da empresa e o status da listagem estavam significativamente associados aos níveis de divulgação, enquanto resultados mistos foram encontrados para alavancagem, rentabilidade e tamanho da empresa de auditoria. Os autores se objetivaram a integrar estudos de divulgação prévia e identificar os fatores subjacentes que moderam a variação aparente nos resultados (ANDERSON et al., 1997).

O método utilizado foi a meta-análise de 29 estudos, assim, foi possível confirmar relações significativas e positivas entre níveis de divulgação e tamanho corporativo, status de listagem e alavancagem. Porém, nenhuma associação significativa foi encontrada entre a rentabilidade corporativa ou o tamanho da empresa de auditoria, com níveis agregados de divulgação. Como conclusão, este estudo também descobriu que, além do erro de amostragem, os resultados são moderados por diferenças na construção do índice de divulgação, diferenças na definição das variáveis explicativas e diferenças nas configurações de pesquisa (AHMED et al., 1999).

Raffournier (1995) teve como objetivo do seu trabalho relacionar a extensão da divulgação nos relatórios anuais das empresas suíças, a fim de listar os possíveis determinantes que representam os custos políticos e de agência. O objeto de estudo foi escolhido pelo fato de, antes da implementação da nova lei das sociedades, em 1 de julho de 1992, os requisitos de divulgação da Suíça eram muito baixos, de modo que a maior parte do conteúdo do relatório anual poderia ser considerada divulgada voluntariamente. A amostra incluiu o relatório anual de 1991 de 161 empresas industriais e comerciais. Onde a extensão da divulgação é medida por um índice com base em informações cuja divulgação é exigida pelas quatro e sétima diretivas da União Europeia.

As variáveis independentes são medidas do tamanho da empresa, alavancagem, rentabilidade, estrutura de propriedade, internacionalidade, tamanho do auditor, porcentagem de ativos fixos e tipo de indústria. As relações são avaliadas usando análises univariadas e regressões múltiplas. 0 principal resultado é que o tamanho e a internacionalidade desempenham um papel importante na política de divulgação das empresas, empresas grandes e internacionalmente diversificadas que tendem a divulgar mais informações do que pequenas 
empresas puramente domésticas

(Raffournier , 1995).

\subsection{PAYBACK SIMPLES}

Para este método foram realizadas buscas por periódicos utilizando como palavras chave os termos "Simple" AND "Payback", o que acabou retornando em dados 769 resultados. Com estas informações, foram analisadas a partir deste tópico, diferentes perspectivas, como o ano das publicações, autores mais publicados, origem das publicações, entre outros.

\subsubsection{ANO DAS PUBLICAÇÕES}

Os dados contidos na Figura 26 demonstram através do gráfico a frequência das publicações por ano no período de 20002018.

Figura 26: Frequência das publicações por ano no período de 2000-2018

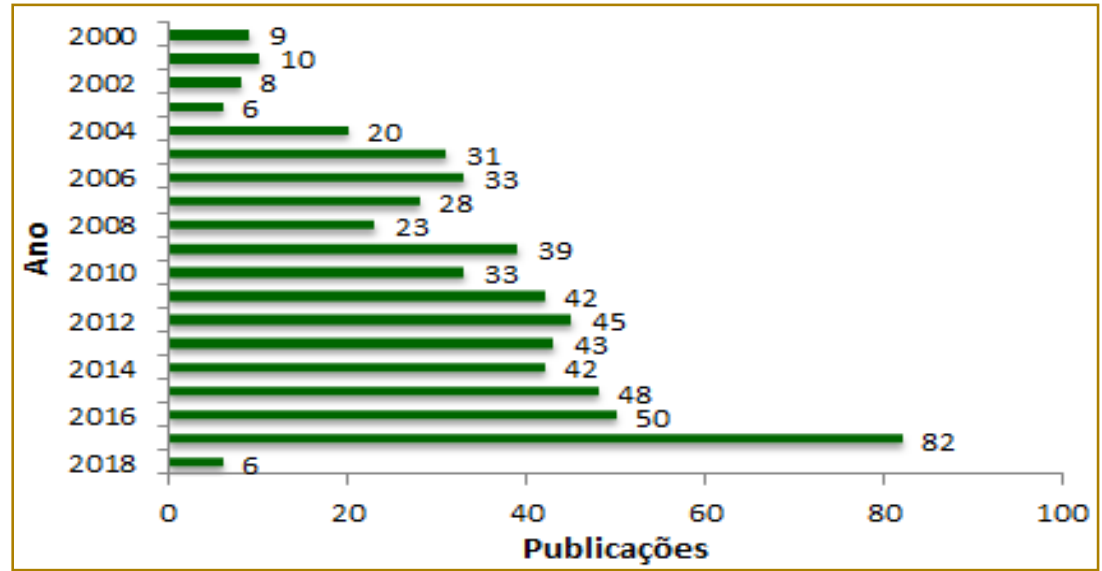

Fonte: Adaptado da Scopus (2018)

Observa-se que há uma linha de tendência crescente nas publicações. O ano de maior publicação foi 2017, com 82 publicações, e o ano de 2018 já se encontra com 6 trabalhos científicos até o momento da realização desta pesquisa.

\subsubsection{AUTORES QUE PUBLICARAM SOBRE O TEMA}

Os dados contidos na Figura 27 demonstram através do gráfico os autores com maior frequência de publicação.

Figura 27: Autores com maior frequência de publicação

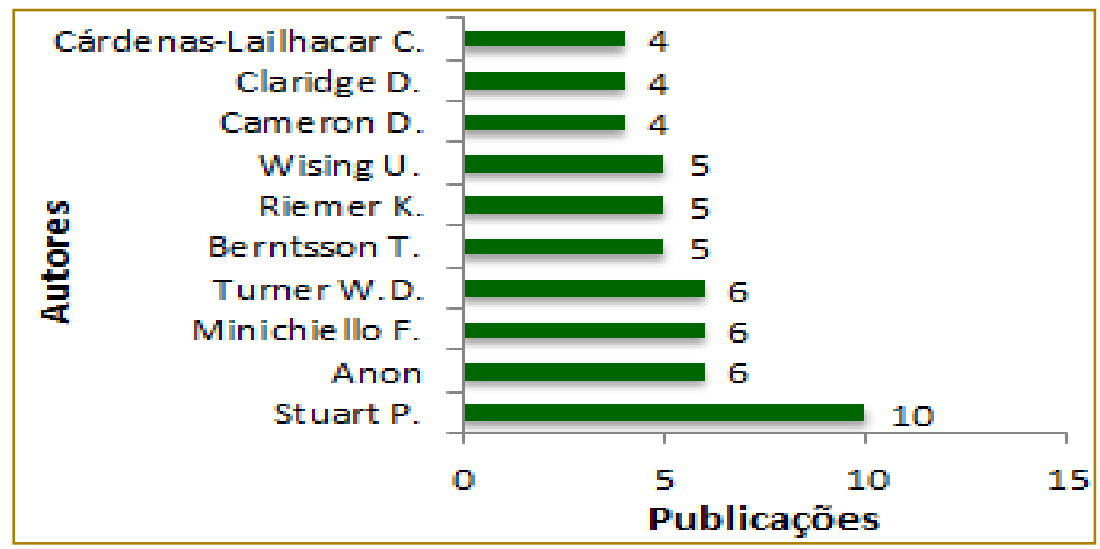

Fonte: Adaptado da Scopus (2018) 
Verifica-se que já um grande destaque para o escritor Stuart P., que possui 10 publicações, estando ainda $40 \%$ à frente do segundo, terceiro e quarto colocados que possuem apenas 6 publicações cada.

\subsubsection{ORIGEM DE PUBLICAÇÃO}

Os dados contidos na Figura 28 demonstram através do gráfico os periódicos com maior frequência de publicação.
Os 10 periódicos mais relevantes fornecidos pela base de dados estão demonstrados na Figura 28. O que mais publicou foi o ASHRAE Transaction (25), seguido do Energy and Buildings (24).

Figura 28: Periódicos com maior frequência de publicação

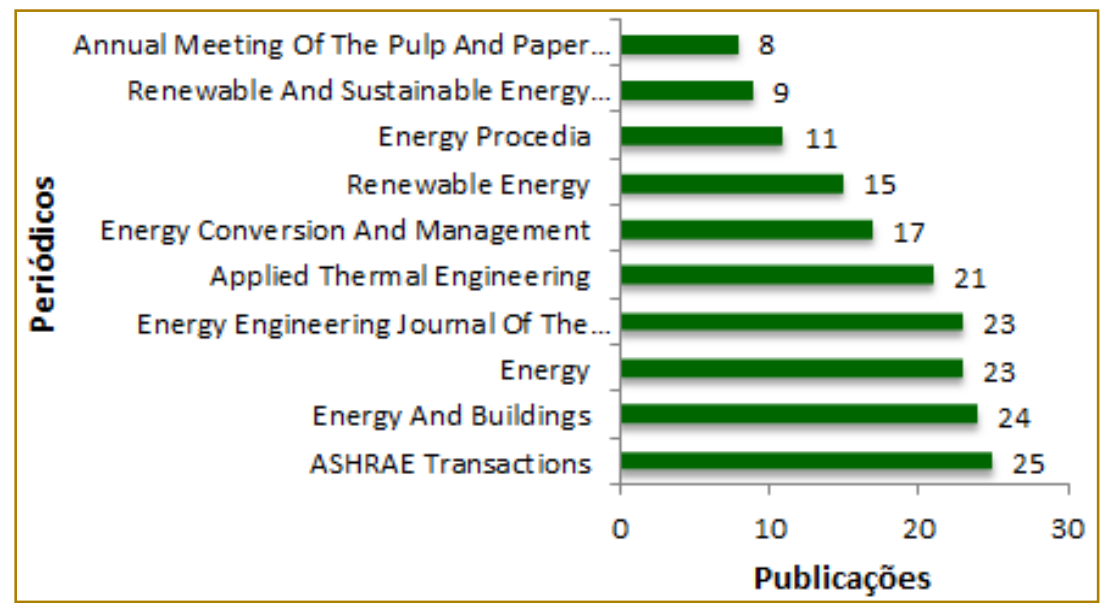

Fonte: Adaptado da Scopus (2018)

\subsubsection{AFILIAÇÃO}

Os dados contidos na Figura 29 revelam, através do gráfico, as afiliações com maior frequência de publicação.

Figura 29: Afiliações com maior frequência de publicação

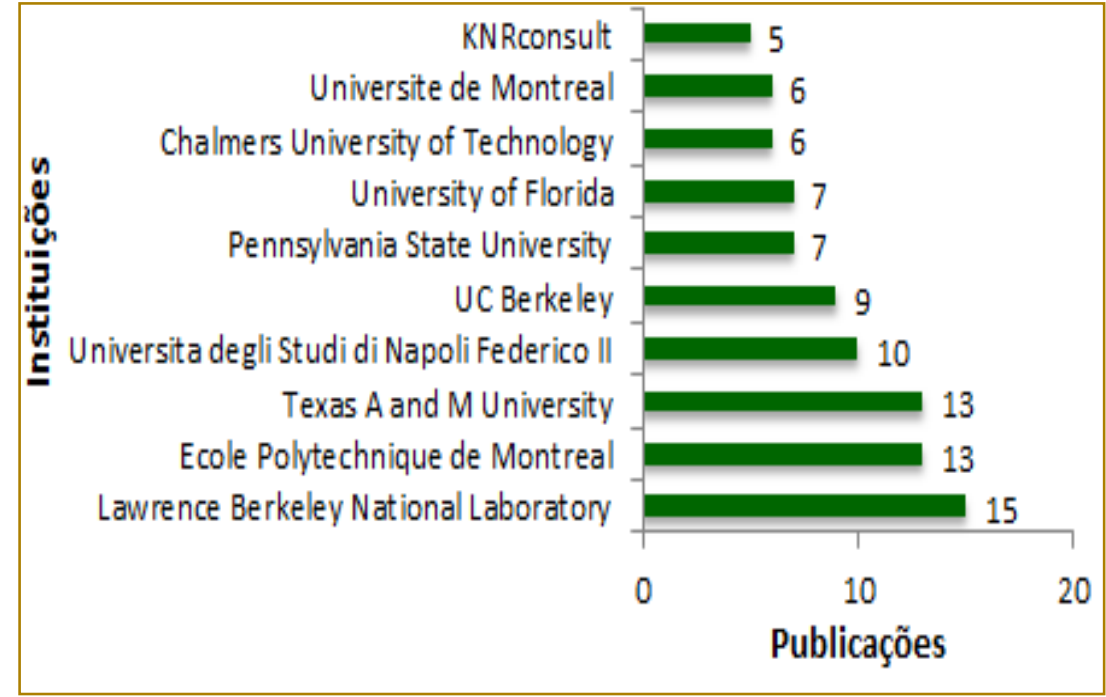

Fonte: Adaptado da Scopus (2018) 
A instituição que mais publicou sobre esse método financeiro foi a Lawrence Berkeley National Laboratory, com 15 trabalhos científicos, seguido de Ecole Polytechnique de Montreal, com 13 e da Texas A and M University com o mesmo número.

\subsubsection{NÚMERO DE PUBLICAÇÃO POR PAÍSES}

Os dados contidos na Figura 30 demonstram através do gráfico os países com maior frequência de publicação.

Figura 30: Países com maior frequência de publicação

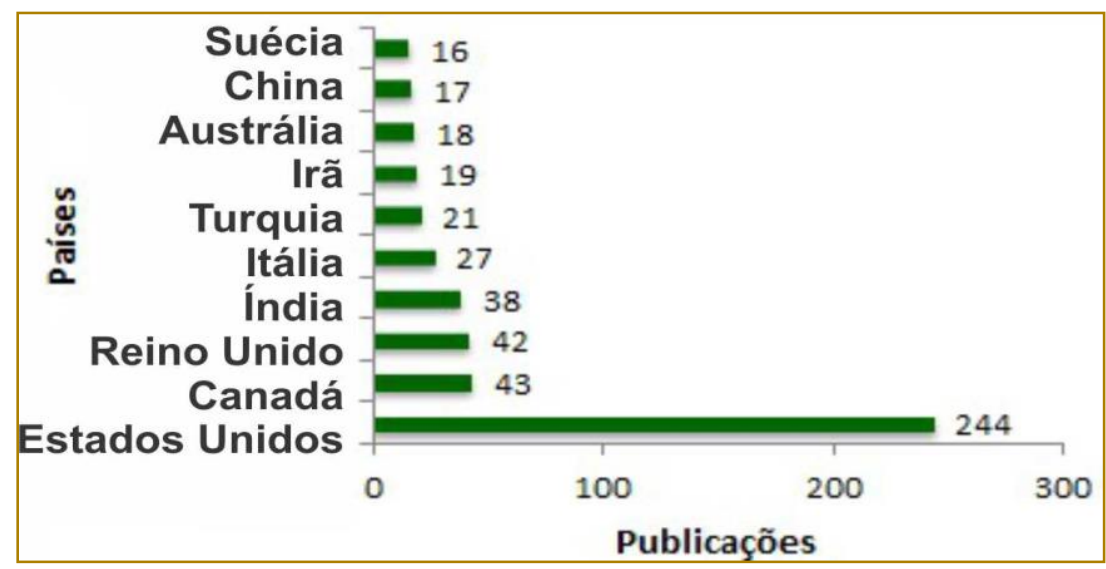

Fonte: Adaptado da Scopus (2018)

Os Estados Unidos aparecem como líderes absolutos nas publicações, sendo responsáveis por 244 delas. Em segundo lugar tem-se o Canadá com 43 publicações e em terceiro lugar o Reino Unido com 42.

\subsubsection{NÚMERO DE PUBLICAÇÕES POR ÁREA}

Os dados contidos na Figura 31 demonstram através do gráfico as áreas de conhecimento com maior frequência de publicação.
Nota-se, observando a Figura 31 que as áreas de conhecimento que mais publicaram foram a Engenharia, com 384 publicações e Energia com 371, bem à frente do terceiro colocado, Ciência Ambiental, que teve apenas 101 publicações.

Figura 31: Áreas de conhecimento com maior frequência de publicação

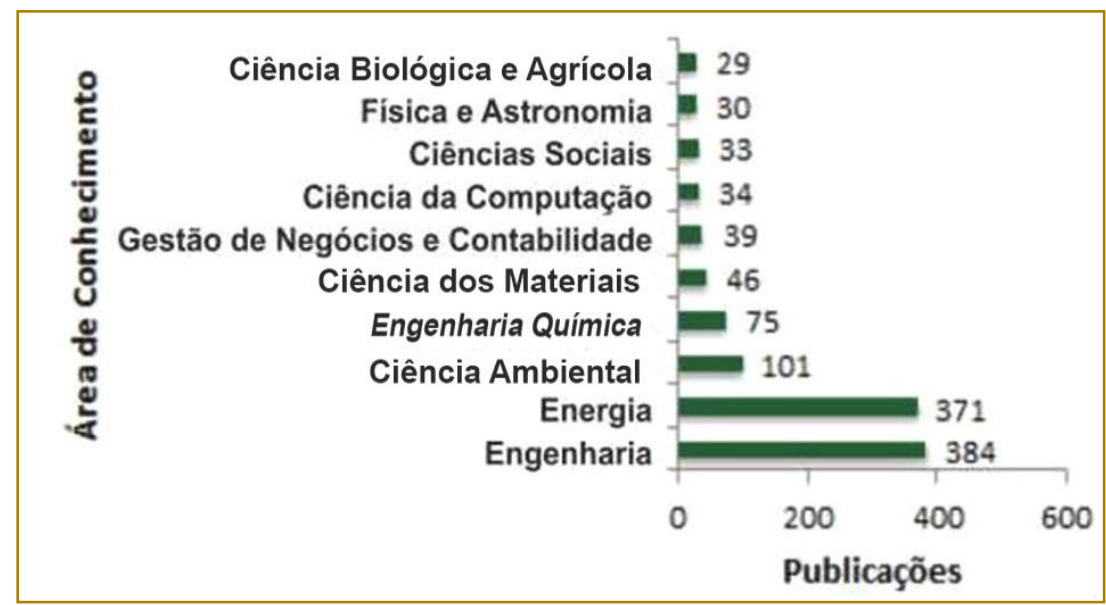

Fonte: Adaptado da Scopus (2018) 


\subsubsection{ANÁLISE DOS ARTIGOS}

$\mathrm{Na}$ Tabela 6 são apresentados os artigos selecionados como mais relevantes pelo autor fornecidos pela base.

Tabela 6: Artigos selecionados para o Método Payback Simples

\begin{tabular}{|c|c|c|c|}
\hline Título & Autor & Ano & Citação \\
\hline $\begin{array}{l}\text { Improved performance and stability in quantum dot solar cells } \\
\text { through band alignment engineering }\end{array}$ & CHUANG et al. & 2014 & 588 \\
\hline $\begin{array}{l}\text { Simulink model for economic analysis and environmental } \\
\text { impacts of a PV with diesel-battery system for remote villages }\end{array}$ & WIES et al. & 2005 & 125 \\
\hline Cost of solar energy generated using PV panels & REHMAN et al. & 2007 & 119 \\
\hline $\begin{array}{l}\text { Dewatering of microalgal culture for biodiesel production: } \\
\text { Exploring polymer flocculation and tangential flow filtration }\end{array}$ & DANQUAH et al. & 2009 & 114 \\
\hline $\begin{array}{l}\text { Intelligent speed adaptation: Accident savings and cost-benefit } \\
\text { analysis }\end{array}$ & CARSTEN et al. & 2005 & 109 \\
\hline
\end{tabular}

Fonte: Adaptado da Scopus (2018).

Chuang et al. (2014) observaram que o processamento de soluções é uma rota promissora para a realização de dispositivos fotovoltaicos de baixo custo, grandes áreas, flexíveis e leves, com tempo de retorno de energia curto e alta potência específica. Mas em contrapartida, as células solares baseadas em materiais orgânicos, inorgânicos e híbridos processados em solução relatados geralmente sofriam de baixa estabilidade do ar, requerendo um ambiente de processamento de atmosfera inerte ou processamento de alta temperatura, o que aumenta as complexidades e os custos de fabricação.

De acordo com Rehman et al. (2007), as condições de fabricação a baixa temperatura e boa estabilidade atmosférica continua a ser um grande desafio técnico, que pode ser abordado, como demonstrado pelos autores, com o desenvolvimento de células solares de ponto quântico $\mathrm{ZnO} / \mathrm{PbS}$ processadas em solução de temperatura ambiente. Foi observado que ao englobar o alinhamento da banda das camadas de pontos quânticos através do uso de diferentes tratamentos de ligando, obteve-se uma eficiência certificada de $8.55 \%$. Além disso, o desempenho de dispositivos não encapsulados permanece inalterado por mais de 150 dias de armazenamento no ar. Este sistema de material introduz uma nova abordagem para o objetivo de células solares estáveis de alto desempenho, compatíveis com processos simples de solução e deposição em substratos flexíveis.
Wies et al. (2005) buscaram discutir a análise econômica e os impactos ambientais da integração de uma Matriz Fotovoltaica (PV) em sistemas de energia diesel-elétrica para aldeias remotas. Assim, o MATLAB Simulink foi usado para combinar a carga com a demanda e distribuir a produção elétrica entre o PV e o gerador diesel-elétrico. Uma vez que a parte econômica do modelo calcula o combustível consumido, o quilowatt/hora obtido por galão de combustível fornecido e o custo total do combustível. Já a parte ambiental do modelo calcula o CO2, a Matéria Particulada (PM) e os NOx emitidos para a atmosfera.

As Simulações foram baseadas em um sistema real na comunidade remota do Alasca de Lime Village foram realizadas para três casos: 1) diesel apenas; 2) bateria diesel; e 3) PV com bateria diesel usando um período de tempo de um ano. Os resultados da simulação foram utilizados para calcular o retorno da energia, o tempo de retorno simples para o módulo fotovoltaico e os custos evitados de $\mathrm{CO} 2$, NOx e PM. A análise pós-simulação inclui a comparação dos resultados com os previstos pelo Modelo de Otimização Híbrida para Energias Renováveis Elétricas (HOMER). O custo do ciclo de vida (LCC) e os resultados das emissões de ar do nosso modelo Simulink foram comparáveis aos previstos pelo HOMER (WIES et al., 2005).

Rehman et al. (2007) utilizaram a média diária da radiação solar e dados de duração do sol para estudar a distribuição e a duração solar 
sobre a Arábia Saudita. A análise também incluiu a produção de energia renovável e a avaliação econômica de uma usina de energia conectada à rede fotovoltaica de 5 MW instalada para geração de eletricidade. $O$ estudo utilizou o software RetScreen para produção de energia e avaliação econômica. Em seus resultados, verificou-se que a radiação solar global varia entre um mínimo de 1,63 MWh / m2 ano-1 em Tabuk e um máximo de 2,56 MWh / m2 ano-1 em Bisha, enquanto a média permaneceu como 2,06 MWh / m2 ano-1. A duração da luz do sol variou entre 7,4 e 9,4 h com uma média global de $8,89 \mathrm{~h}$.

Também se verificou que o rendimento específico varia de 211,5 a 319,0 kWh / m2, com uma média de 260,83 kWh / m2. A energia renovável produzida a cada ano a partir da planta de capacidade instalada de 5 MWp variou entre 8196 e 12.360 MWh enquanto a média permaneceu como 10.077 MWh / ano-1. Os indicadores econômicos, como a taxa de retorno interna, o período de recuperação simples, os anos para os fluxos de caixa positivos, o valor presente líquido, a economia anual do ciclo de vida, o índice de rentabilidade e o custo da produção de energia renovável mostraram que Bishah foi o melhor site para Desenvolvimento de plantas de energia baseadas em PV e Tabuk o pior. Do ponto de vista ambiental, verificou-se que, em média, uma quantidade aproximada de 8182 toneladas de gases de efeito estufa são impedidos de entrar na atmosfera local a cada ano (REHMAN et al., 2007).

\subsection{PAYBACK DESCONTADO}

Para a realização das pesquisas referentes ao método de Payback Descontado, foram utilizadas as palavras chave "Discounted" AND "Payback", retorno como dados 304 resultados.

\subsubsection{ANO DAS PUBLICAÇÕES}

Os dados contidos na Figura 32 demonstram através do gráfico a frequência das publicações por ano no período de 20002018.

Figura 32: Frequência das publicações por ano no período de 2000-2018

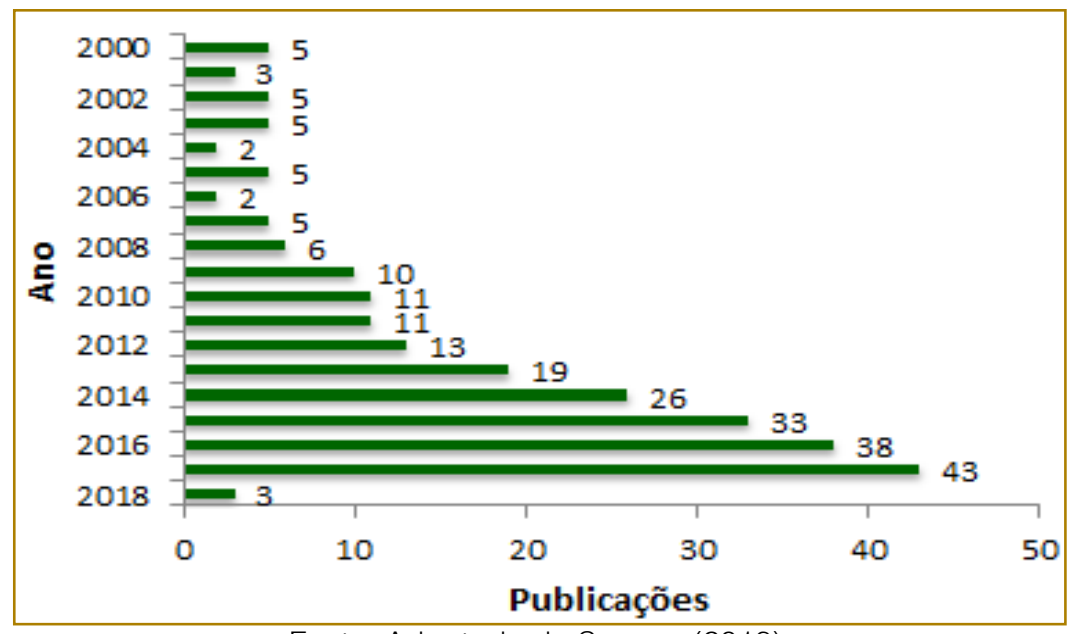

Fonte: Adaptado da Scopus (2018)

Seguindo a tendência apresentada nos outros métodos já analisados, o ano de 2017 foi o ano que obteve maior publicação no recorte temporal realizado, com 43 publicações, seguido do ano de $2016 \mathrm{com} \mathrm{38.} \mathrm{O} \mathrm{ano} \mathrm{de}$ 2018 já apresenta três trabalhos publicados como pode ser visto na Figura 32.

\subsubsection{AUTORES QUE PUBLICARAM SOBRE O TEMA}

Os dados contidos na Figura 33 demonstram através do gráfico os autores com maior frequência de publicação. 
Figura 33: Autores com maior frequência de publicações

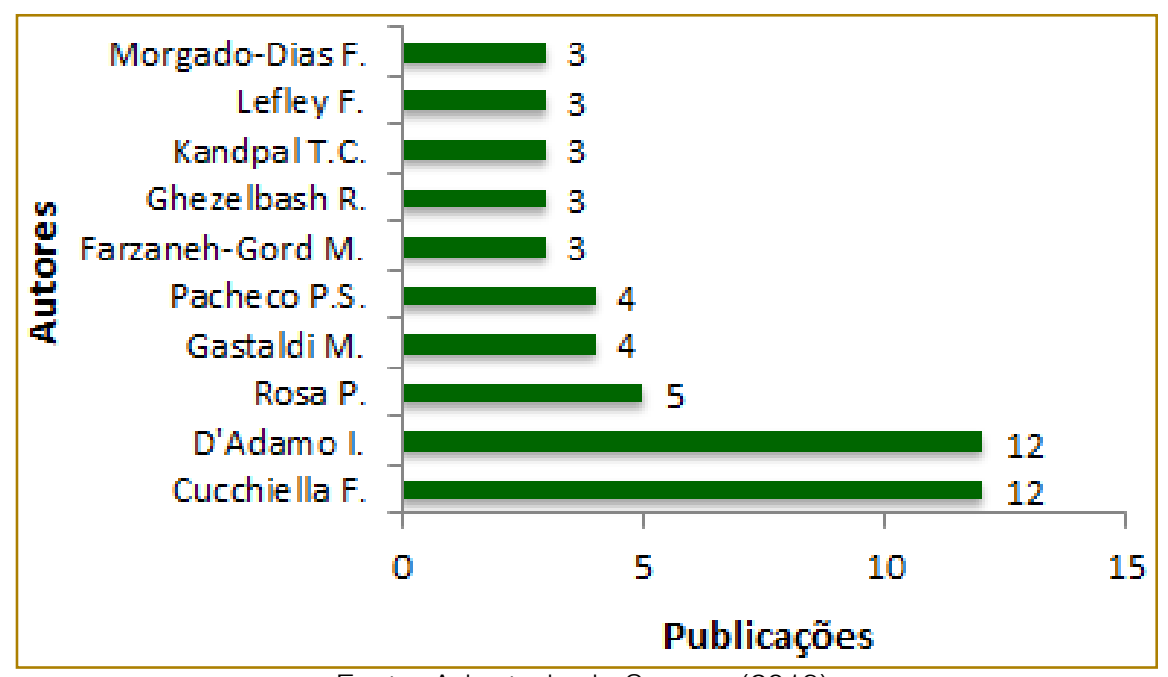

Fonte: Adaptado da Scopus (2018)

Analisando os principais autores representados na Figura 33, nota-se que Cucchiella, F. e D'Adamo, I. se destacam entre os demais por terem mais que o dobro que o terceiro da lista, Rosa, P., que apresenta apenas 5 trabalhos publicados sobre o tema enquanto os anteriormente citados possuem 12 .

\subsubsection{ORIGEM DE PUBLICAÇÃO}

Os dados contidos na Figura 34 demonstram através do gráfico os periódicos com maior frequência de publicação.

Figura 34: Periódicos com maior frequência de publicação

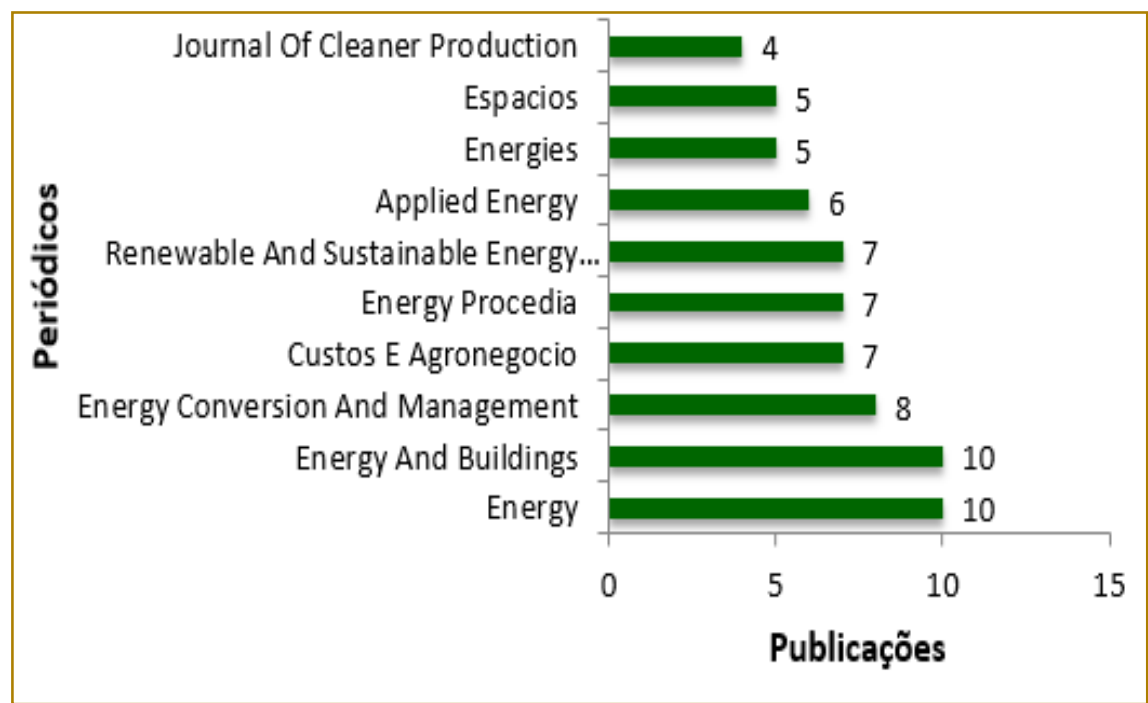

Fonte: Adaptado da Scopus (2018)

Os periódicos principais apresentados como resultado dos dados da pesquisa são voltados para energia, sendo estes: Energy, Energy and Buildings e Energy Conversation and Management. Um brasileiro está presente, o Custos e Negócios, vide Figura 34.

\subsubsection{AFILIAÇÃO}

Os dados contidos na Figura 35 demonstram através do gráfico as afiliações com maior frequência de publicação. 
Figura 35: Afiliações com maior frequência de publicação

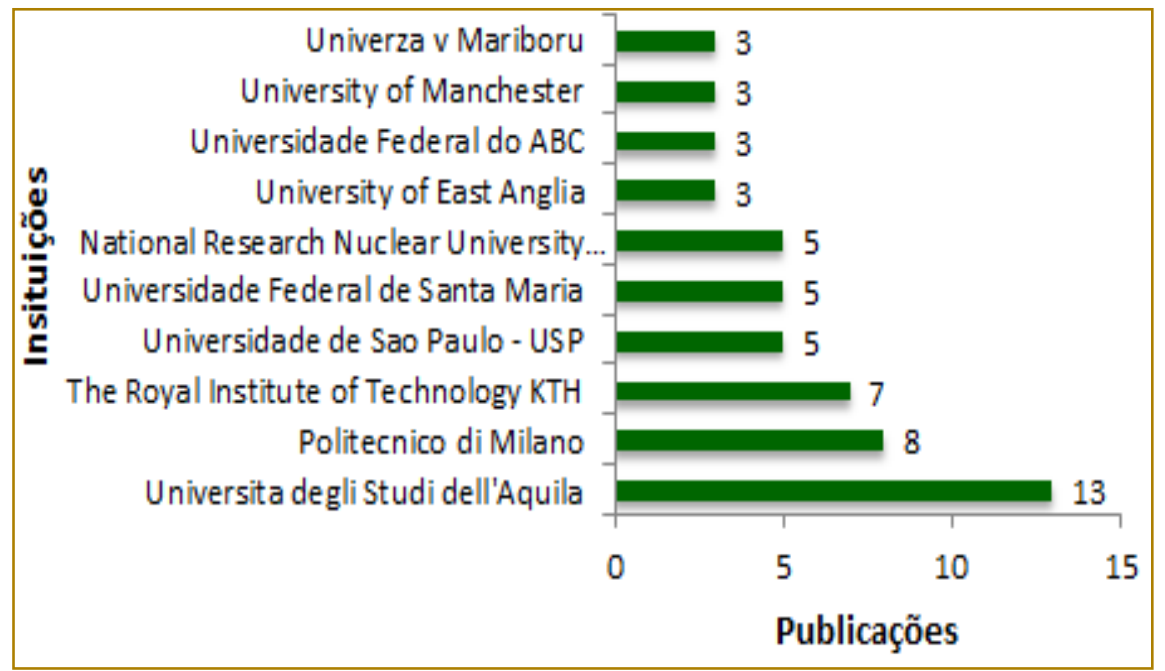

Fonte: Adaptado da Scopus (2018)

Com a Figura 35 é possível observar as instituições mais engajadas nas publicações, sendo, em primeiro lugar com 13 publicações, a Universidad de gli Studi dell'Aquila. Um fato interessante é que a Universidade de São Paulo (USP) está entre as 10 mais relevantes com 5 artigos publicados.

\subsubsection{NÚMERO DE PUBLICAÇÃO POR PAÍSES}

Os dados contidos na Figura 36 demonstram através do gráfico aos países com maior frequência de publicação.

Figura 36: Paises com maior frequência de publicações

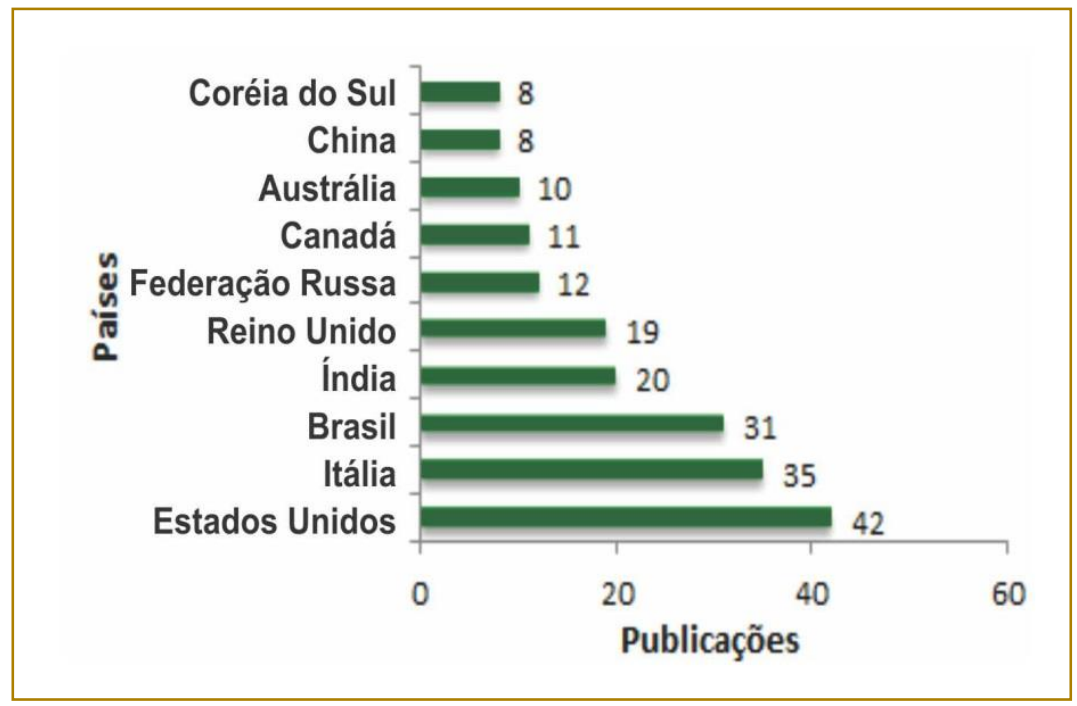

Fonte: Adaptado da Scopus (2018)

Diferente do padrão da maioria dos outros métodos investigados, no método Payback Descontado o Brasil encontra-se na lista dos países mais influentes, com 31 publicações, estando em terceiro lugar atrás apenas dos Estados Unidos, com 42 publicações, e da Itália com 31 publicações.

\subsubsection{NÚMERO DE PUBLICAÇÃO POR ÁREAS}

Os dados contidos na Figura 37 demonstram através do gráfico as áreas de conhecimento com maior frequência de publicação. 
Figura 37: Áreas de conhecimento com maior frequência de publicação

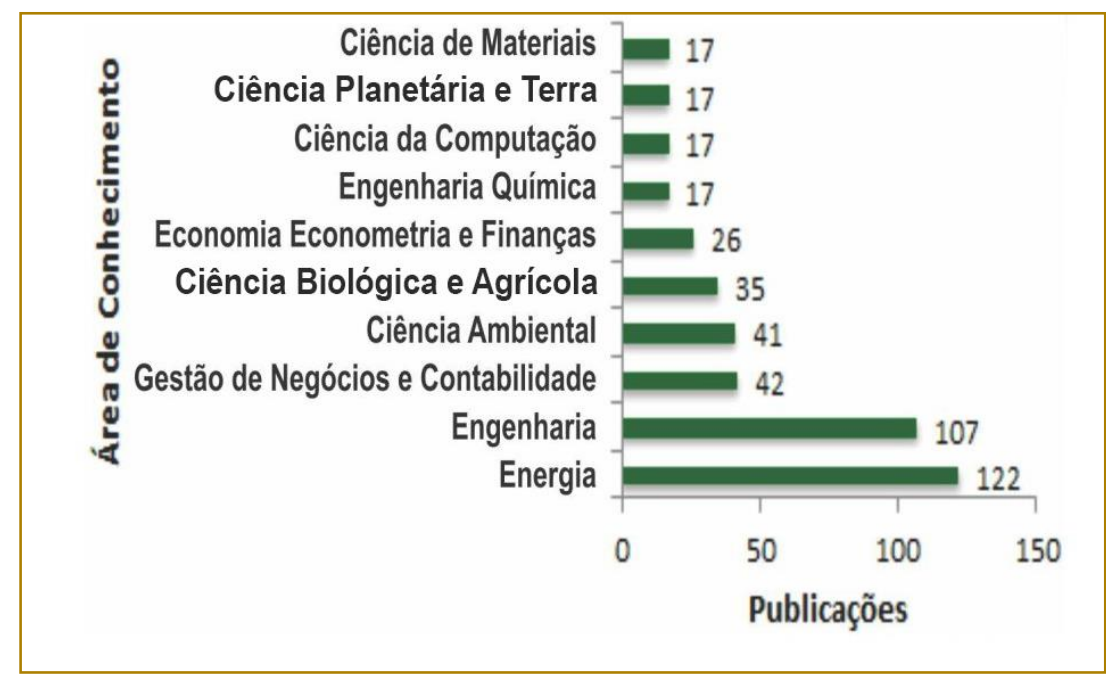

Fonte: Adaptado da Scopus (2018)

Assim como no método anterior, na análise do método de Payback Descontado as áreas de conhecimento que lideram a lista das mais relevantes é a Energia com 122 e Engenharia com 107 publicações.

\subsubsection{ANÁLISE DOS ARTIGOS}

$\mathrm{Na}$ Tabela 7 são apresentados os artigos selecionados como mais relevantes pelo autor fornecidos pela base.

Tabela 7: Artigos selecionados para o Método Payback Descontado

\begin{tabular}{|c|c|c|c|}
\hline Título & Autor & Ano & Citação \\
\hline $\begin{array}{l}\text { Methodology for the design optimisation and the } \\
\text { economic analysis of grid-connected photovoltaic } \\
\text { systems }\end{array}$ & KORNELAKIS et al. & 2009 & 54 \\
\hline $\begin{array}{l}\text { Algal biofuel production for fuels and feed in a 100-ha } \\
\text { facility: A comprehensive techno-economic analysis and } \\
\text { life cycle assessment }\end{array}$ & BEAL et al. & 2015 & 49 \\
\hline $\begin{array}{l}\text { Environmental and economic analysis of building } \\
\text { integrated photovoltaic systems in Italian regions }\end{array}$ & CUCCHIELLA et al. & 2015 & 38 \\
\hline $\begin{array}{l}\text { Hybrid PV and solar-thermal systems for domestic heat } \\
\text { and power provision in the UK: Techno-economic } \\
\text { considerations }\end{array}$ & HERRANDO et al. & 2016 & 36 \\
\hline $\begin{array}{l}\text { Techno-economic analysis of solar photovoltaic power } \\
\text { plant for garment zone of Jaipur city }\end{array}$ & CHANDEL et al. & 2014 & 35 \\
\hline
\end{tabular}

Fonte: Adaptado da Scopus (2018).

Kornelakis et al. (2009) apresentaram uma metodologia para a otimização do projeto e a análise econômica de sistemas conectados à rede fotovoltaica (PVGCSs). O objetivo desta foi sugerir, entre uma lista de dispositivos de sistema comercialmente disponíveis, o número e o tipo de dispositivos de sistema otimizados e os valores ótimos dos detalhes da instalação do módulo fotovoltaico (PV), de modo que o benefício econômico líquido total alcançado durante o período de vida operacional do sistema é maximizado. 
As variáveis de decisão incluídas no processo de otimização foram o número ideal e o tipo de módulos fotovoltaicos e os conversores DC/AC, o ângulo de inclinação ótimo dos módulos fotovoltaicos, a disposição ideal dos módulos fotovoltaicos dentro da área de instalação disponível e a distribuição ideal dos Módulos PV entre os conversores DC/AC. A viabilidade econômica da configuração PVGCS resultante foi explorada pelo o valor presente líquido, o período de retorno descontado e os métodos de taxa interna de retorno. O método proposto foi aplicado para o design ideal de um PVGCS interligado à rede elétrica de uma ilha com significativo potencial de irradiação solar (KORNELAKIS et al., 2009).

Existem inúmeros fatores que contribuem para a definição do desempenho econômico e ambiental dos investimentos em energia solar, como a irradiação anual média, o consumo dos consumidores, o sistema de incentivo tarifário, o portfólio de energia, as emissões produzidas pelo sistema fotovoltaico, o poder nominal do indivíduo módulos, renda disponível do investidor, disponibilidade de superfície para a instalação de painéis fotovoltaicos e missão, que caracterizam o projeto (maximização ambiental, maximização econômica ou autossuficiência do sistema durante o primeiro ano) (KORNELAKIS et al., 2009).

Cucchiella et al. (2015) desenvolveram um estudo na Itália, levando em consideração e estimando a rentabilidade econômica e o impacto ambiental desse sistema, primeiro na escala provincial e depois na escala regional, para delinear as características gerais que não foram causadas por um único cenário. Os indicadores utilizados incluem o seguinte: valor presente líquido (VPL), taxa interna de retorno (IRR), período de retorno descontado (DPbP), taxa de custo / benefício agregado descontado $(\mathrm{BCr})$ e redução de emissões de dióxido de carbono (ERcd).

O objetivo final do trabalho foi definir o número de sistemas fotovoltaicos (PV) necessários para atingir o objetivo da produção de energia renovável nas configurações acima. Onde foi examinado um cenário geral apropriado para atingir o objetivo, bem como a implementação da riqueza total gerada por este quadro e a redução das emissões de $\mathrm{CO} 2$ resultantes da implementação desse plano. Os indicadores utilizados foram o valor presente líquido per capita e a redução das emissões de dióxido de carbono per capita (CUCCHIELLA et al., 2015).

Herrando et al. (2016) analisaram o potencial e a relação custo-eficácia de uma usina de energia solar fotovoltaica para atender a demanda de energia da zona de vestuário em Jaipur (Índia). Além de estimarem a demanda de energia da zona de vestuário para o ano de 2011 (2,21 MW), e, o projeto da usina de energia solar fotovoltaica de 2,5 $\mathrm{MW}$ de capacidade foi proposto, o que requer cerca de 13,14 acres de área de terra. Observando a escassez e o custo da terra perto da cidade, uma proposta para a usina fora de Jaipur também foi considerada e comparada com a opção no local.

Para a taxa interna de retorno da rede de energia solar fotovoltaica no local (IRR) foi $11,88 \%$, a taxa de desconto de NPV $10 \%$ foi 119,52 milhões de INR, o período de retorno simples foi de 7,73 anos e o período de retorno descontado $10 \%$ foi 15,53 anos, enquanto que a IRR do sistema de energia fora do local foi $15,10 \%$, o VPL foi 249,78 milhões de INR, o período de retorno simples foi de 6,29 anos eo período de retorno descontado foi de 10,14 anos.

\subsection{TAXA MÍNIMA DE ATRATIVIDADE}

Foram utilizadas na pesquisa deste método as palavras

chave

"minimum" AND "attractiveness" AND "rate", retornando 55 resultados.

\subsubsection{ANO DAS PUBLICAÇÕES}

Os dados contidos na Figura 38 demonstram através do gráfico a frequência das publicações por ano no período de 20042018. 
Figura 38: Frequência das publicações por ano no período de 2004-2018

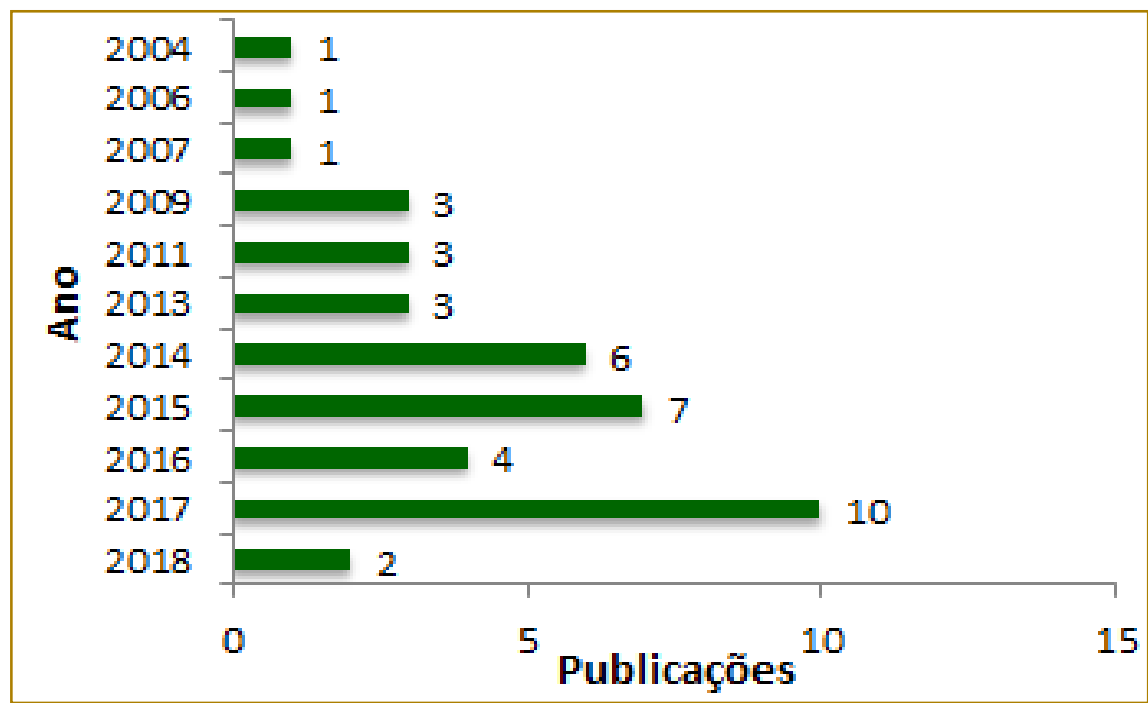

Fonte: Adaptado da Scopus (2018)

Como se pode observar, o ano de maior publicação, como esperado, foi o de 2017 com 10 artigos, seguido do ano de 2015 com 7 publicações.

\subsubsection{AUTORES QUE PUBLICARAM SOBRE O TEMA}

Os dados contidos na Figura 39 demonstram através do gráfico os autores com maior frequência de publicação.

Figura 39: Autores com maior frequência de publicação

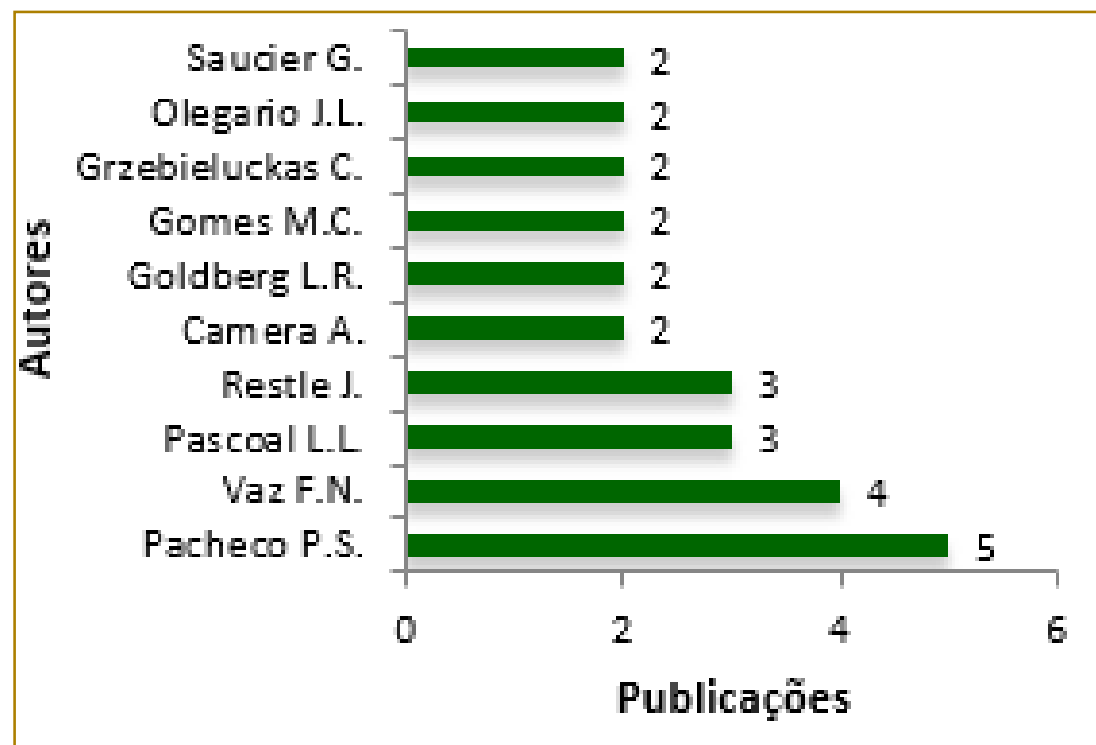

Fonte: Adaptado da Scopus (2018)

Conforme pode ser analisado, o autor que mais publicou no período avaliado no estudo foi o Pacheco, P. S., com 5 artigos, seguido de Vaz, F. N., com 4 publicações, Pacoal, L. L. com 3 trabalhos e Restle, J, também com 3.

\subsubsection{ORIGEM DE PUBLICAÇÃO}

Os dados contidos na Figura 40 demonstram através do gráfico os periódicos 
Figura 40: Periódicos com maior frequência de publicação

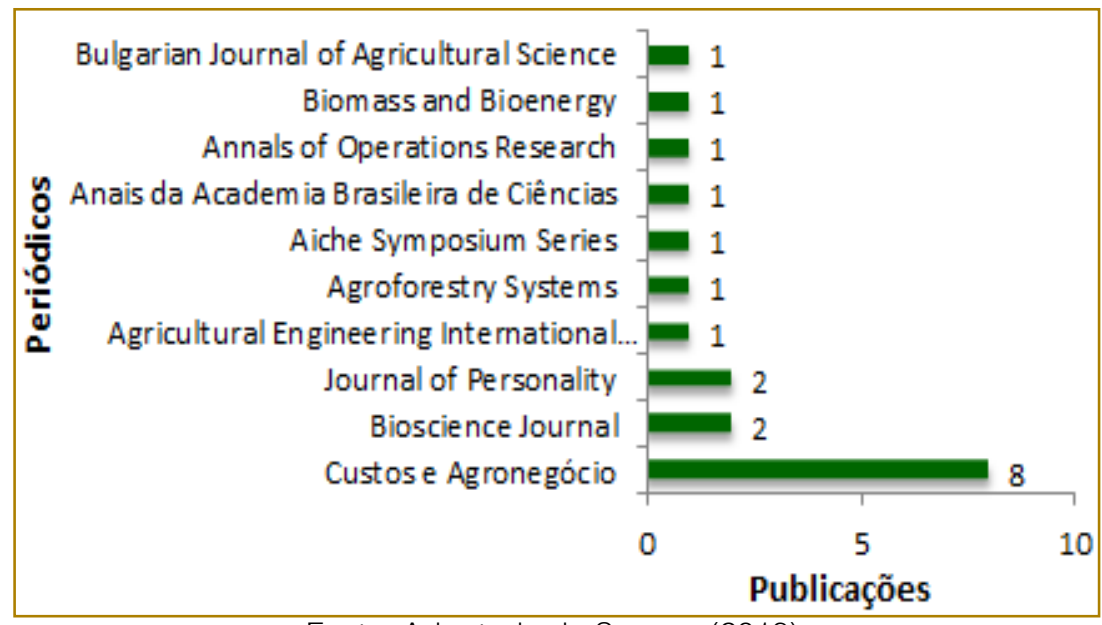

Fonte: Adaptado da Scopus (2018)

Entre os periódicos apresentados na Figura 40 dois brasileiros se destacam: Custos e Agronegócios, liderando a lista com 8 publicações, e Anais da Academia Brasileira com apenas 1 .

\subsubsection{AFILIAÇÃO}

Os dados contidos na Figura 41 demonstram através do gráfico as afiliações com maior frequência de publicação.

Figura 41: Afiliações com maior frequência de publicação

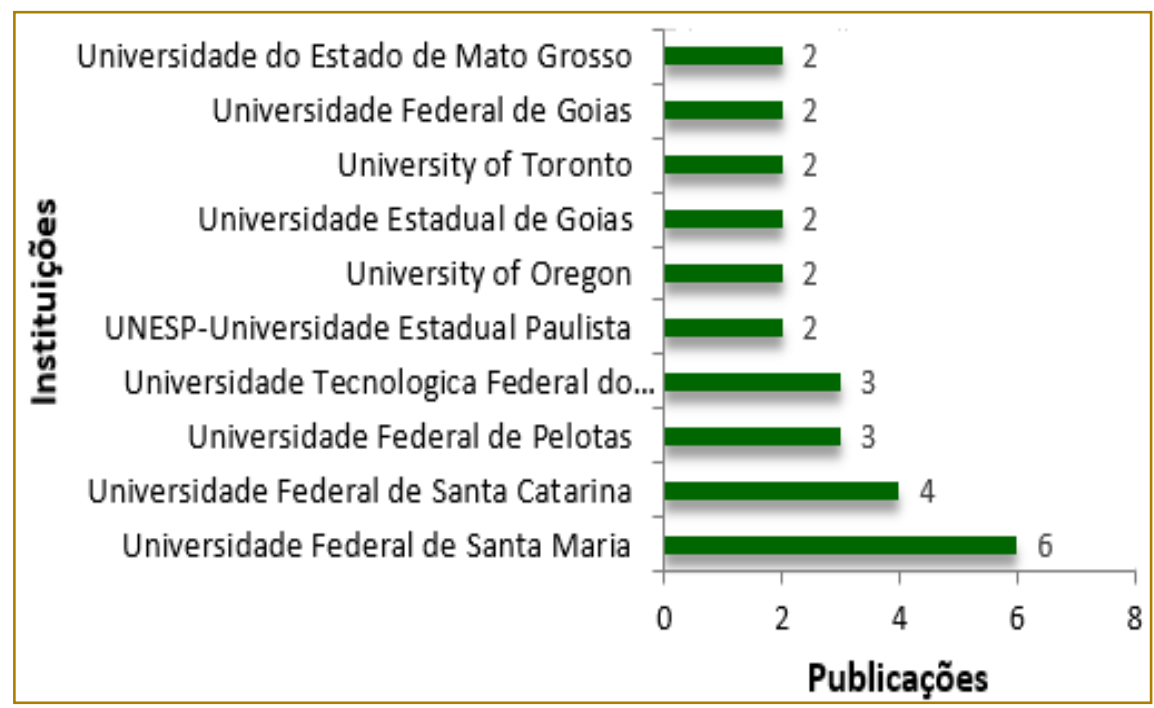

Fonte: Adaptado da Scopus (2018)

No quesito afiliação, novamente o Brasil representa a maioria das instituições que buscam estudar e publicar sobre o tema, como pode ser observado na Figura 41.

\subsubsection{NÚMERO DE PUBLICAÇÃO POR PAÍSES}

Os dados contidos na Figura 42 demonstram através do gráfico os países com maior frequência de publicação. 
Figura 42: Paises com maior frequência de publicações

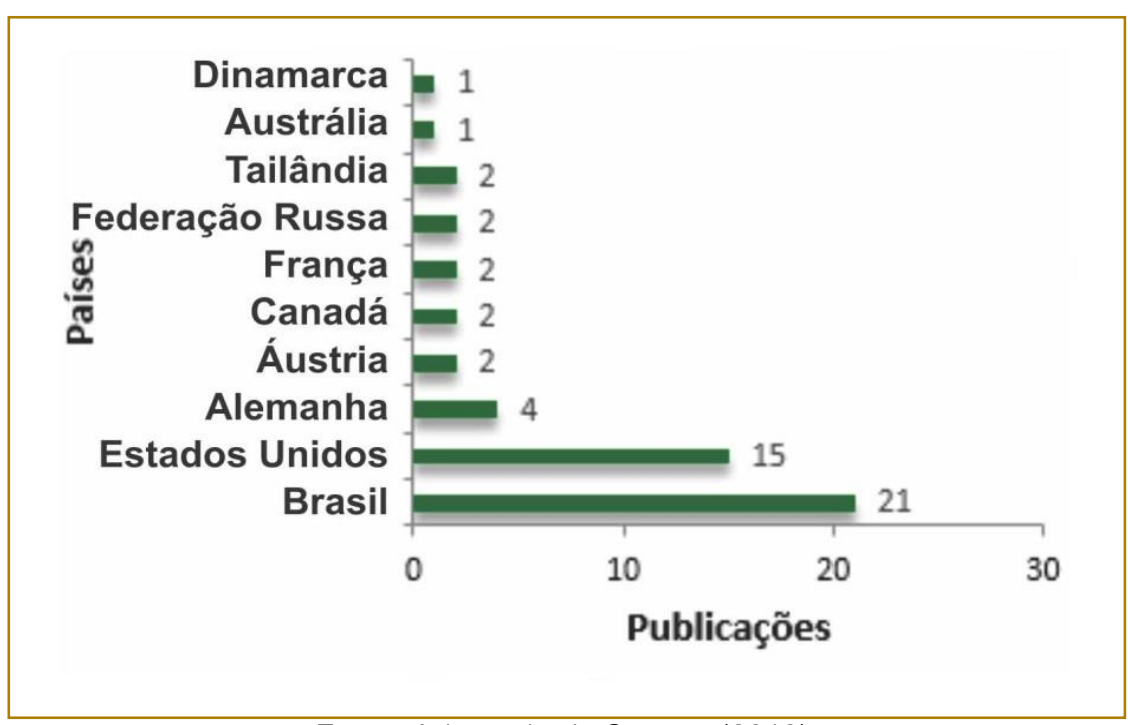

Fonte: Adaptado da Scopus (2018)

Analisando a Figura 42 é possível identificar que os Estados Unidos figuram em segundo lugar, com 15 publicações, seguido pela Alemanha com apenas 4.

\subsubsection{NÚMERO DE PUBLICAÇÃO POR ÁREAS}

Os dados contidos na Figura 43 demonstram através do gráfico as áreas de conhecimento com maior frequência de publicação.

Figura 43: Áreas de conhecimento com maior frequência de publicação

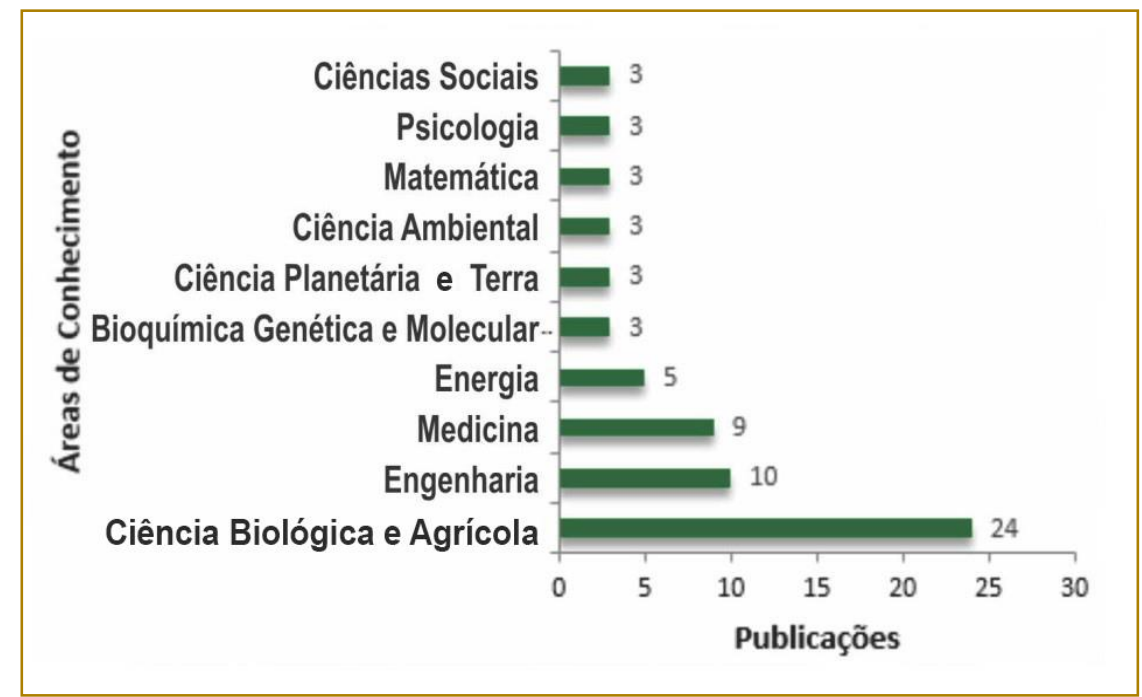

Fonte: Adaptado da Scopus (2018)

Nota-se que a área de conhecimento principal retornada pelos dados da pesquisa foi Agricultura e Ciência Biológica, com 24 publicações, seguida por Engenharia com 10 e Medicina com 9.

\subsubsection{ANÁLISE DOS ARTIGOS}

$\mathrm{Na}$ Tabela 8 são apresentados os artigos selecionados como mais relevantes seguindo a temática do método Taxa Mínima de Atratividade, retornando obras dos autores fornecidos pela base de pesquisa. 
Tabela 8: Artigos selecionados para o Método Taxa Mínima de Atratividade

\begin{tabular}{|c|c|c|c|}
\hline Título & Autor & Ano & Citação \\
\hline $\begin{array}{l}\text { Electric energy production from swine deject: Analysis of } \\
\text { financial feasibility with the use of monte carlo simulation for the } \\
\text { implantation of bio-digester in Brazil }\end{array}$ & CATAPAN et al. & 2015 & 4 \\
\hline $\begin{array}{l}\text { Techno-economic assessment of a heat-integrated process for } \\
\text { hydrogenated renewable diesel production from palm fatty acid } \\
\text { distillate }\end{array}$ & KANTAMA et al. & 2015 & 3 \\
\hline $\begin{array}{l}\text { Methodology for the determination of optimum power of a } \\
\text { Thermal Power Plant (TPP) by biogas from sanitary landfill }\end{array}$ & SILVA et al. & 2017 & 2 \\
\hline $\begin{array}{l}\text { Technical and economic study of a mobile system for extraction } \\
\text { of eucalyptus essential oil }\end{array}$ & VIVAN et al. & 2011 & 2 \\
\hline $\begin{array}{l}\text { Stochastic processes and copula model applied in the } \\
\text { economic evaluation for Brazilian oil fields projects }\end{array}$ & MARQUES et al. & 2014 & 1 \\
\hline
\end{tabular}

Fonte: Adaptado da Scopus (2018).

Catapan et al. (2015) se objetivaram a utilizar a análise técnica de investimentos, determinar o ponto de equilíbrio, em número de animais, para permitir a implantação de bio-digestores para a geração de energia elétrica com o uso de dejetos suínos. Como métodos, foram realizadas entrevistas com proprietários de fazendas, análise de planilhas de custos e controle de orçamento com fornecedores para o projeto de fluxo de caixa. Então, foram calculados os indicadores de viabilidade e foi feita a simulação de Monte Carlo para medir a sensibilidade dos parâmetros de entrada. Os resultados da pesquisa apontaram que 0 ponto de equilíbrio é 1009 suínos.

O Diesel Hidrogenado (HRD), que é definido como hidrocarboneto parafínico derivado de óleo vegetal e gordura animal, recebeu consideração mundial como combustível diesel alternativo. Neste trabalho, foi elaborada a produção de $\mathrm{DRH}$ a partir de matéria-prima de destilado de ácido gordo de palma (PFAD) e foi realizada avaliação tecnoeconômica de uma planta de produção de HRD integrada pelo calor. A produção de HRD para uma taxa de fluxo de alimentação PFAD de $579 \mathrm{~g} \mathrm{~s}-1$ foi simulada no software Aspen Plus ${ }^{\circledR}$ como modelo de base-case; o consumo mínimo de energia foi calculado utilizando análise do ponto de compressão e foi projetada uma rede de permutadores de calor de integração de calor.

Posteriormente, a planta de produção de HRD de integração de calor modificada foi submetida a análise econômica para determinar a capacidade de produção de HRD para o investimento. Verificou-se que o investimento na produção de $\mathrm{DRH}$ seria atraente.
Silva et al. (2017) se objetivaram a determinar teoricamente o poder elétrico ótimo de LFG utilizando a metodologia de Benefício Líquido Máximo (MNB) e levando em consideração os aspectos econômicos, demográficos e regionais do Consórcio Intermunicipal da Micro-região do Alto Sapucaí para Aterro sanitário (CIMASAS, como acrônimo em português), localizado na parte sul do estado de Minas Gerais, Brasil. Para este fim, o prognóstico para um período de 20 anos de geração de resíduos sólidos domésticos nesta região foi estimado e quantificado com base em dados populacionais, a fim de estimar a produção de LFG e a energia que pode ser gerada.

A partir deste ponto, determinou-se a potência ideal para a usina de energia térmica (TPP) por LFG. Os resultados indicaram que o aterro nesta região poderia produzir mais 66.293.282 m3 de $\mathrm{CH} 4$ (com potência máxima de 997 kW em 2036) em vinte anos e que não haveria viabilidade econômica para gerar energia a partir do LFG, pois o Valor Presente Líquido (VPL) seria não seja positivo. A população menor para isso pode atingir uma taxa mínima de atratividade (MAR) de 15\% deve ser de 3.700 .000 habitantes nas condições estudadas. Considerando as Resoluções da Agência Nacional de Energia Elétrica (ANEEL), seria 339,000 habitantes com potência instalada de $440 \mathrm{~kW}$. Além disso, o resultado do estudo de caso CIMASAS demonstrou a aplicabilidade da metodologia MNB para a determinação da potência ótima do TPP. 


\subsection{FLUXO DE CAIXA}

Para as pesquisas realizadas sobre este método, foram utilizadas as palavras chave "Cash" AND "Flow", que retornaram em dados 14.521 resultados, que passaram a compor a base de dados para as análises sobre este tema.

\subsubsection{ANO DAS PUBLICAÇÕES}

Os dados contidos na Figura 44 demonstram através do gráfico a frequência das publicações por ano no período de 20002018.

Figura 44: Frequência das publicações por ano no período de 2000-2018

Fonte: Adaptado da Scopus (2018)

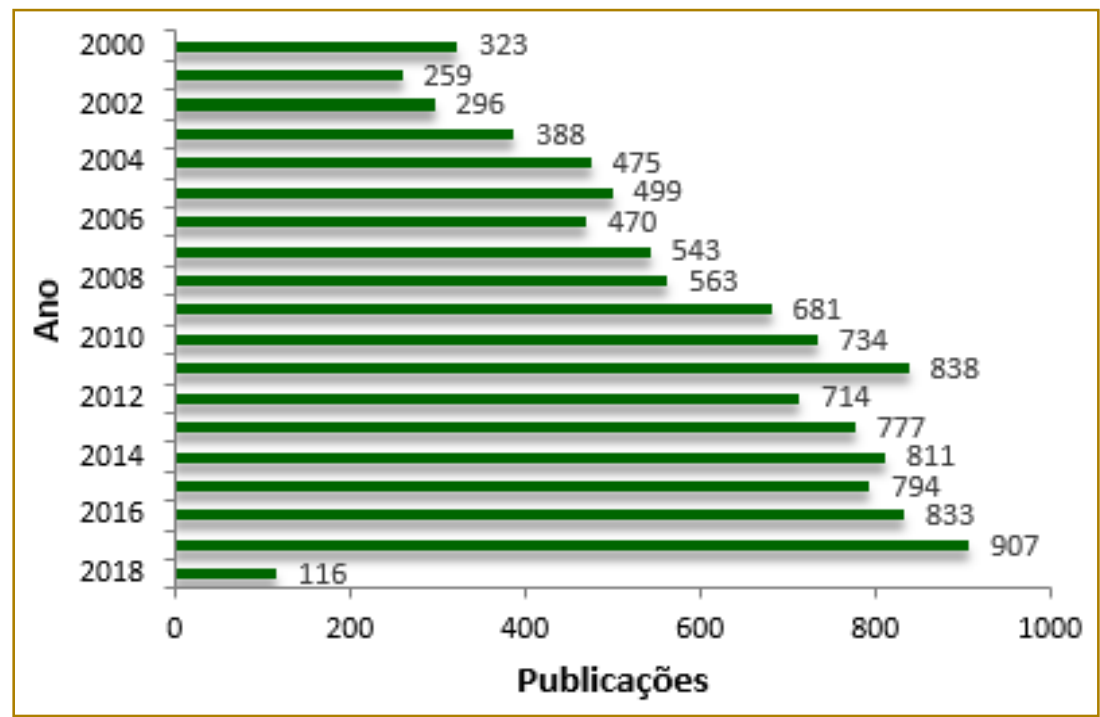

Novamente, como se pode observar na Figura 44 o ano de 2017 segue com o maior número de publicações realizadas, 907, seguido pelo ano de 211 com 838 publicações. Embora entre os anos de 2001 e 2011 tenha havida uma tendência de crescimento exponencial das publicações nesta área, houve certa estabilidade a partir de 2012, com crescimento reduzido.

\section{9..2 AUTORES QUE PUBLICARAM SOBRE O TEMA}

Os dados contidos na Figura 45 demonstram através do gráfico os autores com maior frequência de publicação.

Figura 45: Autores com maior frequência de publicação

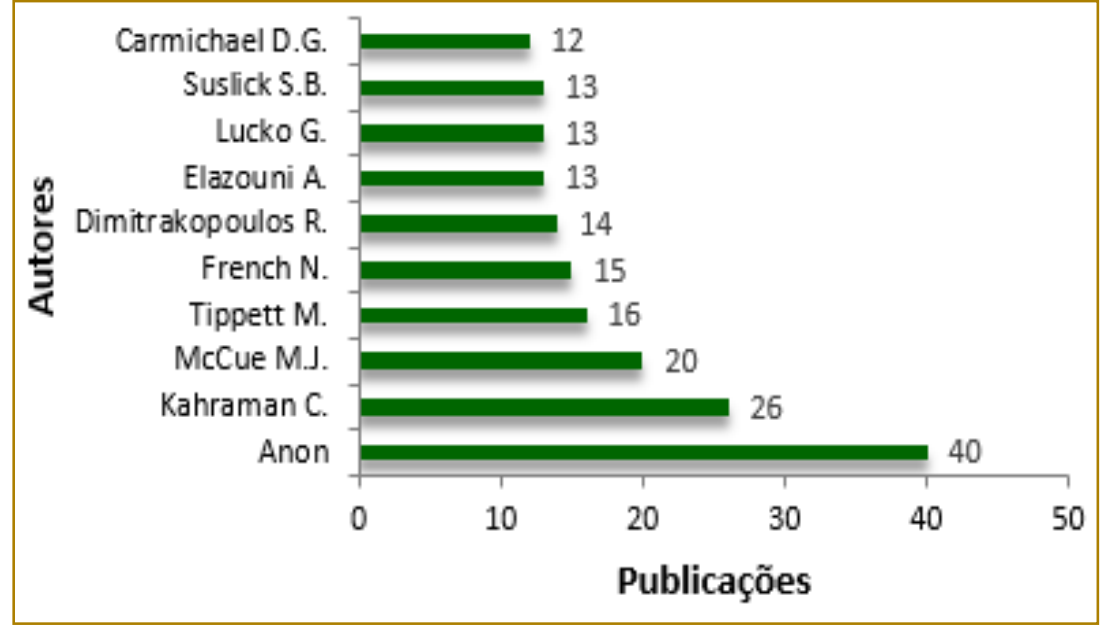

Fonte: Adaptado da Scopus (2018) 
Nestes métodos os dados retornaram um grande número de obras publicadas sem a identificação do autor, ou seja, publicações anônimas. Estas representam a maior parte dos resultados, seguidas por Kahraman C. e McCue M.J., com 26 e 20 publicações, respectivamente.

\subsubsection{ORIGEM DE PUBLICAÇÃO}

Os dados contidos na Figura 46 demonstram através do gráfico os periódicos com maior frequência de publicação.

Entre os periódicos apresentados na Figura 46 destacam-se: Engineering Economist, Journal of Financial Ecnomics e Journal of Finance, com 159, 141 e 136 obras publicadas, respectivamente.

Figura 46: Periódicos com maior frequência de publicação

Fonte: Adaptado da Scopus (2018)

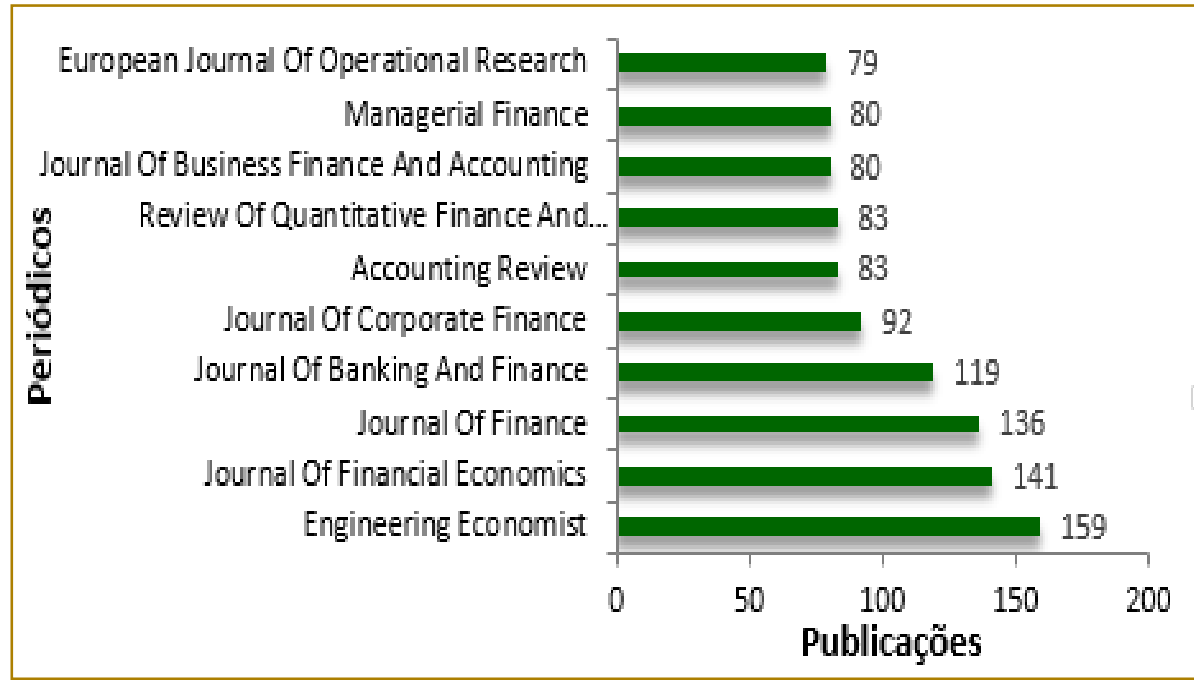

\subsubsection{AFILIAÇÃO}

Os dados contidos na Figura 47 demonstram através do gráfico as afiliações com maior frequência de publicação.

Figura 47: Afiliações com maior frequência de publicação

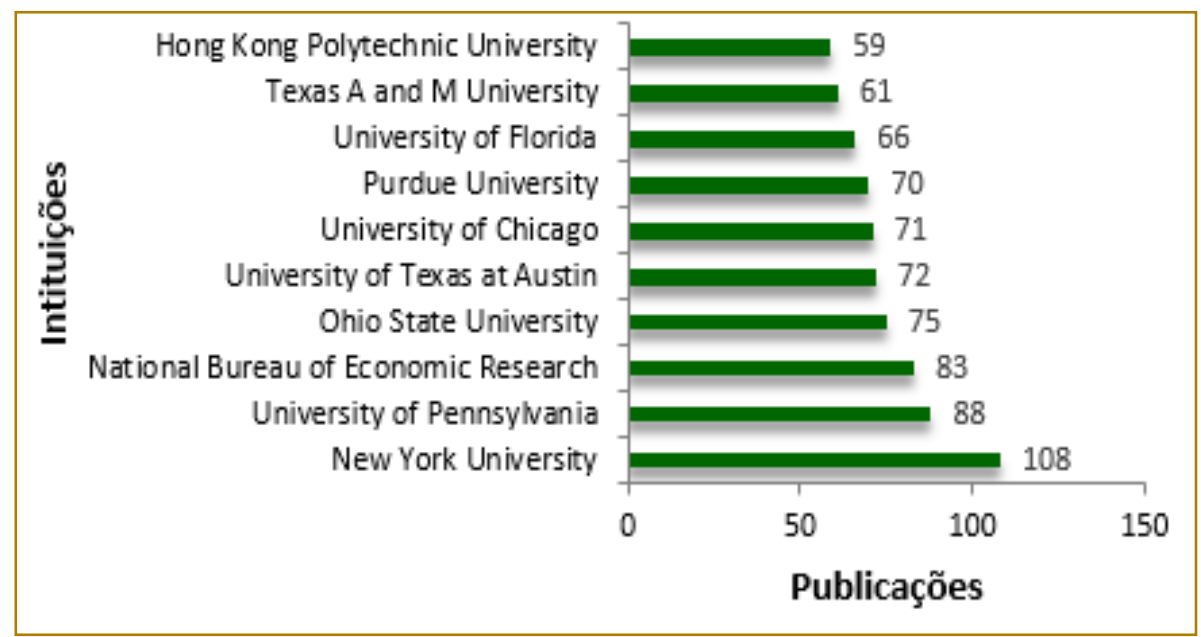

Fonte: Adaptado da Scopus (2018) 
A New York University foi a instituição que mais publicou sobre o método, resultando em 108 artigos publicados.

\subsubsection{NÚMERO DE PUBLICAÇÃO POR PAÍSES}

Os dados contidos na Figura 48 demonstram através do gráfico os países com maior frequência de publicação.

Figura 48: Paises com maior frequência de publicações

Fonte: Adaptado da Scopus (2018)

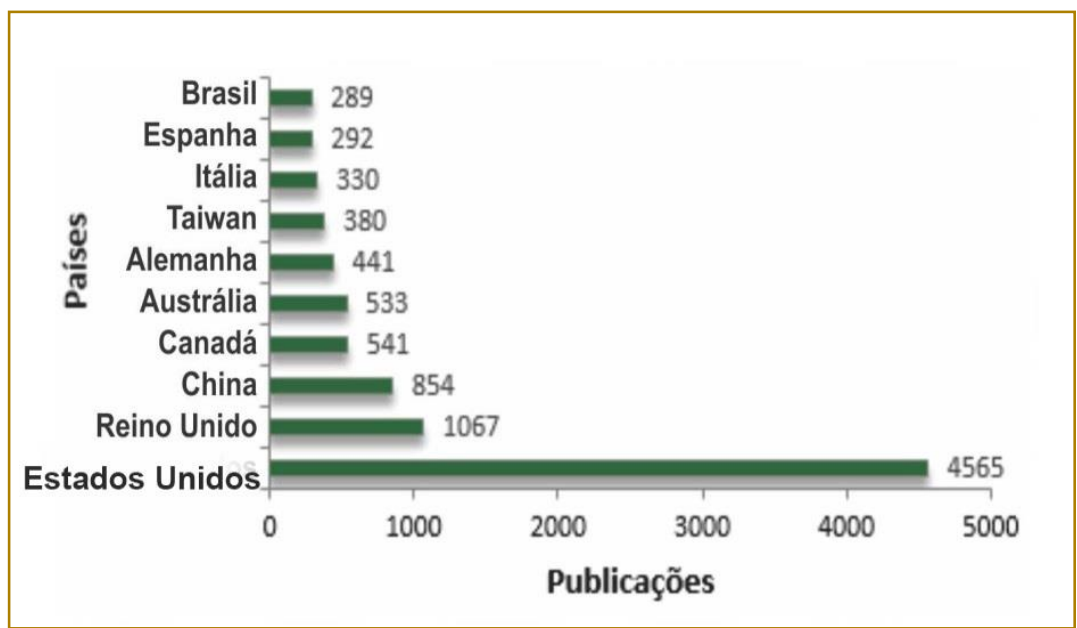

Os Estados Unidos têm mais publicação que a soma dos outros países da lista, com 4.565. O Brasil está no décimo lugar na lista dos países mais relevantes, com 289 publicações.

\subsubsection{NÚMERO DE PUBLICAÇÃO POR ÁREAS}

Os dados contidos na Figura 49 demonstram através do gráfico as áreas de conhecimento com maior frequência de publicação.
Como é possível observar na Figura 49 as publicações mais relevantes são relacionadas às áreas de Negócios, Gestão e Contabilidade, com 5.194 publicações, e Economia Econometria e Finanças, com 5.092 trabalhos publicados.

Figura 49: Áreas de conhecimento com maior frequência de publicação

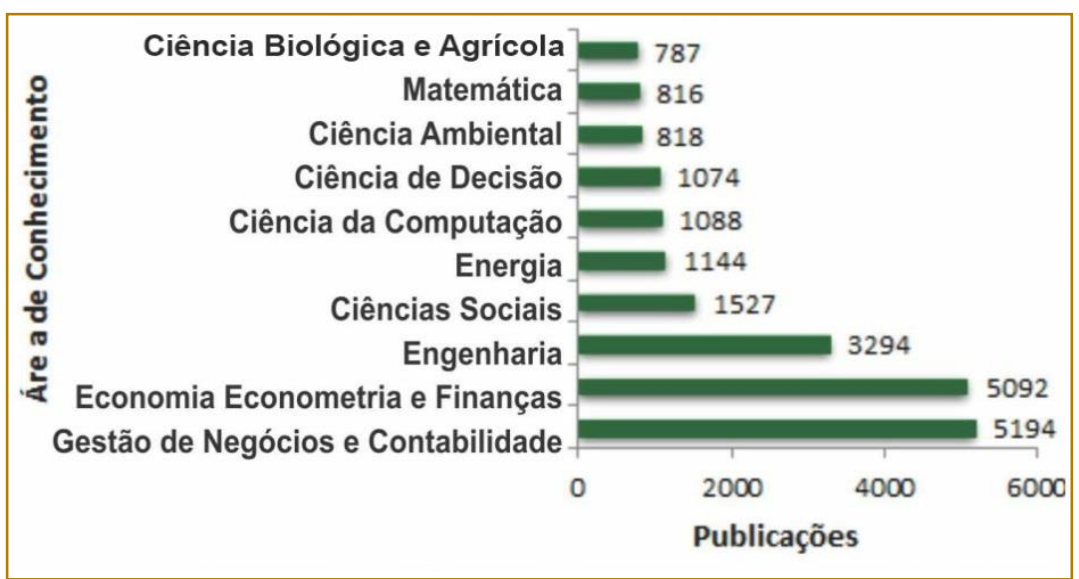

Fonte: Adaptado da Scopus (2018) 


\subsubsection{ANÁLISE DOS ARTIGOS}

$\mathrm{Na}$ Tabela 9 são apresentados os artigos selecionados como mais relevantes pelo autor fornecidos pela base para o método Fluxo de Caixa.

Tabela 9: Artigos selecionados para o Método Fluxo de Caixa

\begin{tabular}{|c|c|c|c|}
\hline Título & Autor & Ano & Citação \\
\hline $\begin{array}{l}\text { Economic analysis of different supporting policies for the production of } \\
\text { electrical energy by solar photovoltaics in western European Union } \\
\text { countries }\end{array}$ & $\begin{array}{l}\text { DUSONCHET } \\
\text { et al. }\end{array}$ & 2010 & 93 \\
\hline $\begin{array}{l}\text { Techno-economic analysis of a wind-solar hybrid renewable energy } \\
\text { system with rainwater collection feature for urban high-rise application }\end{array}$ & CHONG et al. & 2011 & 91 \\
\hline $\begin{array}{l}\text { Economic analysis of power generation from parabolic trough solar } \\
\text { thermal plants for the Mediterranean region-A case study for the island of } \\
\text { Cyprus }\end{array}$ & PULLIKKAS, A. & 2009 & 83 \\
\hline $\begin{array}{l}\text { Technical feasibility and financial analysis of hybrid wind-photovoltaic } \\
\text { system with hydrogen storage for Cooma }\end{array}$ & SHAKYA et al. & 2005 & 77 \\
\hline $\begin{array}{l}\text { Optimization of photovoltaic penetration in distribution systems } \\
\text { considering annual duration curve of solar irradiation }\end{array}$ & LIN et al. & 2012 & 57 \\
\hline
\end{tabular}

Fonte: Adaptado da Scopus (2018).

Dentro de várias tecnologias de energia renovável, a energia fotovoltaica (PV) hoje atrai atenção considerável devido ao seu potencial para contribuir com uma grande parte das energias renováveis no futuro. No entanto, o desenvolvimento do mercado fotovoltaico é, sem dúvida, dependente do apoio político de qualquer país. Dusonchet et al. (2010) após uma breve análise das políticas nacionais de apoio à tecnologia PV nos países da União Europeia Ocidental (UE), realizam uma análise econômica dos principais mecanismos de suporte implementados nos mesmos países, com base no cálculo do fluxo de caixa, os índices do Valor Presente Líquido (NPV) e da Taxa Interna de Retorno (IRR).

A análise mostrou que, em algumas situações, as políticas de suporte podem ser inconvenientes para o proprietário do sistema de geração baseado em PV e que, em muitos casos, as diferenças entre a implementação da mesma política de suporte em diferentes países podem dar origem a resultados significativamente diferentes. A análise realizada neste trabalho poderia ajudar na avaliação do impacto das políticas energéticas fotovoltaicas em diferentes Estados membros da Europa Ocidental, empresas de energia renovável para identificar potenciais mercados fotovoltaicos e investigar o panorama político nos países da UE ocidentais.
No trabalho de Pullikkas (2009), um estudo de viabilidade foi realizado para investigar se a instalação de uma tecnologia solar térmica parabólica para geração de energia na região do Mediterrâneo é economicamente viável. O estudo de caso levou em consideração o potencial solar disponível para Chipre, bem como todos os dados disponíveis sobre a política atual de fontes de energia renováveis do governo de Chipre, incluindo a tarifa de feed-in relevante.

Para identificar a opção viabilizada de menor custo para a instalação da planta solar térmica parabólica, uma análise custobenefício paramétrica foi realizada através de parâmetros variáveis, como capacidade parabólica através da energia solar térmica, investimento parabólico através de energia solar térmica, operação horas, preço do sistema de comércio de emissão de dióxido de carbono, etc. Para todos os casos acima, calculou-se o custo da unidade de eletricidade ou benefício antes de impostos, bem como o fluxo de caixa, o valor presente líquido, a taxa interna de retorno e o período de retorno. Os resultados indicaram que, sob determinadas condições, esses projetos podem ser lucrativos.

O nível de penetração de um sistema fotovoltaico (PV) é muitas vezes limitado devido à violação da variação de tensão introduzida pela grande geração de energia 
intermitente. Lin et al. (2012) discutiram o uso de uma estratégia de redução de energia ativa para reduzir a injeção de energia fotovoltaica durante o pico de irradiação solar para evitar a violação da tensão, de modo que o nível de penetração de PV de um alimentador de distribuição possa ser aumentado para utilizar completamente a energia solar. A geração de energia fotovoltaica foi simulada de acordo com os dados horários de irradiação solar e temperatura fornecidos pela agência meteorológica.

A variação de tensão no Ponto de Acoplamento Comum (PAC) também foi derivada da análise de fluxo, para investigar a injeção máxima de energia fotovoltaica sem causar um problema de violação de tensão. Ao usar o esquema de controle de tensão proposto para limitar a injeção de energia fotovoltaica no alimentador de distribuição de estudo durante períodos de alta irradiação solar, a geração total de energia e a energia total entregue pelo sistema fotovoltaico durante um período de um ano são determinadas de acordo com a duração anual da energia solar irradiação.

O fluxo de caixa anual das vendas de energia fotovoltaica, o custo de $\mathrm{O} \& \mathrm{M}$ ao longo do ciclo de vida do sistema e o investimento de capital no sistema fotovoltaico foram utilizados para calcular os anos de amortização e o valor presente líquido (VPL) do projeto PV. Com o controle de tensão proposto para executar a rejeição de geração parcial de sistemas fotovoltaicos, a capacidade de instalação ideal dos sistemas fotovoltaicos pôde ser determinada pela maximização do valor presente líquido do sistema de modo que uma melhor relação custo-eficácia do projeto PV e uma melhor utilização da energia solar puderam ser obtidos.

\subsection{RETORNO SOBRE O INVESTIMENTO - $\mathrm{ROI}$}

A pesquisa sobre os periódicos relacionados ao método Retorno Sobre Investimento - ROI, utilizou o conjunto de keywords ou termos chave "Return" AND "on" AND "Investment", alcançando 35.152 resultados.

\subsubsection{ANO DAS PUBLICAÇÕES}

Os dados contidos na Figura 50 demonstram através do gráfico a frequência das publicações por ano no período de 20002018.

Figura 50: Frequência das publicações por ano no período de 2000-2018

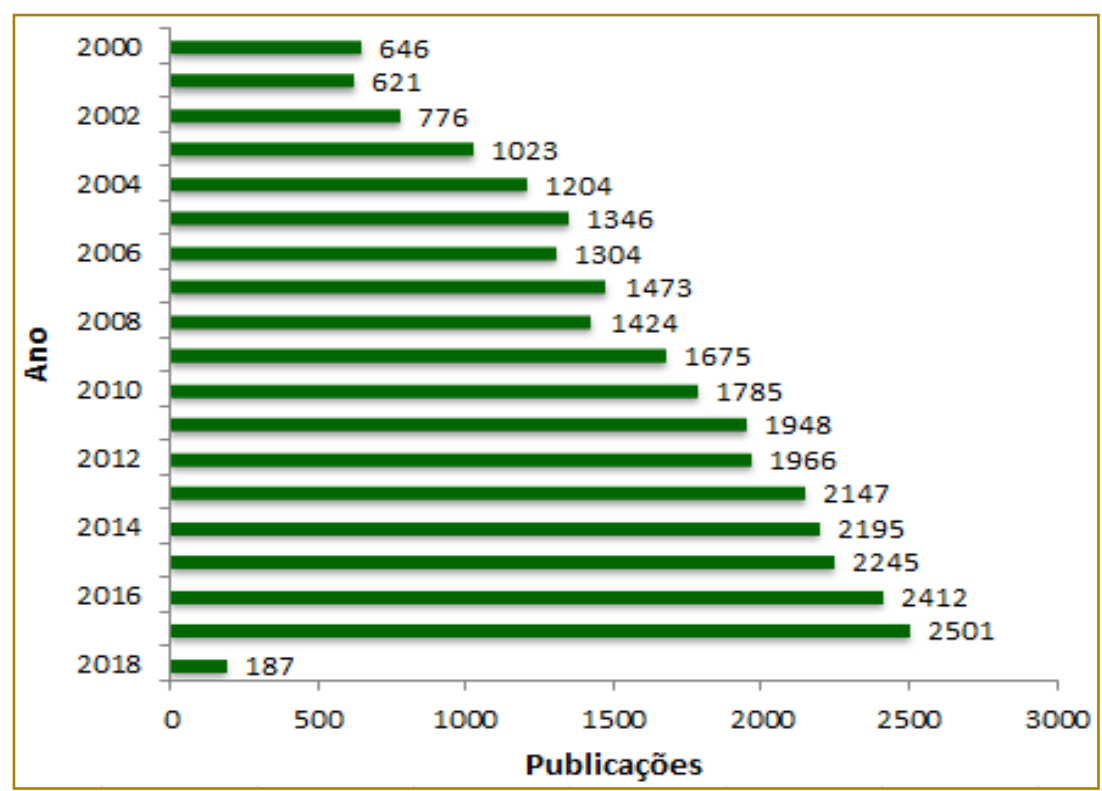

Fonte: Adaptado da Scopus (2018)

Assim como no método anterior, há um aumento gradativo no volume de publicações no passar dos anos de 2000 até 2018. O ano que teve menos publicações foi o de 2001, e 
o que teve mais publicações foi 2017, 2018 apresentou 187 artigos publicados até a data atual desta pesquisa. Essas informações encontram-se na Figura 50.

\subsubsection{AUTORES QUE PUBLICARAM SOBRE O TEMA}

Os dados contidos na Figura 51 demonstram através do gráfico os autores com maior frequência de publicação.

Figura 51: Autores com maior frequência de publicação

Fonte: Adaptado da Scopus (2018)

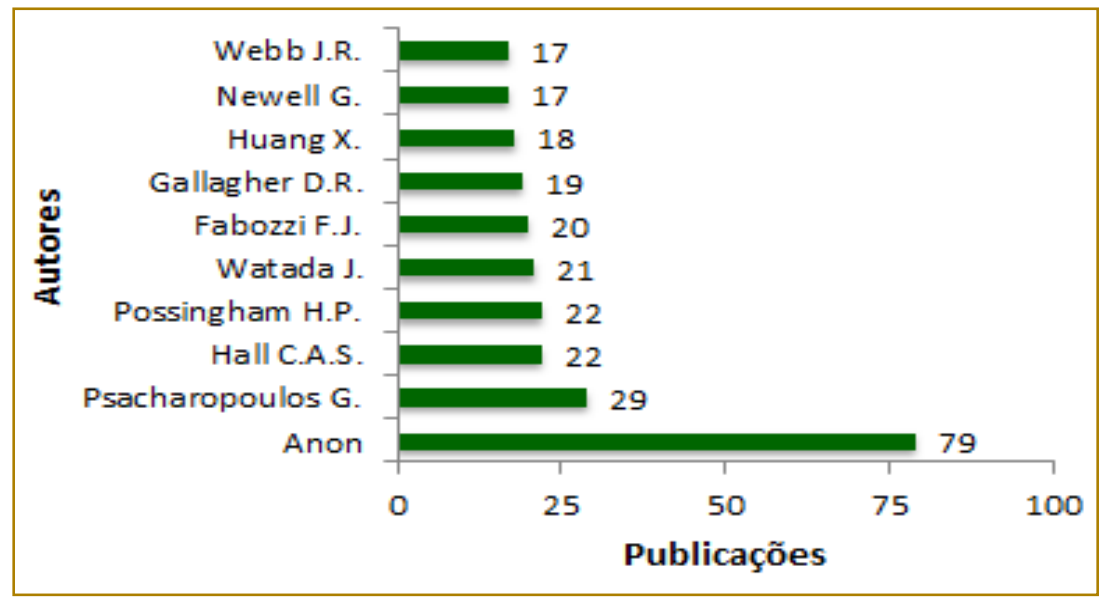

\subsubsection{ORIGEM DE PUBLICAÇÃO}

Os dados contidos na Figura 52 demonstram através do gráfico os periódicos com maior frequência de publicação.

Figura 52: Periódicos com maior frequência de publicação

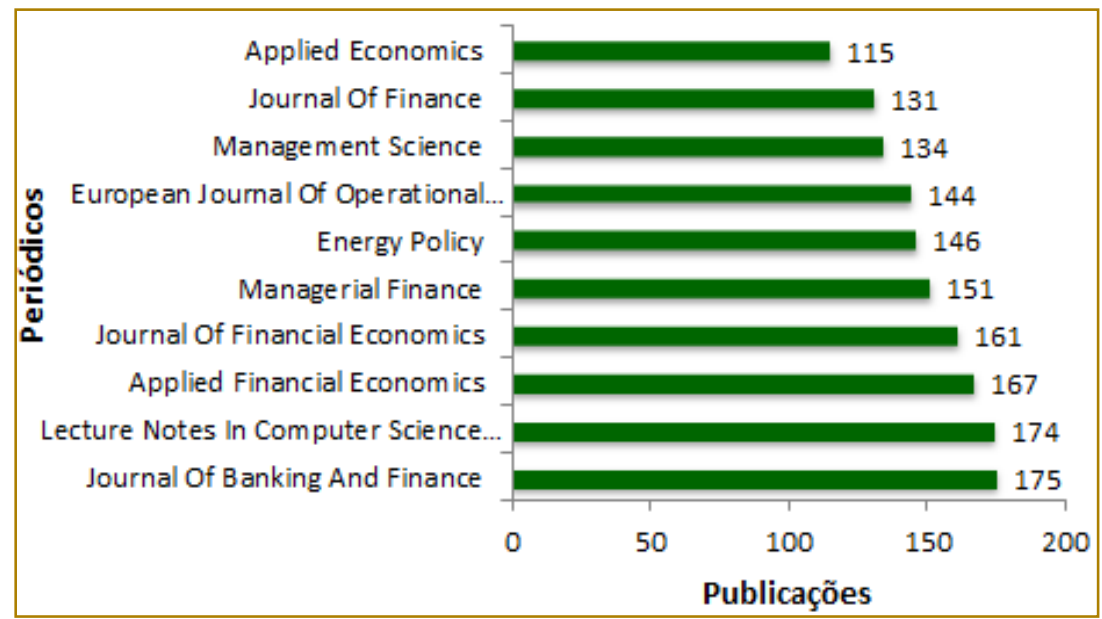

Fonte: Adaptado da Scopus (2018) 
Os periódicos mais relevantes na publicação deste método em questão, como podem ser observados na Figura 52 são o Journal of Banking and Finance e o Lecture Notes in Computer Science Including Subseries Lecture Notes in Artificial Intelligence And Lecture Notes in Bioinformatics.

\subsubsection{AFILIAÇÃO}

Os dados contidos na Figura 53 demonstram através do gráfico as afiliações com maior frequência de publicação.

Figura 53: Gráfico de afiliações com maior frequência de publicações

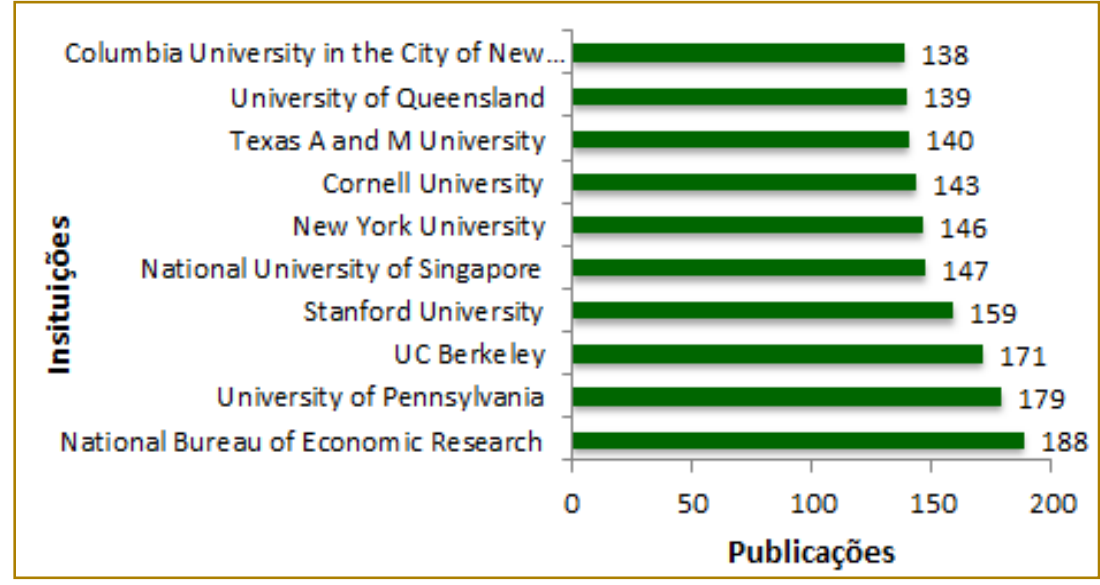

Fonte: Adaptado da Scopus (2018)

Como resultado, pode-se observar na Figura 53 que a National Bureau of Economic Research possui 188 publicações, a University of Pensilvania possui 179 e a UC Berkeley possui 171 artigos publicados.

\subsubsection{NÚMERO DE PUBLICAÇÃO POR PAÍSES}

Os dados contidos na Figura 54 demonstram através do gráfico os países com maior frequência de publicação.
Como é possível perceber, novamente os Estados Unidos lideram a lista de países que mais publicam, com 12.155 artigos publicados, seguidamente pelo Reino Unido (2.951), China (2.092), Austrália (1.523) e Canadá (1.345).

Figura 54: Paises com maior frequência de publicações

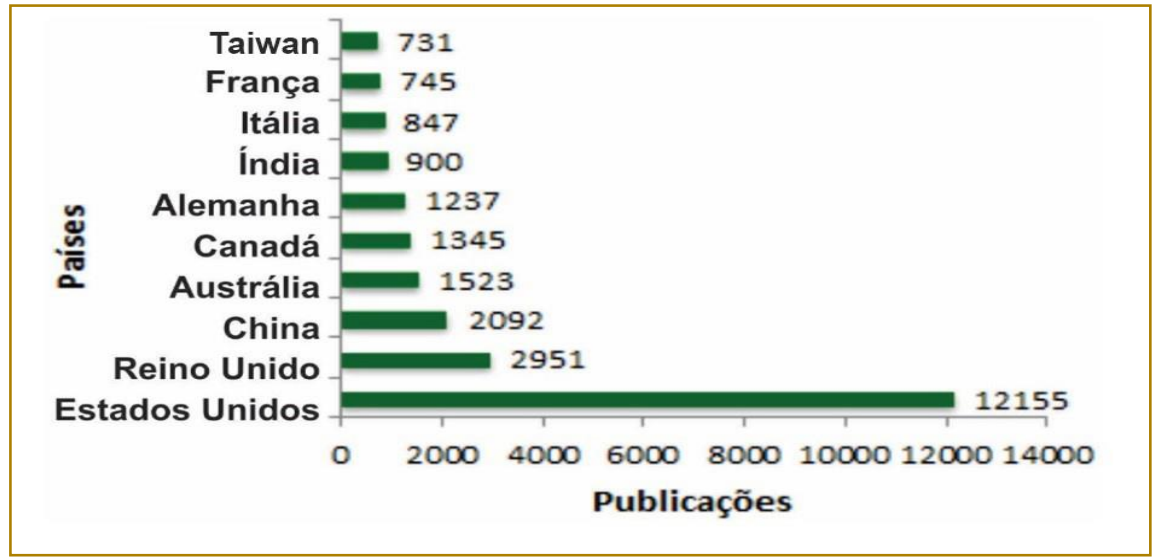

Fonte: Adaptado da Scopus (2018) 


\subsubsection{NÚMERO DE PUBLICAÇÃO POR ÁREAS}

Os dados contidos na Figura 55 demonstram através do gráfico as áreas de conhecimento com maior frequência de publicação.

Figura 55: Áreas de conhecimento com maior frequência de publicação

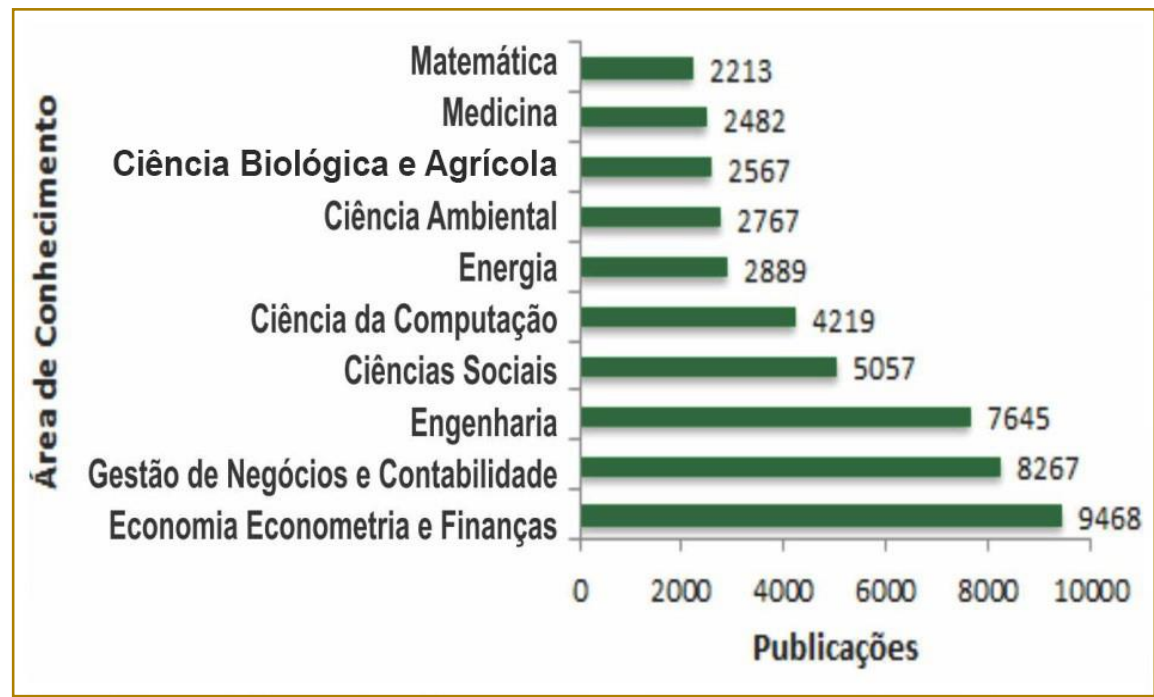

Fonte: Adaptado da Scopus (2018)

É possivel analisar, através da Figura 55 que a área de Economia, Econometria e Finanças possui o maior número de publicações, com 9.468. Em segundo lugar, tem-se Contabilidade, com 8.267 publicações seguida de Engenharia, com 7.645 publicações.

\subsubsection{ANÁLISE DOS ARTIGOS}

$\mathrm{Na}$ tabela 10 são apresentados os artigos selecionados como mais relevantes pelo autor fornecidos pela base.

Tabela 10: Artigos selecionados para o Método Retorno sobre o Investimento - ROI

\begin{tabular}{|l|c|c|c|}
\hline \multicolumn{1}{|c|}{ Título } & Autor & Ano \\
\hline On persistence in mutual fund performance & CARHART, M. M. & 1997 & 3677 \\
\hline The worldwide leaf economics spectrum & WRIGHT, I. J. et al. & 2004 & 2815 \\
\hline $\begin{array}{l}\text { Investor psychology and security market under and } \\
\text { overreactions }\end{array}$ & DANIEL, K. et al. & 1998 & 1541 \\
\hline $\begin{array}{l}\text { On estimating the expected return on the market: An } \\
\text { exploratory investigation }\end{array}$ & MERTON, R. C. & 1980 & 1014 \\
\hline $\begin{array}{l}\text { Open source software and the "private-collective" innovation } \\
\text { model: Issues for organization science }\end{array}$ & VON HIPPEL, E. et al. & 2003 & 1012 \\
\hline
\end{tabular}

Fonte: Adaptado da Scopus (2018).

Carhart (1997) utilizando uma amostra "livre de preconceitos" demonstrou que os fatores comuns nos retornos das ações e despesas de investimento explicam quase completamente persistência em média patrimônio fundos de investimento e retornos ajustados ao risco. $O$ resultado foi principalmente impulsionado pelo efeito de impulso de um ano, porém, foi possível notar que os fundos individuais não ganham retornos mais altos por seguir a estratégia momentânea em ações. Já que a única persistência significativa não explicada é concentrada em um forte desempenho 
insuficiente pelos fundos de investimento de pior retorno. Os resultados não suportam a existência de gestores de portfólio de fundos mútuos qualificados ou informados.

Os autores proporão uma teoria de mercado de títulos e reações exageradas com base em dois vícios psicológicos bem conhecidos: o excesso de confiança do investidor sobre a precisão da informação privada e a auto atribuição tendenciosa, que provoca mudanças assimétricas na confiança dos investidores em função de seus resultados de investimento. Em seus resultados mostraram que o excesso de confiança implica auto correlações negativas de longo prazo, volatilidade excessiva e, quando as ações gerenciais estão correlacionadas com o mispricing de estoque, a previsibilidade de retorno baseada em eventos públicos. Concluíram que a auto atribuição tendenciosa acrescenta auto correlações positivas de curto prazo, ganhos de curto prazo "drift", mas correlação negativa entre os retornos futuros e o desempenho do mercado de ações e contábil no longo prazo. Além de que a teoria também oferece várias implicações e implicações não testadas para a política financeira corporativa (DANIEL et al., 1998).

Acredita que o retorno esperado do mercado é um número frequentemente necessário para a solução de muitos problemas de investimento e de finanças corporativas, mas, em comparação com outras variáveis financeiras, houve pouca pesquisa na estimativa desse retorno esperado. Assim, a prática atual para estimar o retorno do mercado esperado acrescenta a média histórica dos retornos de mercado realizados à taxa de juros observada atual. Porém, mesmo que este modelo reflita explicitamente a dependência do retorno do mercado sobre a taxa de juros, este não contabiliza o efeito de mudanças no nível de risco de mercado.

Com isso, o autor analisou três modelos de equilíbrio que os retornos de mercado esperados que reflitam essa dependência. Os procedimentos de estimativa que incorporam a restrição que os retornos exagerados de equilíbrio no mercado devem ser positivos são derivados e aplicados aos dados de retorno para o período 1926-1978. As principais conclusões desta investigação exploratória são: (1) na estimativa de modelos do retorno esperado do mercado, a restrição de não negatividade do retorno esperado deve ser explicitamente incluída como parte da especificação: (2) os estimadores que usam retornos realizados devem ser ajustados para a heteroscedasticidade1 (MERTON, 1980).

\subsection{CONSIDERAÇÕES FINAIS}

O presente estudo conseguiu alcançar o objetivo proposto ao apresentar um estudo bibliométrico sobre oito métodos financeiros que podem ser aplicados a viabilidade econômica em placas voltaicas, sendo eles: IL; ROI, TIR, TMA, VPL, Payback (simples e descontado) e fluxo de caixa. Foram ressaltados os autores que mais estudam o tema, periódicos com maior número de publicações, países e instituições que voltam seus estudos sobre os métodos e as vias de publicações mais utilizadas e as áreas de concentrações que possuem um foco maior, os quais são apresentados em formato de gráfico neste trabalho.

Com o grande volume de resultados oferecidos pela base de dados, nota-se que é de grande interesse, a nível mundial e global, o estudo de métodos financeiros. Estes possuem uma aplicabilidade muito grande, em diversas áreas como agricultura, educação, medicina, biologia, economia, entre outros. Assim, pode-se dizer que é de suma importância dar continuidade ao estudo destes métodos aplicados a viabilidade econômica para agregar a área de energias renováveis, uma vez que a sustentabilidade e o uso de energias renováveis são de grande interesse da sociedade.

O modelo de estudo bibliométrico utilizado neste trabalho norteia o pesquisador que não possui contato com a área, uma vez que ele encontra, em um único artigo, uma seleção de trabalhos científicos relevantes sobre um determinado tema. Vale salientar que os valores definidos para o recorte temporal do ano 2000 ao ano de 2018, os 10 mais relevantes para cada tópico (autores, países, instituição, tipo de publicação, área de conhecimento e periódico) e a seleção dos artigos foram escolha do autor e não uma regra que sempre deve ser seguida.

Um padrão observado para todos os métodos foi o aumento do número de publicação

\footnotetext{
1 "Fenômeno estatístico que ocorre quando o modelo de hipótese matemático apresenta variâncias para Y e X (X1, $\mathrm{X} 2, \mathrm{X} 3 \ldots, \mathrm{Xn})$ não iguais para todas as observações". Disponível <https://www.dicionarioinformal.com.br/significado/heteroc edasticidade/4318/>. Acesso em: 30 maio 2018.
} 
gradativo com o passar dos anos, tendência esta que demonstra o aumento do interesse sobre os métodos financeiros, o que nos faz acreditar que o tema é bastante relevante e que tem muito a se explorar.

\section{REFERÊNCIAS}

[1] AGATON, C. B. et al. A real option approach to renewable electricity generation in the Philippines. Energy, Sustainability and Society, v. 8, issue 1, 2018

[2] AHMED, K. et al. Associations between corporate characteristics and disclosure levels in annual reports: A metaanalysis. British Accounting Review, v. 31, n. 1, p. 35-61, 1999.

[3] ANDERSON, E. W. et al. Customer satisfaction, productivity, and profitability: Differences between goods and services. Marketing Science, v. 16, n. 2, p. 129-145, 1997.

[4] BEAL, C. M. et al. Algal biofuel production for fuels and feed in a 100-ha facility: A comprehensive techno-economic analysis and life cycle assessment. Algal Research, v. 10, p. 266-279, 2015.

[5] BOURDEUX-REGO, R.; PAULO, G. P.; SPRITZER, I. M. de P. A.; ZOTES, L. P. Viabilidade Economico-Financeira de Projetos. 4 ed. Rio de Janeiro: FGV, 2013.

[6] CAMARGO, C. Análise de Investimentos e Demonstrativos Financeiros. Curitiba: Ibpex, 2007.

[7] CAPAZ, R.; NOGUEIRA, L. Ciências Ambientais para Engenharia. Rio de Janeiro: Elsevier, 2016.

[8] CARHART, M. M. On persistence in mutual fund performance. Journal of Finance, v. 52, n. 1, p. 57-82, 1997.

[9] CARSTEN, O. M. J. et al. Intelligent speed adaptation: Accident savings and costbenefit analysis. Accident Analysis and Prevention, v. 37, n. 3, p. 407-416, 2005.

[10] CATAPAN, A. et al. Electric energy production from swine deject: Analysis of financial feasibility with the use of monte carlo simulation for the implantation of bio-digester in Brazil. Bulgarian Journal of Agricultural Science, v. 21, n. 2, p. 257-260, 2015.

[11] CHANDEL, M. et al. Techno-economic analysis of solar photovoltaic power plant for garment zone of Jaipur city. Case Studies in Thermal Engineering, v. 2, p. 1-7, 2014.
[12] CHENÇO, E. C. Fundamentos em Finanças. Curitiba: IESDE Brasil, 2009.

[13] CHONG, W. T. et al. Techno-economic analysis of a wind-solar hybrid renewable energy system with rainwater collection feature for urban high-rise application. Applied Energy, v. 88, n. 11, p. 4067-4077, 2011.

[14] CHUANG, C. et al. Improved performance and stability in quantum dot solar cells through band alignment engineering. Nature Materials, v. 13, n. 8, p. 796-801, 2014.

[15] COSTA, H. Modelo para webibliomining: proposta e caso de aplicação. Rev. FAE, Curitiba, v. 13, n. 1, p. 115-126, jan./jun. 2010.

[16] CRCRJ - Conselho Regional de Contabilidade do Rio de Janeiro, Elaboração das Demonstrações Contábeis, 2018. Disponível em: <http://webserver.crcrj.org.br/APOSTILAS/A00 91P0203.pdf>. Acesso em: 07 jan. 2018.

[17] CUCCHIELLA, F. et al. Environmental and economic analysis of building integrated photovoltaic systems in Italian regions. Journal of Cleaner Production, v. 98, p. 241-252, 2015.

[18] DANIEL, K. et al. Investor psychology and security market under and overreactions. Journal of Finance, v. 53, n. 6, p. 1839-1885, 1998.

[19] DANQUAH, M. K. et al. Dewatering of microalgal culture for biodiesel production: Exploring polymer flocculation and tangential flow filtration. Journal of Chemical Technology and Biotechnology, v. 84 , n. 7, p. 1078-1083, 2009.

[20] DUSONCHET, L. et al. Economic analysis of different supporting policies for the production of electrical energy by solar photovoltaics in western European Union countries. Energy Policy, v. 38, n. 7, p. 32973308, 2010.

[21] FACULDADE PARAÍSO DO NORTE FAPAN - PAYBACK. Disponível em: <http://www.fapanpr.edu.br/site/docente/arqui vos/PAYBACK\%20SIMPLES\%20E\%20DESCO NTADO.pdf>. Acesso em: 28 fev. 2018. 
[22] FELTHAM, G. A. et al. Valuation and clean surplus accounting for operating and financial activities. Contemporary Accounting Research, v. 11, issue 2, p. 689-731, 1995.

[23] GITMAN, L. J. Princípios de administração financeira. 12 ed. São Paulo: Pearson Prentice Hall, 2010.

[24] HANIFFA, R. M. et al. The impact of culture and governance on corporate social reporting. Journal of Accounting and Public Policy, v. 24, n. 5, p. 391-430, 2005.

[25] HERRANDO, M. et al. Hybrid PV and solar-thermal systems for domestic heat and power provision in the UK: Techno-economic considerations. Applied Energy, v. 161, p. 512-532, 2016.

[26] JAFFE, J.; LAMB, R.; ROSS, S.; WESTERFIELD, R. W. Administração Financeira. Porto Alegre: AMGH, 2015.

[27] JUNG, C. F. Metodologia para pesquisa \& desenvolvimento Aplicada a novas tecnologias, produtos e processos. Axcel-Books, 2004.

[28] KANTAMA, A. et al. Techno-economic assessment of a heat-integrated process for hydrogenated renewable diesel production from palm fatty acid distillate. Biomass and Bioenergy, v. 83, p. 448-459, 2015.

[29] KAPLAN, S. The effects of management buyouts on operating performance and value. Journal of Financial Economics, v. 24, issue 2, p. 217-254, 1989.

[30] KORNELAKIS, A. et al. Methodology for the design optimisation and the economic analysis of grid-connected photovoltaic systems. IET Renewable Power Generation, v. 3, n. 4, p. 476-492, 2009.

[31] KRUEGER, A. B. Economic considerations and class size. Economic Journal, v. 113, n. 485, p. F34-F63, 2003.

[32] LI, F. Annual report readability, current earnings, and earnings persistence. Journal of Accounting and Economics, v. 45, n. 2-3, p. 221-247, 2008.

[33] LIN, C. H. et al. Optimization of photovoltaic penetration in distribution systems considering annual duration curve of solar irradiation. IEEE Transactions on Power Systems, v. 27, n. 2, p. 1090-1097, 2012.

[34] MARQUES, J. B. D. et al. Stochastic processes and copula model applied in the economic evaluation for Brazilian oil fields projects. SPE Hydrocarbon Economics and Evaluation Symposium, p. 379-399, 2014.

[35] MARQUES, W. L. Fluxo de Caixa. 2 ed. São Paulo: Clube dos Autores, 2011.

[36] MARQUES, W. L. Gerenciamento Financeiro. São Paulo: Clube dos Autores, 2007.

[37] MERTON, R. C. On estimating the expected return on the market: An exploratory investigation. Topics in Catalysis, v. 8, n. 4, p. 323-361, 1980.

[38] NEUMANN, E. Introdução à Engenharia Civil. Rio de Janeiro: Elsevier, 2017.

[39] OKUBO, Y. Bibliometric indicators and analysis of research systems. 1997.

[40] OU, J. A. et al. Financial statement analysis and the prediction of stock returns. Journal of Accounting and Ecnonomics, 1989.

[41] PEASNELL, K. V. Some formal connections between economic values and yields and accounting numbers. Journal of Business Finance \& Accounting, v. 9, n. 3, p. 361-381, 1982.

[42] PULLIKKAS, A. Economic analysis of power generation from parabolic trough solar thermal plants for the Mediterranean region-A case study for the island of Cyprus. Renewable and Sustainable Energy Reviews, v. 13, n. 9, p. 2474-2484, 2009.

[43] RAFFOURNIER, B. The Determinants of Voluntary Financial Disclosure by Swiss Listed Companies. Swiss: Université de Genève/HEC, 1995.

[44] REHMAN, S. et al. Cost of solar energy generated using PV panels. Renewable and Sustainable Energy Reviews, v. 11, n. 8, p. 1843-1857, 2007.

[45] ROMEIRO FILHO, E. (Org.). Projeto do Produto. Rio de Janeiro: Elsevier, 2011.

[46] SCHULTZ, T. P. School subsidies for the poor: Evaluating the Mexican Progresa poverty program. Journal of Development Economics, v. 74, n. 1, p. 199-250, 2004.

[47] SEBRAE - Fluxo de Caixa. Disponível em:

<http://www.sebrae.com.br/Sebrae/Portal\%20 Sebrae/Anexos/0_fluxo-de-caixa.pdf>. Acesso em: 28 fev. 2018.

[48] SHAKYA, B. D. et al. Technical feasibility and financial analysis of hybrid 
wind-photovoltaic system with hydrogen storage for Cooma. International Journal of Hydrogen Energy, v. 30, n. 1, p. 9-20, 2005.

[49] SILVA, T. R. et al. Methodology for the determination of optimum power of a Thermal Power Plant (TPP) by biogas from sanitary landfill. Waste Management, v. 65, p. 75-91, 2017.

[50] STARK, O. et al. Migration incentives, migration types: the role of relative deprivation. Economic Journal, v. 101, n. 408, p. 1163-1178, 1991.

[51] STULZ, R. Managerial discretion and optimal financing policies. Journal of Financial Economics, v. 26, issue 1, p. 3-27, 1990.

[52] SYRED, $N$. et al. Combustion in swirling flows: A review. Combustion and Flame, v. 23, n. 2, p. 143-201, 1974.

[53] USIRONO, C. H. Escritório de Processos: BPMO - Business Process Management Office. São Paulo: Brasport, 2015.
[54] VIVAN, G. A. et al. Technical and economic study of a mobile system for extraction of eucalyptus essential oil. Cerne, v. 17, n. 1, p. 23-31, 2011.

[55] VON HIPPEL, E. et al. Open source software and the "private-collective" innovation model: Issues for organization science. Organization Science, v. 14, n. 2, p. 209223+225, 2003.

[56] WEITZMAN, M. L. On the welfare significance of national product in a dynamic economy. Quartely Journal of Economics, v. 90, issue 1, p. 156-162, 1976.

[57] WIES, R. W. et al. Simulink model for economic analysis and environmental impacts of a PV with diesel-battery system for remote villages. IEEE Transactions on Power Systems, v. 20, n. 2, p. 692-700, 2005.

[58] WRIGHT, I. J. et al. The worldwide leaf economics spectrum. Nature, v. 428, n. 6985 , p. 821-827, 2004. 


\section{Bapítulo 4}

\section{A VIABILIDADE ECONÔMICA DE UTILIZAÇÃO DE PLACAS FOTOVOLTAICAS EM UMA EMPRESA}

Resumo: A crescente busca pela modernização das indústrias, com ganho de eficiência, produtividade e redução de custos, coloca em pauta a discussão sobre a utilização de novas tecnologias que promovem ao mesmo tempo a sustentabilidade do negócio e a eficiência produtiva e econômica para empresa do segmento offshore, que atua na bacia de Campos, no município de Macaé/RJ. Este artigo realiza uma análise de viabilidade econômica da utilização de placas fotovoltaicas com o objetivo de mensurar os custos do projeto e destacar os benefícios advindos deste. Para isto foi contatado um fornecedor local para elaboração do orçamento, e o autor utilizou o simulador Pvsyst 6.73 para calcular a energia produzida pelo sistema fotovoltáico e outros parâmetros. Tendo como condição inicial estipulada pela diretoria a taxa mínima de atratividade (TMA) de $8,3 \%$, o resultado demonstrou, através dos métodos utilizados de Payback Simples e Descontado, Índice de Rentabilidade (IL), Retorno sobre Investimento (ROI), Valor presente Líquido (VPL) e Taxa Interna de Retorno (TIR), que o projeto é economicamente viável e a empresa em questão tem capacidade física para instalação dos equipamentos promovendo grande economia financeira no médio e longo prazo contribuindo para produção de energia limpa no Brasil.

Palavras-chave: Energia solar. Painéis fotovoltaicos. Viabilidade econômica. 


\subsection{INTRODUÇÃO}

Sabe-se que com a alta dos conceitos sustentáveis, os países têm demonstrado interesse pela mudança das matrizes energéticas, buscando utilizar fontes renováveis e limpas. Observa-se que a demanda de energia está aumentando, assim, esta torna-se uma vantagem competitiva para algumas empresas e países, o que permite o crescimento da geração de energia limpa e renovável, como a fonte solar.

Um sistema fotovoltaico de geração de energia é formado por um aglomerado de células fotovoltaicas, as quais têm o objetivo de captar a irradiação solar e transformá-la em energia elétrica. Estes sistemas têm como componenete principal as placas fotovoltaicas (PEREIRA; OLIVEIRA, 2011).

A utilização dos métodos para estudo da viabilidade econômica de um projeto de investimento visa estabelecer se há ou não potencialidades de implementação do projeto. Ou seja, a análise tem como objetivo obter respostas para as seguintes indagações: 0 projeto pode ser desenvolvido com sucesso e alcançar os resultados esperados pelos investidores? O projeto tem possibilidades de satisfazer ao retorno esperado pelos investidores e gerar riqueza para a organização? (ABREU FILHO, 2012).

Os métodos de viabilidade econômica abordados pelo presente trabalho foram: Taxa Mínima de Atratividade (TMA), Retorno sobre Investimento (ROI), Valor Presente Líquido (VPL), Taxa Interna de Retorno (TIR), Índice de Rentabilidade (IL) e Payback Simples e Descontado. Estes foram selecionados, pois visam embasar e demonstrar a real situação da viabilidade econômica. Segundo Damodaran (2004), as finanças de uma empresa englobam todas as decisões que envolvem implicações financeiras.

Neste contexto, o presente estudo tem como objetivo abordar sete métodos financeiros para analisar a viabilidade econômica da aplicação de instalações do sistema de geração de energia através das placas fotovoltaicas ligados à rede em uma empresa do município de Macaé/RJ.

\subsection{REVISÃO DA LITERATURA}

\subsubsection{A ENERGIA SOLAR SOB O ASPECTO DA SUSTENTABILIDADE DO NEGÓCIO}

A demanda de energia ao redor do mundo é crescente e uma das soluções sustentáveis é a utilização de energia solar, uma vez que esta é uma fonte renovável e limpa, pois o sol é inesgotável, além de não gerar resíduos.

Segundo Fernandes e Motta (2014), o sistema fotovoltaico se destaca quanto à sustentabilidade dos sistemas, já que se mostra autônomo e limpo, pois a única fonte de energia utilizada é a proveniente do sol, enquanto que a central termoelétrica utiliza parte da energia produzida para sua própria autonomia.

De acordo com os mesmos autores, a energia solar fotovoltaica é considerada uma das principais fontes ambientalmente corretas que estão presentes nas matrizes energéticas atuais. Deste modo, quando um país investe nesse tipo de produção energética, menor é a quantidade de gás carbônico emitida na atmosfera, e como consequência, menos poluição é causada. O cálculo dessas emissões evitadas é de suma importância para o reconhecimento da tecnologia e o aumento dos investimentos e incentivos para o setor (FERNANDES; MOTTA, 2014).

Outra forma de aproveitamento da energia solar para produção de energia elétrica é a geração heliotérmica ou termossolar, onde a energia solar é utilizada para geração de energia térmica e esta em energia elétrica. Em virtude do potencial de aproveitamento, depreende-se que a energia solar está no centro das discussões e definições de política energética de diversos países, tanto desenvolvidos, como emergentes. Suas implicações são transversais, pois o uso da energia solar permite algumas vantagens, como a redução do uso de combustíveis fósseis, redução de emissões de gases de efeito estufa, geração de empregos qualificados, desenvolvimento tecnológico e criação de valor e vetores de sustentabilidade ambiental, social e econômica (ESPOSITO; FUCHS, 2013).

A energia solar oferece diversos benefícios ambientais ao planeta. Um dos principais, como já abordado, é a capacidade de redução de emissão de gases do efeito estufa. Um estudo desenvolvido no ano de 2016, pela Associação Brasileira das Empresas de Serviços de Conservação de 
Energia (ABESCO), indica que uma residência equipada com um sistema fotovoltaico, o qual é capaz de gerar $180 \mathrm{kWh} / \mathrm{mês,} \mathrm{tem} \mathrm{a}$ capacidade de reduzir cerca de 1,3 toneladas de Dióxido de Carbono (CO2) na atmosfera em um ano. Em 25 anos, tempo de garantia dos módulos fotovoltaicos, esse volume pode alcançar cerca de 32 toneladas.

No entanto, a utilização desta fonte energética, assim como todas as outras, possui aspectos negativos, sendo que a maior preocupação é com a produção e o descarte dos painéis fotovoltaicos. O crescimento exponencial da produção de energia fotovoltaica irá criar uma enorme quantidade de lixo eletrônico nas próximas décadas e, ao mesmo tempo, uma crescente demanda por recursos (energia, água e substâncias químicas) para a produção dos módulos (PAIANO, 2015). Assim, Estima-se que no ano de 2035, de acordo com a International Energy Agency (IEA), aproximadamente um milhão de toneladas de módulos solares sejam descartados.

Segundo Pinho e Galdino (2014), os módulos fotovoltaicos são produzidos em fábricas automatizadas com mínima interferência humana. A produção em série dos módulos fotovoltaicos, em larga escala, tem permitido uma significativa redução nos preços e assegurado a manutenção de produtos de alta qualidade.

De acordo com Barbosa (2010), os equipamentos necessários para a utilização da energia solar fotovoltaica resumem-se em:

- Módulo solar - São placas desenvolvidas para converter diretamente a energia da luz do sol em energia elétrica, na forma de corrente contínua (DC).

- Controlador de carga - Aparelho eletrônico que protege as baterias de sobrecargas e descargas excessivas, prolongando sua vida útil.

- Inversor - Aparelho eletrônico que converte a energia elétrica de corrente contínua para corrente alternada, 127 volts ou 220 volts, possibilitando a utilização dos eletrodomésticos.

- Bateria - Utilizadas para armazenar a energia gerada pelos módulos solares, para fornecer energia à noite ou em dias de chuva.
Dentre estes, o principal responsável pelo alto custo de instalação do sistema são os painéis fotovoltaicos. No entanto, Pinho e Galdino (2014) afirmam que o preço dos módulos, que atualmente representa $50 \%$ do custo de instalação de um sistema fotovoltaico de $1 \mathrm{~kW}$ conectado à rede no Brasil, é o principal responsável por essa trajetória de queda dos preços, motivada pela significativa elevação da produção de módulos fotovoltaicos na Europa, nos EUA e, mais recentemente, na China.

Os sistemas fotovoltaicos podem ser classificados em 03 categorias distintas: isolados, híbridos e conectados à rede. Os sistemas isolados "off grid" não se conectam à rede elétrica, já os híbridos conjugam várias fontes de energia e, por fim, os conectados à rede "on grid" se conectam à rede elétrica.

Cada um dos modelos é apropriado para determinada finalidade. Gabardo e Radaskievicz (2013) indicam que os sistemas isolados normalmente utilizados em locais remotos, servem para diversas aplicabilidades, como no bombeamento de água, eletrificação de cercas, postes de iluminação entre outros. Muitas das vezes este é o modo mais econômico de obter energia elétrica nestes lugares. Ainda segundo estes autores, neste sistema, a energia produzida é armazenada em baterias que garantem o abastecimento em períodos sem sol ou ainda na forma de energia gravitacional quando se bombeia água para tanques em sistemas de abastecimento.

Os sistemas ligados à rede, por sua vez, não necessitam de baterias para armazenamento. De acordo com Fernandes e Motta (2014), a energia gerada é diretamente consumida e o excedente é injetado na rede de distribuição gerando créditos na concessionária de energia local. Esses créditos são utilizados em horários em que não há produção de energia solar, como no período noturno. O usuário paga à concessionária apenas a diferença entre quantidade consumida e quantidade injetada na rede elétrica.

Os dados contidos na Figura 56 apresentam um esquema demonstrativo diferenciando o sistema isolado e o conectado à rede. 
Figura 56: Exemplo de utilização da energia solar térmica para produção de energia elétrica

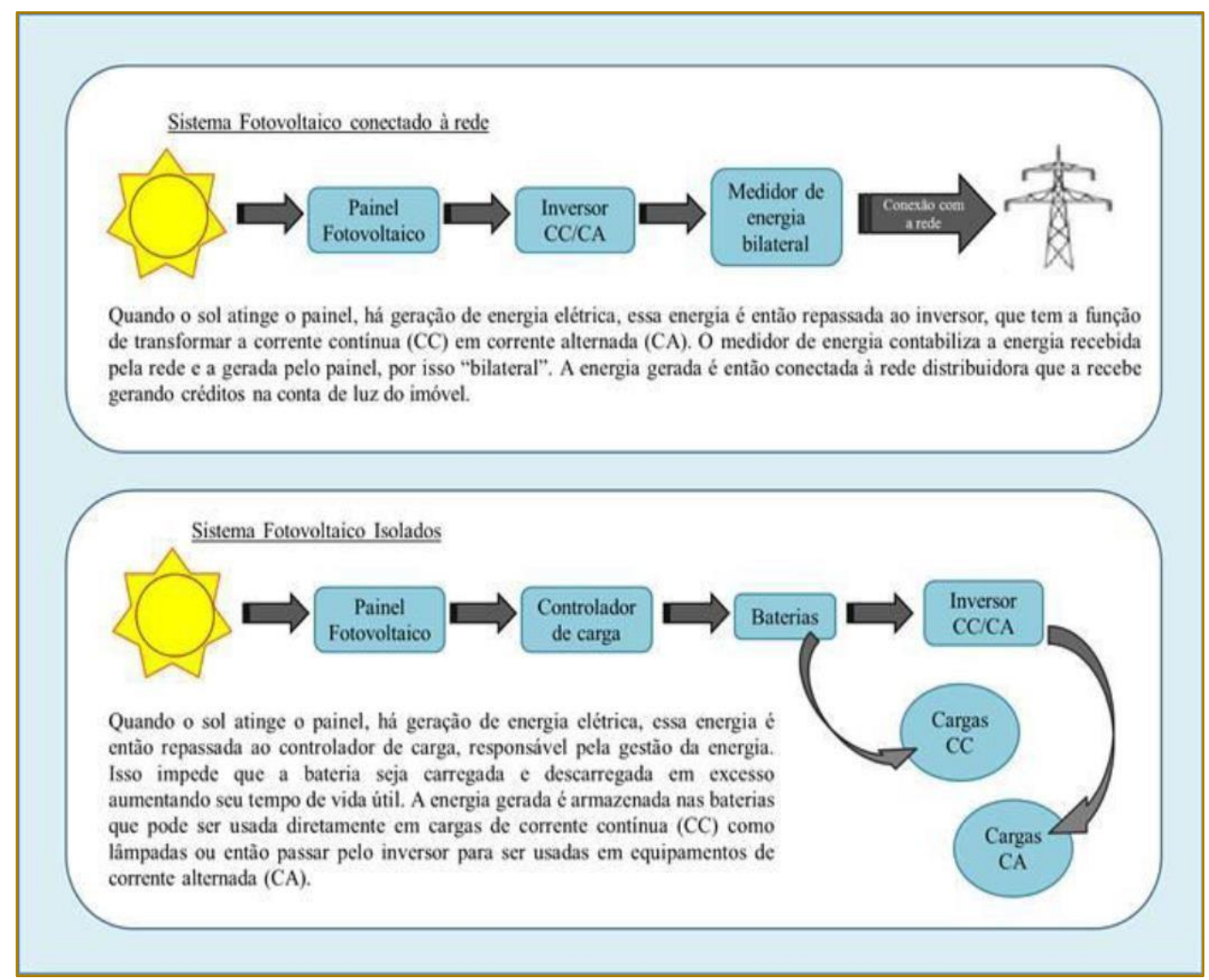

Fonte: Machado e Miranda (2015).

Pelos esquemas de blocos apresentados na Figura 56 nota-se também as necessidades de instalação de um medidor de energia bilateral no sistema conectado à rede, pois em determinado momento ele poderá medir a energia injetada na rede e em outro momento a energia consumida da rede.
Os dados contidos na Figura 57 apresentam, de forma simplificada, a ligação de um sistema híbrido.

Figura 57: Exemplo de sistema solar híbrido

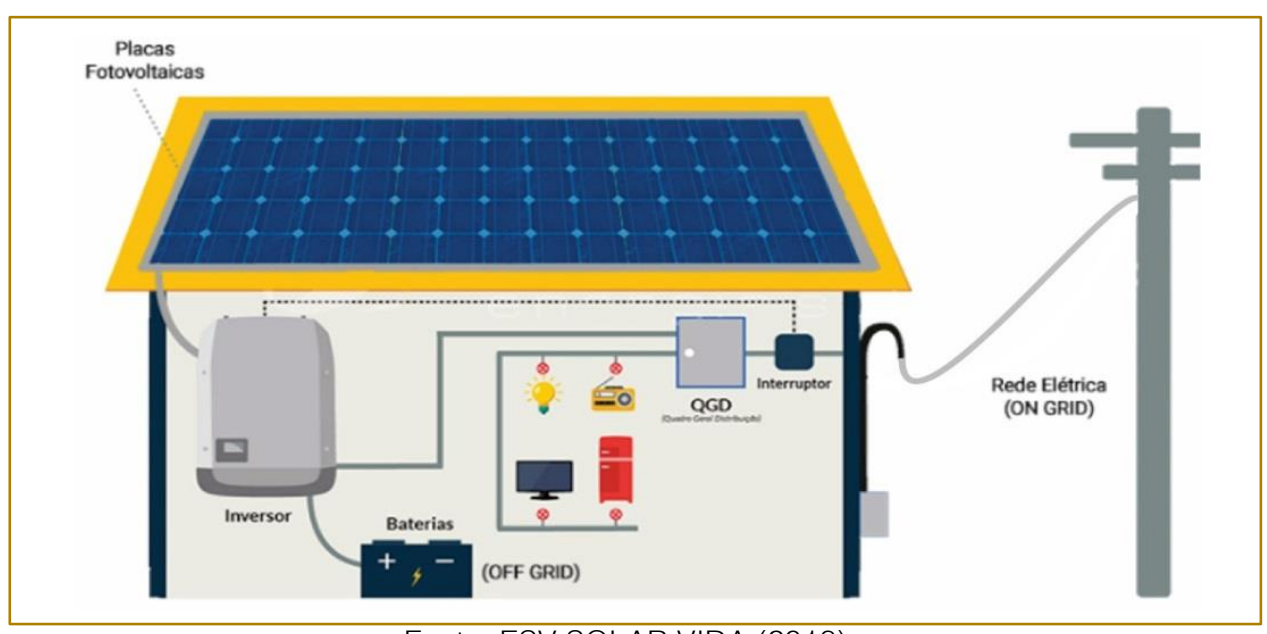

Fonte: ESV SOLAR VIDA (2018). 
Nota-se, de acordo com a figura 57 que os sistemas híbridos estão presentes tanto as baterias, quanto o medidor de energia bilateral, funcionando como sistema isolado, quanto conectado à rede.

De acordo com Fernandes e Motta (2014), o mais importante marco legal para o setor de geração de energias renováveis é a Resolução Normativa Agência Nacional de Energia Elétrica (ANEEL) n.ㅇ 482/2012, posteriormente atualizada pela Resolução Normativa ANEEL n. 687/2015 (ANEEL, 2015), segundo a qual o consumidor brasileiro pode gerar sua própria energia elétrica a partir de fontes renováveis e inclusive fornecer o excedente para a rede de distribuição da concessionária de sua localidade. Trata-se da micro e mini geração distribuídas de energia elétrica, sendo estas inovações que podem aliar economia financeira, consciência socioambiental e auto sustentabilidade.

A partir de então, o governo brasileiro passou a estimular este tipo de geração através de diversas formas. Segundo a Agência Nacional de Energia Elétrica (ANEEL, 2016), já existe um convênio publicado pelo Conselho Nacional de Política Fazendária (CONFAZ), em que, para os Estados que aderirem a este convênio, o Imposto sobre Circulação de Mercadorias e Serviços (ICMS) incide somente sobre a diferença entre a energia consumida e a energia injetada na rede da concessionária. Além disso, a incidência dos tributos do Programa de Integração Social (PIS) e da Contribuição para o Financiamento da Seguridade Social (COFINS) passarão a incidir apenas, da mesma forma que o ICMS, sobre a diferença positiva entre a energia consumida e a energia injetada pela unidade consumidora com micro ou mini geração distribuída.

Por fim, ressalta-se também a criação do Programa de Desenvolvimento da Geração Distribuída de Energia Elétrica (ProGD), lançado por meio da Portaria n. .538 , de 2015, do Ministério de Minas e Energia, com a finalidade de ampliar, ainda mais, as ações de estímulo à geração distribuída, com base em fontes renováveis, como a solar.

Pode-se dizer assim que o alto custo dos painéis fotovoltaicos ainda representa um entrave para disseminação em massa, do uso dessa tecnologia no Brasil, no entanto este custo tende a se reduzir, à medida que os incentivos fiscais e a produção em larga escala seja colocada em prática no território nacional.

\subsubsection{VIABILIDADE ECONÔMICA}

Analisar a fundo o projeto de um novo investimento proposto é de fundamental importância para o sucesso futuro de um negócio. Fundamentando este conceito, a utilização da análise de investimentos busca, através de técnicas avançadas, a utilização da estatística e matemática financeira, para colaborar e facilitar a tomada de decisão entre as soluções desenvolvidas (MOTTA; CALÔBA, 2002).

A utilização da Engenharia Econômica, como um instrumento de análise de investimentos, consiste no auxílio à tomada de decisão entre o tipo de investimento mais apropriado ao negócio, agregando valor ao dinheiro no tempo (BALARINE, 2004).

O fluxo de caixa que proporciona a base das análises necessárias para o estudo de viabilidade que orientará o empreendedor para uma decisão mais assertiva para este projeto (DEGEN; MELLO, 1989).

Neste estudo, foram abordados sete métodos de avaliação (Payback Simples e Descontado, ROI, VPL, TIR, TMA e IL), e estudados de forma isolada, a fim de promover a análise de viabilidade do negócio a partir da projeção futura das previsões de entradas e saídas.

\subsubsection{PAYBACK SIMPLES}

Segundo Degen e Mello (1989), o payback simples é o tempo necessário para que a empresa tenha o retorno do investimento inicial aplicado ao empreendimento. Trata-se de uma técnica simples, que pode ser analisada em qualquer periodicidade e que tem a viabilidade de um projeto definida como positiva quando o período do payback está dentro do previsto pelo empreendedor e que seja menor que o prazo total analisado, ou seja, o tempo que o investidor considera como ideal para a recuperação do seu investimento. O payback pode ser calculado a partir da equação (1): 
Payback $=\frac{\text { Investimento Inicial Total }}{\text { Entrada de caixa no período }}$

Vale ressaltar que na análise realizada pelo método do payback não é considerado o valor do dinheiro no tempo.

\subsubsection{RETORNO SOBRE O INVESTIMENTO (ROI)}

De acordo com Gitman (1997), o índice de Retorno sobre o Investimento, que pode ser calculado com o auxílio da equação (2), mede a rentabilidade das operações básicas da empresa face aos recursos aplicados nessas operações.

Retorno sobre Investimento $=\frac{\text { Lucro Líquido do Período }}{\text { Investimento Inicial Total }} * 100$

\subsubsection{VALOR PRESENTE LÍQUIDO (VPL)}

O Valor Presente Líquido possui a característica de trazer para o tempo presente, os fluxos de caixa futuros de um investimento somando ao valor do investimento inicial, ou seja, esse método leva em consideração o valor temporal dos recursos financeiros.

A viabilidade econômica de um projeto analisado pelo método do Valor Presente Líquido é indicada pela diferença positiva entre receitas e custos, atualizados a determinada taxa de juros (REZENDE; OLIVEIRA, 1993).

Este método apresenta algumas vantagens, como: pode ser aplicado a fluxos de caixa que contenham mais de uma variação de sinal, tanto de entrada, como de saída; leva em consideração o valor do dinheiro no tempo e; depende unicamente dos fluxos de caixa previsionais do projeto e do custo de oportunidade do capital, não sendo afetado pelas preferências do decisor, pelos métodos de contabilização usados pela empresa, pela rentabilidade da atual atividade da empresa ou pela rentabilidade de outros projetos autônomos.

$$
\mathrm{VPL}=-\mathrm{I}_{\mathrm{o}}+\sum_{\mathrm{t}=1}^{\mathrm{n}} \frac{\mathrm{FCt}}{(1+\mathrm{k}) \mathrm{t}}
$$

Sendo,

FCt - Valor presente das entradas de caixa;

lo - Investimento inicial;

k - Taxa de desconto (igual ao custo de capital de empresa);

t - Tempo de desconto de cada entrada de caixa;
No entanto, apresenta desvantagens, entre elas, a determinação da Taxa Mínima de Atratividade, ou seja, a flexibilidade de escolha da taxa de juros; e a impossibilidade de reaplicar os benefícios advindos de projetos exitosos (BRUNI; FAMÁ, 2003).

Segundo alguns autores o VPL pode ser considerado o mais importante método, em virtude de serem destacados o prazo, bem como a cronologia definida no projeto, além de demonstrar o valor presente calculado observando o desconto de cada parcela do fluxo de caixa a uma determinada taxa periódica utilizada pelo mercado (COSTA, 2006).

Segundo Abreu Filho (2012), o VPL pode ser classificado como sendo o parâmetro mais criterioso e tecnicamente completo, podendo ser avaliado como o índice mais indicado para efetuar comparações com diferentes projetos que possuem a mesma expectativa de tempo.

O VPL pode ser calculado através da equação (3) e a representação das variáveis está indicada a seguir.

n - Tempo de desconto do último fluxo de caixa.

Para avaliar se o projeto pode ser aceito como viável, verifica-se o valor de VPL, da seguinte forma:

VPL $>0=>0$ projeto deve ser aceito; 
$\mathrm{VPL}=0=>E ́$ indiferente aceitar ou rejeitar $\mathrm{O}$ projeto;

$\mathrm{VPL}<0=>0$ projeto deve ser rejeitado.

Segundo Lucena (2004), o VPL é um dos métodos de avaliação de investimento de maior uso pelos principais órgãos financeiros do planeta, por ser considerado extremamente conciso e consistente, em comparação com os demais métodos existentes.

\subsubsection{TAXA INTERNA DE RETORNO (TIR)}

Pode-se conceituar a TIR como a taxa de juros para a qual o valor presente dos valores recebidos como resultado do projeto é igual ao valor presente dos desembolsos, anulando o valor presente do fluxo de caixa (FLEISCHER, 1988).

Observando Oliveira (1982), a Taxa Interna de Retorno é definida como aquela que torna o valor dos lucros futuros equivalente ao valor dos gastos realizados com o projeto, assim, esta caracteriza-se como a taxa de remuneração esperada para o capital investido.

Este é um índice que representa a taxa média periódica de retorno de um projeto, suficiente para repor, de forma integral e exata, o investimento realizado. Logo, por informar quanto à empresa irá render em determinado momento, pode ser comparada com as taxas oferecidas no mercado financeiro (BROM, 2007).

Afirma Gomes (2005) que a TIR é um método largamente recomendável para se realizar uma análise da viabilidade de um projeto isoladamente, sem confrontar com outras opções excludentes.

Segundo Lucena (2004) a TIR e o VPL são duas das metodologias mais utilizadas para análise de investimento, tendo inclusive o aval do Banco Mundial.

\subsubsection{TAXA MÍNIMA DE ATRATIVIDADE (TMA)}

Segundo Abreu Filho (2012), a TMA pode ser entendida como uma taxa de juros que significa o menor valor que um investidor está disposto a ter de retorno quando faz um investimento, ou o maior valor que uma pessoa se compromete a pagar no momento que realiza um financiamento. A TMA é singular para cada investidor, ou seja, para cada empresa.

\subsection{8 ÍNDICE DE LUCRATIVIDADE (IL)}

Afirma Bordeaux-Rêgo et al. (2010) que o índice de lucratividade é uma variável coerente entre o valor atual dos fluxos de caixa auferido e o aporte aplicado no projeto. O cálculo desse índice é obtido pelo quociente entre o valor presente dos fluxos de caixa positivos e o valor presente dos fluxos de investimentos. A Tabela 11 ilustra o resultado da utilização desse método.

Tabela 11: Índice de Lucratividade

\begin{tabular}{|l|r|}
\hline $\begin{array}{l}\text { VPL DO FLUXO DE CAIXA } \\
\text { R\$ 9.294.131,58 }\end{array}$ & FLUXO DE CAIXA \\
\hline \multicolumn{2}{|c|}{ Fórmula: $9.294 .131 .324,65$} \\
\hline
\end{tabular}

Fonte: Bordeaux-Rêgo - Adaptado pelo Autor (2018).

Esse método, quando aplicado aos valores da Tabela 11 apresenta um retorno financeiro de 3,70 vezes superior ao investimento inicial.

Entretanto, a análise dessa metodologia deve observar os seguintes critérios: IL > 1 significa que para valor investido a remuneração atende no mínimo a taxa exigida pelo investidor; $\mathrm{IL}=1$, quer dizer que $\mathrm{O}$ investimento pelo menos fica pareado com o investimento inicial realizado; e $\mathrm{IL}<1$, aponta que o investimento se torna inviável no aspecto econômico financeiro. 


\subsubsection{PAYBACK DESCONTADO}

A utilização do método do payback descontado é um tipo de análise que se assemelha ao modelo do payback simples, entretanto, há uma exceção, o payback descontado considera a taxa de atratividade ou taxa de desconto no fluxo de caixa.

\subsection{METODOLOGIA}

Este trabalho é classificado como uma pesquisa exploratória, sendo esta realizada por meio de um estudo de caso desenvolvido numa empresa do ramo offshore em MacaéRJ.

De acordo com Gil (2008), as pesquisas exploratórias têm como principal finalidade desenvolver, esclarecer, modificar conceitos e ideias, tendo em vista a formulação de problemas mais precisos ou hipóteses pesquisáveis para estudos posteriores. Habitualmente envolvem levantamento bibliográfico e documental, entrevistas não padronizadas e estudos de caso.

A pesquisa consistiu, primeiramente, em analisar a viabilidade física para instalação do sistema de energia solar conectado à rede no âmbito da empresa. Para isso contatou-se uma empresa de consultoria em instalação de placas fotovoltaicas e um engenheiro eletricista, para elaboração e dimensionamento do projeto, avaliando a viabilidade deste, tendo como condição inicial estipulada pela diretoria a Taxa Mínima de Atratividade (TMA) de 8,3\%.

O consumo anual observado, através de um estudo realizado nas contas do ano de 2017 da empresa estudada, foi de $371.858 \mathrm{kWh}$, e o sistema de energia solar proposto possui uma produção anual estimada de 156.370 $\mathrm{kWh}$, sendo este o valor da energia produzida no primeiro ano, o que representa uma economia anual de 42\%. Não é viável, assim, para a empresa, neste momento, conseguir uma economia de $100 \%$ através da energia solar em função do capital inicial investido.

O simulador usado pelo autor foi o Pvsyst 6.73, que foi desenvolvido inicialmente pela Universidade de Genebra (Suíça) e é comercializado atualmente pela companhia Pvsyst SA. Permite ao usuário trabalhar em diferentes níveis de complexidade, desde um estágio inicial de representação até um detalhado sistema de simulação. Apresenta também uma ferramenta adicional, tridimensional, que leva em conta as limitações no horizonte e aqueles objetos que possam projetar sombras.

O programa permite importar dados dos programas Meteonorm e TMY2, o que facilita comparar valores simulados com valores medidos. Além disso, tem uma interface para dados e possui base de dados de irradiação de 22 localidades na Suíça e de 200 localidades do resto do mundo. Possui uma ampla base de dados de módulos e inversores. O programa apresenta as perdas do sistema fotovoltaico e a sua taxa de desempenho. O simulador PVsyst 6.73 é especialmente utilizado para Sistemas Fotovoltaicos Conectados a Redes (SFCRs), como é o estudo de caso feito por este autor.

Se o usuário adicionar o custo de cada componente à base de dados existente, o programa pode projetar os custos de produção de energia em adição a uma série de parâmetros técnicos, fornecidos no fim da simulação.

A energia produzida foi calculada através de um banco de dados da Meteonorm, que consta no Pvsyst 6.73, tendo sido considerada a irradiação e condições climáticas da cidade do Rio de Janeiro.

Sabe-se que a cidade do Rio de Janeiro está na latitude (S) 22 54' 10" e longitude (W) 43을 12 ' 27 '.

A respeito do uso do simulador adotado, é importante ressaltar a aleatoriedade da radiação solar, que segundo Lorenzo (2004), por mais que se obtenha dados sobre 0 comportamento da radiação, não se pode assegurar a repetição desse comportamento no futuro, pois há a influência de fatores como mudanças climáticas, aumento da emissão de gases poluentes etc. Além disso, para um mesmo lugar, existem diferentes fontes de informação cujos conteúdos divergem consideravelmente.

Os dados contidos na Figura 58 apresentam os dados utilizados para simulação da energia produzida com o auxílio do simulador Pvsyst 6.73. 
Figura 58: Dados da simulação com o Pvsyst 6.73

\begin{tabular}{|c|c|c|c|c|c|c|c|}
\hline \multicolumn{5}{|c|}{ Geographic site parameters for Rio de Janeiro (PVSyst original database) } & - & $\square$ & $x$ \\
\hline \multicolumn{8}{|c|}{ Geographical Coordinates Meteorologia mensal | Mapa interativo| } \\
\hline Localização & Rio de Jan & geiro (Braz & & & & & \\
\hline \multicolumn{7}{|c|}{ Fonte dos dado: Meteonorm 7.1} & \\
\hline & $\begin{array}{l}\text { rrad. Glob. } \\
\text { kWh/mt.mês! }\end{array}$ & $\begin{array}{l}\text { Difuso } \\
\mathrm{kWh} / \mathrm{m}^{2} . \mathrm{mês}\end{array}$ & $\underset{{ }^{\circ} \mathrm{C}}{\text { Temper. }}$ & $\begin{array}{l}\text { Veloc. Vento } \\
\mathrm{m} / \mathrm{s}\end{array}$ & \multirow{6}{*}{\multicolumn{2}{|c|}{$\begin{array}{l}\text { Dados exigidos } \\
\text { 『 Irradiação global horizontal } \\
\nabla \nabla \text { Temperatura exterior média }\end{array}$}} & \\
\hline Janeiro & 181.5 & 85.9 & 26.8 & 2.00 & & & \\
\hline Fevereiro & 156.5 & 85.1 & 26.9 & 2.00 & & & \\
\hline Março & 162.1 & 73.7 & 26.1 & 1.91 & & & \\
\hline Abril & 121.7 & 63.9 & 24.4 & 1.71 & & & \\
\hline Maio & 119.1 & 48.6 & 22.3 & 1.59 & & & \\
\hline Junho & 96.5 & 44.8 & 20.7 & 1.59 & \multirow{3}{*}{\multicolumn{2}{|c|}{$\begin{array}{l}\text { Dados suplementares } \\
\text { 『 Irradiação difusa horizontal } \\
\text { 『 Velocidade do vento }\end{array}$}} & \\
\hline Julho & 117.6 & 42.6 & 19.9 & 1.70 & & & \\
\hline Agosto & 125.7 & 57.0 & 21.4 & 1.90 & & & \\
\hline Setembro & 126.5 & 72.1 & 21.9 & 2.19 & \multirow{6}{*}{\multicolumn{2}{|c|}{$\begin{array}{l}\text { Unidades de irradiação } \\
\subset \mathrm{kWh} / \mathrm{m}^{2} \text {.dia } \\
\odot \mathrm{kWh} / \mathrm{m}^{2} \text {.mês } \\
\odot \mathrm{MJ} / \mathrm{m}^{2} \text {.dia } \\
\odot \mathrm{MJ} / \mathrm{m}^{2} \text {.mês } \\
\odot \mathrm{W} / \mathrm{m}^{2} \\
\odot \text { Índice de transparência } \mathrm{Kt}\end{array}$}} & \\
\hline Outubro & 151.0 & 89.9 & 24.3 & 2.40 & & & \\
\hline Novembro & 158.3 & 78.4 & 25.1 & 2.30 & & & \\
\hline Dezembro & 174.0 & 98.7 & 26.5 & 2.20 & & & \\
\hline Ano & 1690.5 & 840.7 & 23.9 & 2.0 & & & \\
\hline$?$ & Colar & Colar & Colar & Colar & & & \\
\hline \multicolumn{2}{|c|}{ [S Nova localização } & \multicolumn{3}{|c|}{ 男 Imprimir } & \multicolumn{3}{|c|}{ 员 Fechar } \\
\hline
\end{tabular}

Fonte: Elaborado pelo autor (2018).

Nesta figura é possível verificar os dados contidos no banco de dados Meteonorm 7.1 para a cidade do Rio de Janeiro, como irradiação direta, irradiação difusa, temperatura e velocidade do vento com as suas respectivas médias anuais.

Os dados contidos na Figura 59 mostram a simulação de energia produzida pelo sistema de energia solar para o primeiro ano.

Conforme apresentado na Figura 59, é possível observar a previsão de energia a ser produzida pelo sistema de energia solar no valor de 171,9 MWh para o primeiro ano, onde temos três parâmetros essenciais, tais como: potência instalada, irradiação solar e o rendimento do inversor.

A partir daí é feita uma simulação com dados probabilísticos de condições climáticas, rendimento dos painéis e dados adquiridos de usinas já em funcionamento. Os cálculos consideram o posicionamento ideal dos painéis, onde eles estão voltados para Norte, que é para onde o sol se inclina no nosso hemisfério durante a maior parte do ano.

A inclinação dos painéis se dá de acordo com a latitude da cidade de Macaé-RJ. Como o
Rio de Janeiro se localiza $-22^{\circ}$, os painéis devem estar inclinados com o ângulo de $19^{\circ}$, para não terem perdas com possíveis sombreamento.

O valor considerado da tarifa para o primeiro ano foi retirado referente ao maior valor das 12 faturas da empresa estudada do ano de 2017, aproximadamente, que neste caso foi de 0,5777 .

Utilizou-se como uma premissa que os reajustes de tarifa de energia a partir do ano 1 serão baseado em Miranda (2014, p. 41). O autor afirma que:

Em relação à tarifa de energia, como parte dela é dependente do Índice Geral de Preços do Mercado (IGPM) e seu reajuste é feito através de um coeficiente chamado Índice de Reajuste Tarifário, IRT, é possível estimar a variação dos valores através de estudos econômicos na variação desses indicadores e fatores. Analisando também estudos estatísticos de variação tarifária da energia nas últimas décadas, chegando a um valor de 4,8\% de atualização anual (MIRANDA, 2014, p. 41). 
Pois, nota-se pelo pesquisador, que as tarifas de energia elétrica podem não seguir uma trajetória bem definida, suas alterações podem ser explicadas em razão de políticas adotadas, intervenções governamentais e diferentes fases do próprio setor elétrico brasileiro.

Figura 59: Simulação com o Pvsyst 6.73 da energia produzida para o primeiro ano

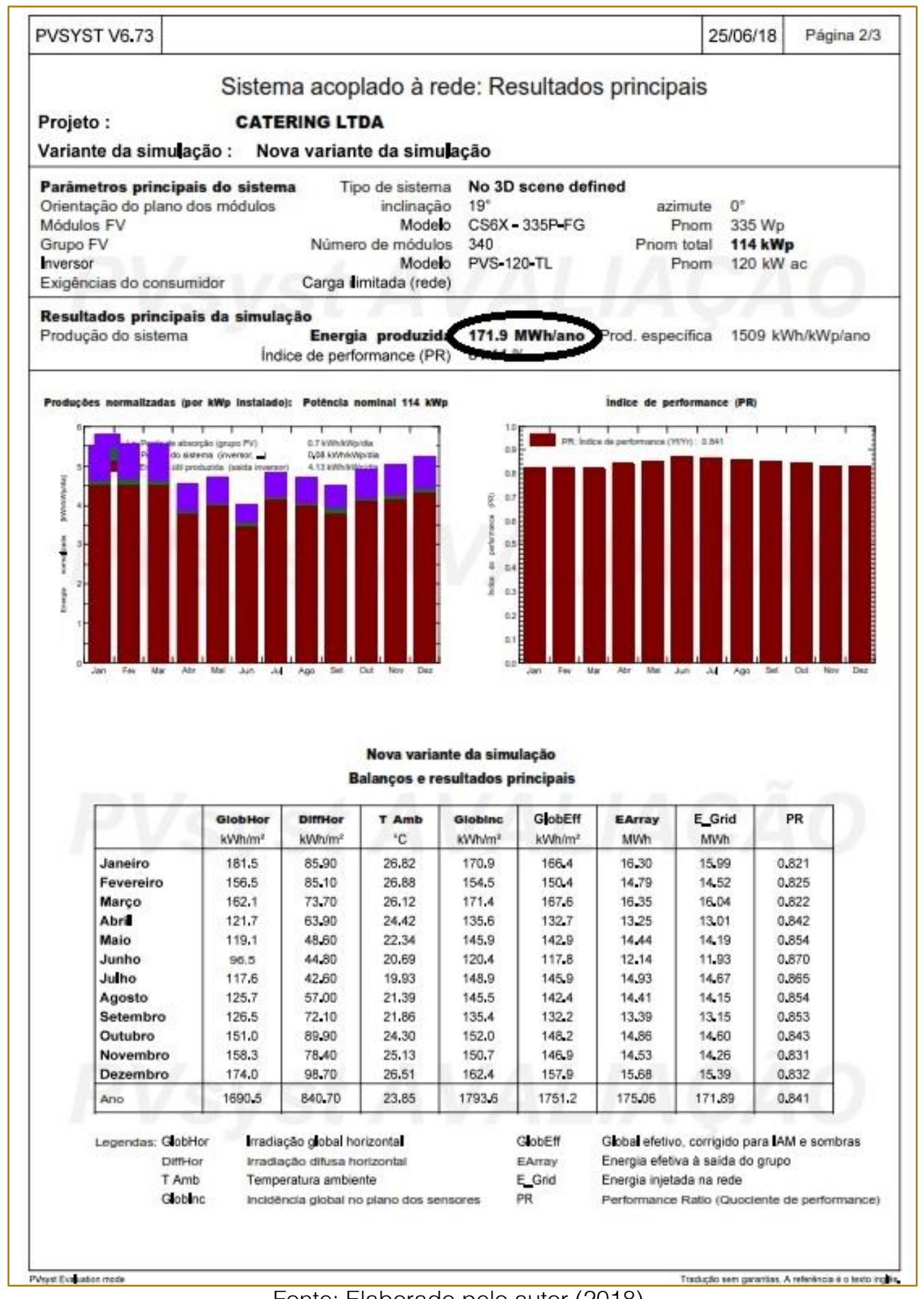

Fonte: Elaborado pelo autor (2018). 
No que tange a manutenção o sistema fotovoltaico tem uma confiabilidade muito alta, e apresenta uma manutenção baixa. Com uma instalação bem feita e o acompanhamento remoto do sistema com frequência, basta a limpeza dos painéis e inspeção termográfica dos quadros elétricos.

A potência de um gerador fotovoltaico varia conforme o fabricante, contudo a ela:

[...] tipicamente é garantida uma potência de pico mínima de $90 \%$ da potência nominal para o período dos 10 a 12 primeiros anos de operação e de $80 \%$ por um período de 20 a 25 anos. Mas existem outras formas, como fabricantes que garantem por 5 anos pelo menos 95\% da potência nominal, durante 12 anos pelo menos 90\%, durante 18 anos pelo menos $85 \%$ e durante 25 anos pelo menos 80\% (PINHO; GALDINO, 2014, p. 132).

Para efeitos deste estudo, utilizou-se para os 12 primeiros anos uma potência mínima de $90 \%$ e para os anos subsequentes ( 13 a 25 anos) a potência mínima de $80 \%$ conforme descrito acima.

Portanto, o produto (multiplicação) entre energia produzida e tarifa de energia traz como resultado a receita deste empreendimento. Para realizar o fluxo de caixa, foi preciso passar a análise para o lado dos custos. Para tanto, para este estudo considera os custos de manutenção e o seguro das peças.

O custo de manutenção foi formado pelo custo da visita quadrimestral de dois funcionários de uma empresa terceirizada que prestarão o serviço. O custo de cada visita foi estimado em $\mathrm{R} \$$ 1.264,73; totalizando um custo anual de manutenção de $\mathrm{R} \$ 3.794,19$. Como se dá os reajustes estimados para os 25 anos seguintes? A metodologia que adota foi de usar medidas aproximadas de reajuste do salário mínimo.

O estudo tomou como base a regra vigente no país para reajustes do salário mínimo que conforme Teixeira e Vianna (2013) corresponde à variação do Produto Interno Bruto (PIB) acrescida da inflação. Os autores são mais específicos ainda afirmando, na nota de rodapé 13, que "[..] os reajustes para a preservação do poder aquisitivo do salário mínimo corresponderão à variação do Índice Nacional de Preços ao Consumidor - INPC [...] à título de aumento real, será aplicado o percentual correspondente à taxa de crescimento real do Produto Interno Bruto PIB" (p. 41).

Para fins exclusivos deste artigo, utilizou-se para isso as previsões de crescimento que Teixeira e Vianna (2013) fazem no cenário mais conservador e provável: $2,0 \%$ a.a. Já o INPC considerou-se a média do indicador entre os anos de 1995 e 2017: 7,23\%.

Por fim, o seguro corresponde a $3 \%$ do custo das peças. Segundo orçamento elaborado dentro da pesquisa, o custo com equipamentos é de $R \$ 362.160,00$ o que gerará um custo de seguro de $\mathrm{R} \$ 10.864,80$. Isto é válido para o primeiro ano. E os reajustes para os anos subsequentes? Alguns seguros no Brasil possuem como indicador de referência para os reajustes o Índice Geral de Preços do Mercado "IGP-M". Para este estudo, consideraremos a média do IGP-M para os anos de 1995 a 2017 que corresponde a $8,36 \%$ como uma proxy para reajustes nos valores do seguro ao longo do período de análise.

Vale resslatar que o Estado do Rio de Janeiro através da Lei n 7122/2015, isentou o Imposto sobre Circulação de Mercadorias e Serviços (ICMS) sobre a energia solar.

A segunda etapa foi avaliar a viabilidade econômica proposta pelo autor de acordo com os índices Valor Presente Líquido (VPL), Payback Descontado, Índice de Lucratividade (IL), Retorno sobre o Investimento (ROI), Taxa Mínima de Atratividade (TMA), além do orçamento elaborado pelo fornecedor para calcular o tempo médio de retorno do investimento e a economia financeira a ser gerada.

\subsection{ESTUDO DE CASO}

A empresa, localizada no município de Macaé/RJ, conta com 250 colaboradores em turnos diurnos e noturnos, e com este número de pessoas ocupadas, e referida empresa é considerada de médio porte, de acordo com metodologia do SEBRAE, descrita por Martins, Leone e Leone (2017).

A estrutura da companhia é composta por 01 auditório, 01 laboratório para ensaios mecânicos, 01 oficina elétrica e diversos setores administrativos. Todos os ambientes são climatizados com aparelhos de ar condicionado de vários modelos e capacidades. Além disso, esta possui uma ampla área descoberta com 
aproximadamente $5500 \mathrm{~m}^{2}$, onde estão instalados diversos postes de luz com lâmpadas do tipo vapor metálico. Assim, pode-se notar que para manter esta infraestrutura é demandada grande quantidade de energia.
Os dados contidos na Figura 60 apresentam o histórico no período de 01 ano do consumo em kwh e os valores correspondentes cobrados pela concessionária.

Figura 60: Histórico de consumo de energia elétrica

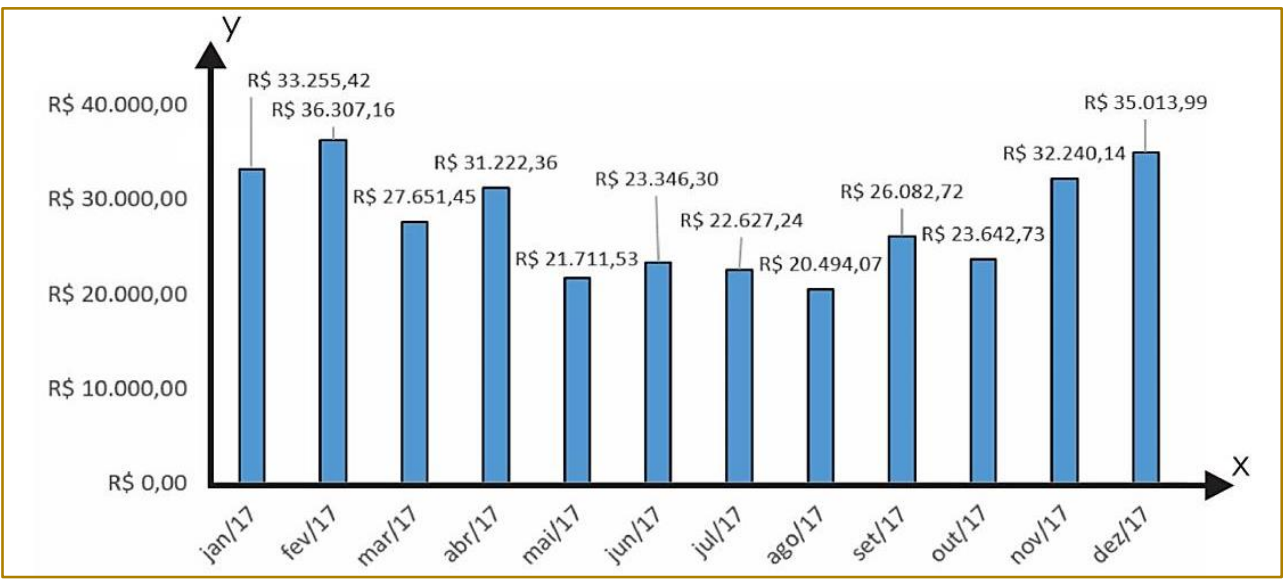

Fonte: Adaptado do simulador Pvsyst 6.73 (2018).

Percebe-se através da Figura $60 \quad 0$ alto consumo de energia demonstrado ao longo do ano de 2017. Observa-se também, que os gastos anuais com energia elétrica da empresa situada em Macaé/RJ se aproximam de $R \$ 333.595,14$. De acordo com a Alta Direção Administrativa desta Empresa, o orçamento para custeio e manutenção da mesma no ano de 2017, autorizado pela Direção, foi de $R \$ 1.000 .000,00$. Dessa forma, os gastos com energia elétrica representam aproximadamente $33,4 \%$ do orçamento para manutenção da empresa offshore, valor que compromete o custeio de materiais para novos projetos e investimentos. Os dados contidos na Tabela 12 apresentam o orçamento calculado pela empresa para instalação do sistema interligado à rede totalizando $\mathrm{R} \$ 484.106,10$.

Tabela 12: Orçamento do projeto

\begin{tabular}{|c|c|}
\hline PEÇAS, ACESSÓRIOS E INSTALAÇÃO & $\mathrm{R} \$ 362.160,00$ \\
\hline Módulo - Inversor - Estrutra & $\mathrm{R} \$ 121.946,10$ \\
\hline Instalação - Projeto & $\mathrm{R} \$ 484.106,10$ \\
\hline Total: &
\end{tabular}

Fonte: Elaboração própria (2018).

Os dados contidos na Tabela 13 apresentam informações sobre equipamentos e dados do sistema fotovoltaico.

Tabela 13: Equipamentos e dados do Sistema Fotovoltaico

\begin{tabular}{|c|c|}
\hline Sistema Fotovoltaico & 114,00 \\
\hline Potência (kWp) & 340 \\
\hline Quantidade de placas fotovoltaicas (unidades) & $664 \mathrm{~m} 2$ \\
\hline Área mínima ocupada pelo sistema & 5 \\
\hline
\end{tabular}

Fonte: Elaboração própria (2018). 
De acordo com os dados contidos na Figura 61 constata-se a economia feita com a energia solar durante o período do ano de 2017.

Figura 61: Economia com a Energia Solar

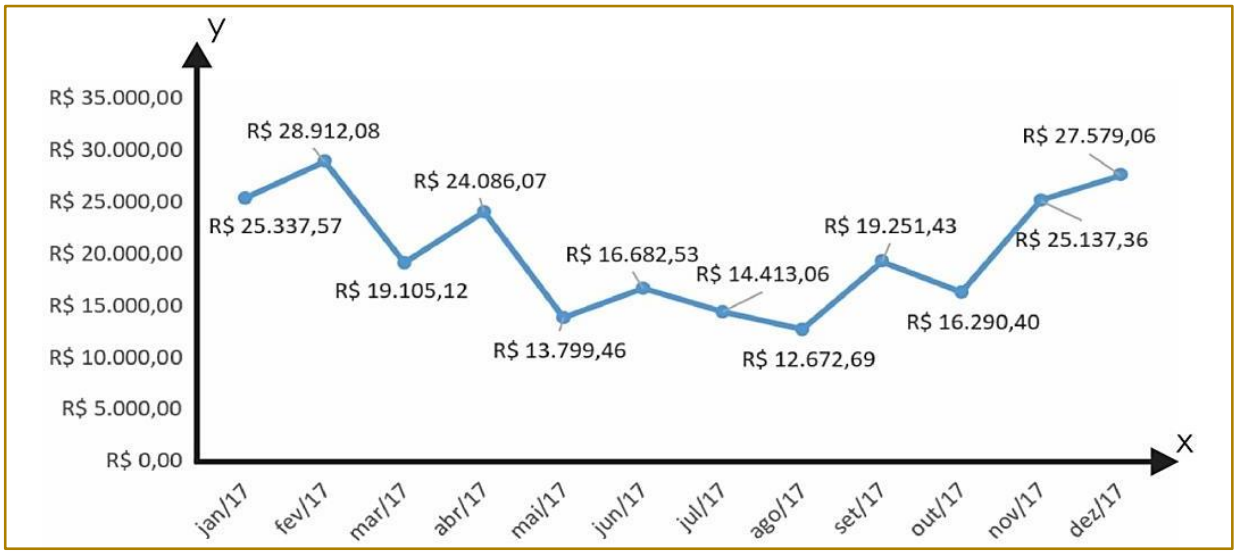

Fonte: Adaptado do simulador Pvsyst 6.73 (2018).

Percebe-se na Figura 61 que com a instalação do sistema fotovoltaico há uma diminuição significativa nas contas de luz pagas no ano de 2017.
Com os dados contidos na figura 62 é possível notar a diferença do custo sem energia solar de todo o sistema fotovoltáico e a economia gerada mensalmente pela energia solar.

Figura 62: Custo sem energia x Economia com Energia Solar

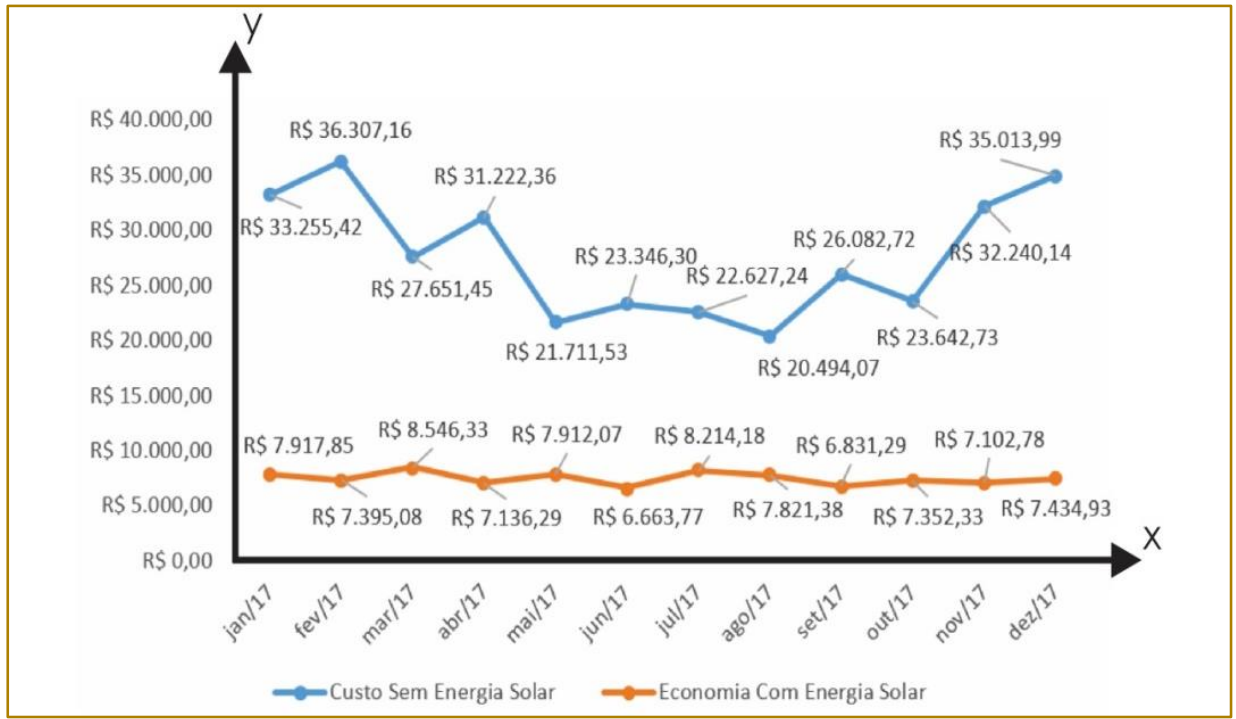

Fonte: Adaptado do simulador Pvsyst 6.73 (2018).

Nota-se a partir da Figura 62 que com a instalação do sistema fotovoltáico há uma projeção de uma economia de $\mathrm{R} \$ 90.328,28$ para o ano de 2017.
Os dados contidos na Figura 63 indicam uma estimativa média da economia mensal de aproximadamente $\mathrm{R} \$ 7.527,36$. 
Figura 63: Estimativa de Economia Mensal para o ano 2017

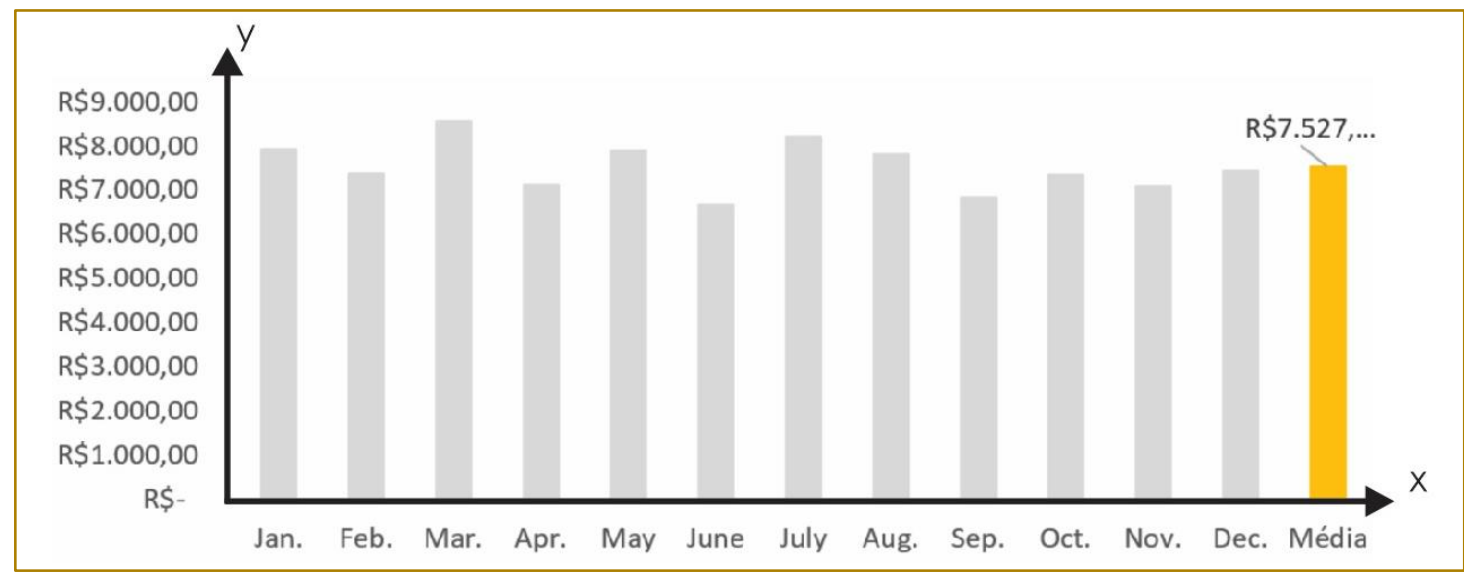

Fonte: Adaptado do simulador Pvsyst 6.73 (2018).

Pode-se observar pela Figura 63 a variação da economia mensal ao longo do ano de 2017.

\subsection{ANÁLISE E DISCUSSÃO DOS} RESULTADOS

Ao considerar o orçamento apresentado na Tabela 12 a economia anual na conta de energia elétrica foi estimada em $\mathrm{R} \$ 90.328,28$ para o ano de 2017, assim sendo elaborou-se a figura 64 e a Tabela 14 os quais apontam o tempo médio de retorno do investimento e a economia gerada com o projeto ao longo dos 25 anos.

O estudo apresenta uma área coberta de aproximadamente $3.000 \mathrm{~m}^{2}$. Foi analisado que grande parte dessa área pode ser utilizada para instalação dos painéis fotovoltaicos, uma vez que está já possui cobertura com telhas que contém a inclinação adequada e facilitam a instalação destes. De acordo com o projeto elaborado pelo engenheiro eletricista, fazemse necessários apenas $664 \mathrm{~m}^{2}$ de telhado, correspondendo a instalação de 340 painéis.

Os dados contidos na Figura 64 apresentam a evolução do retorno do investimento e percebe-se que esse tempo é de, aproximadamente, 6 anos. Ao final dos 25 anos de garantia das placas fotovoltaicas, a economia a ser gerada aos cofres da empresa estudada é de aproximadamente $R \$ 2.015 .095,98$.

Figura 64: Tempo de Retorno de Investimento

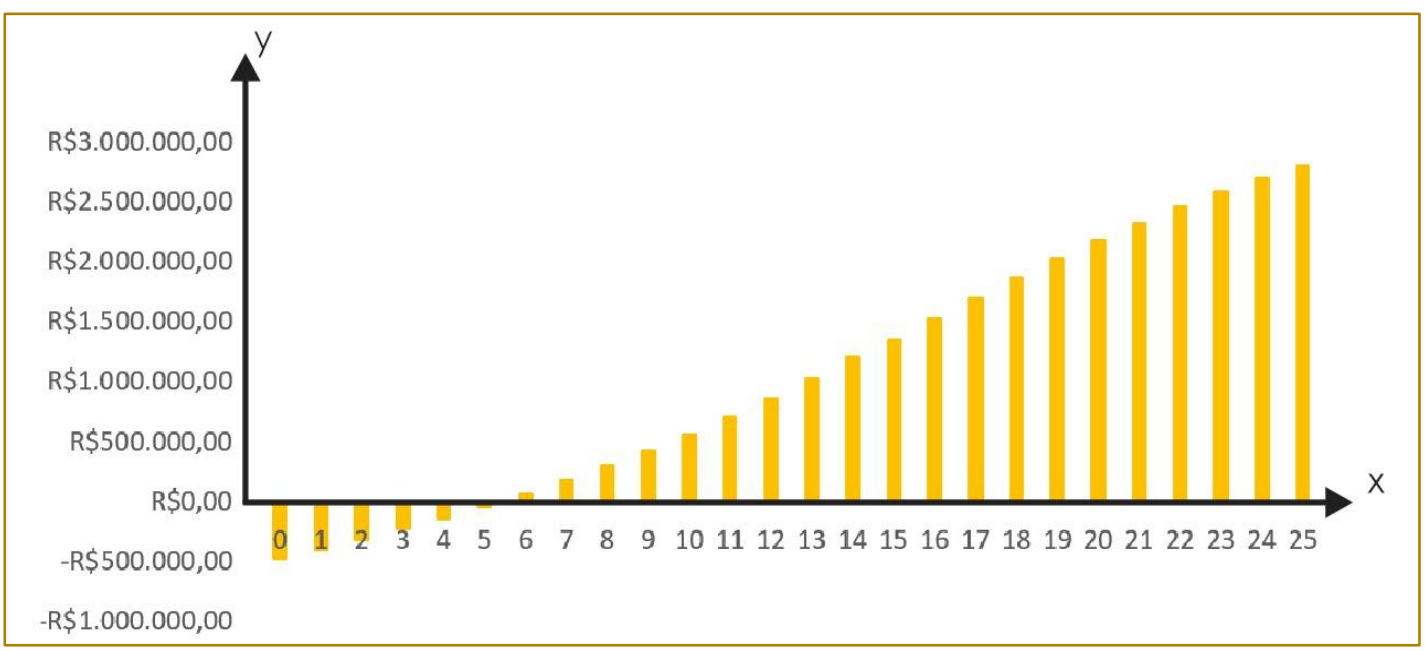

Fonte: Adaptado do simulador Pvsyst 6.73 (2018). 
Ao observar a Figura 64 percebe-se que o tempo de retorno do investimento foi estimado em aproximadamente 6 anos pelo método Payback simples.

Os dados contidos na Tabela 14 apresentam os valores referentes a análise do investimento e custos durante 25 anos, tendo sido separados anualmente, de acordo com os seguintes tópicos: Energia Produzida, Tarifa Elétrica, Receita de Energia Produzida, Seguro anual, Fluxo de Caixa e Fluxo de Caixa Acumulado.

Tabela 14: Análise do Investimento e Custo durante os 25 anos

\begin{tabular}{|c|c|c|c|c|c|c|c|c|c|c|c|}
\hline ANO & $\begin{array}{l}\text { ENERGIA } \\
\text { PRODUZIDA }\end{array}$ & $\begin{array}{c}\text { TARIFA } \\
\text { ELÉTRICA }\end{array}$ & & $\begin{array}{l}\text { RECEITA } \\
\text { DE ENERGIA } \\
\text { PRODUZIDA }\end{array}$ & & $\begin{array}{l}\text { NUTENÇ̄̃o } \\
\text { ANUAL. }\end{array}$ & & $\begin{array}{l}\text { SEGURO } \\
\text { ANUAL }\end{array}$ & FLUXO DE CAIXA & & $\begin{array}{l}\text { UXO DE CAIXA } \\
\text { ACUMULADO }\end{array}$ \\
\hline 0 & 0.00 & 0.0000 & RS & 0.00 & S & 0.00 & RS & 0.00 & -RS 484 & & \\
\hline I & 154.710 .00 & 0.5777 & RS & 89.375 .97 & RS & 3.794 .19 & RS & 10.864 .80 & RS 74.716 .98 & - RS & 409.389 .12 \\
\hline 2 & 153.317 .61 & 0.6068 & RS & 93.035 .59 & RS & 4.144 .46 & RS & 11.855 .67 & RS 77.035 .46 & RS & 332.483 .42 \\
\hline 3 & 151.937 .75 & 0.6374 & RS & 96.845 .06 & RS & 4.527 .07 & RS & 12.936 .91 & RS 79.381 .09 & - RS & 253.364 .29 \\
\hline 4 & 150.570 .31 & 0.6695 & RS & 100.810 .52 & RS & 4.944 .99 & RS & 14.116 .75 & RS 81.748 .78 & - RS & 172 \\
\hline 5 & 149.215 .18 & 0.7033 & RS & 104.938 .35 & RS & 5.401 .50 & RS & 15.404 .20 & RS 84.132 .65 & - RS & 45 \\
\hline 6 & |47.872.24 & 0.7387 & RS & 109.235 .20 & RS & 5.900 .15 & RS & 16.809 .06 & RS 86.525 .98 & - RS & 2.545 .82 \\
\hline 7 & 146.541 .39 & 0.7759 & RS & 113.707 .98 & RS & 6.444 .84 & RS & 18.342 .05 & RS 88.921 .09 & RS & 0.71 \\
\hline 8 & 145.222.52 & 0.8151 & RS & 118.3 & RS & 7.039 .81 & RS & 20.014 .85 & RS 91 & RS & \\
\hline 9 & 143.915 .52 & 0.8561 & RS & 123.210 .49 & RS & 7.689 .71 & RS & 21.840 .20 & RS 93.680 .59 & RS & 268.605 .45 \\
\hline 10 & 142.620 .28 & 0.8993 & RS & 128.255.52 & RS & 8.399 .60 & RS & 23.832 .03 & RS 96.023 .89 & RS & .89 \\
\hline II & & & RS & & RS & 9.17 & RS & & RS 98 & RS & \\
\hline 12 & 140.064 .66 & 0.9922 & RS & 138.973.76 & RS & 10.022 .05 & RS & 28.377 .21 & RS 100.574 .50 & RS & 559.767 .56 \\
\hline 13 & 138.944 .15 & 1,0422 & RS I & 144.810.21 & RS & 10.947 .26 & RS & 30.965 .21 & RS 102.897 .74 & RS & 661.242 .38 \\
\hline 14 & 137.832 .59 & 1.0 & RS & 991.78 & RS & 38 & RS & 3 & RS IC & RS & 81 \\
\hline 15 & 136.729 .93 & 1.1499 & RS & I57.228.75 & RS & 13.061 .80 & RS & 36.870 .82 & RS 107.296 .13 & RS & 5.81 \\
\hline 16 & 135.636 .09 & 1.2079 & RS & 163.831 .85 & RS & 14.267 .63 & RS & 40.233 .43 & RS 109.330 .79 & RS & 978.515 .88 \\
\hline 17 & $|34.551 .0|$ & 1.2688 & RS & I70.7I2.26 & RS & I5.584.78 & RS & 43.902 .72 & RS III.224.76 & RS & 1.088 .263 .19 \\
\hline 18 & 133.474 .60 & 1.3327 & RS & 177.881 .63 & RS & 17.023 .53 & RS & 47.906 .65 & RS II2.95I.46 & RS & 811.60 \\
\hline 19 & 132.406 .80 & 1.3999 & RS & 185.352 .09 & RS & 18.595 .09 & RS & 52.275 .74 & RS II4.48I.26 & RS & 1.313 .012 .44 \\
\hline 20 & 131.347 .55 & 1.4704 & RS & 193.136 .29 & RS & 20.311 .74 & RS & 57.043 .28 & RS II5.78I.26 & RS & I.427.692.1I \\
\hline 21 & 130.296 .77 & 1.5445 & RS & 201.247 .39 & RS & 22.186 .87 & RS & 62.245 .63 & RS 116.814 .89 & RS & I.543.649.4I \\
\hline 22 & 129.254 .39 & 1.6224 & RS: & 209.699 .14 & RS & 24.235 .10 & RS & 67.922 .43 & RS II7.54I.60 & RS & 1.660 .652 .67 \\
\hline 23 & 128.220 .36 & 1.7041 & RS : & 218.505 .83 & RS & 26.472 .43 & RS & 74.116 .96 & RS II7.9I6.45 & RS & I.778.436.59 \\
\hline 24 & 127.194.59 & 1.7900 & RS 2 & 227.682 .38 & RS & 28.916 .29 & RS & 80.876 .43 & RS 117.889 .66 & RS & 1.896 .698 .78 \\
\hline 25 & 126.177.04 & 1,8802 & RS: & $237.244,31$ & RS & $31.585,77$ & RS & 88.252 .36 & RS 117.406 .19 & RS & 2.015 .095 .98 \\
\hline
\end{tabular}

Fonte: Elaboração própria (2018).

Através dos dados apresentados na Tabela 14 foi possível calcular o IL, 1,99\%, e notou-se que o mesmo é maior que 1 , sendo este um ponto favorável ao projeto. Calculou-se também o ROI e o Valor Presente Líquido (VPL), sendo estes, respectivamente, $516,25 \%$ e $R \$ 438.835,34$, outro fator favorável e importante para a tomada de decisão da Diretoria. A TMA foi 8,3\%, mencionado anteriormente, e a TIR corresponde a $17,51 \%$ a.a, maior do que a TMA. Os dados contidos a Tabela 15 demonstram estes resultados. A tabela 14 foi criada pelo autor, e denominada como o modelo AGB-system PV 1.0 . 
Tabela 15: Resultado dos indicadores de Viabilidade Econômica proposta

\begin{tabular}{|l|c|}
\multicolumn{1}{|c}{ Indicadores Econômicos } & Resultados \\
\hline Índice de lucratividade - IL & $1,99 \%$ \\
\hline Retorno Sobre Investimento - ROI & $516,25 \%$ \\
\hline Valor Presente Líquido - VPL & $\mathrm{R} \$ 438.835,34$ \\
\hline Taxa Mínima de Atratividade - TMA & $8,30 \%$ \\
\hline Taxa Interna de Retorno - TIR & $17,51 \%$ a.a \\
\hline Payback Simples & 6 anos e $1 / 2$ mês \\
\hline Payback Descontado & 8 anos e 5 meses \\
\hline
\end{tabular}

Fonte: Elaboração própria (2018).

Com base nos resultados da viabilidade econômica apresentado, pode-se afirmar que o projeto é considerado viável, pois proporciona grande economia financeira no médio e longo prazo, apresentando-se como uma das soluções para o alívio as despesas de manutenção da empresa petrolífera para superar a crise e contribui com a geração de energia limpa, sem emissão de gás carbônico (CO2).

\subsection{CONSIDERAÇÕES FINAIS}

O sistema de geração de energia solar tem se difundido amplamente em vários países no mundo. No Brasil, após a resolução 482/2012 da ANEEL, com a possibilidade de compensação de créditos de geração elétrica, o sistema fotovoltaico passou a ser utilizado em larga escala em residências, indústrias e organizações diversas.

Este trabalho se objetivou a avaliar a possível implantação de um sistema fotovoltaico em uma empresa offshore no município de Macaé, situado no estado do Rio de Janeiro.

\section{REFERÊNCIAS}

[1] ABREU FILHO, J. C. F. et al. Finanças Corporativas. 11 ed. Rio de Janeiro: Editora FGV, 2012. 160 p. (FGV Management).

[2] AGÊNCIA NACIONAL DE ENERGIA ELÉTRICA (ANEEL). Resolução Normativa n. ${ }^{\circ} 482$ de 17 de abril de 2012. Estabelece como condições gerais para o acesso de micro geração e mini-geração distribuida aos sistemas de distribuição de energia elétrica, o sistema de compensação de energia elétrica, e dá outras providências. Disponível em: <http://www2.aneel.gov.br/cedoc/ren2012482.pdf> Acesso em: 28 jun. 2018.
Foi possível observar que a companhia tem capacidade estrutural para abrigar o sistema e que o investimento a ser realizado será revertido em aproximadamente 6 anos, proporcionando grande economia em médio e longo prazo.

Foi observado como inconsistentes as taxas de retorno de investimento considerando o tempo de retorno do investimento menor ou igual a 5 (cinco) anos.

No que tange aos métodos de viabilidade econômica aplicados neste estudo, ressaltase que o VPL e a TIR são os métodos mais completos para tomada de decisão, pois englobam todos os anos do projeto .

Conclui-se que a viabilidade de utilização de placas fotovoltaicas é considerada positiva, proporcionando não só benefícios financeiros, mas também contribuindo para a sustentabilidade, pois a energia solar não utiliza fontes fósseis, não emite gás carbônico na atmosfera e ainda contribui para conservação dos reservatórios das hidrelétricas, preservando assim os recursos hídricos nacionais.

[3] AGÊNCIA NACIONAL DE ENERGIA ELÉTRICA (ANEEL). Resolução Normativa n 687 , de 24 de novembro de 2015. Altera a Resolução Normativa no 482, de 17 de abril de 2012, e os Módulos 1 e 3 dos Procedimentos de Distribuição PRODIST. Disponível em: <http://www2.aneel.gov.br/cedoc/ren2015687.pdf> Acesso em: 28 jun. 2018.

[4] ASSOCIAÇÃO BRASILEIRA DAS EMPRESAS DE SERVIÇOS DE CONSERVAÇÃO DE ENERGIA (ABESCO). Residências podem deixar de emitir 1 tonelada de $\mathrm{CO} 2$ por ano com microgeração fotovoltaica. Disponível em: $<$ http://www.abesco.com.br/pt/novidade/residencia s-podem-deixar-de-emitir-1-tonelada-de-co2-por- 
ano-com-microgeracao-fotovoltaica/>. Acesso em: 28 jun. 2018.

[5] BALARINE, O. F. O. Tópicos de matemática financeira e engenharia econômica. 2 ed. Porto Alegre: EDIPUCRS, 2004.

[6] BARBOSA, F. Z. A utilização dos raios solares como fonte energética. Porto Velho, RO: Fundação Universidade Federal de Rondônia, 2010

[7] BARBOSA FILHO, W. P. et al. Expansão da energia solar fotovoltaica no brasil: Impactos ambientais e políticas públicas. Revista Gestão \& Sustentabilidade Ambiental, v. 4, p. 628, $7 \mathrm{dez}$. 2015. Disponível em: <http://www.portaldeperiodicos.unisul.br/index.php /gestao_ambiental/article/view/3467>. Acesso em: 25 mai. 2018.

[8] BRUNI, A. L.; FAMÁ, R. As decisões de investimento: com aplicações na HP 12C e excel. São Paulo: Atlas, 2003.

[9] COSTA, N. da et al. Planejamento de Programas de Reciclagem de Resíduos de Construção e Demolição no Brasil: Uma análise multivariada. Artigo Técnico, 2006. Disponível em: <http://www.scielo.br/pdf/esa/v12n4/a12v12n4.pdf >. Acesso em: 03 fev. 2018.

[10] DAMODARAN, A. Finanças Corporativas: teoria e prática. 2 ed. Porto Alegre: Bookman, 2004.

[11] DEGEN, R. J.; MELLO, A. A. A. O empreendedor: fundamentos da iniciativa empresarial. São Paulo: McGraw-Hill, 1989.

[12] DIAS, G. P. P. Proposta de processo de previsão de vendas para bens de consumo. In: ENCONTRO NACIONAL DE ENGENHARIA DA PRODUÇÃO, 19., Rio de Janeiro, 1999. Anais... Rio de Janeiro: ABEPRO, 1999.

[13] ESPOSITO, A. S.; FUCHS, P. G. Desenvolvimento tecnológico e inserção da energia solar no Brasil. Revista do BNDES, v. 40, 2013. Disponível em: <https://web.bndes.gov.br/bib/jspui/handle/1408/2 431>. Acesso em: 20 mai. 2018.

[14] ESV SOLAR VIDA - Exemplo de sistema híbrido. Disponível em: <http://esvsolarvida.com.br/hibrido/>. Acesso em: 20 mai. 2018

[15] FERNANDES, M. de A. R.; MOTTA, R. de P. S. de. Geração de energia solar e biomassa: os marcos institucionais brasileiro e holandês e os impactos na viabilidade financeira de projetos na Universidade de Brasília. Brasília: UNB, 2014. Disponível em: <http://www.bdm.unb.br/handle/10483/12297>. Acesso em: 30 jan. 2018.

[16] FLEISCHER, G. A. Teoria da aplicação do capital: um estudo das decisões de investimento. São Paulo: Edgard Blucher, 1988.
[17] GABARDO, R. A.; RADASKIEVICZ, T. Aspectos técnicos e econômicos do uso residenciais de painéis fotovoltaicos ligados à rede. Curitiba: UTFPR, 2013.

[18] GIL, A. C. Métodos e Técnicas de Pesquisa Social. São Paulo: Editora Atlas S.A., $2008 . \quad$ Disponivel em: $<$ https://ayanrafael.files.wordpress.com/2011/08/gil -a-c-mc3a9todos-e-tc3a9cnicas-de-pesquisasocial.pdf>. Acesso em: 4 out. 2017.

[19] GOMES, H. P. Eficiência Hidráulica e energética em saneamento: análise econômica de projetos. Rio de Janeiro: ABES, 2005.

[20] LORENZO, E. La energia que producen los sistemas fotovotaicos conectados a la red: El mito del 1300 y "el cascabel del gato". Era Solar, Madrid, n. 107, p. 22-28, Mar./Abr. 2002. Disponível $<$ http://www.fotovoltaica.com/laenered.pdf >. Acesso em: 19 jun. 2018.

[21] LUCENA, L. F. L. Análise do custo benefício da reciclagem dos resíduos urbanos no Recife e Jaboatão dos Guararapes. Recife: UFPE, 2004.

[22] MACHADO, C. T.; MIRANDA, F. S. Energia Solar Fotovoltaica: Uma Breve Revisão. Revista Virtual de Química, v. 7, n. 1, 2015. Disponível em: $<$ http://www.gnresearch.org/doi/10.5935/19846835.20150008 >. Acesso em: 20 abr. 2018.

[23] MARTINS, J. G. F.; LEONE, R. J. G.; LEONE, N. M. C. P. Guerra. Proposta de Método para Classificação do Porte das Empresas. Revista Científica da Escola de Gestão de Negócios, Ano 6, n. 1, 2017

[24] PAIANO, A. Photovoltaic waste assessment in Italy. Renewable and Sustainable Energy Reviews, v. 41, p. 99-112, 2015. Disponível em:

<https://www.sciencedirect.com/science/article/pii/ S1364032114006686> . Acesso em: 20 jan. 2018.

[25] PEREIRA, F.; OLIVEIRA, M. Curso técnico instalador de energia solar fotovoltaica. Porto: Publindústria, 2011.

[26] PINHO, J.; GALDINO, M. Manual de engenharia para sistemas fotovoltaicos. CEPEL/CRESESB. Rio de Janeiro, 2014

[27] REZENDE, J. L. P.; OLIVEIRA, A. D. Análise econômica e social de projetos florestais: matemática financeira, formulação de projetos, avaliação de projetos, localização de projetos, análise de custo-benefício. Viçosa: Ed. UFV, 1993.

[28] TEIXEIRA, A.; VIANNA, S. W. A saúde no Brasil em 2030: desenvolvimento, estado e políticas de saúde. Rio de Janeiro: FIOCRUZ, 2013. 
CONSIDERACÕES FINAIS 


\subsection{CONCLUSÕES}

Esta pesquisa apresenta em sua primeira etapa uma revisão sistematizada de literatura, realizada na base Scopus Elsevier, referente ao tema de energia solar e viabilidade econômica. Dessa forma, para busca na referida base de dados, foram utilizados os termos "solar photovoltaic system board" OR "pv" AND "economic viability" nos seguintes campos: título, resumo e palavras-chave, apenas de artigos.

Objetivando organizar essa busca, foi utilizado o método de Webblioming. Esse tipo de pesquisa é realizado por meio de mecanismos diretos buscando o texto por palavra-chave, título ou autor.

Para a conclusão da primeira etapa, foi realizada uma revisão de literatura na base de dados Scopus Elsevier, acessada em janeiro de 2018, por meio do Portal de Periódicos da Capes, uma vez que esta contém, não apenas artigos acadêmicos, mas outros tipos de publicações, como as de acesso livre, publicações comerciais, entre outros. Os filtros de exclusão não foram utilizados para que o intervalo de documentos da área encontrado fosse maior.

Apenas os campos: título, palavra-chave e resumo foram incluídos como campo de pesquisa. Este estudo abrangeu todas as áreas de conhecimento presentes no banco de dados. O operador "AND" garante que as publicações encontradas contenham todas as palavras pesquisadas, enquanto o uso do operador "OR" possibilita um ou outro termo.

Após a escolha da base de dados, foram estabelecidos os critérios de busca. Com a finalidade de realizar uma ampla cobertura das publicações sobre o tema de viabilidade econômica da utilização de placas fotovoltaicas, foi investigada a área como um todo, de forma a coletar todos os possíveis estudos desenvolvidos.

Para a segunda etapa foram definidas o conjunto de keywords ou termos-chave ("solar photovoltaic system board" OR "pv" AND "economic viability") no campo de busca correspondente a "título, palavras-chave, resumo", alcançando 187 resultados. Estes termos foram selecionados de modo que pudessem ser encontrados no título do artigo, no resumo, ou nas palavras-chave do mesmo.

Nesta etapa, foram analisados os 187 artigos resultantes e, a partir dessa análise, foi composto um núcleo de dez artigos, que mais se aproximaram, de fato, com o tema deste estudo.

A frequência de publicações por ano tem aumentado gradativamente, mostrando o aumento da conscientização e da preocupação com as condições ambientais, revelando o interesse na utilização das energias renováveis.

O ano de 2017 foi o que apresentou o maior número de publicações, reafirmando que o tema proposto pelo trabalho é atual.

É possível perceber, na análise dos resultados, que este assunto ainda pode ser muito explorado, visto que o número de publicações encontradas com as palavraschave utilizadas foi de 80 artigos, um número relativamente baixo. Os anos que se destacaram na pesquisa por possuírem três artigos publicados, indexados na base Scopus, foram 1998, 2012, 2013 e 2016.

Há um baixo número de publicação entre os autores. Os dois mais relevantes possuem cinco trabalhos acadêmicos cada. Quanto à origem de publicação, o Renewable and Sustainable Energy Review se destaca por conter 14 documentos indexados, seguido do Renewable Energy, com 12 documentos.

Em relação às afiliações, a Covenant University e a University of Lagosse destacam-se com cinco documentos indexados na base. Os Estados Unidos saem na frente com 29 artigos publicados. E, por fim, a área que mais se destaca por conter o maior número de documentos publicados é a Energia, com 141 documentos indexados.

Com base nos resultados e na discussão, nota-se que a energia solar é uma energia renovável que, com o passar dos anos, chama cada vez mais a atenção e tem sido implantada em plantas domésticas, rurais, comerciais e industriais. Porém, ainda são necessários incentivos ou abono do imposto para que esta fonte de energia seja competitiva e viável.

Após a realização da revisão sistematizada de literatura sobre o tema dessa dissertação, objetivando proporcionar melhor conhecimento e embasamento sobre o passo a passo metodológico a ser aplicado, pela visão de diferentes autores, foi realizada uma revisão sistematizada de literatura sobre o método de Viabilidade Econômica, na mesma base de dados da primeira revisão de literatura, a Scopus, acessada através do Portal de Periódicos da Capes. 
Este estudo pretende abordar oito métodos financeiros que são mais comumente utilizados para analisar a viabilidade econômica nas empresas, e deste modo, analisa-los do ponto de vista da aplicação das placas fotovoltaicas em uma empresa do município de Macaé/RJ.

A base de dados utilizada foi a Scopus Elsevier, acessada em janeiro de 2018, através do Portal de Periódicos da Capes. Os critérios de busca foram estabelecidos com a finalidade de realizar uma ampla cobertura das publicações sobre os oito métodos financeiros escolhidos.

A busca deu-se em 01/2018, utilizando os termos "Net" AND "Present" AND "Value", "Internal" AND "Rate" AND "of" AND "Return", "Profitability" AND "Index", "Simple" AND "Payback", "Discounted" AND "Payback", "minimum" AND "attractiveness" AND "rate", "Cash" AND "Flow" e "Return" AND "on" AND "Investment", descrito dessa forma, entre aspas, para que as palavras não fossem buscadas separadamente, e sim como um todo. A pesquisa foi restrita apenas a artigos de periódicos.

Para este método, foram utilizados como termos para pesquisa as palavras "Net" AND "Present" AND "Value", retornando um total de 17.187 resultados.

Utilizando as palavras chave "Internal" AND "Rate" AND "of" AND "Return", a pesquisa realizada em busca de publicações sobre o método Taxa Interna de Retorno - TIR retornou 4.610 resultados, que foram incorporados à base de dados da pesquisa para a elaboração das análises.

Com as palavras chave "Profitability" AND "Index", a pesquisa retornou 2.797 periódicos.

Para este método foram realizadas buscas por periódicos utilizando como palavras chave os termos "Simple" AND "Payback", o que acabou retornando em dados 769 resultados.

Para a realização das pesquisas referentes ao método de Payback Descontado, foram utilizadas as palavras chave "Discounted" AND "Payback", retorno como dados 304 resultados.

Foram utilizadas na pesquisa deste método as palavras chave "minimum" AND "attractiveness" AND "rate", retornando 55 resultados.
Para as pesquisas realizadas sobre este método, foram utilizadas as palavras chave "Cash" AND "Flow", que retornaram em dados 14.521 resultados, que passaram a compor a base de dados para as análises sobre este tema.

A pesquisa sobre os periódicos relacionados ao método Retorno Sobre Investimento - ROI, utilizou o conjunto de keywords ou termos chave "Return" AND "on" AND "Investment", alcançando 35.152 resultados.

O modelo utilizado é o proposto por Costa (2010), o qual é dividido em seis passos. A definição da amostra da pesquisa, a pesquisa na amostra, identificação dos periódicos e dos autores com maior número de publicações sobre o tema, levantamento da cronologia da produção, identificando ciclos de maior produção e a seleção dos artigos para composição do "núcleo de partida" para a pesquisa bibliográfica.

Apresentado este panorama, traça-se como objetivo analisar e identificar os autores, periódicos, países, tipo de publicação e áreas de conhecimento com maiores publicações a respeito de oito métodos financeiros. Buscouse apresentar três trabalhos de aplicação prática do tema estudado para cada método selecionado

Com o grande volume de resultados oferecidos pela base de dados, nota-se que é de grande interesse, a nível mundial e global, o estudo de métodos financeiros. Estes possuem uma aplicabilidade muito grande, em diversas áreas como agricultura, educação, medicina, biologia, economia, entre outros. Assim, pode-se dizer que é de suma importância dar continuidade ao estudo destes métodos aplicados a viabilidade econômica para agregar a área de energias renováveis, uma vez que a sustentabilidade e o uso de energias renováveis são de grande interesse da sociedade.

Um padrão observado para todos os métodos foi o aumento do número de publicação gradativo com o passar dos anos, tendência esta que demonstra o aumento do interesse sobre os métodos financeiros, o que nos faz acreditar que o tema é bastante relevante e que tem muito a se explorar.

Com as revisões de literatura prontas, tem-se aporte teórico para aplicar o passo a passo metodológico no estudo de caso proposto. Este estudo de caso deu-se em uma empresa offshore, localizada no município de 
Macaé/RJ, que conta com 250 colaboradores que trabalham em turnos diurnos e noturnos, e com este número de pessoas ocupadas, a referida empresa é considerada de médio porte, de acordo com metodologia do SEBRAE.

Nesta etapa de resultados contatou-se que os objetivos específicos quanto os gerais foram alcançados, através de uma análise de viabilidade econômica da utilização de placas fotovoltaicas com o objetivo de mensurar os custos do projeto e destacar os benefícios advindos deste. Para isto foi contatado um fornecedor local para elaboração do orçamento, e o autor utilizou o simulador PVsyst 6.73 para calcular a energia produzida pelo sistema fotovoltáico e outros parâmetros. Tendo como condição inicial estipulada pela diretoria a taxa mínima de atratividade (TMA) de $8,3 \%$, o resultado demonstrou, através dos métodos utilizados de Payback Simples e Descontado, Índice de Rentabilidade (IL), Retorno sobre Investimento (ROI), Valor presente Líquido (VPL) e Taxa Interna de Retorno (TIR), que o projeto é economicamente viável e a empresa em questão tem capacidade física para instalação dos equipamentos promovendo grande economia financeira no médio e longo prazo contribuindo para produção de energia limpa no Brasil.

Sendo assim, conclui que este trabalho se objetivou a avaliar a possível implantação de um sistema fotovoltaico em uma empresa offshore no município de Macaé, situado no estado do Rio de Janeiro. Foi possível observar que a companhia tem capacidade estrutural para abrigar o sistema e que o investimento a ser realizado será revertido em aproximadamente 6 anos, proporcionando grande economia em médio e longo prazo.

\section{REFERÊNCIAS}

[1] ABREU FILHO, J. C. F. et al. Finanças Corporativas. 11 ed. Rio de Janeiro: FGV, 2012. $160 \mathrm{p}$.

[2] AGATON, C. B. et al. A real option approach to renewable electricity generation in the Philippines. Energy, Sustainability and Society, v. 8, issue 1, 2018.

[3] AGÊNCIA NACIONAL DE ENERGIA ELÉTRICA (ANEEL). Energia Solar. Disponível em:
Foi observado como inconsistentes as taxas de retorno de investimento considerando o tempo de retorno do investimento menor ou igual a 5 (cinco) anos.

A viabilidade de utilização de placas fotovoltaicas é considerada positiva, proporcionando não só benefícios financeiros, mas também contribuindo para a sustentabilidade, pois a energia solar não utiliza fontes fósseis, não emite gás carbônico na atmosfera e ainda contribui para conservação dos reservatórios das hidrelétricas, preservando assim os recursos hídricos nacionais.

\subsection{TRABALHOS FUTUROS}

Considerando a visão acadêmica, é sugerida a continuidade deste estudo no intuito da metodologia, através da simulação computacional e como método a viabilidade econômica, utilizando diferentes parâmetros, e cenários. No que tange 0 indicador econômico do reajuste da tarifa elétrica, pode-se trabalhar com diversos cenários, pois sabe-se que as tarifas de energia elétrica podem não seguir uma trajetória bem definida e suas alterações podem ser explicadas em razão de políticas adotadas, intervenções governamentais e diferentes fases do próprio setor elétrico brasileiro.

Sugere-se pelo autor também, uma pesquisa mais detalhada sobre a inserção da energia fotovoltáica na nossa matriz energética, na indústria em geral, nas residências e no meio rural durante os próximos anos, e que possa ser oferecido mais incentivos do Governo a nível nacional para o avanço desta tecnologia através Políticas Públicas eficientes, a partir de novas lideranças, pois como sabemos estamos atrasados com relação aos países mais desenvolvidos no uso desta tecnologia.

<http://www2.aneel.gov.br/aplicacoes/atlas/pdf/03energia_solar(3).pdf>. Acesso em: 22 jan. 2018

[4] AGÊNCIA NACIONAL DE ENERGIA ELÉTRICA (ANEEL). Energia Solar Fotovoltaica: Panorama, Oportunidade e Desafios. Disponível em:

<http://www.aneel.gov.br/documents/10184/15266 087/painel+3+ap+7+2017.10.19+ABSOLAR++ Energia+Solar+Fotovoltaica++Dr.+Rodrigo+Lopes+Sauaia.pdf/54f8b161-751b- 
0639-bd04-77a60cac45c3>. Acesso em: 10 jan. 2018.

[5] AGÊNCIA NACIONAL DE ENERGIA ELÉTRICA (ANEEL). Resolução Normativa n. ${ }^{\circ} 482$ de 17 de abril de 2012. Estabelece como condições gerais para o acesso de micro geração e minigeração distribuída aos sistemas de distribuição de energia elétrica, o sistema de compensação de energia elétrica, e dá outras providências. Disponível em: <http://www2.aneel.gov.br/cedoc/ren2012482.pdf> . Acesso em: 27 set. 2017.

[6] AGÊNCIA NACIONAL DE ENERGIA ELÉTRICA (ANEEL). Resolução Normativa $n^{\circ} 687$, de 24 de novembro de 2015. Altera a Resolução Normativa $n^{\circ}$ 482, de 17 de abril de 2012, e os Módulos 1 e 3 dos Procedimentos de Distribuição PRODIST. Disponível em: <http://www2.aneel.gov.br/cedoc/ren2015687.pdf> . Acesso em: 27 set. 2017.

[7] AHMED, K. et al. Associations between corporate characteristics and disclosure levels in annual reports: A meta-analysis. British Accounting Review, v. 31, n. 1, p. 35-61, 1999.

[8] ANDERSON, E. W. et al. Customer satisfaction, productivity, and profitability: Differences between goods and services. Marketing Science, v. 16, n. 2, p. 129-145, 1997.

[9] ASSOCIAÇÃO BRASILEIRA DAS EMPRESAS DE SERVIÇOS DE CONSERVAÇÃO DE ENERGIA (ABESCO). Residências podem deixar de emitir 1 tonelada de $\mathrm{CO} 2$ por ano com microgeração fotovoltaica. Disponível em: <http://www.abesco.com.br/pt/novidade/residencia s-podem-deixar-de-emitir-1-tonelada-de-co2-porano-com-microgeracao-fotovoltaica/>. Acesso em: 27 set. 2017.

[10] ASSOCIAÇÃO BRASILEIRA DE ENERGIA SOLAR FOTOVOLTAICA (ABSOLAR). Geração Distribuída Solar Fotovoltaica. In: ENCONTRO NACIONAL DOS AGENTES DO SETOR ELÉTRICO, 2017. Anais... Rio de Janeiro: ENASE, 2017.

[11] ASUMADU-SARKODIE, S. et al. The potential and economic viability of solar photovoltaic power in Ghana. Energy Sources, v. 38, n. 5, p. 709-716, 2016. Disponível em: <https://www.tandfonline.com/doi/abs/10.1080/155 67036.2015.1122682?journalCode=ueso20 > Acesso em: 20 jan. 2018.

[12] BALARINE, O. F. O. Tópicos de matemática financeira e engenharia econômica. 2. ed. Porto Alegre: EDIPUCRS, 2004.

[13] BARBOSA, F. Z. A utilização dos raios solares como fonte energética. Porto Velho, RO: Fundação Universidade Federal de Rondônia, 2010 .

[14] BARBOSA FILHO, W. P. et al. Expansão da energia solar fotovoltaica no brasil: Impactos ambientais e políticas públicas. Revista Gestão \&
Sustentabilidade Ambiental, v. 4, p. 628, 7 dez. 2015. Disponível em: <http://www.portaldeperiodicos.unisul.br/index.php /gestao_ambiental/article/view/3467>. Acesso em: 27 set. 2017.

[15] BEAL, C. M. et al. Algal biofuel production for fuels and feed in a 100-ha facility: A comprehensive techno-economic analysis and life cycle assessment. Algal Research, v. 10, p. 266279, 2015

[16] BOURDEUX-REGO, R.; PAULO, G. P.; SPRITZER, I. M. de P. A.; ZOTES, L. P. Viabilidade Economico-Financeira de Projetos. 4. ed. Rio de Janeiro: FGV, 2013.

[17] BRUNI, A. L.; FAMÁ, R. As decisões de investimento: com aplicações na HP $12 \mathrm{C}$ e excel. São Paulo: Atlas, 2003.

[18] BRASIL. Conselho Nacional de Política Fazendária - Confaz. Ministério de Minas e Energia. Ajuste SINIEF 2, de 22 de abril de 2015. 2015. Disponível em: <https://www.confaz.fazenda.gov.br/legislacao/ajus tes/2015/AJ_002_15>. Acesso em: 10 jan. 2018

[19] BRASIL. Conselho Nacional de Política Fazendária - Confaz. Ministério de Minas e Energia. Energia Solar no Brasil e Mundo: 2015. Disponível em:

<http://www.mme.gov.br/documents/10584/358049 8/17+-+Energia+Solar+--Brasil+e+Mundo++ano+ref.+2015+\%28PDF\%29/4b03ff2d-14524476-907d-d9301226d26c?version=1.3>. Acesso em: 10 jan. 2018

[20] BYRNE, J.; SHEN, B.; WALLACE, W. The economics of sustainable energy for rural development: a study of renewable energy in rural China. Energy Policy, v. 26, n.1, p. 45-54, 1998. Disponível em: <https://doi.org/10.1016/S03014215(97)00099-2>. Acesso em: 20 jan. 2018.

[21] CAMARGO, C. Análise de Investimentos e Demonstrativos Financeiros. Curitiba: Ibpex, 2007.

[22] CAPAZ, R.; NOGUEIRA, L. Ciências Ambientais para Engenharia. Rio de Janeiro: Elsevier, 2016

[23] CARHART, M. M. On persistence in mutual fund performance. Journal of Finance, v. 52, n. 1, p. 57-82, 1997.

[24] CARSTEN, O. M. J. et al. Intelligent speed adaptation: Accident savings and cost-benefit analysis. Accident Analysis and Prevention, v. 37, n. 3, p. 407-416, 2005.

[25] CATAPAN, A. et al. Electric energy production from swine deject: Analysis of financial feasibility with the use of monte carlo simulation for the implantation of bio-digester in Brazil. Bulgarian Journal of Agricultural Science, v. 21, n. 2, p. 257260, 2015

[26] CARVAlHO, E. F. A.; CALVETE, M. J. F. Energia Solar: Um passado, um presente... um 
futuro auspicioso. Revista Virtual de Química, v. 2, n. 3, p. 192-203, 2010.

[27] CERAGIOLI, P. C. Manual de Energia
$\begin{aligned} & \text { Solar Fotovoltaica. } \\ & \text { <http://rf.com.br/sites/ }\end{aligned}$
rf.com.br/iles/docs/SolarMan97.pdf>. Acesso em:
03 mar. 2018.

[28] CHANDEL, $M$. et al. Techno-economic analysis of solar photovoltaic power plant for garment zone of Jaipur city. Case Studies in Thermal Engineering, v. 2, p. 1-7, 2014.

[29] CHENÇO, E. C. Fundamentos em Finanças. Curitiba: IESDE Brasil, 2009.

[30] CHONG, W. T. et al. Techno-economic analysis of a wind-solar hybrid renewable energy system with rainwater collection feature for urban high-rise application. Applied Energy, v. 88, n. 11, p. 4067-4077, 2011.

[31] CHUANG, C. et al. Improved performance and stability in quantum dot solar cells through band alignment engineering. Nature Materials, v. 13, n. 8, p. 796-801, 2014.

[32] CONSELHO REGIONAL DE CONTABILIDADE DO RIO DE JANEIRO (CRCRJ). Elaboração das Demonstrações Contábeis, 2018. Disponível em: <http://webserver.crcrj.org.br/APOSTILAS/A0091P0 203.pdf>. Acesso em: 07 jan. 2018.

[33] COSTA, H. Modelo para webibliomining: proposta e caso de aplicação. Revista. FAE, Curitiba, v.13, n.1, p. 115-126, jan-jun 2010. Disponível em: <https://revistafae.fae.edu/revistafae/article/view/22 6>. Acesso em: 20 jan. 2018.

[34] COSTA, N. da et al. Planejamento de Programas de Reciclagem de Resíduos de Construção e Demolição no Brasil: Uma análise multivariada. Artigo Técnico, 2006. Disponível em: <http://www.scielo.br/pdf/esa/v12n4/a12v12n4.pdf >. Acesso em: 03 fev. 2017.

[35] CUCCHIELLA, F. et al. Environmental and economic analysis of building integrated photovoltaic systems in Italian regions. Journal of Cleaner Production, v. 98, p. 241-252, 2015.

[36] DA CUNHA KEMERICH, P. D. et al. Paradigmas da energia solar no Brasil e no mundo. Electronic Journal of Management, Education and Environmental Technology (REGET), v. 20, n. 1, p. 241-247, 2016.

[37] DAMODARAN, A. Finanças corporativas: teoria e prática. 2 ed. Porto Alegre: Bookman, 2004.

[38] DAMODARAN, A. Finanças Corporativas Aplicadas. Porto Alegre: Bookman, 2002.

[39] DANIEL, K. et al. Investor psychology and security market under and overreactions. Journal of Finance, v. 53, n. 6, p. 1839-1885, 1998.
[40] DANQUAH, M. K. et al. Dewatering of microalgal culture for biodiesel production: Exploring polymer flocculation and tangential flow filtration. Journal of Chemical Technology and Biotechnology, v. 84, n. 7, p. 1078-1083, 2009.

[41] DEGEN, R. J.; MELLO, A. A. A. O empreendedor: fundamentos da iniciativa empresarial. São Paulo: McGraw-Hill, 1989.

[42] DIAS, G. P. P. Proposta de processo de previsão de vendas para bens de consumo. In: ENCONTRO NACIONAL DE ENGENHARIA DA PRODUÇÃO, 19., Rio de Janeiro, 1999. Anais... Rio de Janeiro: ABEPRO, 1999.

[43] DUSONCHET, L. et al. Economic analysis of different supporting policies for the production of electrical energy by solar photovoltaics in western European Union countries. Energy Policy, v. 38, n. 7, p. 3297-3308, 2010.

[44] ELSEVIER, B. V. Pesquisadores e Profissionais de P\&D: O maior acervo de soluções eletrônicas para pesquisadores da comunidade científica. Rio de Janeiro, 2016. Disponível em: <https://www.Elsevier.com.br/solucoes-digitais/>. Acesso em: 20 jan. 2018.

[45] ENEL SOLUÇÕES. Custo de energia solar despenca nos últimos 40 anos. Disponível em: $<$ https://www.enelsolucoes.com.br/blog/2017/01/cu sto-de-energia-solar-despenca-nos-ultimos-40anos/>. Acesso em: 10 jan. 2018.

[46] ENERGIA SOLAR 3. Disponível em: <http://www2.aneel.gov.br/aplicacoes/atlas/pdf/03energia_solar(3).pdf>. Acesso em: 10 jan. 2018.

[47] ESPOSITO, A. S.; FUCHS, P. G. Desenvolvimento tecnológico e inserção da energia solar no Brasil. Revista do BNDES, v. 40, 2013. Disponível em: <https://web.bndes.gov.br/bib/jspui/handle/1408/2 431>. Acesso em: 27 set. 2017.

[48] ESV SOLAR VIDA. Exemplo de sistema híbrido. Disponível em: $<$ http://esvsolarvida.com.br/hibrido/>. Acesso em: 26 mar. 2018.

[49] FARIAS, L. M.; SELLITTO, M. A. Uso da energia ao longo da história: evolução e perspectivas futuras. Revista Liberato, v. 12, n. 17, p. 1-106, 2011.

[50] FACULDADE PARAÍSO DO NORTE FAPAN - PAYBACK. Disponível em: <http://www.fapanpr.edu.br/site/docente/arquivos/P AYBACK\%20SIMPLES\%20E\%20DESCONTADO.pd f>. Acesso em: 28 fev. 2018.

[51] FELTHAM, G. A. et al. Valuation and clean surplus accounting for operating and financial activities. Contemporary Accounting Research, v. 11, issue 2, p. 689-731, 1995.

[52] FERNANDES, M. de A. R.; MOTTA, R. de P. S. de. Geração de energia solar e biomassa: os marcos institucionais brasileiro e holandês e os 
impactos na viabilidade financeira de projetos na Universidade de Brasília. Brasília: UNB, 2014. Disponível em: <http://www.bdm.unb.br/handle/10483/12297>. Acesso em: 27 set. 2017

[53] FLEISCHER, G. A. Teoria da aplicação do capital: um estudo das decisões de investimento. São Paulo: Edgard Blucher, 1988.

[54] GABARDO, R. A.; RADASKIEVICZ, T. Aspectos técnicos e econômicos do uso residenciais de painéis fotovoltaicos ligados à rede. Curitiba: UTFPR, 2013.

[55] GIL, A. C. Métodos e Técnicas de Pesquisa Social. São Paulo: Editora Atlas S.A., $2008 . \quad$ Disponível em: $<$ https://ayanrafael.files.wordpress.com/2011/08/gil -a-c-mc3a9todos-e-tc3a9cnicas-de-pesquisasocial.pdf>. Acesso em: 4 out. 2017.

[56] GITMAN, L. J. Princípios de administração financeira. 12 ed. São Paulo: Pearson Prentice Hall, 2010.

[57] GOIÁS, L. K. T. Governador do Estado de Goiás. A importância da energia solar para o desenvolvimento sustentável e social. Goiás: Agência Goiana de Habitação - AGEHAB, 2016. 29 slides, color.

[58] GOMES, H. P. Eficiência Hidráulica e energética em saneamento: análise econômica de projetos. Rio de Janeiro: ABES, 2005.

[59] GUEDES, J. C. de S. Manual de Tarifação da Energia Elétrica. Disponível em: <http://www.eletrobras.com>. Acesso em: 9 out. 2017.

[60] HANIFFA, R. M. et al. The impact of culture and governance on corporate social reporting. Journal of Accounting and Public Policy, v. 24, n. 5 , p. 391-430, 2005.

[61] HEMÉRY, D. et al. Uma história da energia. Brasília: Editora Universidade de Brasília, 1993.

[62] HERRANDO, M. et al. Hybrid PV and solarthermal systems for domestic heat and power provision in the UK: Techno-economic considerations. Applied Energy, v. 161, p. 512-532, 2016.

[63] HOLDERMANN, C. et al. Distributed photovoltaic generation in Brazil: An economic viability analysis of small-scale photovoltaic systems in the residential and commercial sectors. Energy Policy, v. 67, p. 612-617, 2014. Disponível em:

<https://energypedia.info/images/temp/2/27/20140 508121514! phpS4CvG4.pdf>. Acesso em: 20 jan. 2018.

[64] IMHOFF, J. Desenvolvimento de Conversores Estáticos para Sistemas Fotovoltaicos Autônomos. 2007. 146 f. Dissertação (Mestrado em Engenharia Elétrica) - Engenharia Elétrica -
Universidade Federal de Santa Maria, Santa Maria. $2007 . \quad$ Disponível em: <http://repositorio.ufsm.br/bitstream/handle/1/8608/ JOHNINSONIMHOFF.pdf>. Acesso em: $23 \mathrm{fev}$. 2018.

[65] INTERNATIONAL ENERGY AGENCY (IEA). Energy statistics: matriz energética do Brasil. Disponível em: <https://www.iea.org/stats/WebGraphs/BRAZIL5.pd f>. Acesso em: 23 jan. 2018.

[66] JAFFE, J.; LAMB, R.; ROSS, S.; WESTERFIELD, R. W. Administração Financeira. Porto Alegre: AMGH, 2015.

[67] JARDIM, C. da S.; SILVA, C. da. A inserção da geração solar fotovoltaica em alimentadores urbanos enfocando a redução do pico de demanda diurno. Universidade Federal de Santa Catarina, Florianópolis, 2007. Disponível em: <https://repositorio.ufsc.br/xmlui/handle/123456789 190237>. Acesso em: 26 set. 2017.

[68] JeSUS, I. R. D. de; COSTA, H. G. Interfaces between production engineering and the public affairs: evidences from bibliometric analysis. Scientometrics, [s.I.], v. 105, n. 2, p.1183-1193, 30 ago. 2015. Springer Nature. http://dx.doi.org/10.1007/s11192-015-1724-1.

[69] JUNG, C. F. Metodologia para pesquisa \& desenvolvimento Aplicada a novas tecnologias, produtos e processos. Axcel-Books, 2004.

[70] KANTAMA, A. et al. Techno-economic assessment of a heat-integrated process for hydrogenated renewable diesel production from palm fatty acid distillate. Biomass and Bioenergy, $\mathrm{v}$. 83, p. 448-459, 2015.

[71] KAPLAN, S. The effects of management buyouts on operating performance and value. Journal of Financial Economics, v. 24, issue 2, p. 217-254, 1989.

[72] KHALID, A.; JUNAIDI, H. Study of economic viability of photovoltaic electric power for Quetta - Pakistan. Renewable Energy, v. 50, p. 253-258, 2013. Disponível em: $<$ https://www.infona.pl/resource/bwmeta1.element. elsevier-c1a8057e-b848-3448-9f9a-

6e957f26220d>. Acesso em: 23 jan 2018.

[73] KORNELAKIS, A. et al. Methodology for the design optimisation and the economic analysis of grid-connected photovoltaic systems. IET Renewable Power Generation, v. 3, n. 4, p. 476492, 2009.

[74] KRUEGER, A. B. Economic considerations and class size. Economic Journal, v. 113, n. 485, p. F34-F63, 2003.

[75] LI, F. Annual report readability, current earnings, and earnings persistence. Journal of Accounting and Economics, v. 45, n. 2-3, p. 221247, 2008. 
[76] LI, Z.; BOYLE, F.; REYNOLDS, A. Domestic application of solar PV systems in Ireland: The reality of their economic viability. Energy, v. 36, n. 10, p. 5865-5876, 2011. Disponível em: <https://doi.org/10.1016/j.energy.2011.08.036>. Acesso em: 23 jan. 2018.

[77] LIN, C. H. et al. Optimization of photovoltaic penetration in distribution systems considering annual duration curve of solar irradiation. IEEE Transactions on Power Systems, v. 27, n. 2, p. 1090-1097, 2012

[78] LISITA, O. Sistemas Fotovoltaicos Conectados à Rede: Estudo de caso - 3 kWp instalados no estacionamento do IEE-SP. São Paulo: USP, 2005. 87 p. Tese (Mestrado) - Instituto de Física, Programa de Mestrado em Energia, Universidade de São Paulo, 2005.

[79] LORENZO, E. La energia que producen los sistemas fotovotaicos conectados a la red: El mito del 1300 y "el cascabel del gato". Era Solar, Madrid, n. 107, p. 22-28, Mar./Abr. 2002. Disponível

<http://www.fotovoltaica.com/laenered.pdf> Acesso em: 20 jun. 2004

[80] LUCENA, L. F. L. Análise do custo benefício da reciclagem dos resíduos urbanos no Recife e Jaboatão dos Guararapes. Recife: UFPE, 2004

[81] MACHADO, C. T.; MIRANDA, F. S. Energia Solar Fotovoltaica: Uma Breve Revisão. Revista Virtual de Química, v. 7, n. 1, 2015. Disponível em: <http://www.gnresearch.org/doi/10.5935/19846835.20150008>. Acesso em: 27 set. 2017.

[82] MARQUES, J. B. D. et al. Stochastic processes and copula model applied in the economic evaluation for Brazilian oil fields projects. SPE Hydrocarbon Economics and Evaluation Symposium, p. 379-399, 2014

[83] MARQUES, W. L. Fluxo de Caixa. 2 ed. São Paulo: Clube dos Autores, 2011.

[84] MARQUES, W. L. Gerenciamento Financeiro. São Paulo: Clube dos Autores, 2007.

[85] MARTINS, J. G. F.; LEONE, R. J. G.; LEONE, N. M. C. P. Guerra. Proposta de Método para Classificação do Porte das Empresas. Revista Científica da Escola de Gestão de Negócios, Ano 6, n. 1, 2017.

[86] MERTON, R. C. On estimating the expected return on the market: An exploratory investigation. Topics in Catalysis, v. 8, n. 4, p. 323361,1980

[87] MINISTÉRIO DAS MINAS E ENERGIA MME. Energia Solar no Brasil e no Mundo - Ano de referência 2015. Disponível em: < http://www.mme.gov.br/documents/10584/3580498/ 17+-+Energia+Solar+-+Brasil+e+Mundo++ano+ref.+2015+\%28PDF\%29/4b03ff2d-14524476-907d-d9301226d26c? version=1.3>. Acesso em: 22 jan. 2018
[88] MITSCHER, M.; RÜTHER, R. Economic performance and policies for grid-connected residential solar photovoltaic systems in Brazil. Energy Policy, v. 49, p. 688-694, 2012. Disponível em:

$<$ https://ideas.repec.org/a/eee/enepol/v49y2012icp 688-694.html>. Acesso em: 23 jan. 2018.

[89] MONDAL, A. H. Economic viability of solar home systems: Case study of Bangladesh. Renewable Energy, v. 35, n. 6, p. 1125-1129, 2010. Disponível em: <https://doi.org/10.1016/j.renene.2009.10.038>. Acesso em: 20 jan. 2018.

[90] NASCIMENTO, R. L. Energia solar no Brasil: situação e perspectivas. 2017.

[91] NEUMANN, E. Introdução à Engenharia Civil. Rio de Janeiro: Elsevier, 2017.

[92] NEVES, R. B.; PEREIRA, V.; COSTA, H. G. Auxílio multicritério à decisão aplicado ao planejamento e gestão na indústria de petróleo e gás. Production, [s.I.], v. 25, n. 1, p. 43-53, mar. 2015. FapUNIFESP (SciELO). http://dx.doi.org/10.1590/s010365132013005000060

[93] OKUBO, Y. Bibliometric indicators and analysis of research systems. 1997.

[94] OU, J. A. et al. Financial statement analysis and the prediction of stock returns. Journal of Accounting And Ecnonomics, 1989

[95] PAIANO, A. Photovoltaic waste assessment in Italy. Renewable and Sustainable Energy Reviews, v. 41, p. 99-112, 2015. Disponível em:

<https://www.sciencedirect.com/science/article/pii/ S1364032114006686>. Acesso em: 1 out. 2017.

[96] PEASNELL, K. V. Some formal connections between economic values and yields and accounting numbers. Journal of Business Finance \& Accounting, v. 9, n. 3, p. 361-381, 1982.

[97] PEREIRA, F. A. de S.; OLIVEIRA, M. A. S. Curso técnico instalador de energia solar fotovoltaica. 2 ed. Porto: Publindústria, 2015.

[98] PINHO, J.; GALDINO, M. Manual de engenharia para sistemas fotovoltaicos. CEPEL/CRESESB. Rio de Janeiro, 2014

[99] PINTO, R. et al. Impact of rural gridconnected photovoltaic generation systems on power quality. Energies, v. 9, n. 9, p. 739, 2016. Disponível em: <https://pdfs.semanticscholar.org/299a/5a21a7b44 95f04f99e3d36d58fc693568d2b.pdf>. Acesso em: 20 jan. 2018.

[100] PORTAL SOLAR LTDA. A regulamentação dos créditos de energia solar. São Paulo. Disponível em: <https://www.portalsolar.com.br/aregulamentacao-dos-creditos-de-energia.html>. Acesso em: 10 jan. 2018. 
[101] PULLIKKAS, A. Economic analysis of power generation from parabolic trough solar thermal plants for the Mediterranean region-A case study for the island of Cyprus. Renewable and Sustainable Energy Reviews, v. 13, n. 9, p. 24742484, 2009

[102] RAFFOURNIER, B. The Determinants of Voluntary Financial Disclosure by Swiss Listed Companies. Swiss: Université de Genève/HEC, 1995.

[103] REHMAN, S. et al. Cost of solar energy generated using PV panels. Renewable and Sustainable Energy Reviews, v. 11, n. 8, p. 18431857,2007

[104] REZENDE, J. L. P.; OLIVEIRA, A. D. Análise econômica e social de projetos florestais: matemática financeira, formulação de projetos, avaliação de projetos, localização de projetos, análise de custo-benefício. Viçosa: Ed. UFV, 1993.

[105] ROCHA, L. C. S. et al. Photovoltaic electricity production in Brazil: A stochastic economic viability analysis for small systems in the face of net metering and tax incentives. Journal of Cleaner Production, v. 168, p. 1448-1462, 2017. Disponível em: <DOI: 10.1016/j.rser.2018.03.078>. Acesso em: 20 jan. 2018.

[106] ROMEIRO FILHO, E. (Org.). Projeto do Produto. Rio de Janeiro: Elsevier, 2011.

[107] RÜTHER, R. Edifícios solares fotovoltaicos: o potencial da geração solar fotovoltaica integrada a edificações urbanas e interligada à rede elétrica pública no Brasil. Florianópolis: Editora da Universidade Federal de Santa Catarina, 2004. 114 p.

[108] SCHULTZ, T. P. School subsidies for the poor: Evaluating the Mexican Progresa poverty program. Journal of Development Economics, v. 74, n. 1, p. 199-250, 2004

[109] SEBRAE. Fluxo de Caixa. Disponível em: $<$ http://www.sebrae.com.br/Sebrae/Portal\%20Sebra e/Anexos/0_fluxo-de-caixa.pdf>. Acesso em: 28 fev. 2018.

[110] SHAKYA, B. D. et al. Technical feasibility and financial analysis of hybrid wind-photovoltaic system with hydrogen storage for Cooma. International Journal of Hydrogen Energy, v. 30, n. 1, p. 9-20, 2005.

[111] SILVA, T. R. et al. Methodology for the determination of optimum power of a Thermal Power Plant (TPP) by biogas from sanitary landfill. Waste Management, v. 65, p. 75-91, 2017.

[112] STARK, O. et al. Migration incentives, migration types: the role of relative deprivation.
Economic Journal, v. 101, n. 408, p. 1163-1178, 1991.

[113] STULZ, R. Managerial discretion and optimal financing policies. Journal of Financial Economics, v. 26, issue 1, p. 3-27, 1990.

[114] SYRED, N. et al. Combustion in swirling flows: A review. Combustion and Flame, v. 23, n. 2, p. 143-201, 1974.

[115] TEIXEIRA, A.; VIANNA, S. W. A saúde no Brasil em 2030: desenvolvimento, estado e políticas de saúde. Rio de Janeiro: FIOCRUZ, 2013.

[116] TUBINO, D. F. Planejamento e Controle da Produção: Teoria e Prática. 2 ed. São Paulo: Atlas S. A., 2009.

[117] USIRONO, C. H. Escritório de Processos: BPMO - Business Process Management Office. São Paulo: Brasport, 2015.

[118] VALE, A. et al. Analysis of the economic viability of a photovoltaic generation project applied to the Brazilian housing program "Minha Casa Minha Vida". Energy Policy, v. 108, p. 292-298, $2017 . \quad$ Disponível em: <DOl: 10.1016/j.enpol.2017.06.001>. Acesso em: 20 jan. 2018.

[119] VIVAN, G. A. et al. Technical and economic study of a mobile system for extraction of eucalyptus essential oil. Cerne, v. 17, n. 1, p. 23-31, 2011

[120] VON HIPPEL, E. et al. Open source software and the "private-collective" innovation model: Issues for organization science. Organization Science, v. 14, n. 2, p. 209-223+225, 2003.

[121] WEITZMAN, M. L. On the welfare significance of national product in a dynamic economy. Quartely Journal of Economics, v. 90, issue 1, p. 156-162, 1976.

[122] WIES, R. W. et al. Simulink model for economic analysis and environmental impacts of a PV with diesel-battery system for remote villages. IEEE Transactions on Power Systems, v. 20, n. 2, p. 692-700, 2005

[123] WORDLE. Nuvem de palavras. Disponível em:

http://www.wordle.net/show/wrdl/7813322/nuvem_d e_palavras/>. Acesso em: 02 jan. 2018.

[124] ZILLES, R. et al. Sistemas fotovoltaicos conectados à rede elétrica. São Paulo: Oficina de Textos, 2012. 208 p. 


\section{Sobre o Autor}

\section{André Gomes Barros}

- Mestre em Engenharia de Produção pela UCAM - Campos dos Goytacazes-2018.

- Engenheiro de Segurança do Trabalho pela UNESA - Rio de Janeiro $-2008$.

- Engenheiro Eletricista com Ênfase em Telecomunicações pela UNESA-Rio de Janeiro 2006.

- Técnico em Eletrotécnica com ênfase em Automação pelo Colégio Iba-Wakigawa-Rio de Janeiro - 2004. 


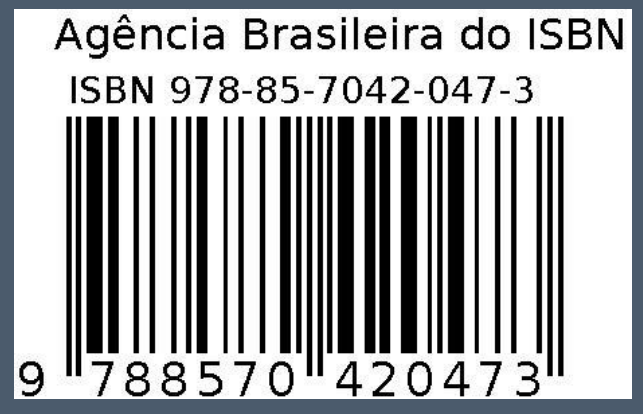

